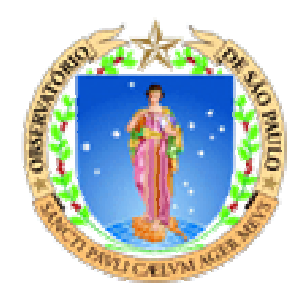

Instituto de Astronomia, Geofísica e Ciências Atmosféricas IAG/USP

\title{
Caracterização Geofísica da Estrutura de Impacto de Araguainha, MT/GO.
}

MARCOS ALBERTO RODRIGUES VASCONCELOS

ORIENTADOR: EDER CASSOLA MOLINA 


\title{
Caracterização Geofísica da Estrutura de impacto de Araguainha,MT/GO.
}

\author{
por \\ Marcos Alberto Rodrigues Vasconcelos
}

Orientador: Eder Cassola Molina

DISSERTAÇÃO DE MESTRADO

INSTITUTO DE ASTRONOMIA, GEOFÍSICA E CIÊNCIAS

ATMOSFÉRICAS -IAG UNIVERSIDADE DE SÃO PAULO-SP 
À minha família, sustento da minha vida, aos meus amigos, apoios da minha alegria, ao meu Amado, Jesus Eucarístico, vivo e presente, sustento da minha alma. 


\section{Agradecimentos}

À Fundação de Amparo à Pesquisa do Estado de São Paulo, FAPESP, pelo apoio financeiro para a realização desta pesquisa, processo $N^{\circ}$ 055-51530-3.

Ao CNPq pela concessão da bolsa de mestrado junto ao IAG.

À professora Yára Regina Marangoni pelo convite para participação do projeto junto à FAPESP e pelo auxílio nas discussões ao longo do trabalho.

À CNEN/DNPM/CPRM pela liberação dos dados aeromagnéticos do Projeto Alto Garças, 1972.

Ao Francisco Andrade, AGP-LA, pela disponibilidade dos dados da estação magnética terrestre para correção dos dados de Araguainha.

Ao Cristiano Lana, da Universidade de Stellenbosch, África do Sul, pela contribuição com os mapas e principalmente nas informações e discussões geológicas.

Ao professor Álvaro Crósta, da UNICAMP, pelas discussões iniciais e informações sobre Araguainha.

Ao professor Carlos Roberto Souza Filho, da UNICAMP, pelo fornecimento das imagens Landsat.

Ao Elder Yokoyama, pela cessão dos dados de magnetização e amostras para análise que fazem parte do seu mestrado, fundamentais para os resultados deste trabalho, além das discussões e atualização do banco de artigos.

A todos os professores do IAG/USP que de alguma maneira me auxiliaram nas discussões e informações relevantes ao escopo do trabalho, entre eles: à professora Naomi Ussami nas discussões, ao professor Wladimir Shukowsky pelas rotinas cedidas que auxiliaram na interpretação dos dados, ao professor Carlos Alberto Mendonça pelas discussões dos testes sintéticos e disponibilidade, e ao professor Ricardo Trindade pelas discussões geológicas na parte de interpretação dos dados.

Agradeço aos funcionários desta instituição pela amizade, carinho e paciência durante estes dois anos, em especial à Magda, à Virgínia e à Teca, pelas quais tenho muito carinho.

À professora Sandra pelo tempo dedicado de ensino de inglês, francês e grego. 
Aos meus novos amigos, a quem sempre me lembrarei com carinho como a Gil, a Manuelle, o Eduardo, o Bob, o trio de "marcelos": Marcelo Perez, Marcelo Bianchi e Marcelo Guarido, a Selma, o Gelvam, o Marcus, o Itu, a Andréa, o Danillo, a Lucieth, o Gaúcho. Um especial agradecimento ao Thiago e ao Marcelo Bianchi por toda a ajuda e paciência em ensinar-me a programar; à Alanna por toda disponibilidade no auxílio aos softwares de modelamento e inversão, e por teu coração tão bondoso; ao Miguel pelo auxílio nas discussões sobre o campo gravimétrico regional e pelo auxílio nos programas de interpolação; ao Daniel, por toda informação de formatação do trabalho; ao Wanderley e ao Clarino pela ajuda na coleta dos dados gravimétricos e aos meus recém-amigos de Ponte Branca: Elexandres e esposa.

Aos meus companheiros de turma e sala, Sérgio e Franklin, pela alegria proporcionada em nossa sala. Pelas piadas, gargalhas e discussões. Um especial abraço fraterno ao meu grande amigo Franklin, que comigo partilhou alegrias, tristezas, desânimos, madrugadas de estudo, brigas e tudo que compõe a arte da amizade. Jamais me esquecerei de seu companheirismo, humildade e amizade. Aprendi muito com você. Agradeço também à Alê, sua namorada e minha amiga, pela alegria e apoio nestes tempos.

Ao meu grande "pai" aqui em São Paulo, que zelou por mim mesmo indiretamente ao longo destes dois anos. Pela disponibilidade em conseguir o alojamento pra mim antes mesmo de me conhecer, pela atenção, paciência e alegria nas horas que os problemas assolaram. Pelos grandes incentivos que me tornaram um profissional melhor e mais dedicado. Pelos elogios quando os resultados estavam bons ou até mesmo ruins, mas que me impulsionaram a querer fazer sempre o melhor. Sim, um grande "pai" e um verdadeiro orientador, muito obrigado por tudo, professor Eder. Ganhei um amigo na pesquisa e na vida.

À minha família aqui de São Paulo, verdadeiros presentes de Deus pra mim, o Ministério Cântico dos Cânticos: Clau, Dani, Márcio, Nathi, Rogério e Carlos. Muito obrigado pelos inúmeros momentos de alegria, diversão, oração, expressão musical e principalmente pela amizade de vocês. À tia Lívia, tio Carlos, Rodrigo e vó, que também fazem parte desta família e me conquistaram com vosso amor de família. Como não agradecer à tia Terezinha, ao tio Toni, à Sandra, ao Rafa, à Larissa, à Camila, à Bê, à Michelle, ao Marcelo Lie, ao Júnior, e a todos que compõem esta grande família Cântico dos Cânticos. Sou mais santo por ter vocês comigo. Podem ter certeza que parte do meu coração aqui residirá. 
A todos os meus amigos do Movimento Universidades Renovadas e ao Pe. João Sérgio pelos momentos de orientação espiritual que fortaleceram a minha fé.

Aos meus queridos afilhados Márcio e Cíntia, Fabrício e Cássia, Robson e Lucélia, Dângelo e Stella, que a mim confiaram seus testemunhos de casados nestes dois anos, prova de seu carinho para comigo.

A todos os meus amigos que deixei em Brasília, e que souberam me entender pelas vezes em que não tive tempo para visitá-los. À minha grande amiga Sheila, que faz mestrado no INPE, por quem sempre torço e rezo e ao Titi por toda ajuda mesmo à distância.

À minha Princesa, que nestes 108 dias de existência em minha vida me compreendeu e se fez presença em meio à ausência.

Ao meu precioso ministério de música, os Arcanjos do Senhor, de Brasília: Robson, Fabrício, Ebinho, Lucélia, Kati, Cyntia, Carlinhos, Hellora, Aline, Ari e Kell, que me compreenderam e acolheram a vontade de Deus de me ausentar desta missão por estes dois anos. Muito me alegra saber que a missão de Deus continua firme e que tenho amigos de fé como vocês que me amam e torcem por mim. Ainda louvaremos a Deus juntos com nossa música por um grande tempo!

À minha maravilhosa família que me compreendeu nesta descontinuidade do tempo, e que mesmo nas inúmeras despedidas banhadas de lágrimas me apoiaram e sempre estavam abertos a acolher seu filho amado. São saudades que ficam e que foram capazes de expressar em versos de canção meu amor por vocês: papai, mamãe, Daniel, Ebinho e Carlinhos.

Por fim, agradeço ao Eterno e Santo dos Santos, minha rocha firme e proteção, e à N. Senhora por tua intercessão. Sem teu amor e fidelidade, meu Deus Amado, nada disso serviria, nada disso adiantaria nem seria possível. 


\section{Resumo}

Araguainha é a maior e mais bem exposta cratera complexa da América do Sul, formada em sedimentos horizontais da Bacia do Paraná. Sua portentosa estrutura com aproximados $40 \mathrm{~km}$ de diâmetro e $25 \mathrm{~km}$ de cavidade transiente revela um contraste negativo de densidade $\mathrm{e}$ susceptibilidade magnética na região do soerguimento central. Esta feição permite inferir um limite de propriedade física entre o Núcleo Central Soerguido (NCS) e o Embasamento Granítico Soerguido (EGS), que por sua vez apresenta baixa razão de Koenigsberger.

A caracterização geofísica de Araguainha é sustentada por modelamento 2,5D com base em informações gravimétricas, aeromagnéticas e magnéticas terrestres, o que permite classificá-la como uma estrutura concêntrica e simétrica, com profundidade média do embasamento a 1,0 km, exceto para a borda sul, que apresenta soerguimento mais acentuado. A interface embasamento/sedimento é seccionada por pares espelhados de falhas radiais que surgem no estágio de modificação da cratera. Estas estruturas rúpteis conferem as maiores profundidades à região da bacia anelar e promovem constricção dos sedimentos com tensão horizontal radial. A observação e interpretação destas deformações permitem caracterizar Araguainha como uma estrutura de impacto de domínio rúptil-dúctil.

Palavras-chave: magnetometria, gravimetria, cratera, modelagem geofísica 


\begin{abstract}
Araguainha is the largest and the best-exposed complex crater of South America, formed in horizontal sediments of the Paraná Basin. Its portentous structure with $40 \mathrm{~km}$ in diameter and $25 \mathrm{~km}$ of transient cavity reveals a negative contrast of density and magnetic susceptibility in the central uplift. That feature allows to infer a limit of physical property between the uplifted central core and the uplifted granite basement, which shows a low Konigsberger's ratio.
\end{abstract}

The geophysical characterization of Araguainha is sustained by $2,5 \mathrm{D}$ modeling with gravity, aeromagnetic, and ground magnetic information and It allows to classify it as a concentric, symmetrical structure, with average basement depth of $1.0 \mathrm{~km}$, except in the southern rim, that shows a bigger uplift. The basement/sediment interface is cut by specular pairs of radial faults that appears in the modification stage of the crater. These brittle structures are responsible for the biggest depths in the annular basin region, and they promote a sediment constriction with horizontal radial tension. The observation and interpretation of these deformations allow to characterize Araguainha as an impact brittle-ductile domain structure.

Key-words: magnetometry, gravity, crater, geophysical modeling 


\section{Índice}

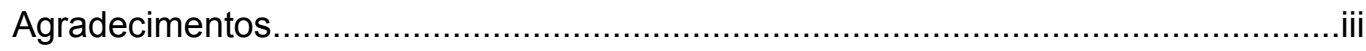

Resumo

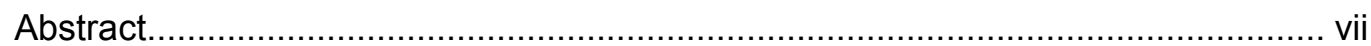

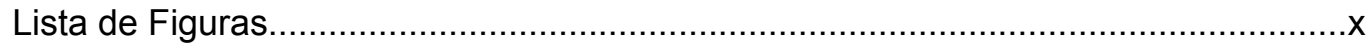

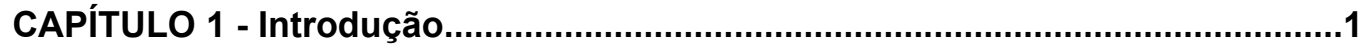

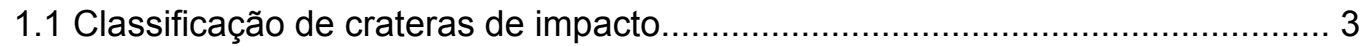

1.2 Estágios de formação de crateras de impacto................................................... 4

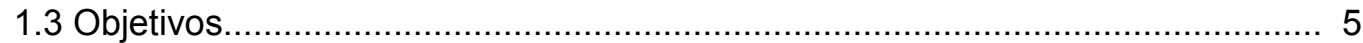

CAPÍTULO 2 - Geologia da área de estudo...................................................... 7

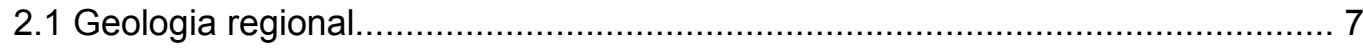

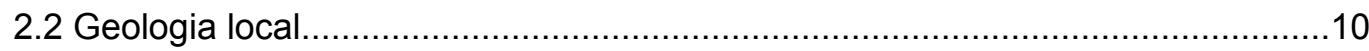

CAPÍTULO 3 - Caracterização Geofísica de crateras de impacto........................ 15

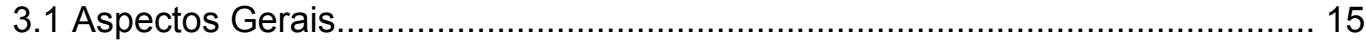

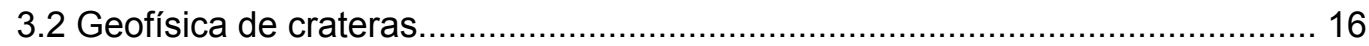

CAPÍTULO 4 - Processamento dos dados e métodos de trabalho...................... 19

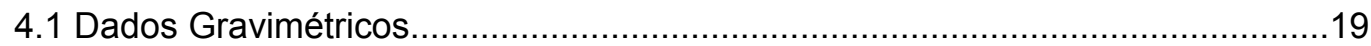

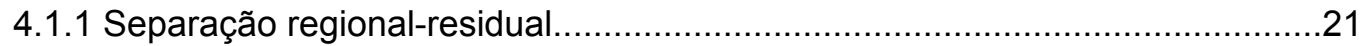

4.1.1.1 Ajuste polinomial por mínimos quadrados............................................ 23

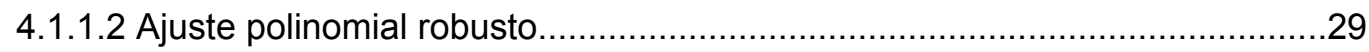

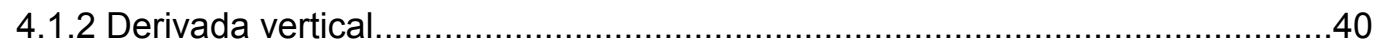

4.1.3 Propriedades físicas das amostras......................................................... 41

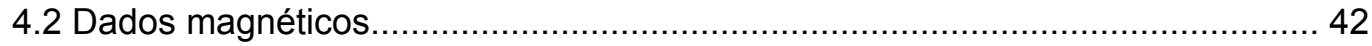

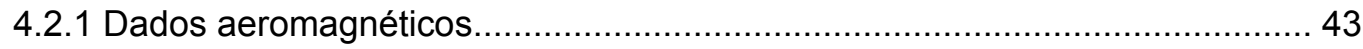

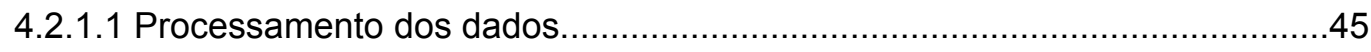

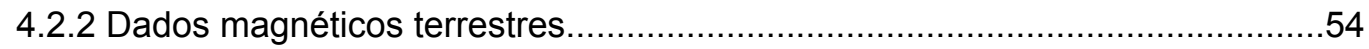

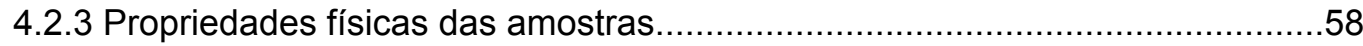


4.2.3.2 Magnetização remanescente. .59

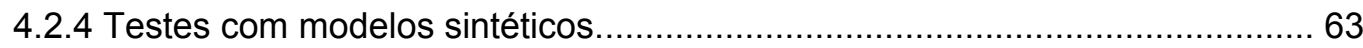

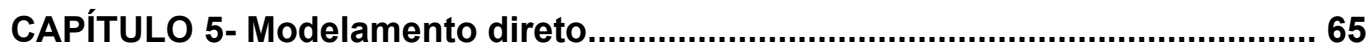

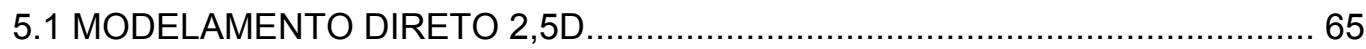

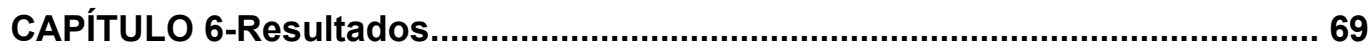

6.1 Modelamento direto $2,5 \mathrm{~d}$ de dados gravimétricos e magnéticos individuais...... 71

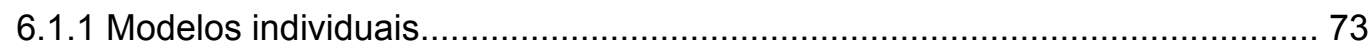

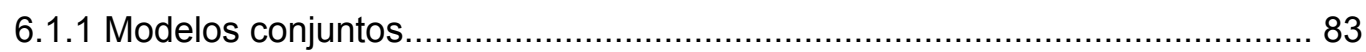

CAPÍTULO 7- Discussão e interpretação dos dados.......................................... 89

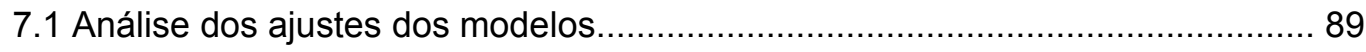

7.2 Análise da assinatura gravimétrica e magnética de Araguainha.......................90

7.3 Profundidade média do embasamento de Araguainha.................................93

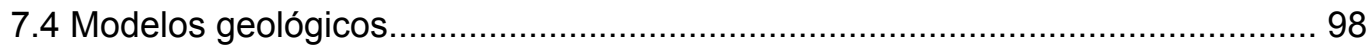

7.5 Proposta de evolução para Araguainha.................................................. 108

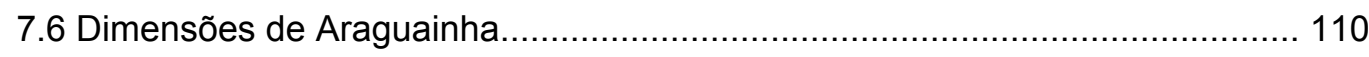

7.7 Estrutura tridimensional de Araguainha.............................................. 111

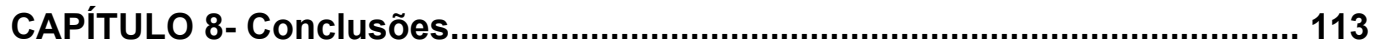

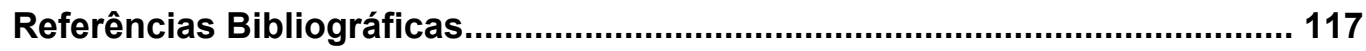

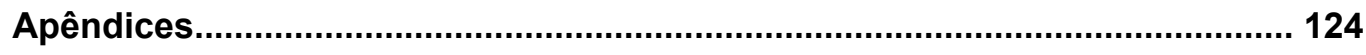




\section{Lista de Figuras}

Figura 1.1. Mapa de localização da estrutura de impacto de Araguainha com detalhe mostrado na imagem Landsat TM composição RGB 457 fundida à Banda 8 (Souza Filho, 2006).

Figura 1.2. Modelo topográfico tridimensional da cratera de Araguainha gerado a partir das curvas de nível. Observa-se o núcleo da cratera $\left(-53,0^{\circ}\right.$; $-16,8^{\circ}$ ) com elevação de aproximadamente 600 metros e topografia fortemente arrasada com exceção da borda noroeste. Exagero vertical=20vezes

Figura 1.3. Diferenças entre uma cratera simples e complexa. O pico central da cratera complexa é formado como resultado do soerguimento do material abaixo do piso da cratera. Este por conseqüência é espessado e soerguido como resposta à compressão causada pelo impacto (modificado de Melosh, 1989).

Figura 1.4. Principais parâmetros morfométricos descritos em crateras complexas. $\mathrm{D}=$ diâmetro crítico, $\mathrm{Df}=$ diâmetro do piso, $\mathrm{h}_{\mathrm{R}}=$ altura da borda, $\mathrm{W}_{\mathrm{t}}=$ espessura da zona de terraço $\mathrm{H}=$ profundidade da cratera, $\mathrm{h}_{\mathrm{cp}}=$ altura do pico central acima do piso da cratera, $D_{c p}=$ diâmetro do pico central, $\mathrm{D}_{\mathrm{ba}}=$ diâmetro da bacia anelar (Adaptado de Melosh, 1989).

Fig. 2.1. Mapa geológico simplificado da Bacia do Paraná, com o contorno estrutural (profundidade) do embasamento cristalino. Modificado de Milani (2004).

Figura 2.2. Mapa geotectônico esquemático do embasamento da bacia do Paraná. Ressalta-se a continuação do Lineamento Transbrasiliano na porção norte da bacia (Modificado de Cordani et al., 1984).

Figura 2.3. Elevação topográfica na região central de Araguainha correspondente ao núcleo granítico soerguido (Foto cedida por Cristiano Lana, Universidade de Stellenbosch, África do Sul)

Figura 2.4. Coluna estratigráfica representativa da estrutura de impacto de Araguainha (Modificado de Lana et al., 2006b).

Figura 2.5. Mapa geológico da estrutura de impacto de Araguainha (modificado de Projeto Alto Garças-PROSPEC S.A., 1971).....

Figura 4.1. Mapa de anomalia Bouguer de toda a área superposto pelas estações gravimétricas. Os cinco perfis ao longo dos quais foram realizadas as correções regionais estão representados com símbolos de cores distintas.

Figura 4.2. Perfil A-A' comparativo entre o campo Bouguer e o campo regional obtido pelo ajuste polinomial por mínimos quadrados de grau 1 a 5 , de "a" até "e", respectivamente, e seus referentes resíduos de " $\mathrm{f}$ " a "j". 
Figura 4.3. Perfil B-B' comparativo entre o campo Bouguer e o campo regional obtido pelo ajuste polinomial por mínimos quadrados de grau 1 a 5 , de "a" até "e", respectivamente, e seus referentes resíduos de "f" a "j".

Figura 4.4. Perfil C-C' comparativo entre o campo Bouguer e o campo regional obtido pelo ajuste polinomial por mínimos quadrados de grau 1 a 5 , de "a" até "e", respectivamente, e seus referentes resíduos de "f" a "j"......

Figura 4.5. Perfil D-D' comparativo entre o campo Bouguer e o campo regional obtido pelo ajuste polinomial por mínimos quadrados de grau 1 a 5 , de "a" até "e", respectivamente, e seus referentes resíduos de "f" a "j"

Figura 4.5. Perfil D-D' comparativo entre o campo Bouguer e o campo regional obtido pelo ajuste polinomial por mínimos quadrados de grau 1 a 5 , de "a" até "e", respectivamente, e seus referentes resíduos de "f" a "j".

Figura 4.7. Perfil A-A' com curva de ajuste por polinômio robusto de graus 1 a 5 mostrados nas letras "a" até "e", respectivamente. Nas figuras "f" a "j" mostrase os respectivos regionais para cada grau.

Figura 4.8. Perfil B-B' com curva de ajuste por polinômio robusto de graus 1 a 5 mostrado nas letras "a" até "e", respectivamente. Nas figuras "f" a "j" mostrase os respectivos regionais para cada grau.

Figura 4.9. Perfil C-C' com curva de ajuste por polinômio robusto de graus 1 a 5 mostrado nas letras "a" até "e", respectivamente. Nas figuras "f" a "j" mostra-se os respectivos regionais para cada grau.

Figura 4.10. Perfil D-D' com curva de ajuste por polinômio robusto de graus 1 a 5 mostrado nas letras "a" até "e", respectivamente. Nas figuras " $\mathrm{f}$ " a "j" mostra-se os respectivos regionais para cada grau.

Figura 4.11. Perfil E-E' com curva de ajuste por polinômio robusto de graus 1 a 5 mostrado nas letras "a" até "e", respectivamente. Nas figuras "f" a "j" mostrase os respectivos regionais para cada grau.

Figura 4.12. Mapa de anomalia Bouguer sobreposto por isolinhas correspondentes ao ajuste regional pelo método do polinômio robusto de terceiro grau.

Figura 4.13. Mapa Bouguer residual obtido através da remoção do polinômio robusto de terceiro grau. Destacam-se os altos valores gravimétricos na região centro-sul da área.

Figura 4.14. Mapa de confiabilidade do interpolador, que corresponde à diferença entre o valor Bouguer interpolado e o valor medido.

Figura 4.15. Representação conjunta dos dados de anomalia Bouguer e os dados topográficos. Destaca-se a coincidência entre regiões de elevada topografia com regiões que apresentam alto gravimétrico. A forte anomalia presente na região centro sul foge a esta análise

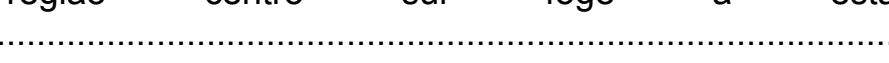


Figura 4.16. Exemplo da aplicação do método da derivada vertical de segunda ordem na delimitação de corpos com densidades distintas. A linha preta tracejada mostra a relação entre pico da derivada e alto do embasamento.

Figura 4.17. Perfis residuais obtidos ao longo da linha A-B (Figura 4.18). Notase pouca diferença entre as três análises realizadas. O perfil de cor vermelha, correspondente aos dados residuais que serão adotados para este trabalho, corrigidos a partir de dados da de Motta e Barreto (1992)

Figura 4.18. Mapa do campo magnético residual obtido dos dados aeromagnéticos a partir do modelo previsto por Motta e Barreto (1992).......

Figura 4.19. Mapas aeromagnéticos anômalos continuados para cima (a) 0,5 $\mathrm{km}$, (b) 1,0 km, (c) 1,5 km, (d) 2,0 km.

Figura 4.20. Perfil A-B comparativo entre o campo magnético anômalo obtido por meio do modelo de Motta e Barreto (1992) e os residuais do mesmo campo continuado para cima em 0,5 km, $1 \mathrm{~km}, 1,5 \mathrm{~km}, 2 \mathrm{~km}$ e $3 \mathrm{~km}$.

Figura 4.21. Mapa do campo magnético anômalo referente aos dados aeromagnéticos. A partir destes dados são extraídos os perfis para modelagem.

Figura 4.22. Mapa da amplitude do sinal analítico sobreposto por lineamentos estruturais. Observa-se o contorno do embasamento granítico soerguido (EGS) e a borda oeste da estrutura bem delimitados.

Figura 4.23. Mapa de lineamentos estruturais com localização dos perfis aeromagnéticos utilizados para o cálculo do espectro de potência. As linhas vermelhas marcam a posição onde os perfis foram extraídos.

Figura 4.24. Espectros de potência da anomalia magnética em função da freqüência. A inclinação das retas determina a profundidade média das fontes ajustadas aos pontos. $\mathrm{h}=$ profundidade da primeira fonte magnética, e $\mathrm{H}=$ profundidade da segunda fonte magnética, aqui relacionada ao embasamento.

Figura 4.25. Mapa das profundidades das primeiras fontes magnéticas obtidas com o cálculo do espectro de potência dos dados aeromagnéticos correlacionado aos lineamentos estruturais

Figura 4.26. Articulação dos perfis magnéticos terrestres (pontos vermelhos) coletados até às 13 horas de cada dia com espaçamento de 50 metros.

Figura 4.27. Comparação entre as estações de Palmas (pontos em azul) e Araguainha (cruzes em preto) para o dia 27.02. Há boa sobreposição dos dados importante na utilização da estação de Palmas para correção da variação diurna. 
Figura 4.28. Comparação entre as estações de Palmas (pontos em azul) e Araguainha (cruzes em preto) coletadas no dia 28.02. Nota-se a boa sobreposição dos dados importante para que a estação base de Palmas seja utilizada para correção da variação diurna dos dados

Figura 4.29. Comparação entre as estações de Palmas (pontos em azul) e Araguainha (cruzes em preto) coletadas no dia 01.03. Percebe-se boa sobreposição dos dados, com exceção para dados coletados na parte da tarde.

Figura 4.30. Distribuição das susceptibilidades (SI) dos diversos litotipos diferenciáveis na porção central do núcleo soerguido, (a) granitos, (b) pseudotaquilitos, (c) brechas e (d) melts. Dados cedidos por Yokoyama (2006).

Figura 4.31. Distribuição das medidas de intensidade da magnetização remanescente realizadas em amostras de granito do EGS. Dados cedidos por Yokoyama (2006)....

Figura 4.32. Distribuição das medidas de inclinação remanescente realizadas no granito do EGS. Dados cedidos por Yokoyama (2006).

Figura 4.33. Distribuição dos valores da Razão de Konigsberger (Q) para as amostras do NCS. Dados fornecidos por Yokoyama (2006).

Figura 4.34. Teste com dados sintéticos simulando a estrutura de uma cratera de impacto tipo simples através de polígonos justapostos homogêneos. $\mathrm{N}=$ número de polígonos.

Figura 4.35. Teste com dados sintéticos simulando a estrutura de uma cratera de impacto tipo complexa através de polígonos justapostos homogêneos. $\mathrm{N}=$ número de polígonos.

Figura 5.1. Corpo tridimensional com densidade $\rho\left(x^{\prime}, y^{\prime}, z^{\prime}\right)$ e forma arbitrária observada no ponto $P(x, y, z)$ (Modificado de Bakely, 1995).

Figura 5.2. Aproximação de um corpo bidimensional por um polígono de $n$ lados (Modificado de Blakely, 1995).

Figura 5.3. Elementos geométricos envolvidos na atração gravitacional de um polígono de $\mathrm{n}$ lados (Modificado de Talwani et al., 1959).

Figura 6.1. Articulação dos 14 perfis extraídos dos dados aeromagnéticos e gravimétricos para realização do modelamento $2,5 \mathrm{D}$

Figura 6.2. Mapa geológico da estrutura de Araguainha com distâncias dos principais perfis modelados (perfis 3,9,13 e 14) para o núcleo granítico. Estas e outras informações são utilizadas como medidas inseridas no modelamento (Modificado de Lana et al., 2006b). 
Figura 6.3. Perfil geológico confeccionado utilizado como base para a confecção dos modelos (Modificado de Lana et al., 2006a).

Figura 6.4. Modelo para a estrutura de Araguainha gerado a partir de dados gravimétricos extraídos ao longo do perfil 3. Nota-se um soerguimento maior do NCS e borda sul comparado às mesmas regiões a norte. As setas indicam os valores correspondentes a cada região, $d=$ diferença de soerguimento entre as bordas sul e norte; $b=$ região de borda da estrutura.

Figura 6.5. Modelo para a estrutura de Araguainha gerado a partir de dados gravimétricos extraídos ao longo do perfil 14.Nota-se estrutura praticamente simétrica ao longo da direção do perfil; $b=$ região de borda. Os valores correspondem às profundidades do embasamento em casa região ao longo do perfil.

Figura 6.6. Modelo para a estrutura de Araguainha gerado a partir de dados aeromagnéticos extraídos ao longo do perfil 3 .

Figura 6.7. Outra proposta de modelo gravimétrico em comparação com o perfil 14 da figura 6.7 para a estrutura de Araguainha. Os círculos azuis mostram as anomalias incompatíveis geradas nas bordas da anomalia central negativa, a letra "b" marca as regiões de borda.

Figura 6.8. Modelo construído a partir de dados gravimétricos ao longo do perfil 9. As regiões das bordas leste e oeste marcadas pela letra "b"mostram soerguimento simétrico, com profundidades do embasamento de $0,9 \mathrm{~km} ; \mathrm{a} / \mathrm{b}=$ região de transição entre anéis e borda.

Figura 6.9. Modelo gravimétrico gerado a partir de dados gravimétricos extraídos ao longo do perfil 13. Destaca-se a simetria do soerguimento no NCS, mostrado nas setas e nas bordas, representadas pela letra 'b'.

Figura 6.10. Modelo para a cratera de Araguainha gerado a partir de dados gravimétricos ao longo do perfil 1. Nota-se na porção norte soerguimento de aproximadamente $0,4 \mathrm{~km}$ com $0,2 \mathrm{~km}$ de expressão topográfica acima da média da região..

Figura 6.11. Modelo para a estrutura de Araguainha gerado a partir dos dados magnéticos terrestres. A linha vermelha tracejada marca o limite do início das elevações de borda noroeste. O modelo apresenta cerca de 0,8 km de diferença entre o piso da cratera e o soerguimento da borda.

Figura 6.12. Modelo para a região do EGS gerado a partir dos dados magnéticos terrestres. Mostra o contato entre a brecha de impacto de matriz fundida e o granito. Intensidade da magnetização remanescente adotada= 0,5 $\mathrm{m} / \mathrm{A}(\mathrm{SI})$; inclinação remanescente $=-35^{\circ}$.

Figura 6.13. Mapa geológico da porção interna do núcleo soerguido. A linha vermelha tracejada mostra o caminho traçado pelo perfil magnético terrestre de número 8 que define o contato entre a brecha de impacto com matriz fundida do corpo granítico (Modificado de Engelhardt et al., 1992). 
Figura 6.14. Modelamento conjunto dos dados aeromagnéticos e gravimétricos extraídos ao longo do perfil 13. As setas azuis conduzem à observação das regiões que em geral apresentam menores profundidades do embasamento; a seta verde conduz à observação das regiões que se mostram com maior espessamento; a letra "b" marca a região de borda; NCS $=$ Núcleo Central Soerguido; $\mathrm{E}=$ Espessamento ao redor do NCS.

Figura 6.15. Modelo conjunto baseado nos dados gravimétrico e magnéticos terrestres extraídos ao longo do perfil 6. A seta vermelha marcada pela letra "b" indica a região da borda nordeste da cratera; a seta vermelha indica o ponto a partir do qual os sedimentos tendem apresentar horizontalidade dos estratos com maior estabilidade e fora da área deformacional do impacto. Os estratos sedimentares tendem a diminuir sua espessura na região da borda......

Figura 6.16. Modelo conjunto baseado nos dados gravimétrico e magnéticos terrestres extraídos ao longo do perfil 8. O limite entre o corpo vermelho (granito) e o corpo cinza (brecha) marca a região contato entre ambos. Intensidade da magnetização remanescente adotada= 0,5 m/A (SI); inclinação remanescente $=-35^{\circ} ; \quad d g=$ densidade do granito, $d b=$ densidade da brecha.

Figura 6.17. Modelo conjunto baseado nos dados gravimétrico e magnéticos terrestres extraídos ao longo do perfil 9 . O modelo revela cerca de 0,8 km de diferença entre o soerguimento do NCS e o piso da cratera

Figura 7.1. Mapa regional de lineamentos mostrando a continuidade expressiva do Lineamento Transbrasiliano.

Figura 7.2. Interpretação para o limite de propriedade física que separa o embasamento abaixo das supracrustais do EGS, traçado a partir da necessidade de explicar baixos gravimétrico e magnético do centro de Araguainha.

Figura 7.3. Assimetria da assinatura gravimétrica observada no perfil 3 . Destaca-se uma anomalia de $-1 \mathrm{mGal}$ para a região norte contrastante com uma anomalia de aproximadamente $4 \mathrm{mGal}$ na região sul, ambas localizadas na bacia anelar.

Figura 7.4. Modelo gravimétrico gerado ao longo do perfil 1 mostrando soerguimento do NCS $0,3 \mathrm{~km}$ maior na porção sul se comparado à região norte (linhas tracejadas em verde). A linha tracejada azul mostra a profundidade média do embasamento na região, que serve como parâmetro inicial para comparação.

Figura 7.5. Anomalias gravimétricas relacionadas aos perfis 3 (a), e 9 (b), nos quais se observa altos gravimétricos marcados pelos círculos em azul. São interpretados como resultantes do soerguimento do embasamento abaixo das Formações Furnas e Ponta Grossa....

Figura 7.6. Proposta de modelo genético para o soerguimento central da estrutura de impacto de Araguainha. Há um maior soerguimento na região central correspondente ao EGS em relação ao NCS. O tamanho dos vetores resulta em região de maior soerguimento. 
Figura 7.7. Modelo representativo dos sedimentos da bacia gerado ao longo do perfil $11 \mathrm{com}$ base em informações aeromagnéticas. A diferença de aproximadamente $0,5 \mathrm{~km}$ refere-se à diferença a profundidade média do embasamento na região (linha tracejada vermelha), e o soerguimento da borda (linha tracejada azul). O soerguimento estaria refletindo em cerca de 0,2 $\mathrm{km}$ de expressão topográfica, o que resultaria em aproximadamente $0,3 \mathrm{~km}$ de erosão estimada na borda NW de Araguainha.

7.8. Seção geológica esquemática gerada através das informações obtidas do modelamento do perfil 3 . Nota-se a região da borda sul mais soerguida em relação à borda norte. Na borda norte há espessamento dos estratos sedimentares a partir da atuação de falhas que convergem para a região da bacia anelar. Exagero vertical $=9$ vezes...

7.9. Seção geológica esquemática com base nos resultados obtidos para o perfil 9 gravimétrico e aeromagnético. Observam-se as bordas marcadas por falhas de colapso gravitacional que convergem para a região da bacia anelar. Esta por sua vez é deformada e espessa. Exagero vertical $=9$ vezes...

Figura 7.10. Seção geológica esquemática com base em interpretação dos resultados do modelamento $2,5 \mathrm{D}$ ao longo do perfil 13 . Ressalta-se o espessamento e constricção dos sedimentos na região da bacia anelar causado pelas falhas normais. Exagero vertical $=11$ vezes

Figura 7.11. Seção geológica esquemática confeccionada com base no perfil 14. Nota-se a região da bacia anelar intensamente dobrada e com maior espessamento devido à atuação de falhas normais. Exagero vertical $=11$ vezes.

Figura 7.12. Modelos de formação do núcleo soerguido a partir de modelagem numérica. Destaca-se as regiões de espessamento assinaladas pela seta azul, que são concordantes com o espessamento observado na bacia anelar dos modelos 2,5D gerados.(Modificada de Collins et al., 2002).

7.13. Seções geológicas esquemáticas das principais estruturas de Araguainha com base em modelamento conjunto de dados gravimétricos e magnéticos terrestres (a) perfil 1, borda sudoeste, (b) perfil 6 , borda nordeste, (c) perfil 7, borda sudeste e (d) perfil 11, borda noroeste.

Figura 7.14. Banda 4 da imagem Landsat TM, sobreposta por domínios vigentes em cada região de Araguainha interpretados com base nos perfis geológicos. $R=$ domínio rúptil nas bordas e $E G S ; D=$ domínio dúctil na região da bacia anelar. As setas azuis indicam a principal tensão atuante em cada localidade no estágio de modificação da cratera. A tensão demonstrada se propaga da mesma forma radialmente em todas as direções. Imagem cedida por Souza Filho (2006). 
Figura 7.15. Proposta de evolução para a estrutura de impacto de Araguainha com base nas interpretações dos modelos geológicos e partir dos modelos French (1998) e Melosh (1989). As setas vermelhas indicam a principal tensão atuante na região. As dimensões estão fora de escala

Figura 7.16. Estimativa da profundidade de escavação obtida com base nas informações dos modelos 2,5D gerados (Modificado de Lana et al., 2006a)......

Figura 7.17. Dimensões estimadas para as principais medidas da cratera de Araguainha com base nos modelos gerados. Os valores são apresentados em quilômetros.

Figura 7.18. (a) Modelo 3D de profundidades do embasamento da estrutura de impacto de Araguainha confeccionado com base nos modelamentos 2,5D. Para obtenção deste resultado utilizou-se dos seguintes perfis: Perfil 1 conjunto aeromagnético e gravimétrico; Perfil 2 gravimétrico; Perfis 3 e 4 gravimétricos; Perfil 5 conjunto aeromagnético e gravimétrico; Perfis 6 e 7 gravimétricos; Perfil 8 conjunto aeromagnético e gravimétrico; Perfis 9, 10, 11, 13 e 14 gravimétricos. (b) Mapa 2D de profundidades do embasamento sobreposto por lineamentos estruturais. Destaca-se a região do núcleo central soerguido (NCS). As maiores profundidades se apresentam na região da bacia anelar, com cerca de 1,4 km. 


\section{CAPÍTULO 1}

\section{Introdução}

Crateras de impacto de meteorito são feições observadas em todos os astros e satélites não gasosos do Sistema Solar (French, 1998), delineadas por uma depressão circular rodeada por um anel montanhoso.

Araguainha é reconhecida como a maior cratera de impacto dentre oito existentes na América do Sul (Earth Impact Database, 2005). Foi definida por ThenWillige (1981) e Crósta et al. (1981) como uma cratera formada pelo impacto de meteorito, através de evidências geomorfológicas, petrográficas, e geofísicas. Com cerca de $40 \mathrm{~km}$ de diâmetro, é caracterizada morfologicamente como uma estrutura do tipo complexa formada em sedimentos da Bacia do Paraná. Dividida pelo Rio Araguaia entre os Estados de Goiás e Mato Grosso, engloba os municípios de Araguainha/MT e Ponte Branca/GO, com núcleo soerguido situado nas coordenadas $16^{\circ} 47^{\prime}$ S e $52^{\circ} 59^{\prime} \mathrm{W}$ (Figura 1.1). O núcleo soerguido apresenta cerca de $5 \mathrm{~km}$ de rocha com composição granítica, envolvida por $7 \mathrm{~km}$ de rochas sedimentares dobradas e falhadas com $\mathrm{o}$ impacto.

Sua topografia é relativamente acidentada, com maior destaque para a borda noroeste, que apresenta maiores elevações (Figura 1.2). É envolta por anéis e bordas bem preservados e definidos por falhas radiais e concêntricas (Lana et al., 2006b) que mergulham em direção ao centro da estrutura (Crósta, 1999). No entanto, suas camadas superiores revelam elevado grau de erosão principalmente na região rebaixada, na porção sudeste da estrutura.

A estrutura possui diversas feições típicas de impacto, tais como brechas e bombas de impacto, cones de estilhaçamento, e outros produtos que evidenciam intensa deformação e fusão no centro da estrutura.

Engelhardt et al. (1992) e Hammerschmidt e Engelhardt (1995) obtiveram quatro idades Ar-Ar para os produtos de fusão do centro do impacto variando entre $243,3 \pm 3$ Ma e $247 \pm 5,5 \mathrm{Ma}$, indicando que o impacto teria ocorrido perto do limite PermoTriássico. 


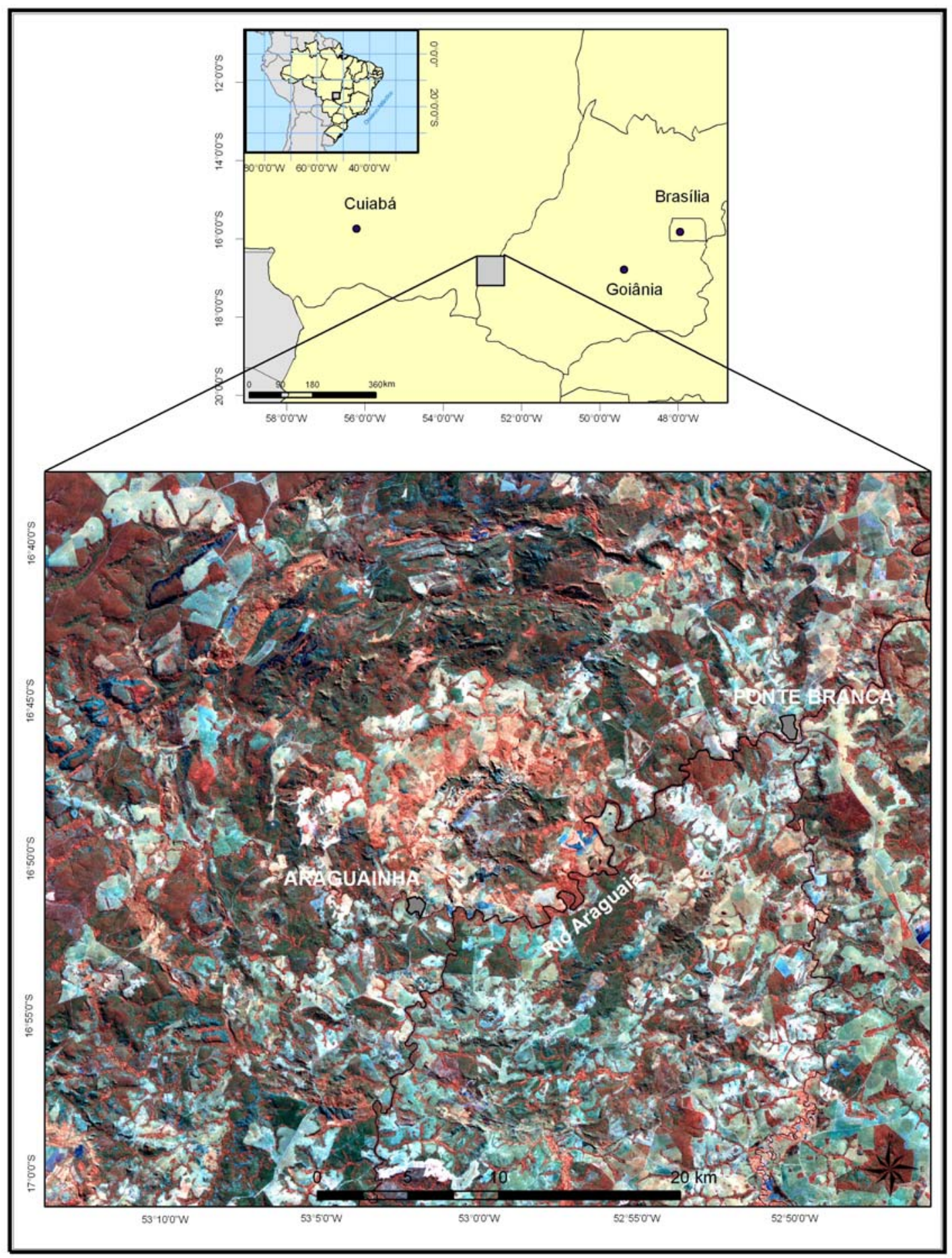

Figura 1.1. Mapa de localização da estrutura de impacto de Araguainha com detalhe mostrado na imagem Landsat TM composição RGB 457 fundida à Banda 8 (Souza Filho, 2006). 


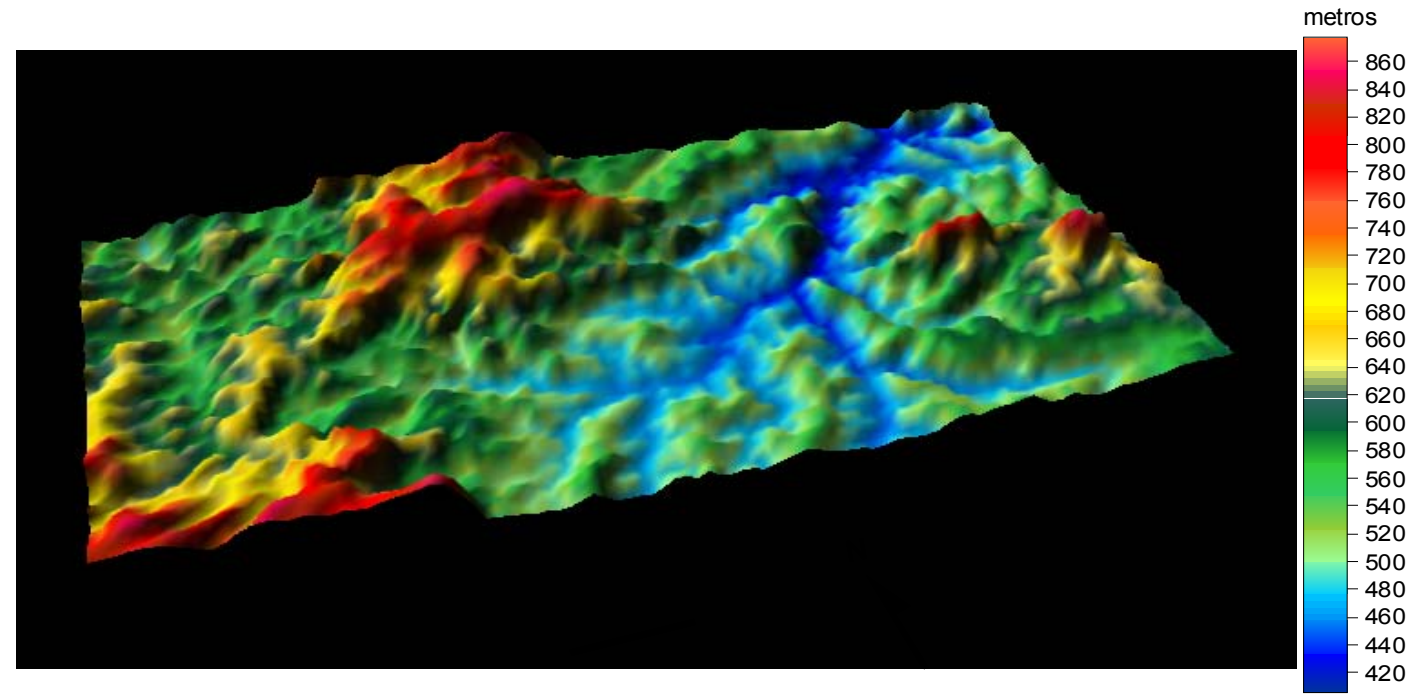

Figura 1.2. Modelo topográfico tridimensional da cratera de Araguainha gerado a partir das curvas de nível. Observa-se o núcleo da cratera $\left(-53,0^{\circ} ;-16,8^{\circ}\right)$ com elevação de aproximadamente 600 metros e topografia fortemente arrasada com exceção da borda noroeste. Exagero vertical $=20$ vezes.

\subsection{CLASSIFICAÇÃO DE CRATERAS DE IMPACTO}

As crateras de impacto formadas na Terra são subdivididas em dois grupos principais: crateras simples e crateras complexas (Figura 1.3). Sua morfologia depende da dimensão, velocidade e ângulo de incidência do projétil, composição da rocha-alvo e da gravidade do planeta (Pike, 1980 apud Pilkington \& Grieve, 1992).

As crateras simples são estruturas menores com diâmetro de até $20 \mathrm{~km}$ caracterizadas por uma geometria uniformemente côncava, sugerindo pouco ou nenhum colapso gravitacional após o impacto. Possuem profundidade máxima no centro da estrutura e são desprovidas de núcleo soerguido e terraços nas bordas (Melosh, 1989).

Já as crateras complexas apresentam o núcleo soerguido, escarpas anelares e terraços de borda condicionados a falhas normais. Seu assoalho achatado (Melosh, 1989) é formado como o resultado de colapsos gravitacionais de grande escala na cratera transiente (O'Keefe and Ahrens, 1999). O diâmetro é variável em geral entre 20 e $150 \mathrm{~km}$ com razão profundidade/diâmetro relativamente baixa. O diâmetro final da cratera costuma ser de 20 a 30 vezes maior que o diâmetro do projétil. 


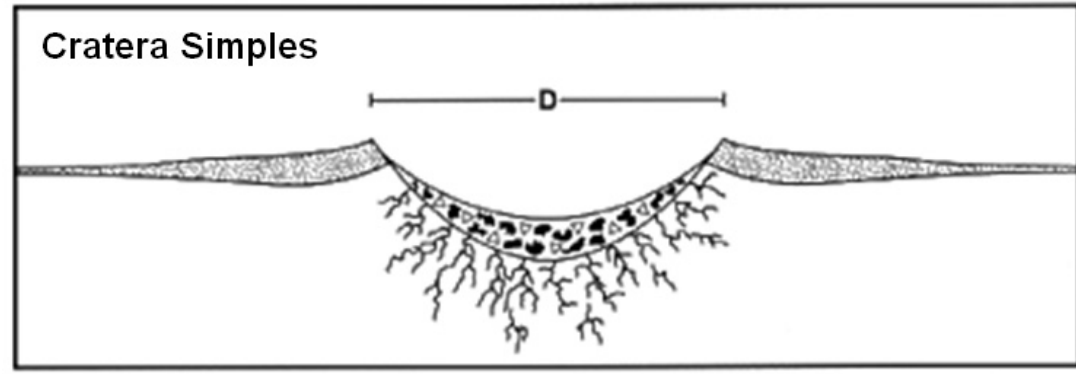
$\triangle$ Brecha
กิt
Substrato fraturado
Material fundido
Material ejetado

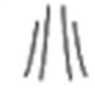
Núcleo central soerguido

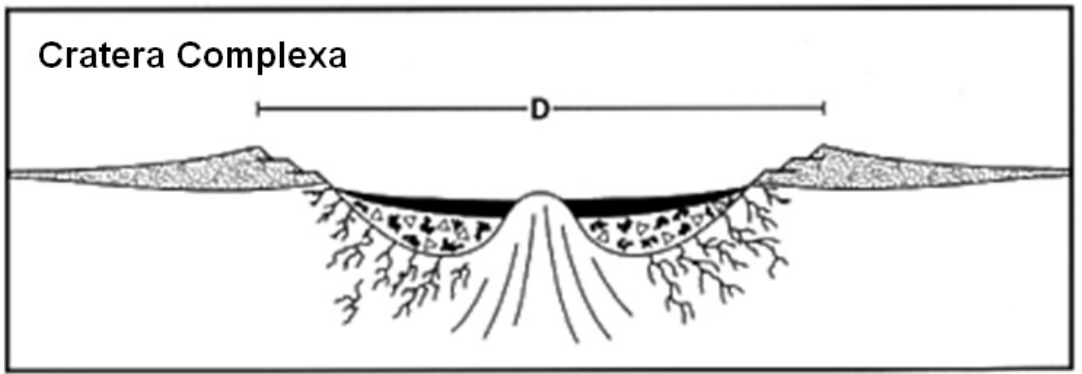

Figura 1.3. Diferenças entre uma cratera simples e complexa. O pico central da cratera complexa é formado como resultado do soerguimento do material abaixo do piso da cratera. Este por conseqüência é espessado e soerguido como resposta à compressão causada pelo impacto (modificado de Melosh, 1989).

\subsection{ESTÁGIOS DE FORMAÇÃO DE CRATERAS DE IMPACTO}

Os processo envolvido na formação de crateras de impacto é contínuo e complexo. French (1998) o divide em três estágios distintos, nos quais predominam diferentes forças e mecanismos: compressão, escavação e modificação.

O estágio de compressão inicia-se quando o projétil entra em contato com a superfície-alvo transferindo energia cinética por ondas de choque. No ponto de impacto a pressão pode exceder $100 \mathrm{GPa}$, produzindo fusão total ou mesmo vaporização do projétil em poucos segundos. Acredita-se que devido à pressão este processo não produza deformação permanente nas rochas. Entretanto, as ondas sísmicas podem produzir brechação, fraturamento e falhas.

O processo de escavação inicia-se imediatamente após o término da compressão, convertendo energia de onda de choque em energia cinética. As rochasalvo são direcionadas para fora do ponto de impacto, produzindo fluxo de escavação simétrico rodeando o centro afetado. O movimento do material para cima e para baixo produz a cavidade transiente. A cavidade transiente é uma depressão com borda 
soerguida com formato aproximadamente esférico e profundidade de $1 / 3$ do seu diâmetro.

A escavação então termina quando a cavidade transiente atinge seu tamanho máximo, dando imediato início à modificação. O soerguimento central em crateras complexas inicia-se na transição entre os dois estágios. Na modificação as ondas de choque decaem para ondas de tensões elásticas para além região de borda. Então, a cavidade transiente é modificada por fatores de gravidade com a formação das falhas de colapso gravitacional.

\subsection{OBJETIVOS}

Apesar do grande número de trabalhos em Araguainha envolvendo principalmente mapeamento e caracterização mineralógica, o conhecimento de sua estruturação em profundidade é ainda desprovido de detalhes. Trabalhos de mapeamento pioneiros são descritos por Theilen-Willige (1981) e Crósta et al. (1981), além de dados magnetotelúricos coletados por Masero et al. $(1994,1997)$ e Schnegg \& Fontes (2002).

O escopo deste trabalho é estudar a estrutura de Araguainha utilizando a interpretação conjunta de dados derivados de métodos potenciais (gravimetria e magnetometria), bem como caracterizar, do ponto de vista petrofísico (densidade, susceptibilidade magnética e magnetização remanescente), os diferentes produtos de impacto. Estes dados permitem investigar a forma tridimensional de Araguainha definindo parâmetros de interesse na caracterização dessa estrutura, incluindo as dimensões da cavidade transiente, seu diâmetro crítico,a bacia anelar, o soerguimento total e a profundidade de escavamento (Figura 1.4), e outras questões deformacionais. Além disso, esta análise permite comparar a assinatura geofísica a outras crateras de impacto complexas da Terra. Pilkington \& Hildebrand (2003), por exemplo, mostram que é possível estimar as dimensões de estruturas de impacto por meio de anomalias magnéticas.

A investigação da estrutura de impacto de Araguainha, abordada nesta dissertação, envolve modelamento 2,5D das anomalias gravimétricas e magnetométricas subsidiado por estudos disponíveis no grupo de paleomagnetismo do IAG/USP (Yokoyama, 2006).

Theilen-Willige (1981) chamou a atenção para anomalias negativas nos mapas aeromagnéticos coincidentes com a porção central do Domo de Araguainha; entretanto, 
nenhum modelamento destes dados foi realizado. Poucas estruturas de impacto foram modeladas com métodos potenciais até o momento. Dentre elas, destaca-se Vredefort (Henkel \& Reimold, 1998), Chicxulub (Espindola et al., 1995, Pilkington \& Hildebrand, 2000; Ebbing et al., 2001) e Morokweng (Henkel et al., 2002). Desta forma, este trabalho pretende apresentar uma contribuição no entendimento geofísico da estruturação e gênese de crateras complexas.

Os perfis ao longo dos quais os dados são modelados cobrem toda a estrutura de forma a auxiliar na comparação dos dados e ajudar no entendimento tridimensional de Araguainha.

Para auxiliar o entendimento deste trabalho alguns termos utilizados devem ser definidos, tais como:

- Núcleo Central Soerguido (NCS) - região soerguida localizada abaixo dos estratos sedimentares das formações Furnas, Ponta Grossa e do granito aflorante.

- Embasamento Granítico Soerguido (EGS) - corresponde ao corpo granítico soerguido e rochas associadas (brechas, melts, pseudotaquilitos e xenólitos) da porção central da cratera.

- Embasamento - rochas localizadas abaixo dos estratos sedimentares que demonstram menores mudanças de propriedade física que o EGS.

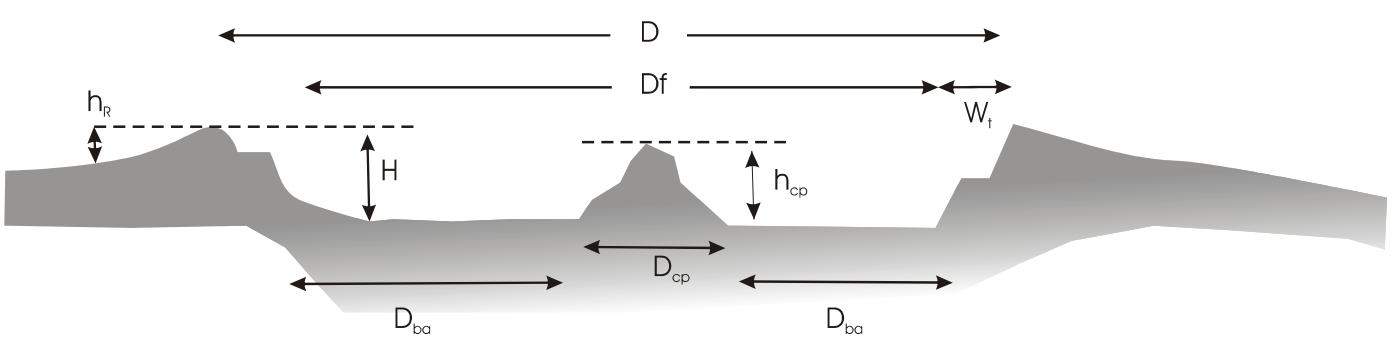

Figura 1.4. Principais parâmetros morfométricos descritos em crateras complexas. $D=$ diâmetro crítico, $\mathrm{Df}=$ diâmetro do piso, $\mathrm{h}_{\mathrm{R}}=$ altura da borda, $\mathrm{W}_{\mathrm{t}}=$ espessura da zona de terraço $\mathrm{H}=$ profundidade da cratera, $h_{c p}=$ altura do soerguimento central acima do piso da cratera, $D_{c p}=$ diâmetro do pico central, $D_{b a}=$ diâmetro da bacia anelar (Adaptado de Melosh, 1989). 


\section{CAPÍTULO 2}

\section{Geologia da área de estudo}

\subsection{GEOLOGIA REGIONAL}

Considerada uma das mais proeminentes sinéclises do continente sul-americano (Milani, 1997), a Bacia do Paraná cobre uma vasta região formada por uma sucessão sedimentar-magmática situada na porção centro-oriental da América do Sul (Figura 2.1). Evoluiu durante o Paleozóico e o Mesozóico e abriga um registro estratigráfico posicionado entre o Neo-Ordoviciano e o Neocretáceo. Nesse transcorrer do tempo geológico, sucessivos episódios de sedimentação acomodaram seus depósitos no que viria a ser uma bacia de registro policíclico (Milani, 2004 apud Mantesso-Neto et al. ,2004).

O condicionamento tectônico estabelecido pelas estruturas do embasamento teve grande importância na origem das bacias sedimentares brasileiras (Cordani et al., 1984). As sinéclises do Paraná e do Maranhão implantaram-se sobre áreas formadas ou reativadas durante o Neoproterozóico. Estas sinéclises formavam uma enorme área com mais de 2 milhões de $\mathrm{km}^{2}$, coberta por sedimentação paleozóica. Do lado africano, bacias paleozóicas relativamente menores são correlatas às brasileiras, como a bacia do Etjo, que está em continuidade física aparente com a Bacia do Paraná na reconstrução pré-deriva (Cordani et al., op.cit.).

$\mathrm{Na}$ Bacia do Paraná as primeiras incursões marinhas se iniciaram no Neoordoviciano ( $\pm 450 \mathrm{Ma}$ ). A Bacia passou por estágios de glaciação no Neocarbonífero e desertificação do interior continental no intervalo Triássico-Jurássico e registrou ainda um importante evento magmático Mesozóico, até o encerramento do processo sedimentar com depósitos continentais no neo-Cretáceo ( $\pm 65 \mathrm{Ma})$. Esta história evolutiva representa um intervalo de cerca de $385 \mathrm{Ma}$, no qual estão registrados períodos descontínuos de sedimentação limitados por discordâncias regionais, relacionados a variações eustáticas do nível do mar, associada a eventos de subsidência ocorridos no continente, em resposta aos esforços orogênicos paleozóicos na borda oeste e ao processo de abertura do oceano Atlântico Sul (Milani, 1997).

Geograficamente, a bacia inclui porções territoriais do Brasil meridional, Paraguai oriental, nordeste da Argentina e norte do Uruguai, totalizando uma área que ultrapassa $1.500 .000 \mathrm{~km}^{2}$ (Fig. 2.1). É caracterizada como uma bacia intracratônica, de 
forma ovalada, com eixo maior NNE-SSW. Sua atual configuração reflete a reativação de estruturas tectônicas mais velhas do embasamento, causada por fenômenos póspaleozóicos do continente sul-americano. Esta reativação promoveu uma grande subsidência nas direções NNE, NE e NW (Melfi et al., 1988).

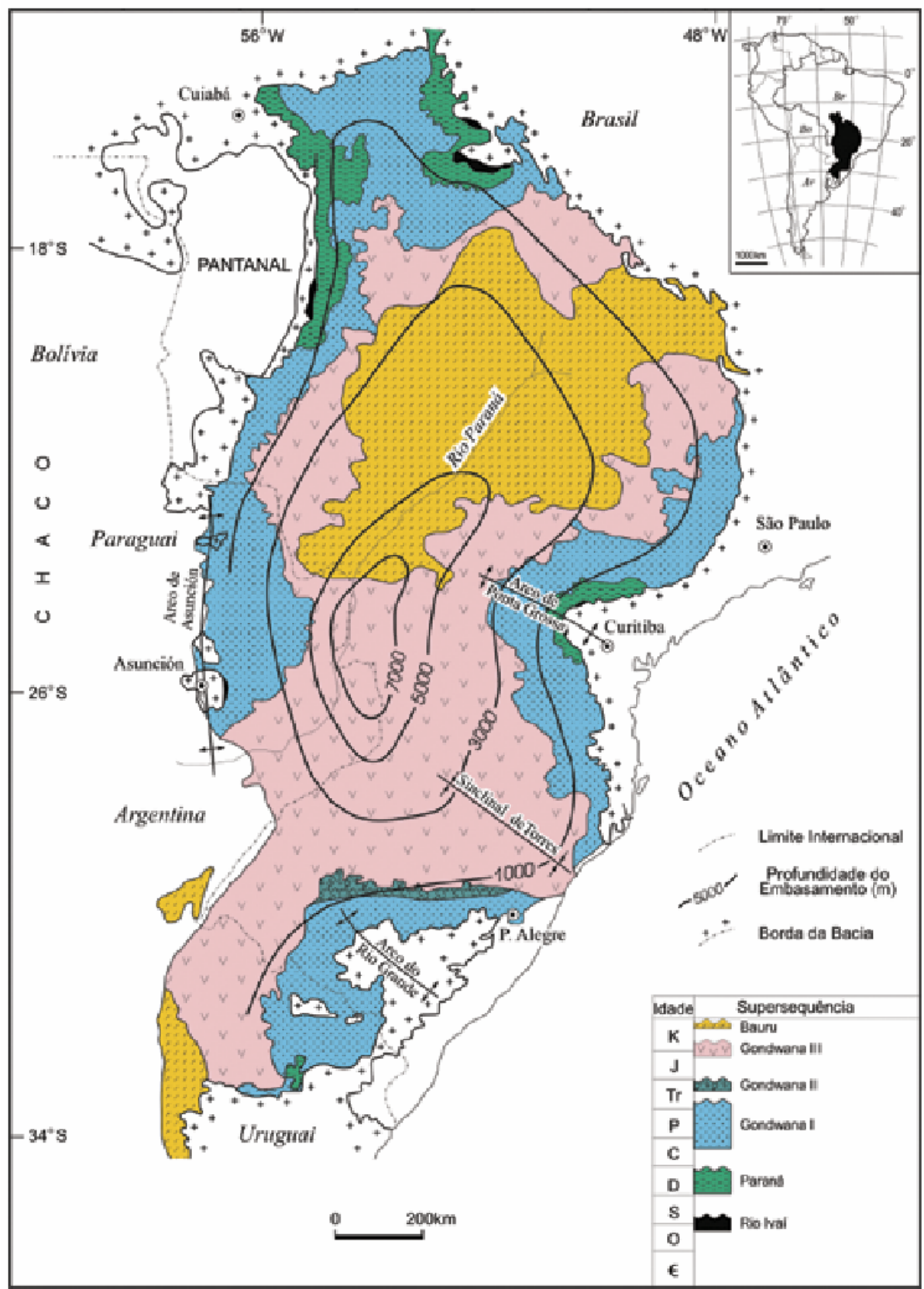

Fig. 2.1. Mapa geológico simplificado da Bacia do Paraná, com o contorno estrutural (profundidade) do embasamento cristalino. Modificado de Milani (2004, apud MantessoNeto et al. ,2004). 
O embasamento da bacia é constituído pela interação de blocos crustais que foram soldados durante o processo colisional Brasiliano, por ocasião da consolidação do Gondwana (Filho et al., 2005). Informações extraídas do mapa de Milani (2004, apud Mantesso-Neto et al. ,2004) e as isolinhas de Zalan et al. (1986 apud Molina et al., 1989) feitas com base em furos de sondagem e sísmica mostram um embasamento com profundidade aproximada de $1 \mathrm{~km}$ na região noroeste da bacia.

O flanco leste da bacia foi esculpido pela erosão em função do soerguimento marginal ao rifte sul-atlântico, expondo profundamente o embasamento cristalino. $\mathrm{Na}$ porção oeste, a Bacia do Paraná é limitada pelo Arco de Assunção, uma feição positiva originada pela sobrecarga litosférica imposta ao continente pelo cinturão andino (Milani, 2004 apud Mantesso-Neto et al., 2004).

As mais significantes feições ao longo dos limites e dentro da bacia são estruturas tipo-arco alongadas, as quais limitam o embasamento e seccionam as bordas da bacia. Os limites norte da Bacia do Paraná são marcados por intenso dobramento e zona pré-cambriana superior na margem do cráton Amazônico, que é interrompida em seu segmento leste por uma série de grandes falhas (Cordani et al., 1984). A continuação destas falhas adentra a bacia e pode representar um significante lineamento NE-SW do embasamento na porção norte da Bacia do Paraná (Figura 2.2).

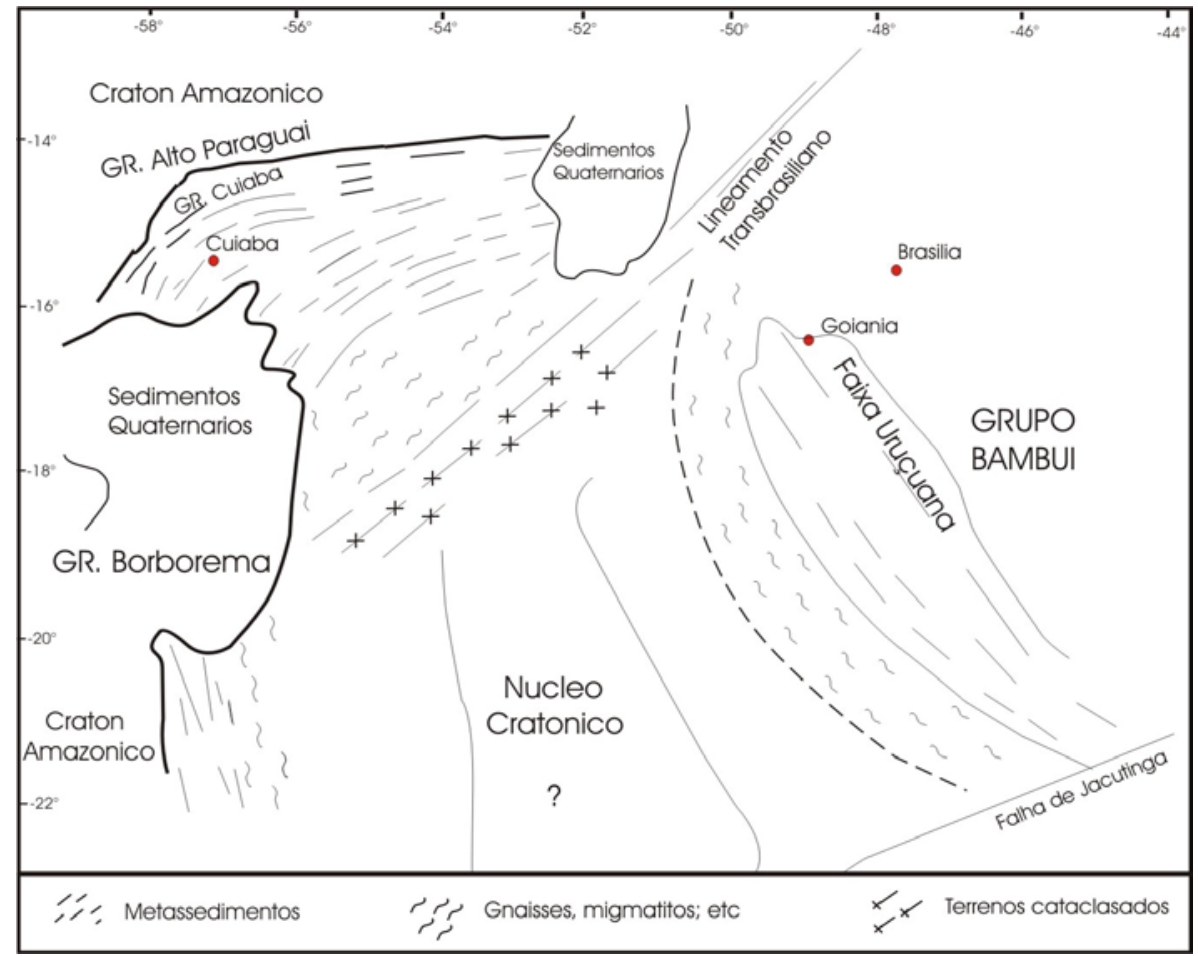

Figura 2.2. Mapa geotectônico esquemático do embasamento da bacia do Paraná. Ressalta-se a continuação do Lineamento Transbrasiliano na porção norte da bacia (Modificado de Cordani et al., 1984). 


\subsection{GEOLOGIA LOCAL}

A cratera de Araguainha foi formada em sedimentos horizontalizados da Bacia do Paraná (250Ma) na porção central do Brasil (Engelhardt et al., 1992; Hippertt \& Lana, 1998), e compreende estratos do Devoniano ao Permiano-Triássico e rochas do embasamento cristalino subjacentes. Mapeamentos de campo ao longo da estrutura (Theilen-Willige, 1981; Crósta et al., 1981; Engelhardt et al., 1992) mostram a presença de sedimentos dos Grupos Grupo Passa Dois, Tubarão e Paraná.

O núcleo soerguido de Araguainha, com aproximadamente $12 \mathrm{~km}$ de diâmetro, é circundado por uma zona variando de $8-10 \mathrm{~km}$ de anéis montanhosos, onde a maior parte dos estratos foram dobrados e falhados durante o impacto. A zona intermediária entre a região dos anéis e o núcleo soerguido que engloba as formações Ponta Grossa e Aquidauana é definida por Lana et al. (2006b) com bacia anelar. A parte central do núcleo soerguido (Figura 2.3), com aproximadamente $4 \mathrm{~km}$ de diâmetro, é formada pelo embasamento granítico alcalino, de granulometria fina a grosseira, que exibe feições de metamorfismo de choque (Crósta, 2004). É envolto por 3 a 4 km de largura de arenitos, siltitos e argilitos do Grupo Paraná.

As rochas expostas em torno do núcleo soerguido e nas bordas da estrutura compreendem arenitos Carboníferos do Grupo Tubarão e sedimentos Permianos do Grupo Passa-Dois. Os arenitos Carboníferos estão expostos dentro e fora da estrutura. O anel externo da cratera é constituído por cristas, representando os remanescentes de grábens semi-circulares, formados por falhas de colapso que mergulham em direção ao centro da estrutura (Crósta, 1999). Esses grábens são formados por sedimentos permianos do Grupo Passa Dois, altamente deformados (Crósta, 2004).

O Grupo Paraná apresenta cerca de 1000 metros de sedimentos fluviais e marinhos devonianos das formações Furnas e Ponta Grossa espessura (Engelhardt et al., 1992). Lana et al. (2006b) afirmam que o mesmo atinge $3 \mathrm{~km}$ de espessura na região do soerguimento central. Para os autores, este fato confirmaria a sugestão de que o espessamento do pacote de rochas pode ocorrer durante o colapso. O referido espessamento deste estrato sedimentar ao redor do soerguimento central estaria relacionado à constricção de sedimentos na parte central da cratera que atinge escala quilométrica dobrando as rochas do piso da cratera.

Os sedimentos da Formação Furnas são formados por arenitos marinhos e conglomerado basal (Crósta, 2004). O conglomerado ocorre com 2 a 3 metros de espessura, sobreposto por arenito grosso intercalado com camadas centimétricas de 
arenito fino e siltito (Fig. 2.4). Correlação estratigráfica e dados de furo de sondagem (Engelhardt et al., 1992) indicam aproximadamente $250 \mathrm{~m}$ de espessura para esta formação.

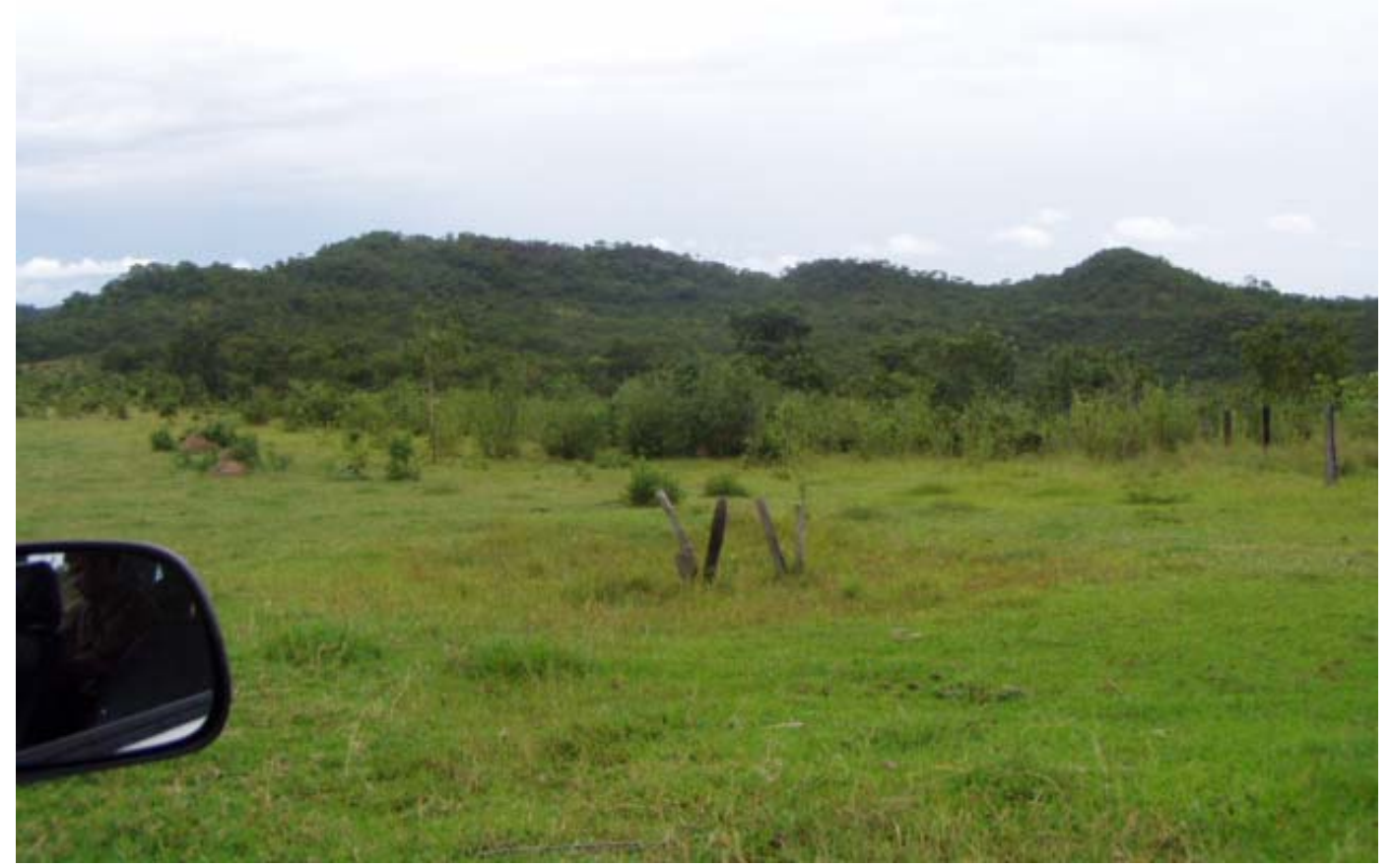

Figura 2.3. Elevação topográfica na região central de Araguainha correspondente ao núcleo granítico soerguido (Foto cedida por Cristiano Lana, Universidade de Stellenbosch, África do Sul).

A Formação Ponta Grossa é formada por um pacote de $465 \mathrm{~m}$ fora dos limites da cratera, nas proximidades da cidade de Alto Garças (Engelhardt et al., 1992). Consiste dominantemente de siltitos e arenitos ricos em ferro dispostos em camadas plano-paralelas que variam em sua tonalidade de ocre a vermelho.

O contato entre a Formação Ponta Grossa e o Grupo Tubarão é marcado por uma superfície erosiva causada por regressão marinha no Carbonífero (Milani \& Zalan, 1999). A sedimentação do Grupo Tubarão é marcada na região de estudo pela Formação Aquidauana. Esta, por sua vez, atinge aproximadamente 800 metros (Engelhardt et al., 1992) de conglomerados continentais ricos em ferro, além de arenitos marinhos e lacustres. As estratificações cruzadas são freqüentes. 
O Grupo Passa Dois é constituído na região pela Formação Irati, que é formada por carbonatos, folhelhos escuros, além de siltitos e chert. As camadas de chert podem se apresentar brechadas baixo do contato com a Formação Aquidauana.

Muitos sills cretáceos de composição basáltica intrudem os sedimentos do Grupo Passa-Dois. Estes são intrusivos equivalentes às rochas vulcânicas da Formação Serra Geral (Lana et. al, 2006b). Uma proposta de coluna estratigráfica é apresentada na figura 2.4).

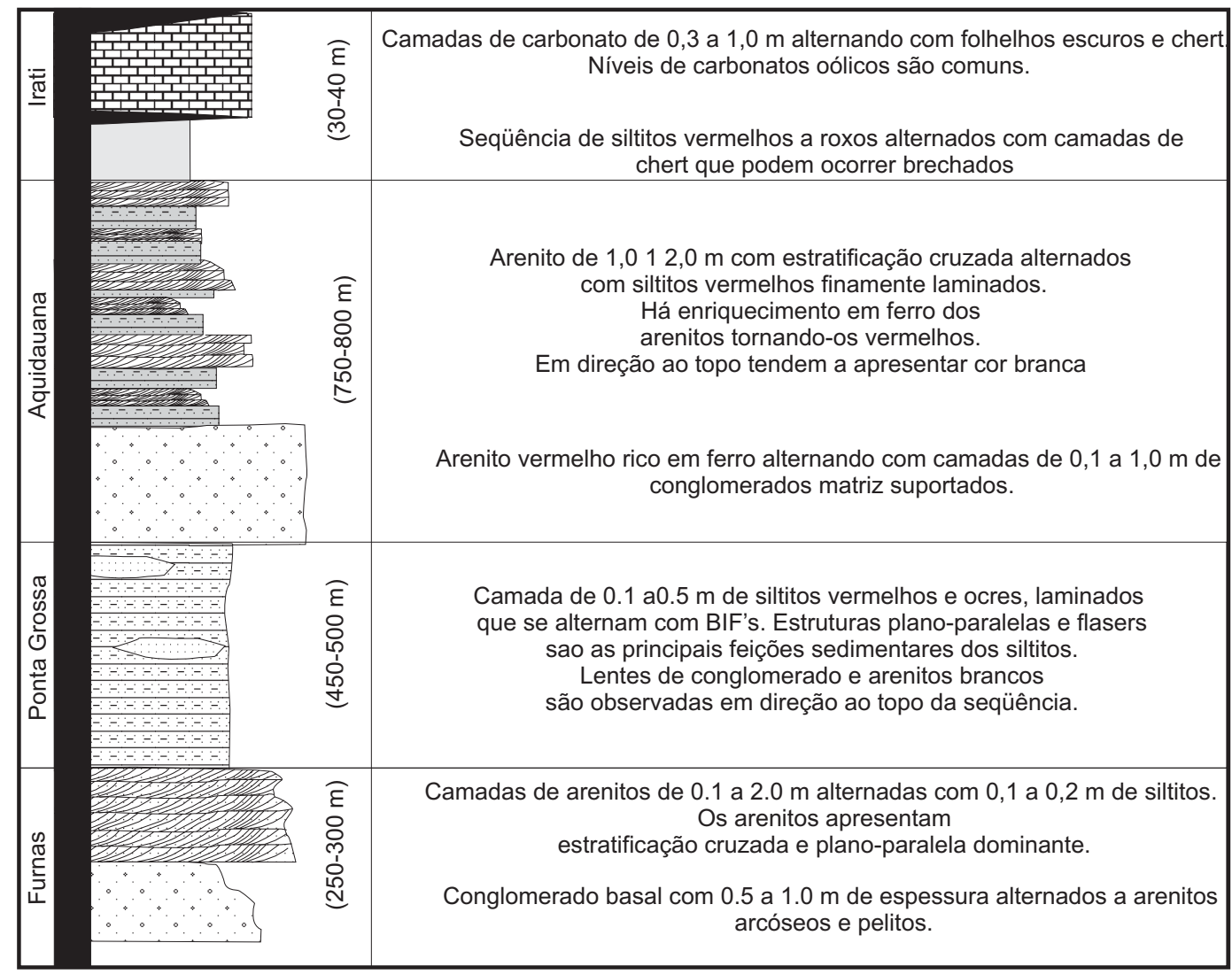

Figura 2.4. Coluna estratigráfica representativa da estrutura de impacto de Araguainha (Modificado de Lana et al., 2006b).

Masero et al. (1994) realizaram um levantamento magnetotelúrico ao longo da cratera e concluíram que o embasamento forma uma anel simétrico bem definido a uma profundidade de $1 \mathrm{~km}$, entre os raios de 9 a $20 \mathrm{~km}$ a partir do centro, decaindo após o raio de $20 \mathrm{~km}$. Com o auxílio de modelagem magnetotelúrica 2-D e 3-D Masero et al. (1997) também descobriram um corpo no formato discóide no interior do granito a profundidades entre 3 e $7 \mathrm{~km}$, caracterizados por valores de resistividade abaixo do 
valor da crosta superior, e o relacionam a processos de falhamento e brechação induzidos pelo impacto.

A profundidade de escavação induzida pelo impacto é estimada por Engelhardt el al. (1992) em 2400 metros, que representa 1/10 do diâmetro da cratera transitória estimada em 24 km. Muito próximo a estes valores, Lana et al. (2006a) afirmam que a geração de uma cratera de $40 \mathrm{~km}$ de diâmetro requer 2 a 2,5 km de profundidade de escavação e 20 a 25 km de cavidade transiente.

Atualmente Araguainha não é uma cratera de impacto sensu stricto. As camadas superiores que normalmente recobrem uma cratera de impacto completa (camada superior de material fundido, depósitos de brechas e outros produtos de fusão superiores) já foram em grande parte erodidas, expondo os principais elementos estruturais, que definem a geometria e a morfologia de uma estrutura de impacto (Melosh, 1989). Somente poucos remanescentes de depósitos de impacto foram preservados, tais como finas camadas de brechas intra-formacionais na parte central da estrutura (Engelhardt et al., 1992). Associados ao embasamento soerguido há xenólitos de arenitos arcóseo e biotita-muscovita xisto com mais de 5 metros de extensão (Lana et al., 2006b). O contato exposto entre o embasamento e os estratos supracrustais é caracterizado por fraturamentos em geral e brechação como resultado do soerguimento central (Lana et al., op. cit.).

O material relacionado ao impacto pode ser dividido em brechas monomíticas, polimíticas e brechas de impacto com matriz fundida (IBM) (Crósta et al., 1981; TheilenWilige, 1981; Engelhard et al., 1992). Junto ao corpo granítico ainda ocorrem pseudotaquilitos e melts (rochas com graus diferenciados de fusão por impacto). Os pseudotaquilitos são produtos de impacto que estão encaixados nas fraturas do granito soerguido. Já os melts são rochas que tendem apresentar matriz fanerítica, mega cristais subédricos a anédricos de K-Feldspato marcados por cominuição de bordas, matriz parcialmente vítrea com bolsões vítreos situados no interior de alguns cristais, além de feições de recristalização de grão de quartzo (Yokoyama, 2006).

As feições de metamorfismo de impacto reconhecidas em Araguainha incluem a presença de shatter cones em arenitos da Formação Furnas, diversos tipos de brechas de impacto, feições planares em grãos de quartzo, feldspato e mica, tanto no embasamento granítico quanto nas brechas, feições de intensa deformação e bombas de impacto compostas por hematita.

Uma proposta do mapa geológico é apresentada na figura 2.5 . 


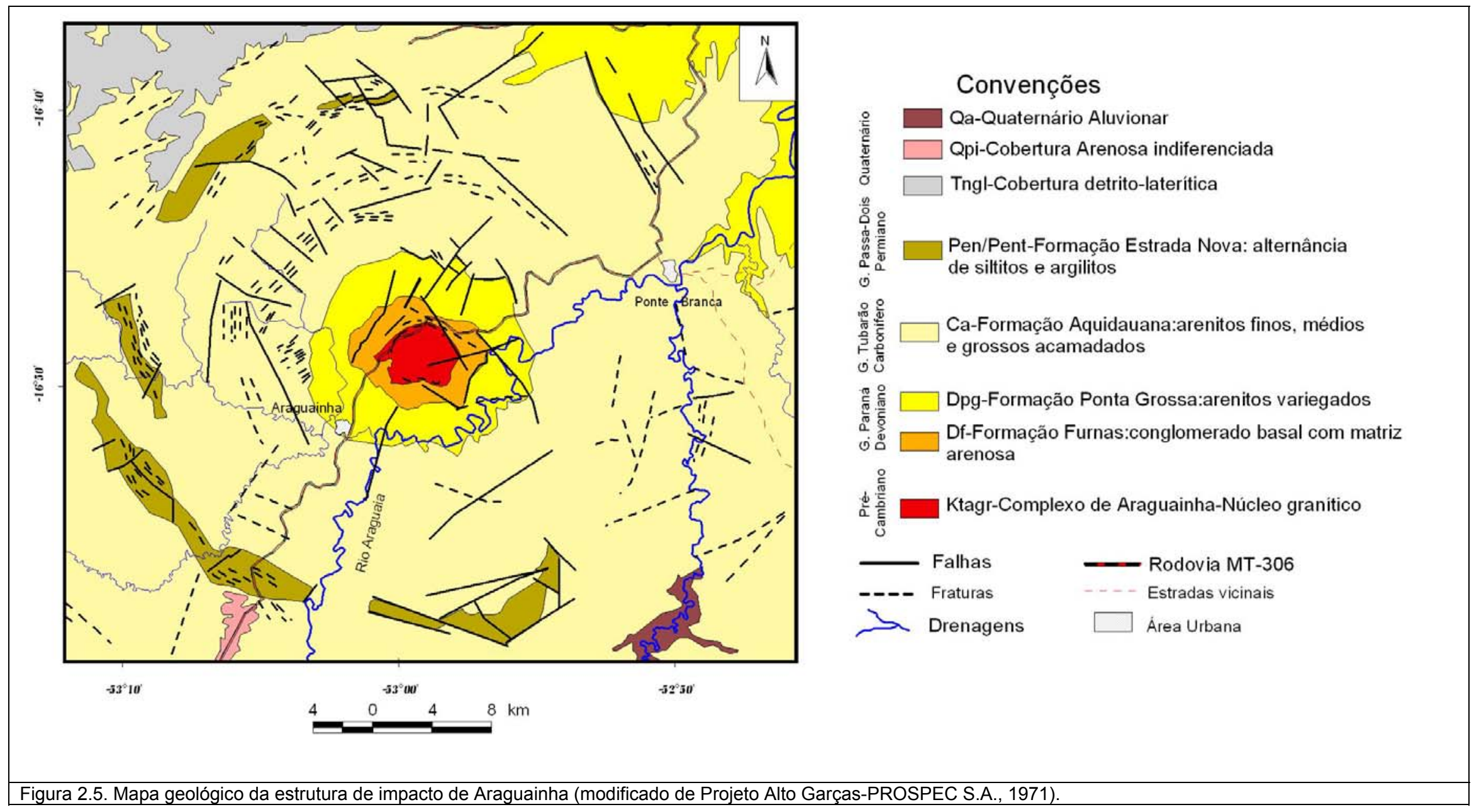




\section{CAPÍTULO 3}

\section{Caracterização geofísica de crateras de impacto}

Aproximadamente $20 \%$ das crateras terrestres estão enterradas sob sedimentos pós-impacto. Desta maneira, muitas destas estruturas foram identificadas inicialmente por meio de anomalias geofísicas (Pilkington \& Grieve, 1992). Investigações geofísicas em estruturas de impacto revelam que uma variedade de assinaturas pode resultar de mudanças físicas induzidas pelo choque. De forma geral, as crateras de impacto na superfície terrestre apresentam assinaturas geofísicas típicas (Pilkington \& Grieve, op. cit;; Pilkington e Hildebrand, 2003). Entretanto, diferenças nas rochas-alvo, dimensões e tipo de deformação produzida podem resultar em campos potenciais que fogem aos padrões esperados.

Apresenta-se neste capítulo de forma resumida as características geofísicas gerais destas estruturas e as propriedades de algumas crateras mais importantes a fim de correlacioná-las a Araguainha.

\subsection{ASPECTOS GERAIS}

Impactos de meteoritos modificam o campo de gravidade e o campo magnético no local do impacto, que passa a apresentar assinaturas diferentes das rochas ao redor. Por isso, métodos geofísicos, especialmente os potenciais, têm sido utilizados para delinear os locais das crateras de impacto do mundo.

Há uma tendência de muitas das maiores estruturas complexas de exibir um alto gravimétrico central. O estágio de compressão seria o responsável pela redução da porosidade inicial provocando o aumento de densidade (Grieve, 1988, apud Pilkington \& Grieve, 1992). Quando se trata de uma anomalia gravimétrica negativa em seu centro, esta pode estar relacionada ao forte fraturamento das rochas impactadas nesta região ou mesmo à presença de níveis de brecha.

É válido ressaltar que a presença de um alto de gravidade central não implica na existência de uma anomalia magnética central associada. As características gerais das anomalias magnéticas associadas com crateras de impacto são mais complexas do que as características de assinatura gravimétrica. O motivo reside no fato das 
crateras apresentarem maior variedade nas propriedades magnéticas das rochas e direção de magnetização (Rajasekhar e Mishra, 2005).

A mais comum assinatura magnética em crateras é um baixo (Cowan \& Cooper, 2005). A tensão produzida pelo choque pode causar tanto desmagnetização como remagnetização do alvo (magnetização remanescente de choque-MSR) (Henkel \& Reimold, 2002). A intensidade da MSR é proporcional à força do campo ambiente (Pohl et al., 1975) e descresce com a distância do ponto de impacto. Nos choques que produzem pressão maior que $10 \mathrm{GPa}$, Kumar e Ward (1963) detectaram uma redução na susceptibilidade magnética das rochas (apud Pilkington \& Grieve, 1992). Em geral, estruturas com diâmetro < $10 \mathrm{~km}$ apresentam baixos magnéticos, enquanto estruturas com diâmetro $>40 \mathrm{~km}$ exibem anomalias centrais de alta amplitude. Quando se trata de altos magnéticos o efeito pode estar relacionado ao magnetismo de choque (piezomagnetismo).

\subsection{GEOFÍSICA DE CRATERAS}

A maior estrutura de impacto conhecida no planeta, a cratera de Vredefort/África do Sul (300 km), apresenta anomalias magnéticas simétricas, negativas e curto comprimento de onda com alto gradiente. Hart et al. (2000) caracterizam as rochas localizadas em seu núcleo como "super-magnéticas", devido à forte magnetização remanescente adquirida com o impacto.

A magnetização anômala de Vredefort é relacionada por Henkel \& Reimold (2002) ao melt de impacto e à formação de suevito na parte central. Esses autores associam a aquisição de remanescência por magnetização termal com o aquecimento das rochas pela passagem das ondas de choque. Isto caracteriza a magnetização termal como tardia no processo de crateramento e posterior ao colapso da estrutura. A susceptibilidade atribuída aos seus litotipos varia de 0,001 a 0,015 SI para granito gnaisse, 0,0001 a 0,001 SI para rochas sedimentares e 0,006 a 0,1 SI para granitóides.

Análises realizadas em amostras do embasamento mostram que os valores de densidade aumentam sistematicamente com a profundidade, o que foi definido por velocidades de ondas P (Henkel \& Reimold, 1998). 
Diferindo de Vredefort, Chicxulub/México apresenta um alto magnético em seu centro e aproximadamente $7 \mathrm{mGal}$ de anomalia gravimétrica (Ebbing et al., 2001). É considerada a mais jovem e bem preservada das três maiores crateras da Terra e mostra cerca de 3 a 4 km de escavação (Pilkington \& Hildebrand, 2000). Sua anomalia magnética central coincide com o alto gravimétrico e ambos mostram-se alongados segundo uma direção NW-SE (Schultz \& D'Hondt, 1996). Essa assimetria expressa no campo gravimétrico é também apresentada na distribuição do ejecta. A assimetria, neste caso, é atribuída por Schultz \& D'Hondt (1996) como resultado de um impacto oblíquo do projétil. Informações petrofísicas mostram valores de intensidade da magnetização remanescente de 0,12 a $0,35 \mathrm{~A} / \mathrm{m}$ para a brecha, associada a 0,003 (SI) de susceptibilidade magnética. Já a densidade atribuída para estes corpos que estão dispostos nas regiões de borda é de $2,1 \mathrm{~g} / \mathrm{cm}^{3}$.

Outras estruturas de impacto menores estão ganhando expressão no cenário mundial pelos seus resultados de modelamentos obtidos. Morokweng/África do Sul com seus $70 \mathrm{~km}$ de diâmetro é em grande parte formada em granitóides Arqueanos. Apresenta uma anomalia aeromagnética central irregular e positiva coincidente com a anomalia de gravidade (Henkel et al., 2002). Dados de gravidade revelam grande anomalias relacionadas à ocorrência de litologias pré-impacto. Rochas da cobertura que rodeiam a região central geralmente estão associadas com anomalias de gravidade positivas. Ao embasamento é atribuída densidade de $2,5 \mathrm{~g} / \mathrm{cm}^{3}$ e susceptibilidade magnética de $8.10^{-4}$ a $4.10^{-2} \mathrm{SI}$.

Considerada a única cratera de impacto em rochas basálticas do mundo, Lonar/Índia, apresenta -2,25 mGal e $550 \mathrm{nT}$ de anomalias gravimétrica e magnética, respectivamente (Rajasekhar e Mishra, 2005). Os autores descrevem que o impacto responsável por esta cratera modificou o vetor de magnetização e a densidade da rocha a aproximadamente 500-600 metros abaixo da superfície. O impacto remagnetizou esta região, alterando a magnetização remanescente previamente existente. Isto implica em que a temperatura no impacto deve ter sido abaixo de $550^{\circ} \mathrm{C}$, temperatura que corresponde ao ponto de Curie da magnetita.

Os autores ainda descrevem que parte da zona brechada apresenta alta susceptibilidade, de aproximadamente $4 \times 10^{-3} \mathrm{SI}$, sugerindo concentração de magnetita nesta região, que pode representar parte do meteorito. $O$ modelo geofísico gerado mostra uma alta susceptibilidade abaixo do alto magnético associada a um baixo gravimétrico. 
Baseado nestes e outros estudos, pretende-se analisar as anomalias magnética e gravimétrica da estrutura de impacto de Araguainha, investigando as similaridades e diferenças aos dados de literatura, com o objetivo de caracterizar geofisicamente esta estrutura. 


\section{CAPÍTULO 4}

\section{Processamento dos dados e métodos de trabalho}

A base dos dados geofísicos utilizada neste trabalho é composta de dados gravimétricos, aeromagnéticos e magnéticos terrestres. Além destes, utilizam-se informações geológicas que servem como vínculos na estruturação dos modelos finais gerados.

Há diferenças significativas no comportamento dos campos gravimétrico e magnético. As variações de densidade são relativamente pequenas e uniformes quando comparadas às mudanças de susceptibilidade magnética. Além disso, anomalias gravimétricas são menores e muito mais suaves que as magnéticas (Telford, 1990).

Compreendidas estas diferenças gerais, este capítulo descreve minuciosamente a aquisição, o processamento e a metodologia aplicados, de forma a se obter um banco de dados apropriado ao modelamento geofísico.

\subsection{DADOS GRAVIMÉTRICOS}

Os dados gravimétricos utilizados neste trabalho foram coletados em uma campanha realizada no mês de julho de 2006 envolvendo uma área maior que a estrutura de impacto. Foram coletadas 230 estações gravimétricas em 90\% na área da cratera e o restante em uma área maior, além de seus limites. O levantamento gravimétrico foi realizado com um Gravímetro LaCoste \& Romberg, Modelo G, do Laboratório de Geodésia e Gravimetria do IAG/USP. As coordenadas geodésicas foram obtidas por posicionamento por satélite, usando o sistema GPS. O uso do GPS em levantamentos geodésicos ou topográficos proporciona as coordenadas retilíneas geocêntricas (X, Y, Z) referenciadas ao World Geodetic System 1984 - WGS 84, que podem ser transformadas em latitude, longitude e altitude geométrica. Para que possa ser explorada a potencialidade do GPS na altimetria, faz-se necessário o conhecimento da altura geoidal com precisão compatível com a do nivelamento. Portanto, as estações foram monitoradas pelo GPS por um período de quinze minutos, coletando-se altitudes geométricas. Realizou-se também aquisição de seis horas em algumas RN's na área de estudo (Araguainha, Ponte Branca e Alto Garças) a fim de melhorar a 
transformação da altitude geométrica em ortométrica. Para este processo foi utilizado o Geóide Gravimétrico da América do Sul (Sá, 2004). O posicionamento das estações é apresentado na figura 4.1.

Foram usadas bases próximas de Mineiros (GO), Jataí (GO) e Alto Garças (MT) no transporte de gravidade $(\mathrm{g})$ para três pontos escolhidos como bases na área de estudo. Obtiveram-se, desta forma, resultados consistentes em circuitos com deriva muito baixa, com erro de $g$ obtido para estas bases entre $\pm 0,04$ e 0,06 mGal.

Os dados da anomalia Bouguer foram interpolados pelo método da krigagem e o mapa obtido mostra uma conspícua tendência NE-SW de longo comprimento de onda que demonstra não ter relação com a estrutura de impacto (Figura 4.1).

A redução dos dados gravimétricos consiste na realização das correções de variações temporais do campo de gravidade causadas pela atração luni-solar e derivas estática e dinâmica do gravímetro, resultando no valor da aceleração da gravidade no ponto. Em seguida subtrai-se da aceleração da gravidade do ponto o valor da gravidade normal para cada estação, fornecido pela fórmula do Sistema Geodésico de Referência de 1980 (Moritz, 1984) e obtém-se a anomalia ar-livre após sua correção.

A correção ar-livre é empregada para compensar os efeitos da diferença de altitude das estações em relação ao geóide. A massa que porventura existir entre as estações e o geóide não é considerada. Assim, a anomalia ar-livre é obtida pela equação

$$
\Delta \mathrm{g}_{\mathrm{AL}}=\mathrm{g}_{\mathrm{obs}}+0,3086 \mathrm{~h}-\mathrm{g}_{\mathrm{n}}
$$

onde $g_{\mathrm{n}}$ é a gravidade normal, $h$ é a diferença entre o geóide e o ponto medido, dada em metros e $\Delta \mathrm{g}_{\mathrm{AL}}$ é dada em $\mathrm{mGal}$.

A correção Bouguer consiste em adicionar ao valor normal da gravidade a atração de um cilindro de raio infinito e altura igual à altitude do terreno no ponto de observação. $\mathrm{O}$ cilindro deve ter densidade igual à do material localizado entre o geóide e a estação

$$
\Delta g_{B}=g_{\text {obs }}+0,3086 h-g_{n}-0,04191 \rho h
$$

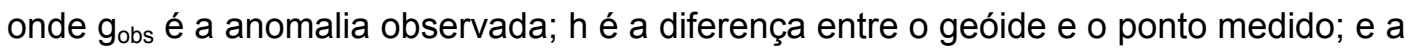
densidade $\rho$ adotada como $2,67 \mathrm{~g} / \mathrm{cm}^{3}$. 


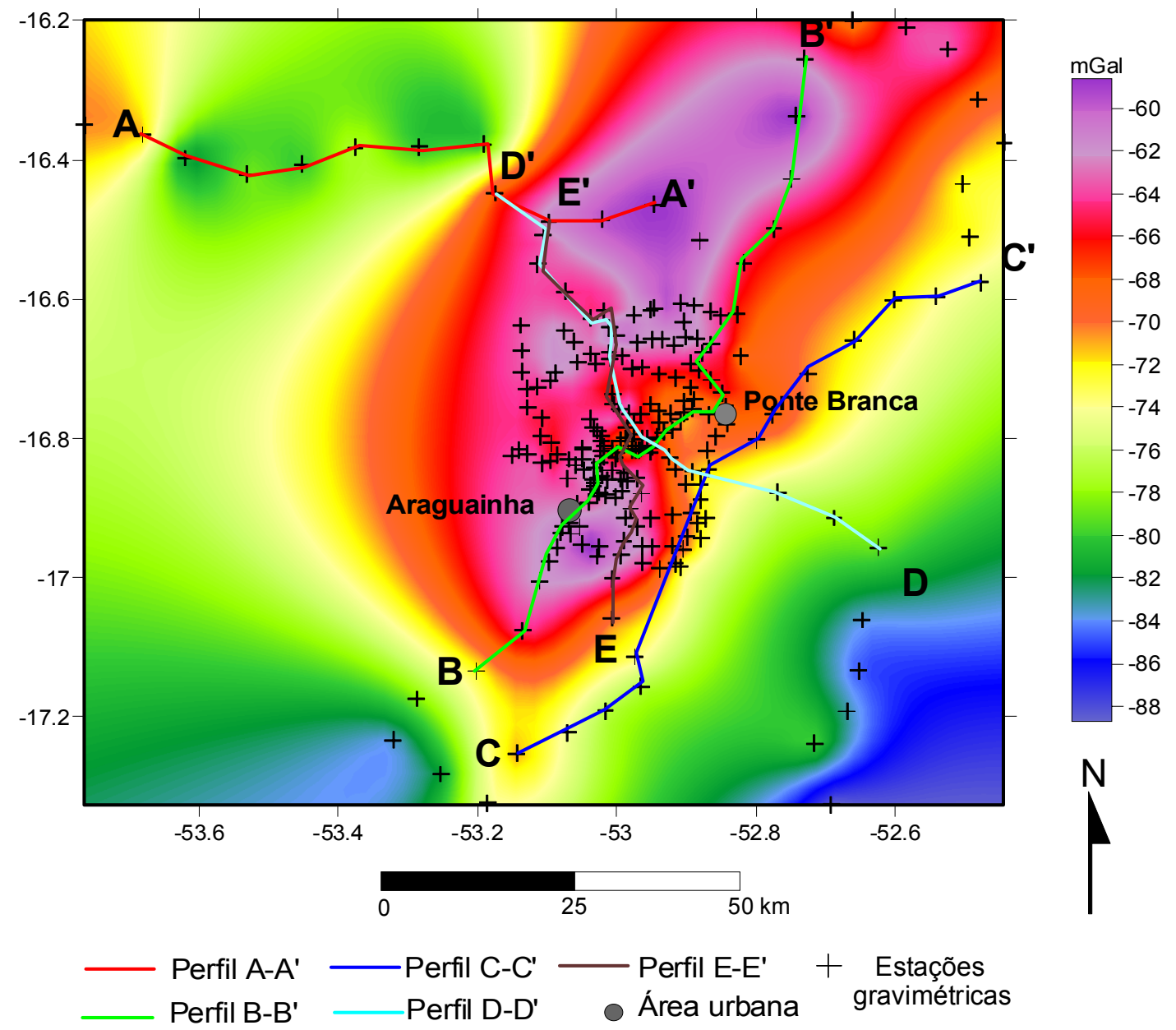

Figura 4.1. Mapa de anomalia Bouguer de toda a área superposto pelas estações gravimétricas. Os cinco perfis ao longo dos quais foram realizadas as correções regionais estão representados com símbolos de cores distintas.

\subsubsection{Separação regional-residual}

Uma vez obtidas as anomalias Bouguer, o próximo passo é tentar separar as anomalias gravimétricas com diversas profundidades de origem. Para tanto, é necessário estabelecer um padrão de anomalias regional, e a partir deste calcular as anomalias residuais.

A informação contida no mapa Bouguer total refere-se à soma vetorial da aceleração da gravidade produzida por massas anômalas de corpos em profundidades variadas, normalmente indo desde a base da crosta até a superfície. Para se obter somente a informação referente às massas anômalas deve-se estimar o campo gravimétrico regional, ou seja, aquele campo que possui maiores comprimentos de onda, e subtraí-lo dos valores medidos. O resultado obtido é o isolamento das 
anomalias gravimétricas de menor comprimento de onda, geradas por corpos menores e mais rasos. Isto é denominado separação regional-residual.

Deve-se ressaltar que o conceito de regional e residual é relativo, sendo que mesmo em levantamentos locais o conceito de regional-residual também se aplica. Neste trabalho pretende-se retirar o efeito anômalo causado pelas estruturas mais profundas, que não demonstrem relação com o impacto, de forma a isolar a resposta da estrutura de interesse.

Como a distribuição espacial dos dados é irregular, é necessário utilizar um interpolador para gerar os mapas e analisar a informação ajustada pelos diferentes métodos. Para identificar o método e o polinômio que se situem na posição mais adequada neste trabalho são utilizados perfis calculados a partir dos pontos de amostragem, e não a partir dos valores das grades geradas para a representação. Foram selecionados cinco perfis (A-A', B-B', C-C', D-D' e E-E', figura 4.1) regionais de forma que o segundo, quarto e quinto passam pela região do núcleo granítico soerguido.

Para a separação do campo gravimétrico regional utilizou-se de dois métodos distintos: i)ajuste polinomial por mínimos quadrados e ii) ajuste por polinômio robusto, todos aplicados nos cinco perfis extraídos.

A escolha do melhor regional é feita de maneira qualitativa a partir da análise dos perfis comparativos para o polinômio de cada grau. É importante o conhecimento geológico da região de estudo para escolher criteriosamente o melhor método que a represente e o grau que melhor ajuste o campo regional. Por isso, alguns critérios devem ser estabelecidos, como a preservação de valores negativos, visto que a área de estudo situa-se em uma região de bacia sedimentar. Além do mais, devem-se preservar os valores mais negativos que estão compreendidos na região do núcleo granítico soerguido. Esta análise por perfis regionais em estrutura de impacto é minuciosa porque, em geral, não se conhece a geometria da fonte anômala, com exceção do estereótipo circular geral das crateras. 


\subsubsection{Ajuste polinomial por mínimos quadrados}

Este método consiste em determinar a função que melhor represente o comportamento geral dos dados. A função objetivo é a soma dos quadrados das diferenças entre cada observação e o valor do ajuste funcional no ponto de observação. Desta maneira, o estimador pode ser obtido pela minimização da função objetivo.

O método apresenta algumas desvantagens, como o fato dos polinômios de alta ordem se ajustarem à parte do residual, além de ser um método estritamente matemático, não levando em conta vínculos com variações reais de massa causadas pela variação geológica.

O perfil A-A' (Figura 4.2) localiza-se a noroeste da cratera de Araguainha. Notase em seus ajustes alta similaridade entre os diversos polinômios. Os polinômios de graus 4 e 5 começam a se adaptar à forma da anomalia, gerando falsas anomalias positivas e negativas. Já dentre os polinômios de grau 1 a 3 , este último representa melhor o campo regional, principalmente porque a porção oeste do perfil residual (Figura 4.2c) está mais próxima de valores negativos que os graus 1 e 2 .

O perfil B-B', constitui o perfil mais importante para análise polinomial juntamente com os perfis D-D' e E-E', por seccionar toda a área da cratera, o núcleo central soerguido e ultrapassar seus limites. Os graus 4 e 5 evoluem, da mesma forma do visto anteriormente, para uma assimilação do padrão da anomalia (Figura 4.3d e 4.3e). Seus residuais são semelhantes aos do grau 3 (Figura 4.3c), e tendem a anular os valores gravimétricos mais altos observados nas extremidades sul e norte, que demonstram não estar relacionadas ao impacto. Esta é uma feição importante a ser separada, o que não foi possível com os ajustes de 1 e 2 graus, principalmente na região sudeste do perfil. Todos os residuais mostram-se com valores coerentemente negativos para a região central da cratera. Desta maneira, nota-se que o ajuste de grau 3 é o melhor para este perfil.

O perfil C-C', delineado a leste dos limites da cratera, permanece com valores praticamente constantes ao longo dos seus quase $150 \mathrm{~km}$ de extensão (Figura 4.4). Os residuais para os polinômios de todos os graus mostram pouca diferença, de maneira que se escolhe o polinômio de grau 3 como o mais adequado.

Para o perfil D-D' os ajustes de grau 1 a 3 mostram-se muito semelhantes, com ligeiras diferenças na região central e fora dos limites da cratera (Figura 4.5). Entretanto, o polinômio de grau 3 ajusta-se melhor na porção sudeste da cratera, gerando valores menos negativos nesta e na região noroeste, conforme pode ser visto 
nos dados residuais s figura 4.5h. Para os residuais de todos os graus a região central da cratera apresenta valores negativos.
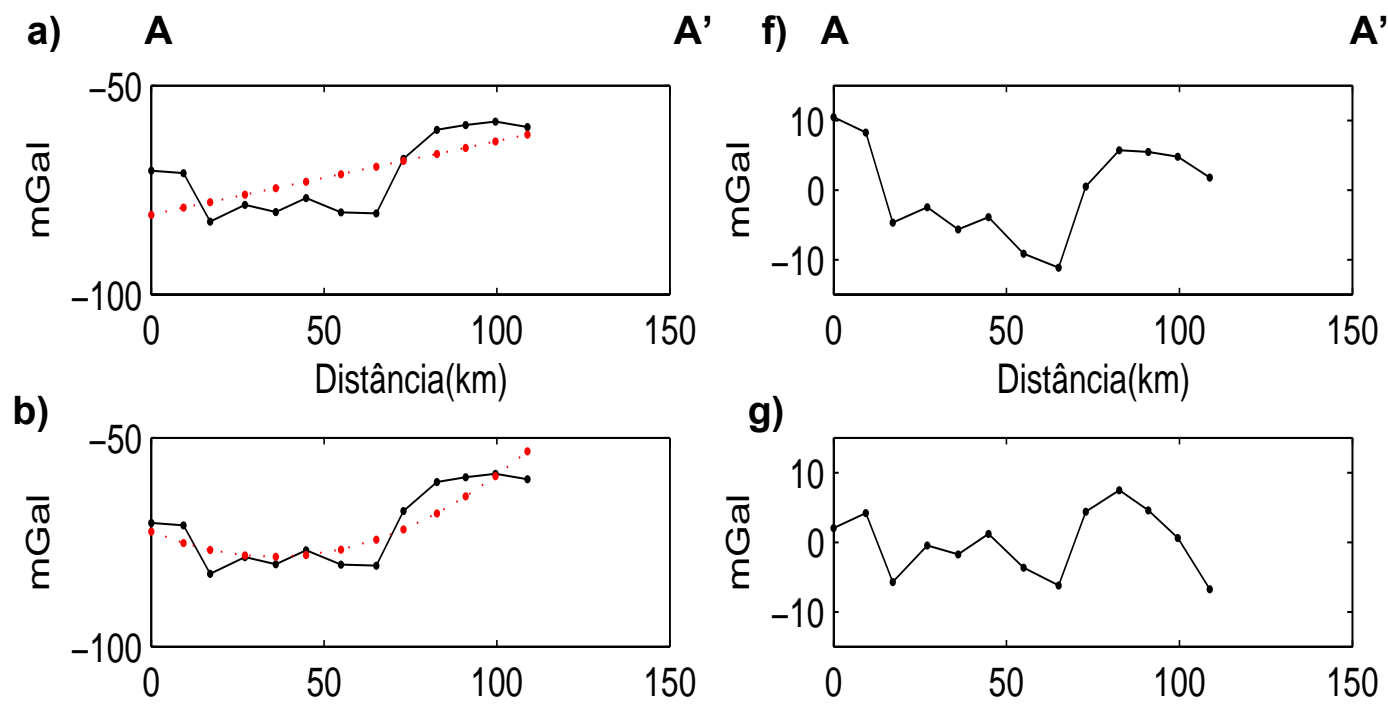

\section{g)}
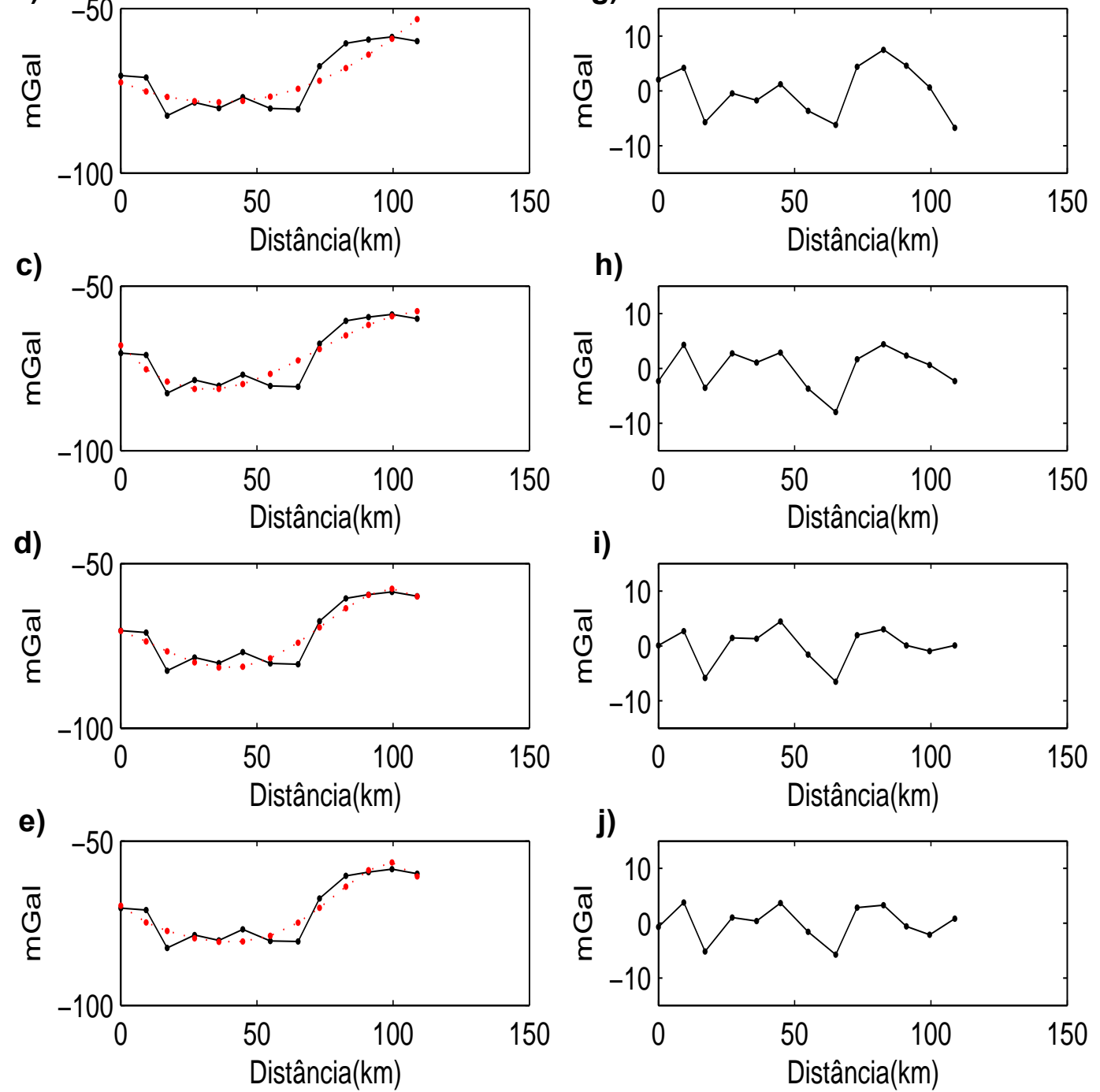

Figura 4.2. Perfil A-A' comparativo entre o campo Bouguer e o campo regional obtido pelo ajuste polinomial por mínimos quadrados de grau 1 a 5 , de "a" até "e", respectivamente, e seus referentes resíduos de "f" a "j". 

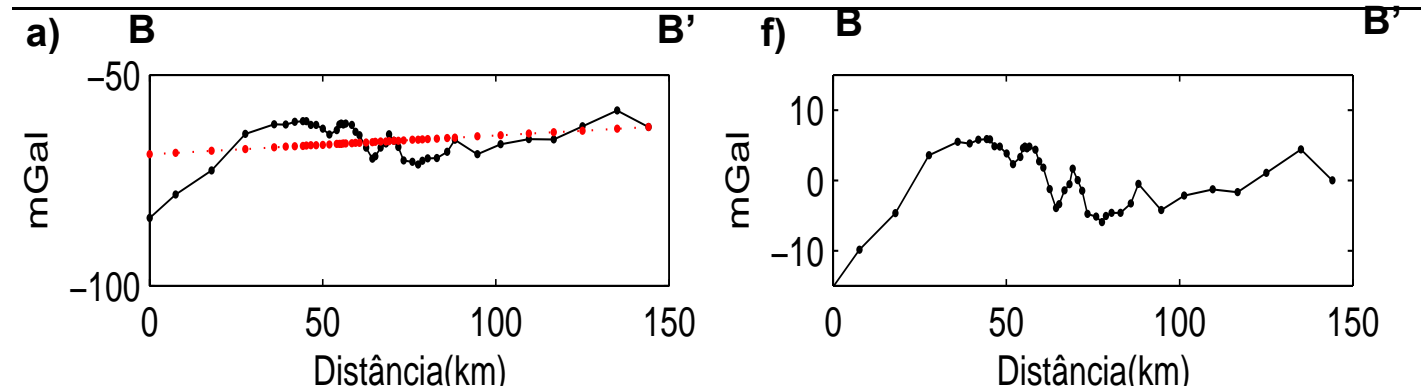

b)
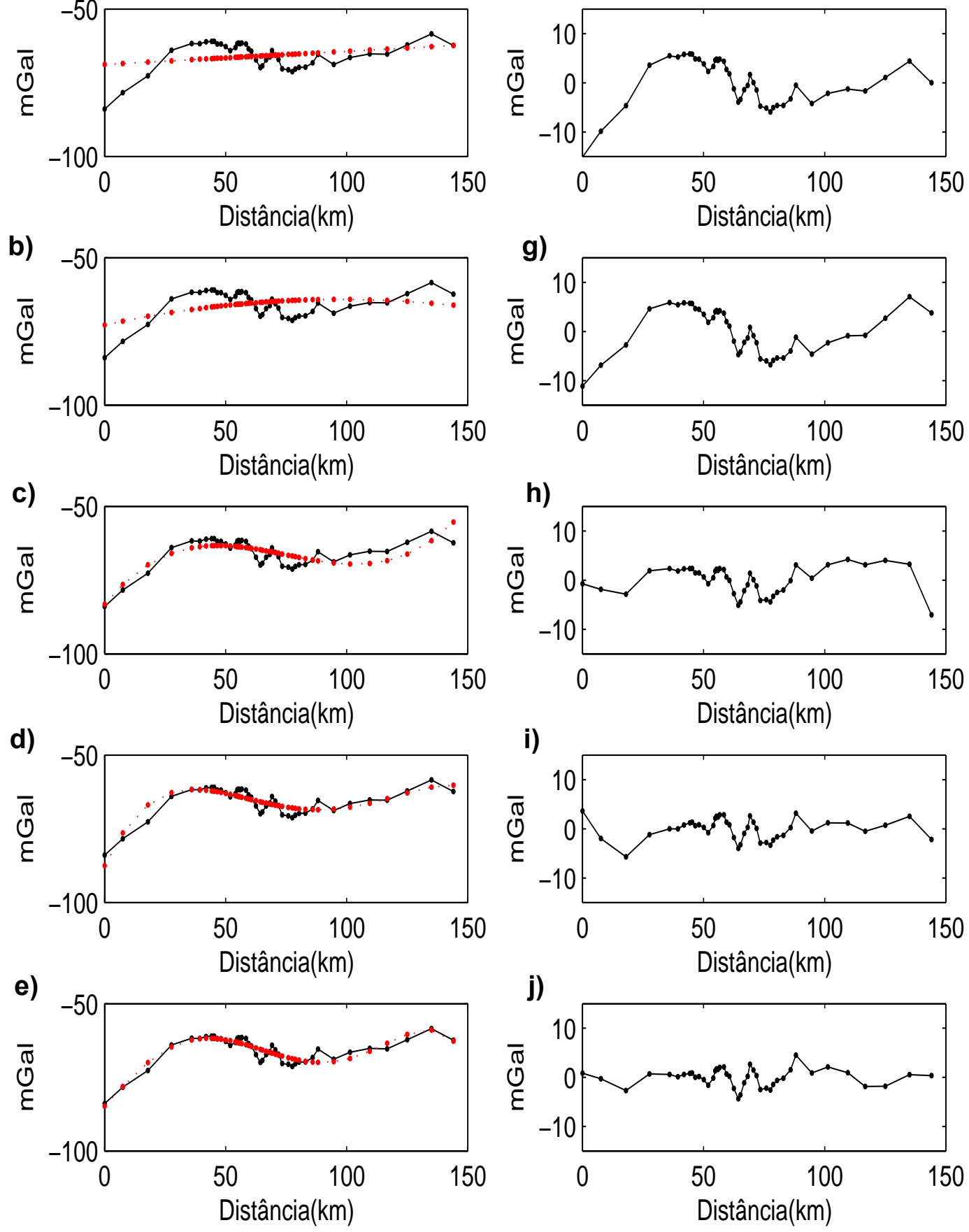

Figura 4.3. Perfil B-B' comparativo entre o campo Bouguer e o campo regional obtido pelo ajuste polinomial por mínimos quadrados de grau 1 a 5 , de "a" até "e", respectivamente, e seus referentes resíduos de "f" a "j". 


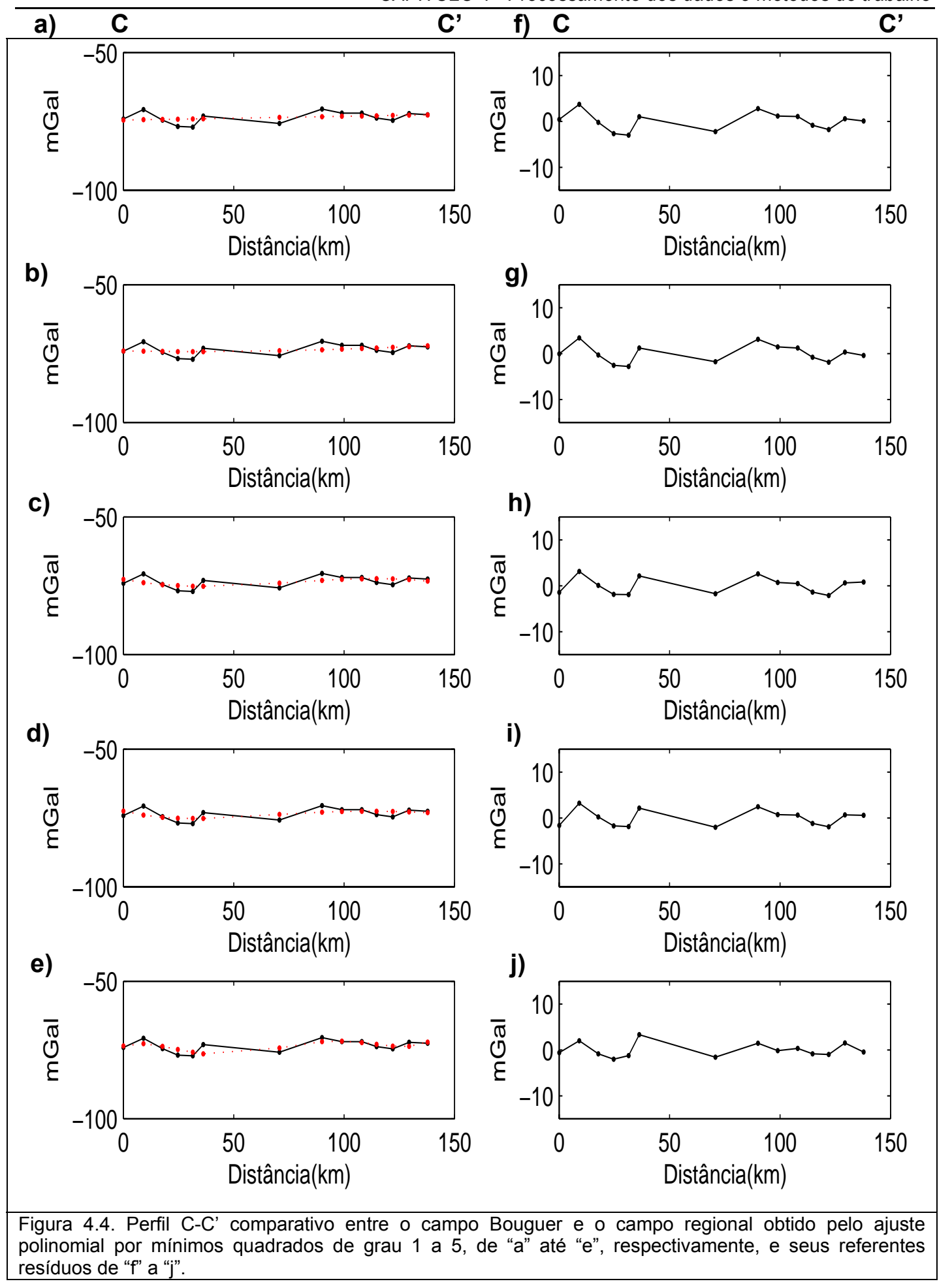




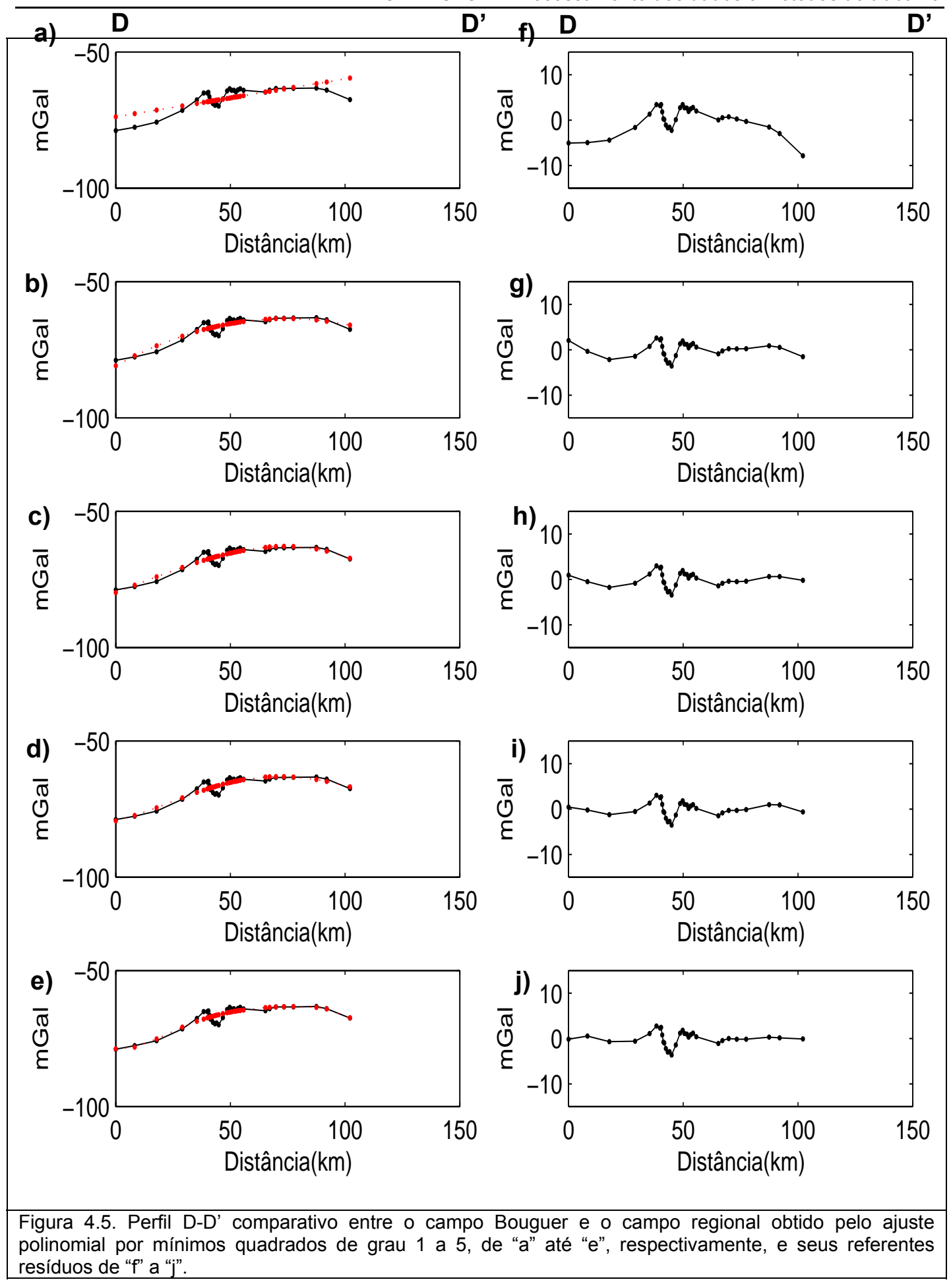

O perfil E-E' (Figura 4.6) secciona a cratera de sul a norte passando pela região do núcleo granítico soerguido. As anomalias de borda e do núcleo da estrutura parecem relativamente bem realçadas. Os polinômios de grau 1 a 3 mostram-se como os melhores ajustes (Figura 4.6a, 4.6b e 4.6c, respectivamente). Destes, destaca-se o polinômio de grau 3 como o melhor representante regional porque a curva se ajusta 
melhor na região fora da borda sul, gera valores menos positivos para a borda sul, além de realçar melhor a anomalia negativa do núcleo granítico soerguido.

a)

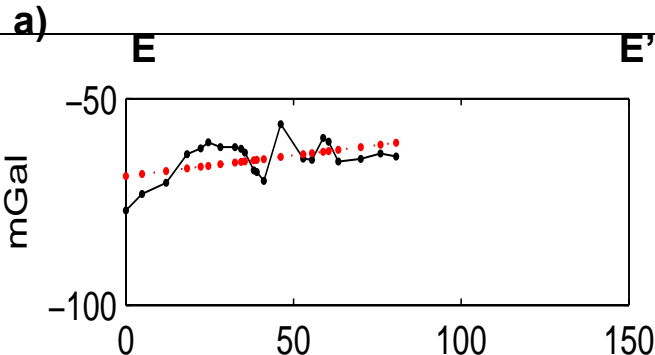

b)

Distância(km)
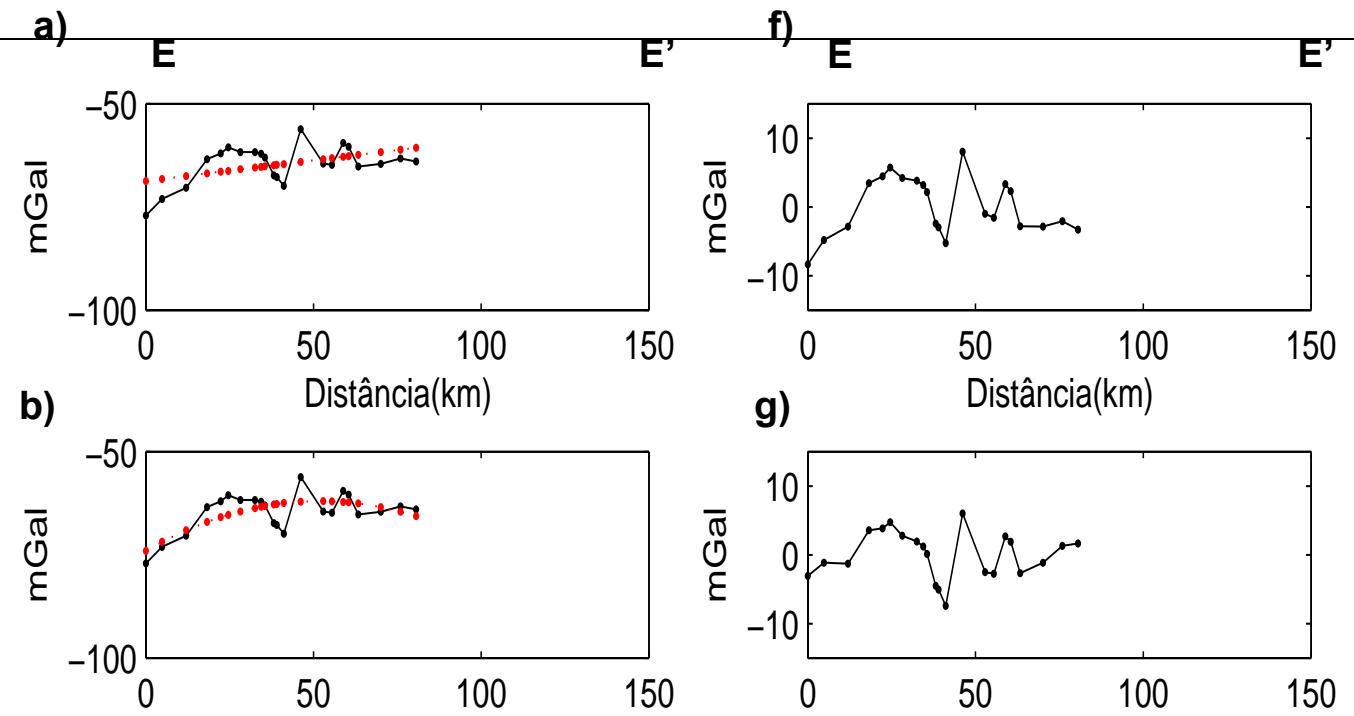

g) Distância(km)
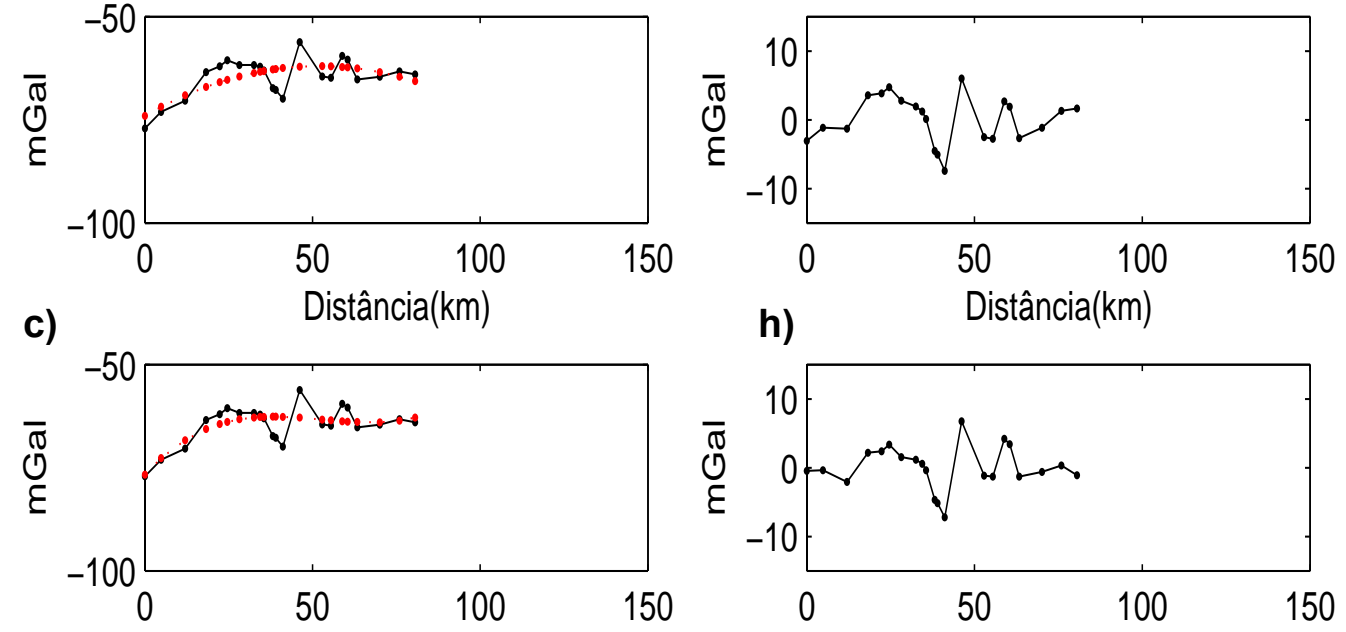

h) Distância(km)
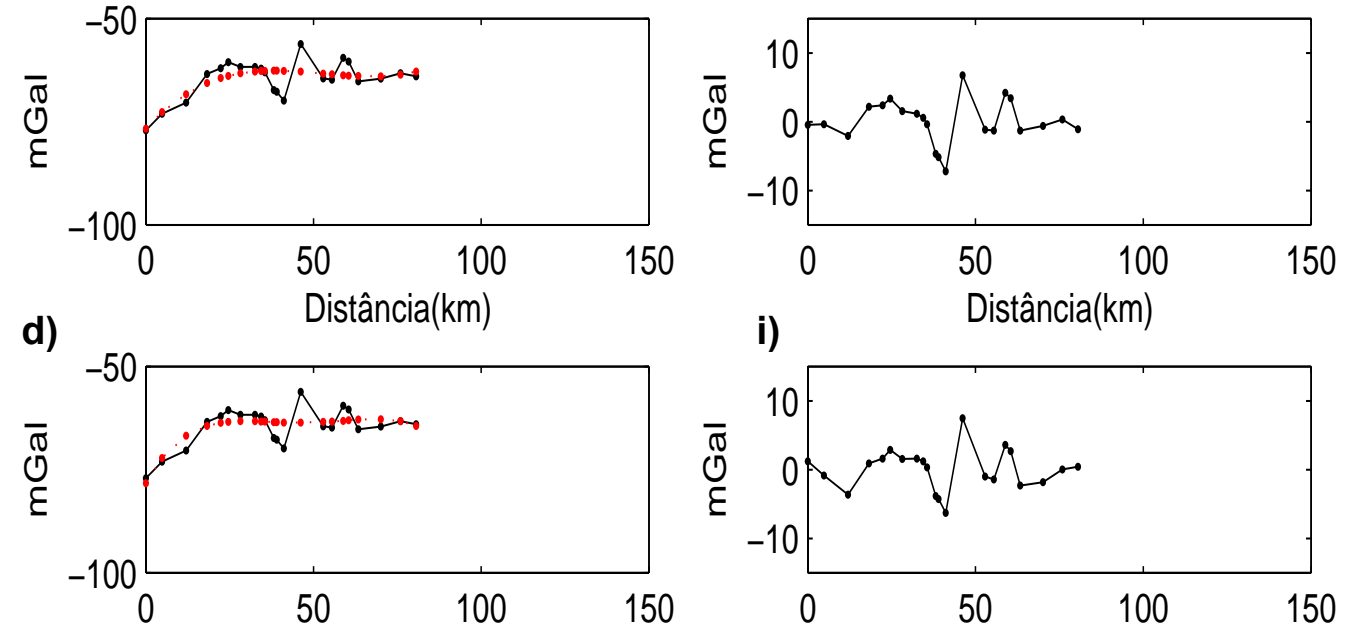

i) Distância(km)
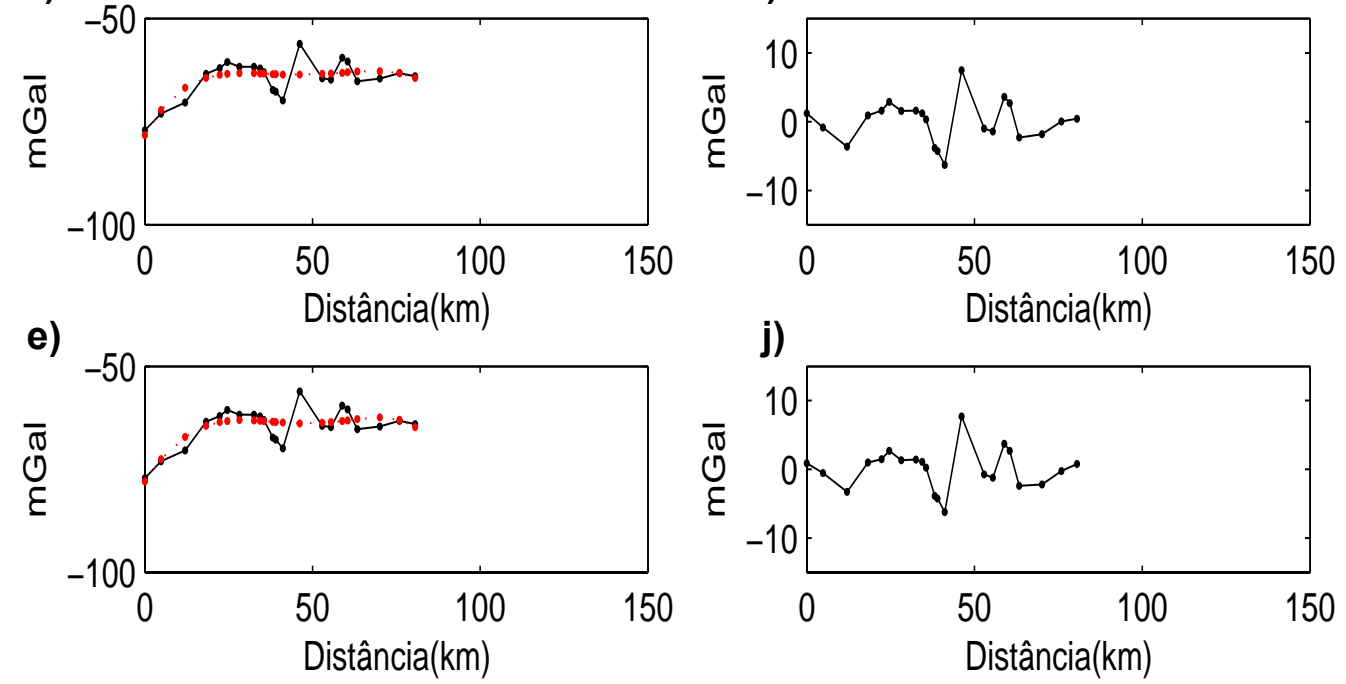

Figura 4.5. Perfil D-D' comparativo entre o campo Bouguer e o campo regional obtido pelo ajuste polinomial por mínimos quadrados de grau 1 a 5 , de "a" até "e", respectivamente, e seus referentes resíduos de "f" a "j". 
Analisando os cinco perfis comparativos para os cinco graus de polinômio calculados, percebe-se que os residuais de graus 1 a 3 demonstram muita similaridade para a maioria dos perfis, sendo que o polinômio de grau 3 é o que situa o regional em uma posição mais adequada para fins de modelagem para o presente método de remoção do regional.

\subsubsection{Ajuste polinomial robusto}

Enquanto no método dos mínimos quadrados toda observação é atribuída com o mesmo grau de importância indiferentemente do valor residual que produz, o procedimento robusto (Beltrão et al.,1991) atribui importância maior para observações que produzem valores residuais pequenos. Deste modo evita-se que valores muito grandes ou muito pequenos que não sejam representativos forcem uma superestimativa ou subestimativa dos coeficientes do polinômio, colocando o campo regional calculado muito abaixo ou acima da posição ideal. O polinômio robusto para os diversos perfis foi calculado com base na rotina ROBFIT1DB2 (Shukowsky,2000).

Para o perfil A-A' (Figura 4.7) os polinômios de graus 1 e 2 resultam em anomalias positivas em suas bordas e muito negativas nas regiões centrais. $O$ polinômio de grau 3 representa melhor a tendência geral da anomalia, atribuindo-lhe pesos mais coerentes. Os polinômios de graus 4 e 5 mostram-se claramente adaptados à curva da anomalia, englobando parte de sua resposta gravimétrica, principalmente em suas extremidades. 

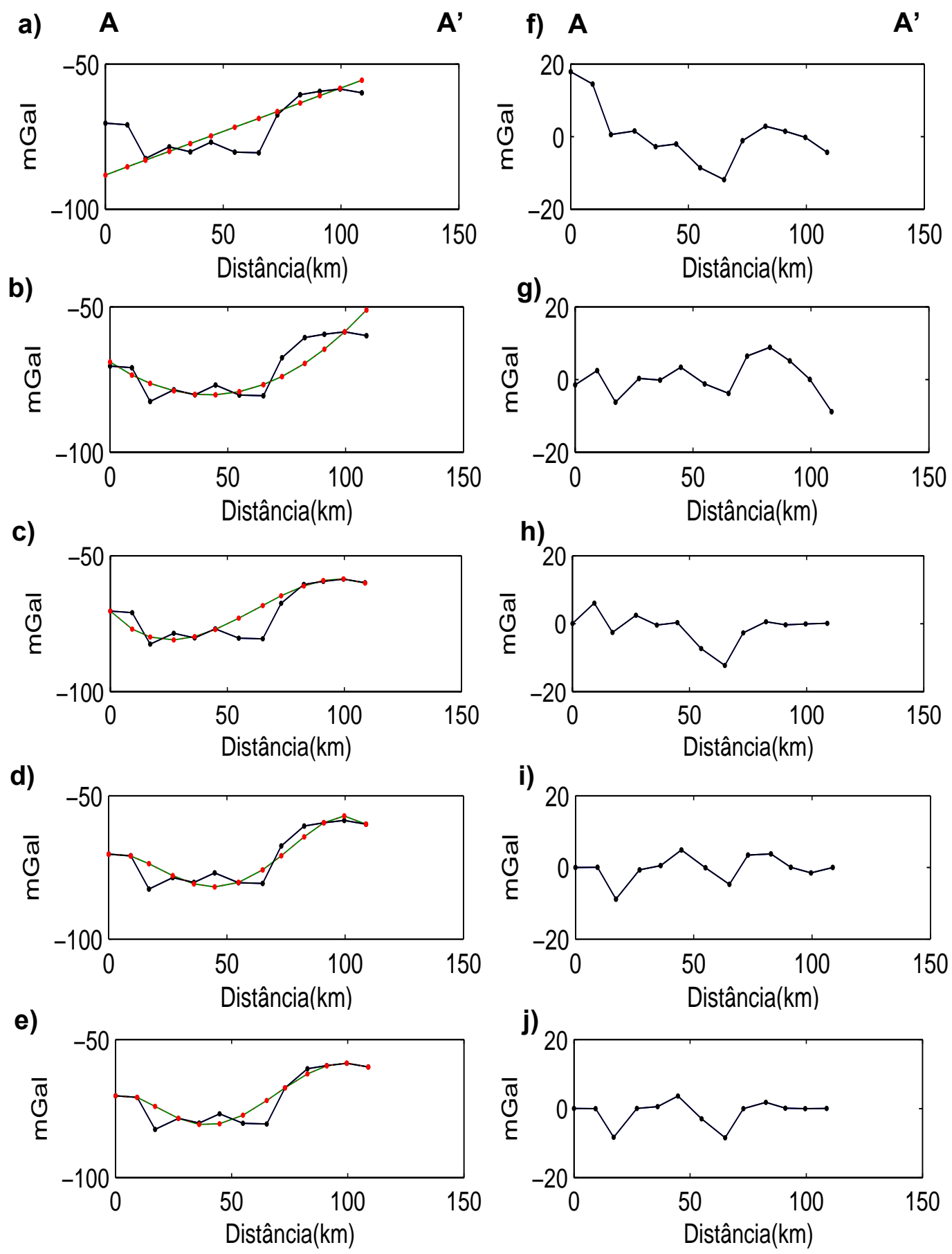

Figura 4.7. Perfil A-A' com curva de ajuste por polinômio robusto de graus 1 a 5 mostrados nas letras "a" até "e", respectivamente. Nas figuras "f" a "j" mostra-se os respectivos regionais para cada grau. 
No perfil B-B' (Figura 4.8) os polinômios robustos de graus 1 e 2 mostram-se relativamente bem ajustados para região do núcleo, entretanto à porção sul da curva foi atribuído menor peso, o que preservou estes valores extremamente negativos. Os polinômios de graus 1, 2 e 3 mostram-se muito semelhantes. Apesar disto, o polinômio de grau 3 apresenta um maior destaque para suas anomalias na porção central e adjacências, referentes à cratera transiente, que mostraram-se menos positivas que nos outros dois.

O perfil C-C' (Figura 4.9) apresenta um padrão geral linear e mostra-se difícil no ajuste com outros graus por apresentar grande variação anômala pico a pico. A grande distância entre pontos também dificulta consideravelmente este ajuste polinomial. Desta maneira o polinômio que mais se adequa ao regional é o de grau 1.

Os ajustes relacionados ao perfil D-D' podem ser vistos na figura 4.10. O ajuste atribui peso muito baixo para a porção sudeste do perfil. O polinômio de grau 2, apesar de gerar valores negativos na região central, gera pseudo-anomalias positivas e negativas nas extremidades. O polinômio de grau 3 remove relativamente bem o efeito regional para além dos limites da cratera, com exceção da região noroeste que mostrase com resíduo extremamente positivo, com pico em $6 \mathrm{mGal}$. Já o grau 4 apresenta valores muito semelhantes ao grau 3, mas apresenta a anomalia residual melhor posicionada na porção noroeste. O polinômio de grau 5 começa a se ajustar à anomalia, gerando valores residuais indesejáveis nas regiões de borda da cratera.

$\mathrm{Na}$ análise do perfil E-E' (Figura 4.11) percebe-se que pouco peso é atribuído para a região sul do polinômio de grau 1. O polinômio de grau 2 mostra-se secionando o topo de anomalias com valores mais altos, na região norte do perfil, gerando falsas anomalias negativas. Os demais polinômios mostram-se muito semelhantes com valores residuais negativos para a região do núcleo, algumas anomalias positivas para a região da cratera transiente e falsas anomalias nas extremidades da ordem de no máximo $5 \mathrm{mGal}$. No entanto, optou-se por trabalhar com o polinômio 3, de mais baixo grau dentre estes. 

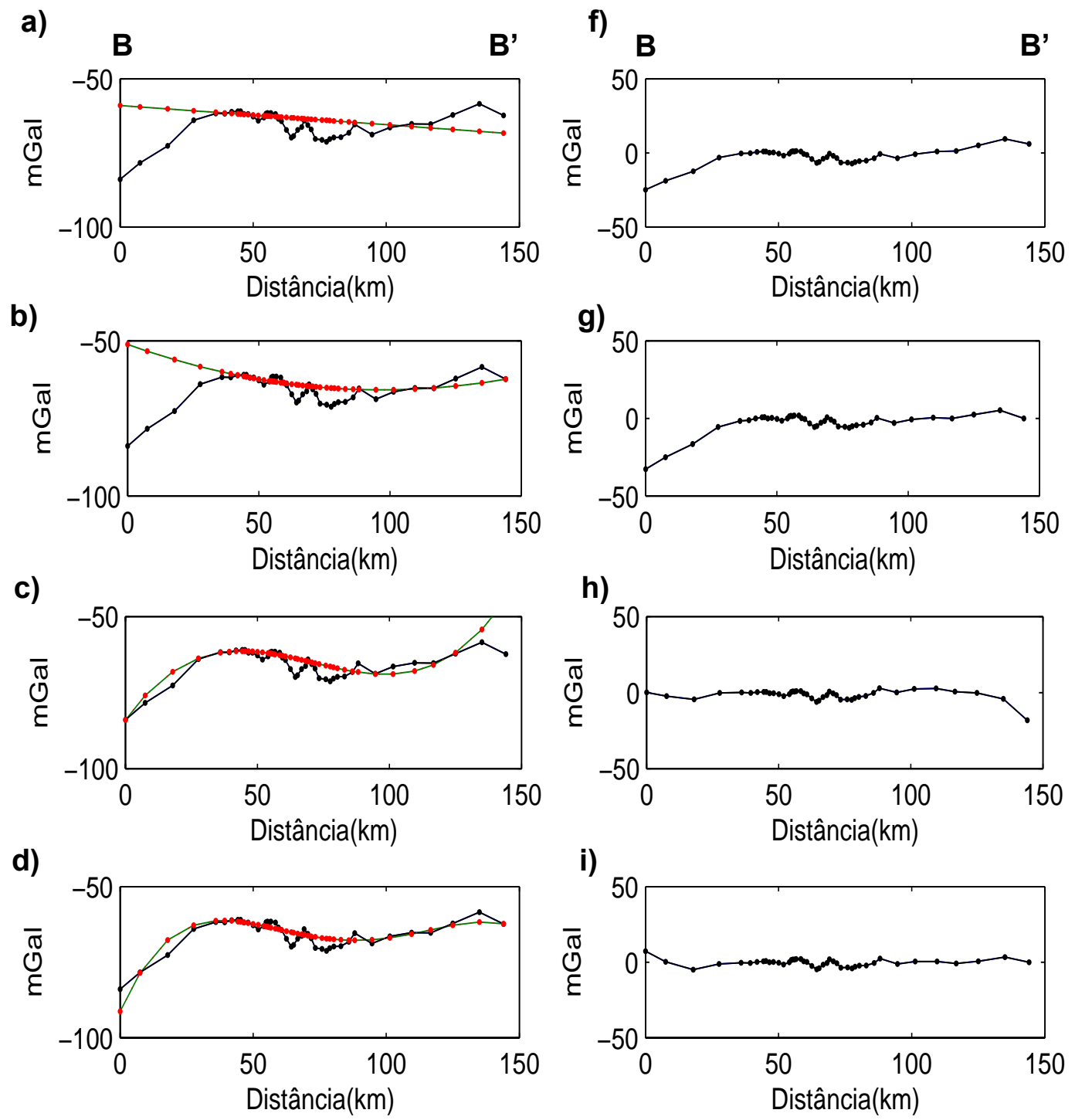

e)
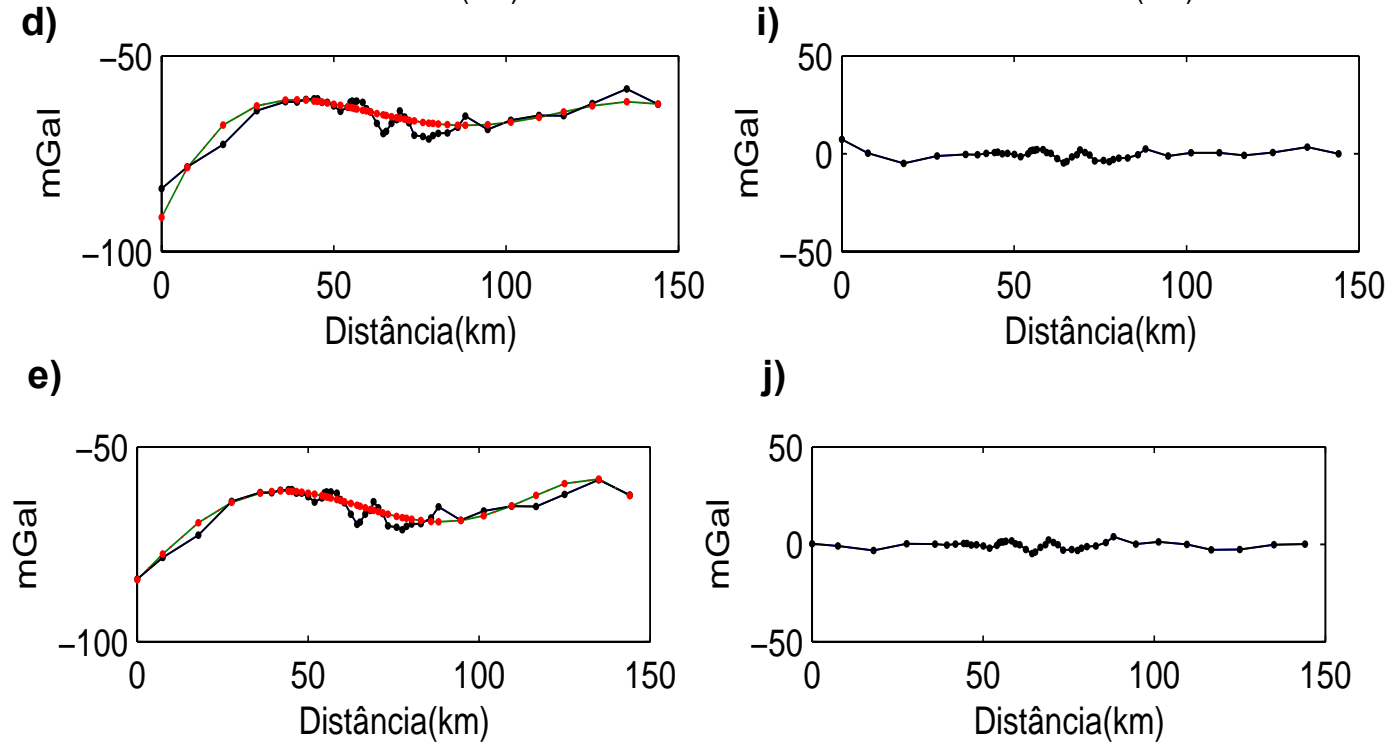

Figura 4.8. Perfil B-B' com curva de ajuste por polinômio robusto de graus 1 a 5 mostrado nas letras "a" até "e", respectivamente. Nas figuras "f" a "j" mostra-se os respectivos regionais para cada grau. 


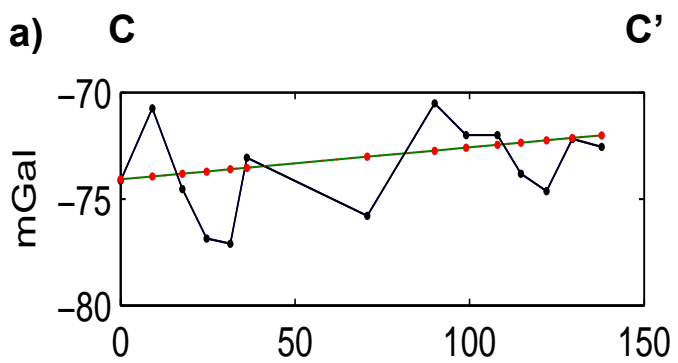

f) $C$

$C^{\prime}$

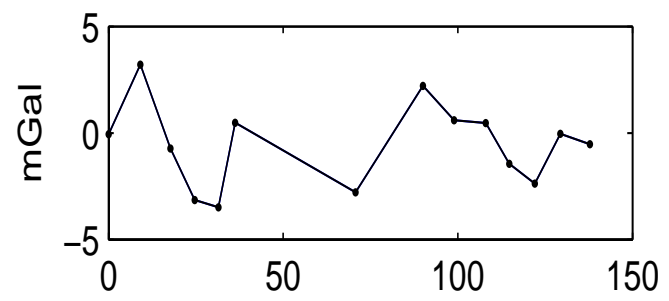

b)

Distância(km)

g) Distância $(\mathrm{km})$
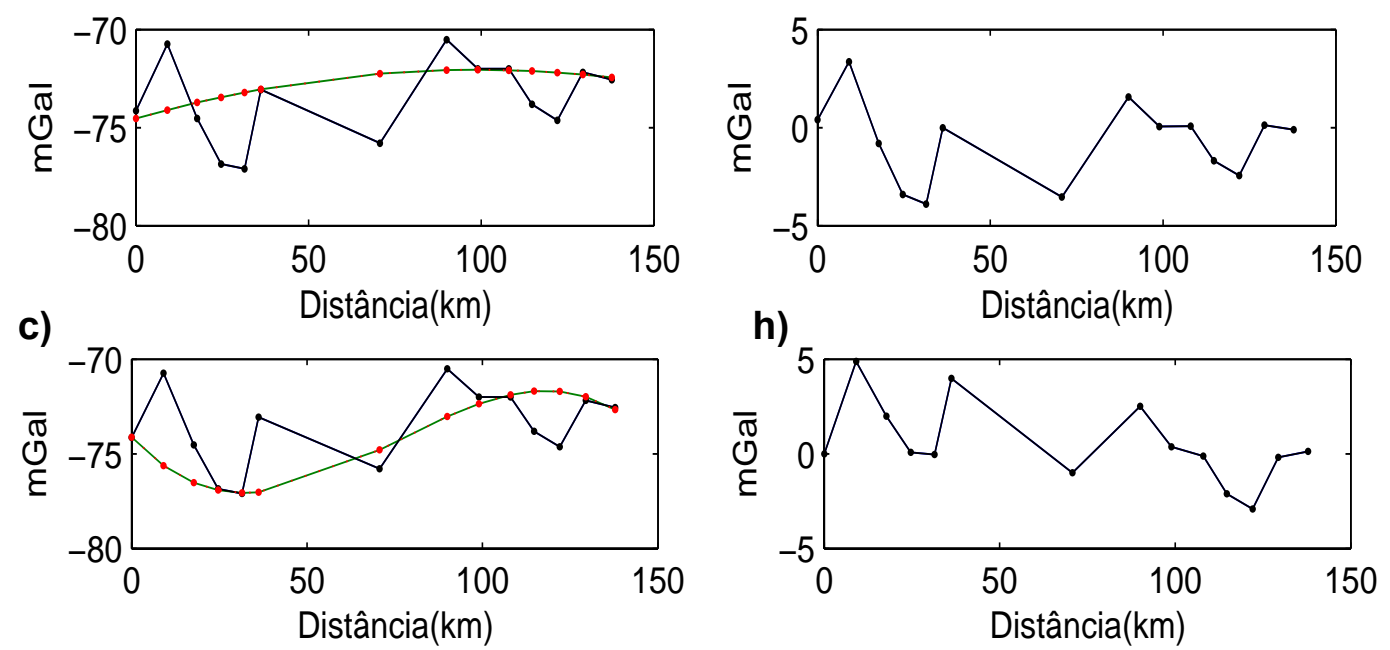

d)

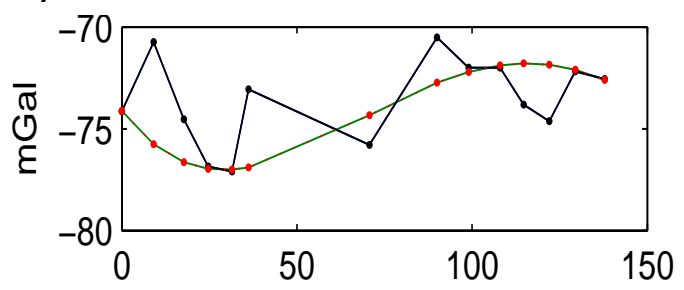

i)

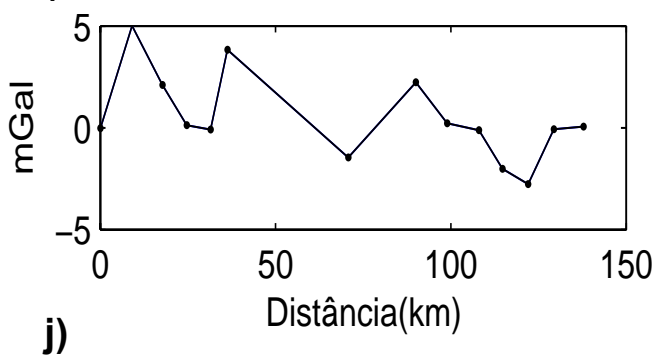

e)

Distância $(\mathrm{km})$
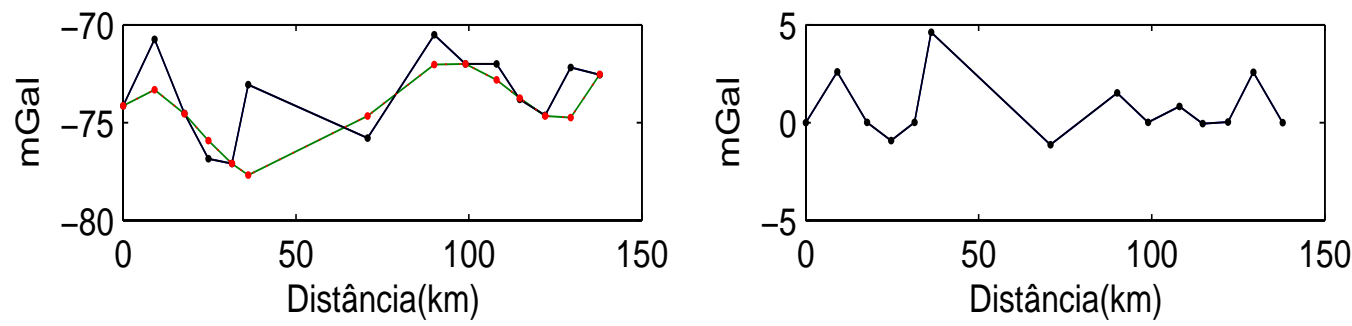

Figura 4.9. Perfil C-C' com curva de ajuste por polinômio robusto de graus 1 a 5 mostrado nas letras "a" até "e", respectivamente. Nas figuras "f" a "j" mostra-se os respectivos regionais para cada grau. 

a)
D' f) D
D’

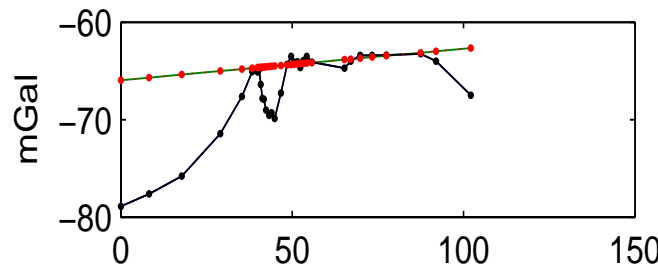

b)
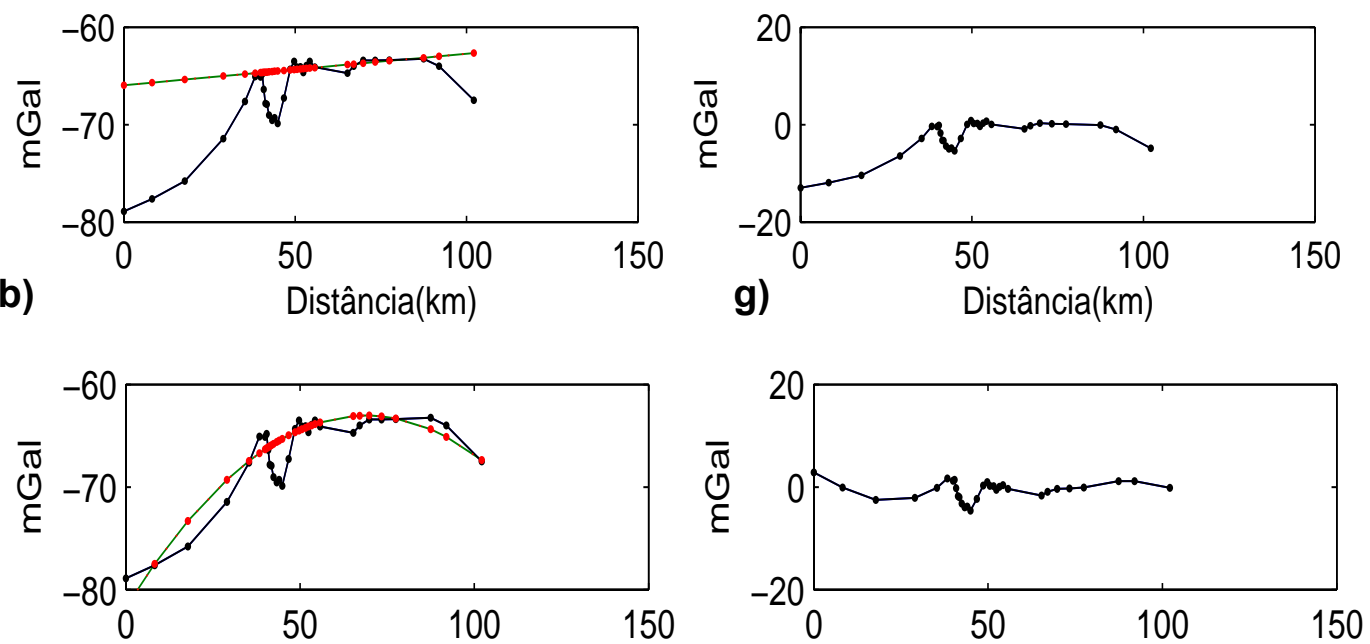

c)

Distância(km)

h)

Distância(km)

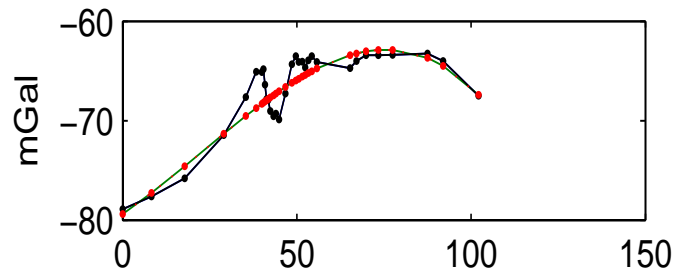

d)

Distância(km)

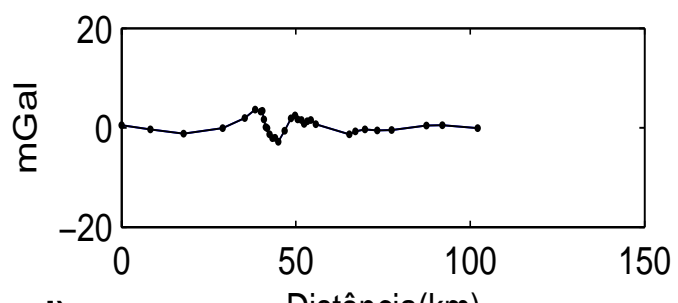

i)

Distância(km)

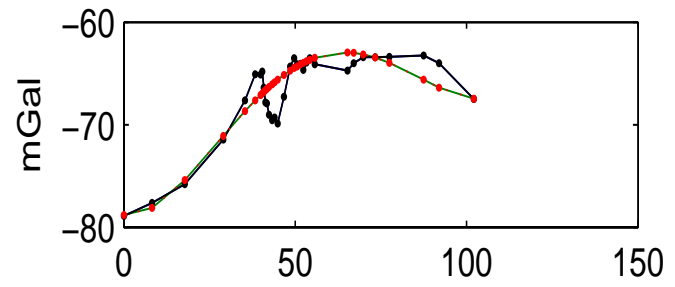

e)

Distância(km)

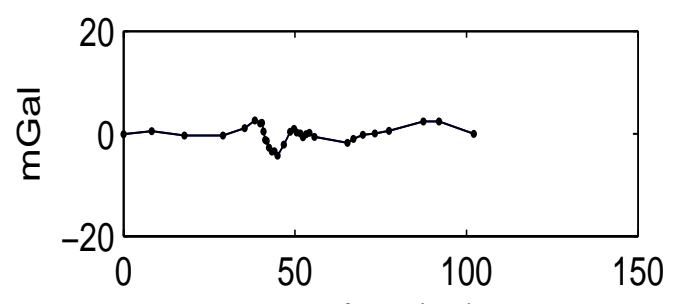

j) Distância(km)
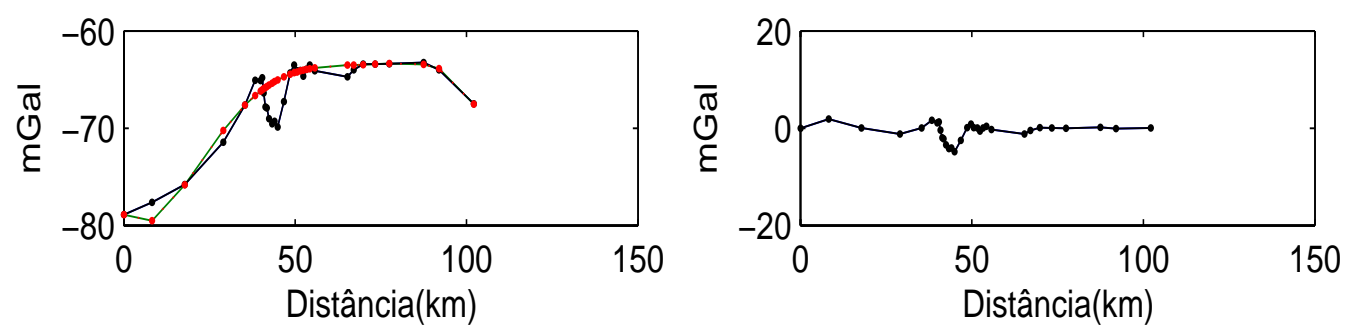

Figura 4.10. Perfil D-D' com curva de ajuste por polinômio robusto de graus 1 a 5 mostrado nas letras "a" até "e", respectivamente. Nas figuras "f" a "j" mostra-se os respectivos regionais para cada grau. 

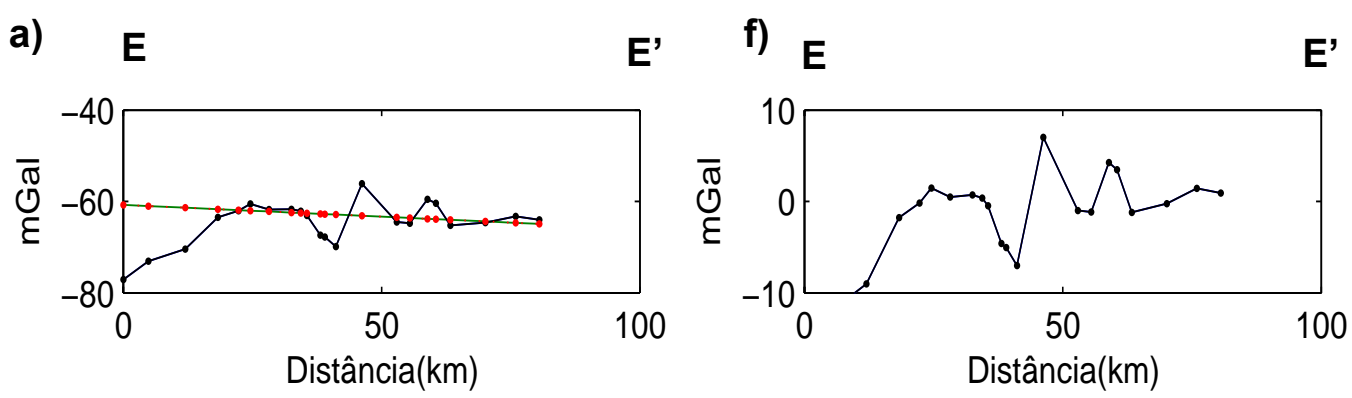

b)

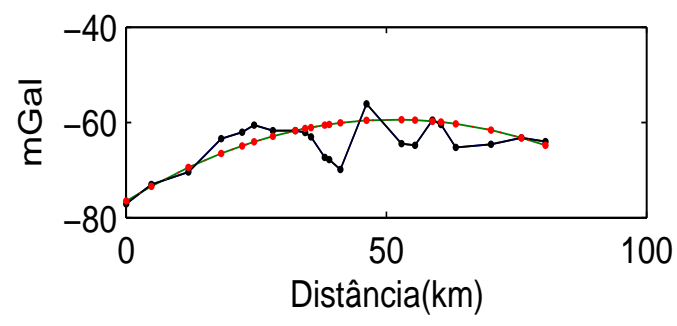

g)

c)
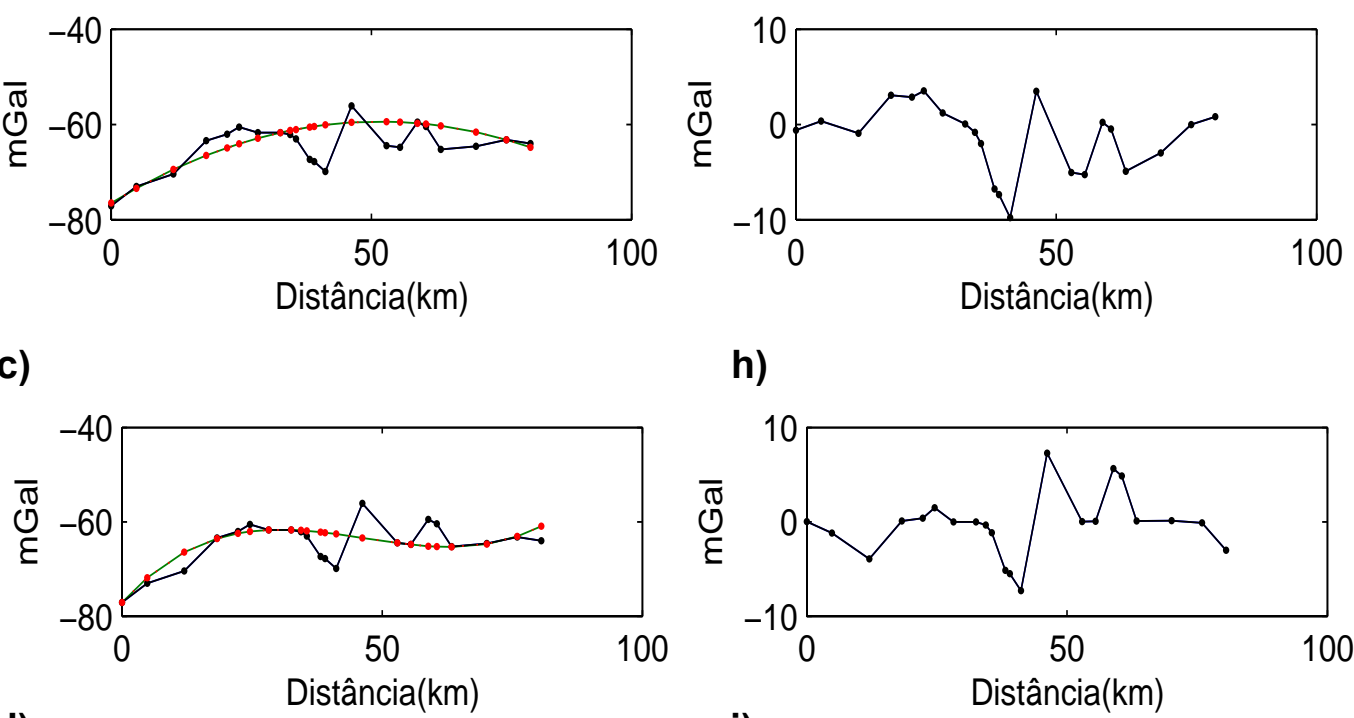

h)
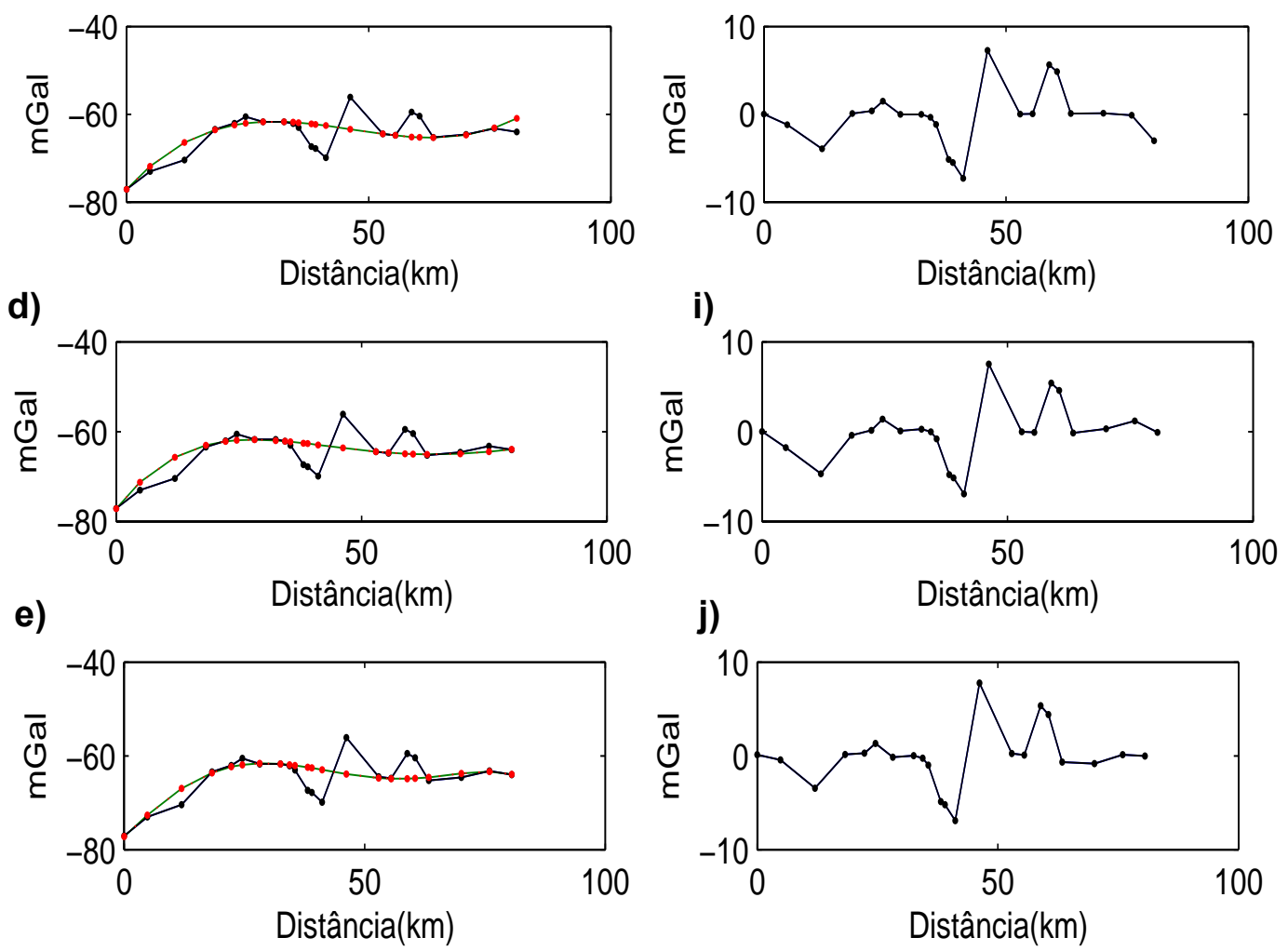

Figura 4.11. Perfil E-E' com curva de ajuste por polinômio robusto de graus 1 a 5 mostrado nas letras "a" até "e", respectivamente. Nas figuras "f" a "j" mostra-se os respectivos regionais para cada grau. 
Ao comparar o resultado dos dois métodos, percebe-se que o polinômio de grau 3 obtido pelo método robusto é o mais adequado para uma consistente remoção do regional, apesar de apresentar sutil diferença entre o polinômio do mesmo grau obtido por mínimos quadrados. Também se testaram polinômios de graus acima de 6 , que coincidem com as anomalias e portanto não foram utilizados para análise neste trabalho.

Os dados da anomalia Bouguer foram interpolados pelo método da krigagem com espaçamento entre pontos de 500 metros. Para obtenção mais precisa desta malha a interpolação foi aplicada para uma área que se restrinja unicamente aos limites da cratera, de forma que a distribuição de pontos mostre-se mais homogênea (Figura 4.12).

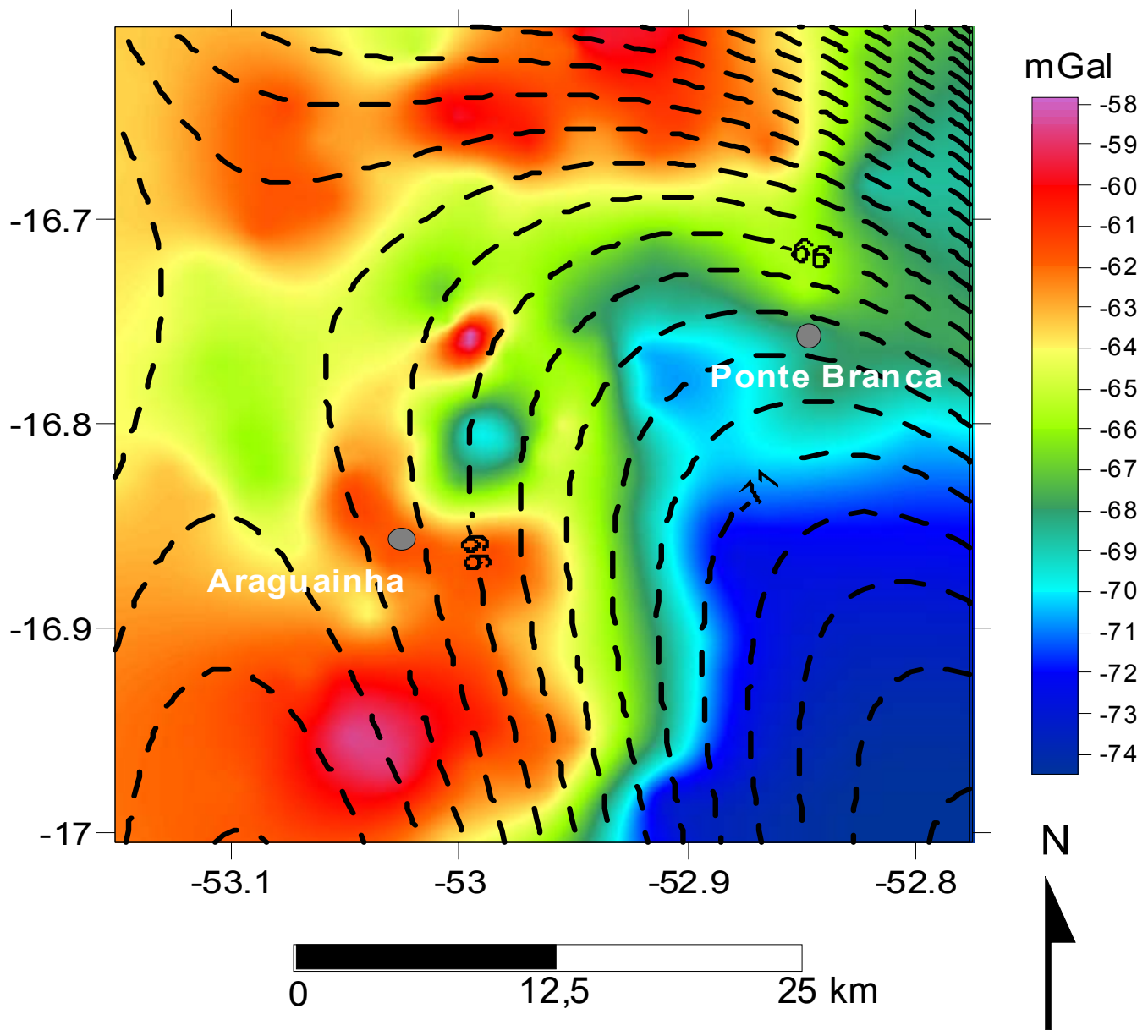

Figura 4.12. Mapa de anomalia Bouguer sobreposto por isolinhas correspondentes ao ajuste regional pelo método do polinômio robusto de terceiro grau. 
Desta forma, obtém-se o mapa de anomalia Bouguer residual (Figura 4.13) subtraindo-se do mapa de anomalia Bouguer original a superfície polinomial robusta de terceiro grau.

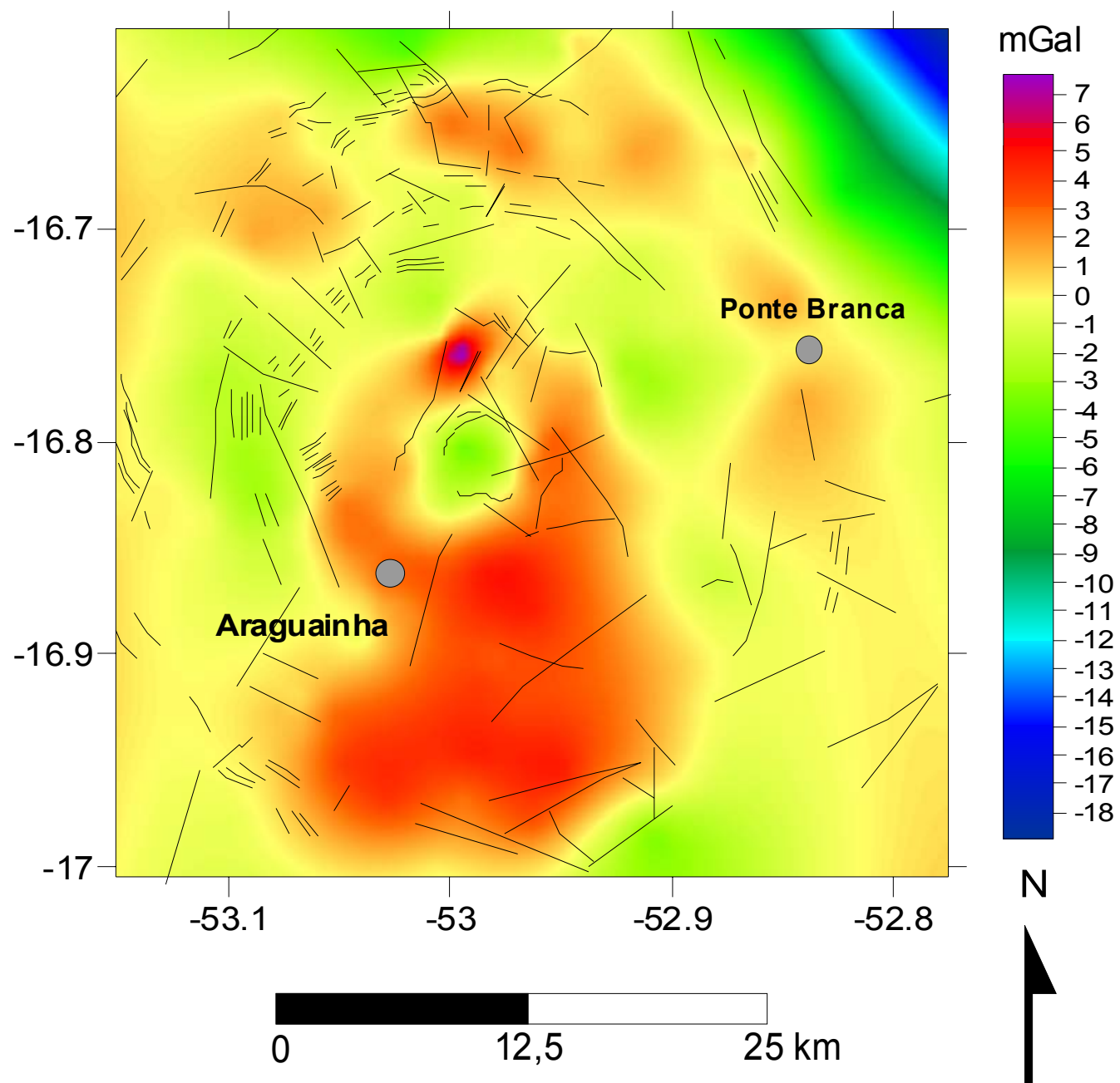

Figura 4.13. Mapa Bouguer residual obtido através da remoção do polinômio robusto de terceiro grau. Destacam-se os altos valores gravimétricos na região centro-sul da área.

O método da krigagem mostra-se mais adequado para a representação dos dados, pois obtém melhor realce da anomalia de borda, diferenciando-a das anomalias referentes à cratera transiente e do núcleo central soerguido (NCS) (Figura 4.13). Sabe-se, entretanto, que o interpolador incrementa ou reduz dados em algumas regiões da malha falseando anomalias. Com o intuito de se conhecer a ponderação dos dados para a krigagem elabora-se um mapa de sua confiabilidade com base na diferença entre a malha interpolada e os dados medidos em campo (Figura 4.14). O resultado mostra que nas regiões de borda o método foi extremamente eficiente com valores próximos de zero; os valores negativos devem-se principalmente às regiões com ausência de pontos, e uma anomalia pontual com valores muito altos no centro- 
norte da área que o método foi incapaz de ajustar. Desta forma, percebe-se que o método da krigagem é eficiente para representar a anomalia Bouguer da estrutura de Araguainha.

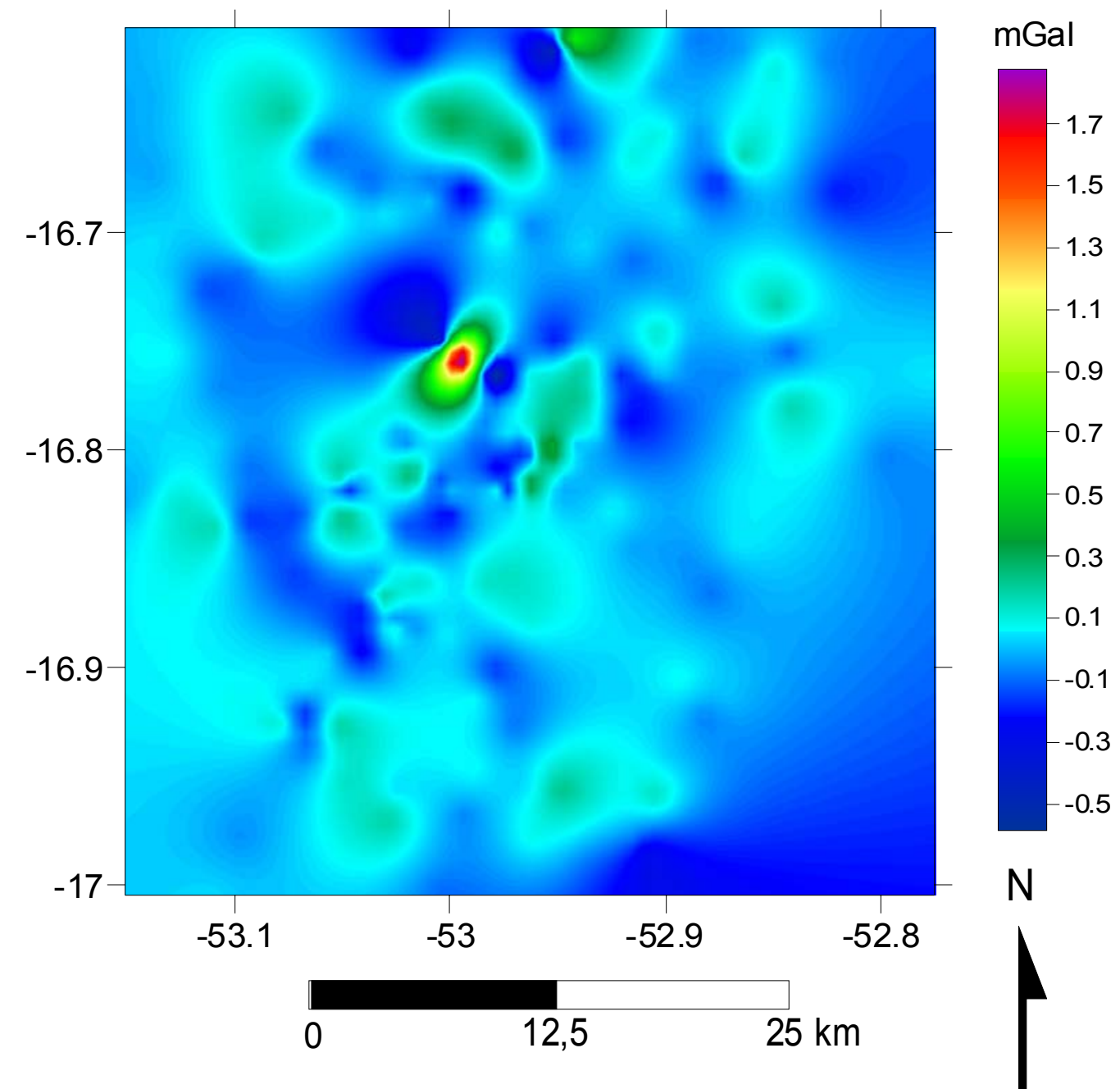

Figura 4.14. Mapa de confiabilidade do interpolador, que corresponde à diferença entre o valor Bouguer interpolado e o valor medido.

Os dados de anomalia Bouguer residual apresentados na figura 4.13 mostram valores bem definidos para a borda e anéis da estrutura. Estes variam em torno de 3 $\mathrm{mGal}$, em contraste com valores de $-3 \mathrm{mGal}$ apresentados na região da cratera transiente. Os valores mais altos da anomalia Bouguer estão concentrados na região correspondente ao soerguimento central, mais precisamente às localidades das formações Furnas e Ponta Grossa, que variam de 4 a 5 mGal. O alto anômalo persiste e possui formato alongado para a região sul da cratera, alcançando a borda aí localizada. Este valor anômalo é coincidente geologicamente à Formação Aquidauana; mas, no entanto, foge completamente aos padrões deste litotipo no restante da estrutura. O EGS apresenta uma baixo gravimétrico em torno de $-4 \mathrm{mGal}$, que é 
semelhante à parte da assinatura gravimétrica da cratera transiente. No extremo nordeste da área os dados mostram os valores mais negativos da área, inferiores a -6 mGal. Esta fonte está após os limites da cratera e demonstra não estar relacionada ao impacto.

Percebe-se uma relação quase que direta da anomalia Bouguer nas bordas com sua topografia (Figura 4.15), principalmente no que diz respeito à borda noroeste da estrutura. Entretanto, a assimetria da anomalia central que se estende para o sul contraria esta análise para esta borda. De certa forma, o relevo aí presente pode expressar o elevado grau de erosão da cratera de Araguainha. Esta análise é importante para a construção dos modelos.

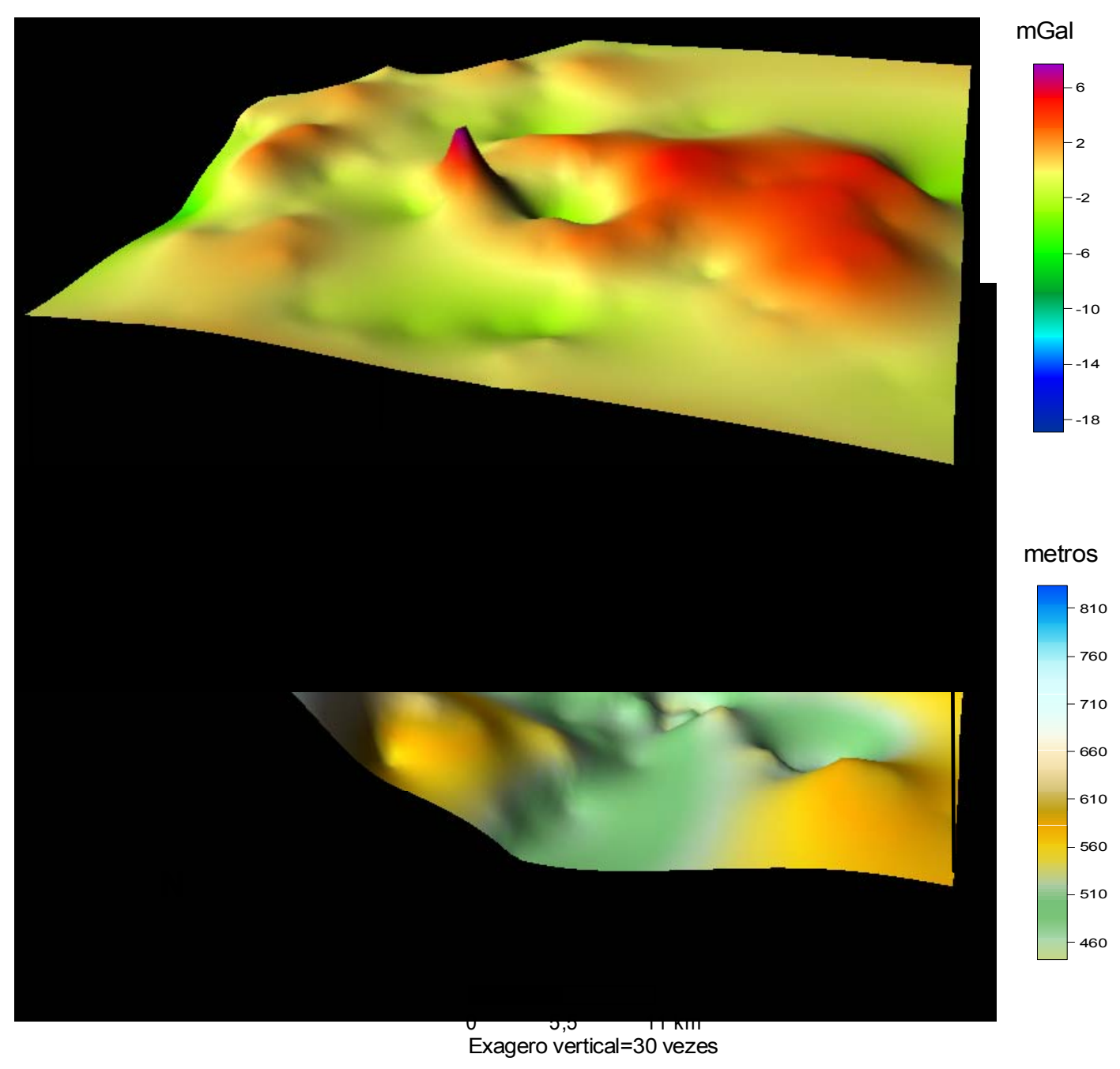

Figura 4.15. Representação conjunta dos dados de anomalia Bouguer e os dados topográficos. Destaca-se a coincidência entre regiões de elevada topografia com regiões que apresentam alto gravimétrico. A forte anomalia presente na região centro sul foge a esta análise. 


\subsubsection{Derivada vertical}

Outra classe de transformações úteis engloba as derivadas de primeira e segunda ordem direcionais ou verticais. Em termos dos coeficientes da transformada de Fourier, ou seja, no domínio de freqüência, basta derivar o termo que depende da variável em que a derivada está sendo calculada, e multiplicar cada termo dos coeficientes de Fourier pela freqüência ikx, iky ou kz, no caso das derivadas primeira, ou pelo quadrado das freqüências no caso de derivadas segunda. A equação geral é apresentada abaixo

$$
\frac{d}{d z} g_{Z}(x, y, z)=\sum_{n=0}^{N x} \sum_{n=0}^{N y} k_{Z} \widetilde{g}\left(k_{X}, k_{Y}\right) \exp \left[-i\left(k_{X} x+k_{Y} y\right) \exp \left(k_{Z} z\right)\right]
$$

onde $g_{z}$ é a componente vertical do campo potencial, $\widetilde{g}$ é a componente no domínio da freqüência, $k_{x}$ é a freqüência na direção $x, k_{y}$ é a freqüência na direção $y, k_{z}$ é a freqüência na direção $z, N_{x}$ é o número de amostras na direção $x$ e $N_{y}$ é o número de amostras na direção $y$.

Para calcular as derivadas de ordem superior, segunda, por exemplo, basta derivar a exponencial, e no caso da derivada segunda vertical, o termo $k z^{2}$ deverá multiplicar cada coeficiente de Fourier associado a esta freqüência.

As derivadas dos mapas gravimétricos e magnéticos são úteis para delimitar os limites de corpos e estruturas causadoras das principais anomalias, além de também funcionarem como um método de separação regional-residual. As anomalias de curto comprimento e maior gradientes são realçadas, e estas têm origem próxima da superfície. Os pontos em que a derivada segunda se anulam podem ser utilizados para limitar as extremidades do corpo.

A aplicabilidade da derivação do campo neste trabalho é a delimitação de estruturas em profundidade relacionadas ao limite entre blocos. Isto auxilia na determinação do contato entre o embasamento e as rochas sedimentares ou mesmo regiões de falha. Sua aplicação será enfatizada no capítulo 6 , referente aos resultados dos modelamentos realizados. O cálculo foi realizado com base na rotina DERV2B (Shukowsky, 2006) e um exemplo é mostrado na figura 4.16. 


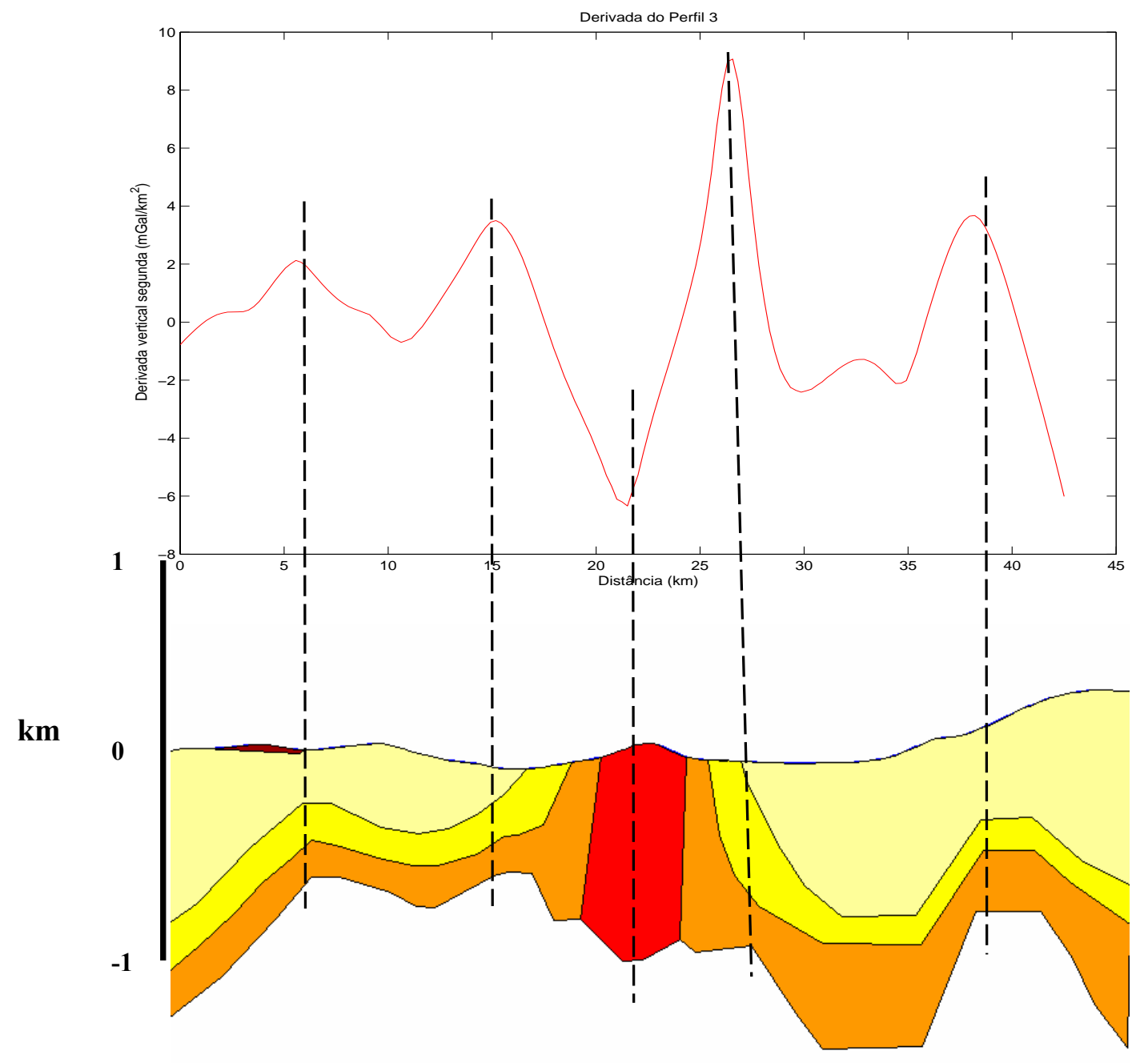

Figura 4.16. Exemplo da aplicação do método da derivada vertical de segunda ordem na delimitação de corpos com densidades distintas. A linha preta tracejada mostra a relação entre pico da derivada e alto do embasamento.

\subsubsection{Propriedades físicas das amostras}

Para uma modelagem confiável dos dados gravimétricos é necessária a coleta de amostras para determinação dos valores de densidade dos materiais geológicos presentes na área.

Os dados de densidades foram obtidos com medidas do peso da amostra no ar e submersa em água. As medidas realizaram-se sobre as fácies presentes no centro da estrutura e sedimentos da bacia. Nem todos os litotipos da bacia dentro e fora da estrutura de impacto foram amostrados e, portanto, alguns valores de densidade para 
estas supracrustais foram estimados com base em informações bibliográficas. As amostras fazem parte do acervo coletado por Yokoyama (2006) e consistem em 66 amostras que são destinadas à geração de informações paleomagnéticas.

A análise apresenta média de $2,22 \pm 0,01 \mathrm{~g} / \mathrm{cm}^{3}$ para um siltito carbonático do Grupo Passa-Dois. As amostras de arenito da Formação Aquidauana mostram-se com média de 2,36 $\pm 0,07 \mathrm{~g} / \mathrm{cm}^{3}$, com $3,13 \pm 0,05 \mathrm{~g} / \mathrm{cm}^{3}$ para as amostras da Formação Ponta Grossa e 2,22 $\pm 0,06 \mathrm{~g} / \mathrm{cm}^{3}$ para as amostras da Formação Furnas. Ressalta-se que as amostras coletadas da Formação Ponta Grossa correspondem à fácies rica em ferro, o que resulta em densidades elevadas. Não se tem informação da espessura deste pacote dentro do restante dos sedimentos. Desta maneira, para o restante do pacote, foi adotada a mesma densidade encontrada para as amostras da Formação Aquidauana. Todos os valores são próximos aos 2,32 g/cm citados por Dobrin (1960) para amostras de arenito.

As medidas de densidades realizadas nas 32 amostras do granito apresentam média de $2,45 \pm 0,04 \mathrm{~g} / \mathrm{cm}^{3}$. Esta informação é próxima aos valores de densidade para amostras de granito encontradas por Henkel et al. (2002), de 2,5 g/cm ${ }^{3}$ para granitóides do embasamento. No entanto, contrapõem-se à informação gravimétrica que revela um baixo na região do EGS, já que a densidade do granito mostra-se superior aos sedimentos. A maneira encontrada para solucionar esta questão é atribuir o valor encontrado para a região do embasamento em subsuperfície, e para a região do EGS adotar o valor de 2,15 $\mathrm{g} / \mathrm{cm}^{3}$. Esta consideração é coerente em que pese a presença de brechas, que em geral apresentam valores de $2,09 \mathrm{~g} / \mathrm{cm}^{3}$ (Ebbing et al., 2001), xenólitos de siltitos e do intenso fraturamento.

A tabela detalhada das medidas de densidade consta no Apêndice A.

\subsection{DADOS MAGNÉTICOS}

A informação magnética utilizada neste trabalho se desmembra em dados aeromagnéticos e magnéticos terrestres. Os dados aeromagnéticos, com comprimentos de ondas maiores e informações mais regionais, auxiliam no entendimento do aspecto geral da estrutura de impacto. Por outro lado, os dados magnéticos terrestres, com comprimentos de onda menores, complementam a análise aérea e fornecem maior detalhe da deformação da estrutura com o impacto. 


\subsubsection{Dados Aeromagnéticos}

A base de dados aeromagnéticos que subsidia o projeto da área estudada provém do levantamento denominado Projeto Alto Garças (Prospec S.A., 1972). Estes dados compreendem uma cena limitada pelas coordenadas geográficas $16^{\circ} 30^{\prime}$ $\mathrm{S} / 53^{\circ} 24^{\prime} \mathrm{W}$ e $17^{\circ} 00^{\prime} \mathrm{S} / 52^{\circ} 45^{\prime} \mathrm{W}$ com linhas de vôo espaçadas em $1 \mathrm{~km}$ e altitude de 120 metros, fornecidos em formato digital ASCII, em escala 1:500000. A CPRM informa em sua base de dados que estes foram redigitalizados devido à perda da fita magnética original. Com este processo os dados são suavizados e anomalias de pequeno comprimento de onda podem se perder.

A malha foi interpolada pelo método da mínima curvatura e aos valores brutos foi somado o "datum" de $16000 \mathrm{nT}$, correspondente ao campo geomagnético a uma altitude de 1000 metros, conforme recomendação da CPRM. Ao subtrair o IGRF de $23376 \mathrm{nT}$ as anomalias persistem com valores unicamente positivos. Para eliminar este efeito foram realizados três testes:

(1) Escolheu-se uma anomalia que apresenta valor relativamente constante e subtraiuse seu valor de todos os dados (linha azul da figura 4.17) do campo magnético;

(2) Foi traçado um plano de ajuste médio nestes dados que posteriormente foi removido dos mesmos. O resultado pode ser visto na linha verde da figura 4.17;

(3) Foi removida a componente magnética prevista pelo modelo geomagnético de Motta e Barreto (1992) ao invés de utilizar o IGRF, e dos dados residuais foram subtraídos os valores de uma superfície média (linha vermelha da figura 4.17).

Observa-se na figura 4.16 que os dados retirados ao longo do perfil A-B (Figura 4.17) apresentaram alto grau de semelhança e que o resultado obtido pelo procedimento (1) é o mais discrepante dos três. Portanto, opta-se por trabalhar neste projeto com os dados residuais obtidos do procedimento (3). Os valores de declinação e inclinação adotados correspondem a $-11,8^{\circ}$ e $-9,7^{\circ}$, respectivamente, representativos da época e região de estudo.

Obtém-se através deste procedimento o mapa do campo aeromagnético residual da figura 4.18. Nota-se que estes dados definem um tênue contorno da borda externa da estrutura, marcado com valor de aproximadamente $-20 \mathrm{nT}$ na porção sudeste e por valores baixos a intermediários em seu complemento. Theilen-Willige (1981) já havia observado o contorno anômalo circular pouco definido. Ainda há de se ressaltar que a região correspondente ao núcleo é marcada por valores próximos aos valores de borda e mostram o núcleo com valores intermediários. 


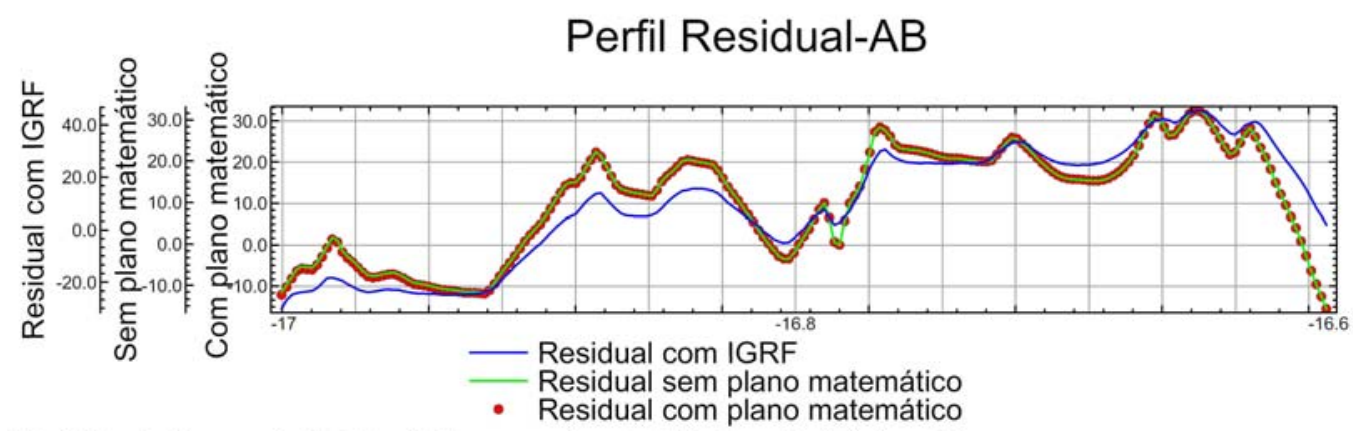

Figura 4.17. Perfis residuais obtidos ao longo da linha A-B (Figura 4.18). Nota-se pouca diferença entre as três análises realizadas. O perfil de cor vermelha, correspondente aos dados residuais que serão adotados para este trabalho, corrigidos a partir de dados da de Motta e Barreto (1992).

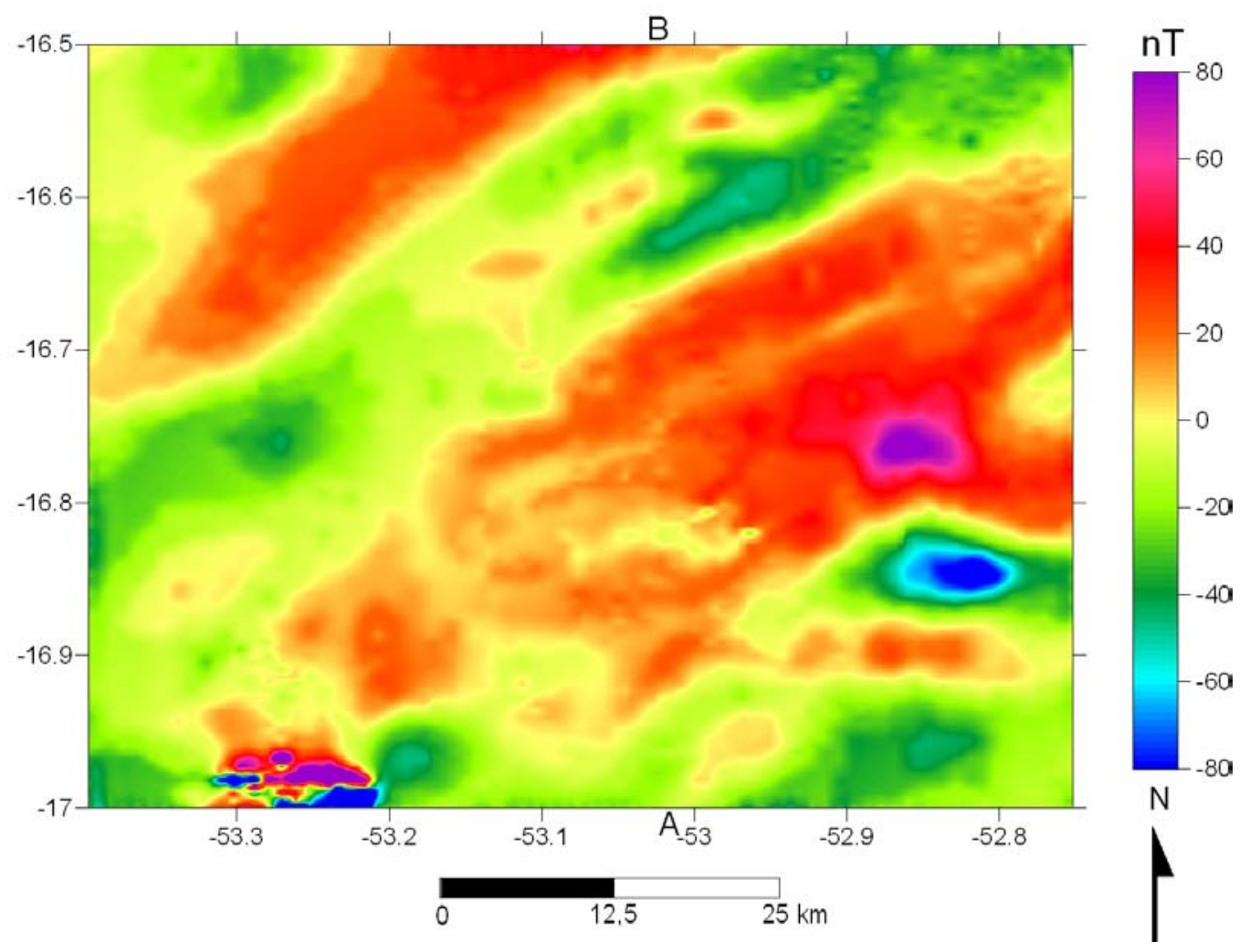

Figura 4.18. Mapa do campo magnético residual obtido dos dados aeromagnéticos a partir do modelo previsto por Motta e Barreto (1992). 


\subsubsection{Processamento dos dados}

Dados magnéticos na forma de mapas e perfis são normalmente submetidos a transformações lineares e não-lineares com o intuito de realçar aspectos do campo anômalo (Blakely, 1995). Busca-se neste processo identificar a continuidade de fontes, discriminar fontes interferentes, distinguir fontes rasas de fontes profundas e, geralmente o mais importante, posicionar campos transformados sobre as fontes magnéticas no substrato.

No domínio de Fourier uma transformação linear pode genericamente ser expressa como:

$$
F\{C\}=F(k x, p) F\left\{T_{m}^{t}\right\}
$$

sendo $F\{C\}$ a Transformada de Fourier do campo filtrado $C, F(K x, p)$ o filtro associado a esta transformação e $F\left\{T_{m}^{t}\right\}$ a Transformada de Fourier da anomalia magnética de campo total

\section{Continuação de campos}

A continuação de campos é um processo matemático que permite inferir a configuração de um campo potencial em uma altura diferente daquela na qual foi medido. O cálculo em um nível inferior ao de medida configura a continuação para baixo e o cálculo em um nível superior define a continuação para cima (Duarte, 2003).

A expressão matemática do filtro de continuação é dada por

$$
F c(K x)=e^{z|k x|}
$$

onde $z$ corresponde à altura da continuação.

Na continuação para cima o termo exponencial na equação 4.5 é negativo e tende a atenuar as anomalias de curto comprimento de onda (ou alta freqüência), o que corresponde a diminuir o efeito das fontes rasas. Na continuação para baixo, o termo exponencial em 4.5 é positivo e a operação de filtragem acarreta o realce do conteúdo de alta freqüência do sinal. Isso corresponde a realçar os campos associados a fontes mais rasas, embora tenha o efeito de amplificar ruídos existentes nos dados (Tuma, 2006). 
Pelo exposto nota-se que é possível utilizar esta transformação para estimar a componente regional no processo de separação das anomalias com diferentes profundidades de origem. Esta transformação também pode ser utilizada na integração de dados obtidos em diferentes alturas visando produzir uma base de dados unificada.

Apesar da remoção da componente regional magnética, nota-se uma forte tendência de direção NE-SW superpondo-se aos dados (Figura 4.18). Na tentativa de removê-la, aplicou-se a continuação para cima a alturas de $0,5 \mathrm{~km}, 1,0 \mathrm{~km}, 1,5 \mathrm{~km}, 2,0$ $\mathrm{km}$ e $3,0 \mathrm{~km}$ (Figura 4.19). Observa-se que esta fonte persiste com os dados continuados até $2,0 \mathrm{~km}$ (Figura 4.19) e também para os dados continuados a 3,0 km, o que a caracteriza sua origem em grandes profundidades.

Estas malhas foram então removidas da malha do campo magnético residual e posteriormente traçado um perfil A-B (Figura 4.18) para comparação dos resultados. Os dados referentes ao residual obtido pelo modelo previsto de Motta e Barreto (1992) mostram uma diferença que atinge cerca de $30 \mathrm{nT}$ em algumas regiões quando comparados aos residuais das continuações (Figura 4.20). Escolheu-se para a remoção final dos dados residuais o campo magnético continuado a 2,0 km, já que a esta altura a influência da fonte ainda persiste. Obtém-se, desta forma, o mapa relativo ao campo magnético anômalo, do qual os perfis destinados à modelagem são extraídos (Figura 4.21). Deve-se ressaltar que, apesar de grandes esforços em eliminar a componente magnética regional, ainda pode-se observar faixas com a tendência NESW superpondo-se à anomalia da cratera. Isto de certa forma pode comprometer o ajuste dos modelos gerados se não for criteriosamente levado em consideração. 

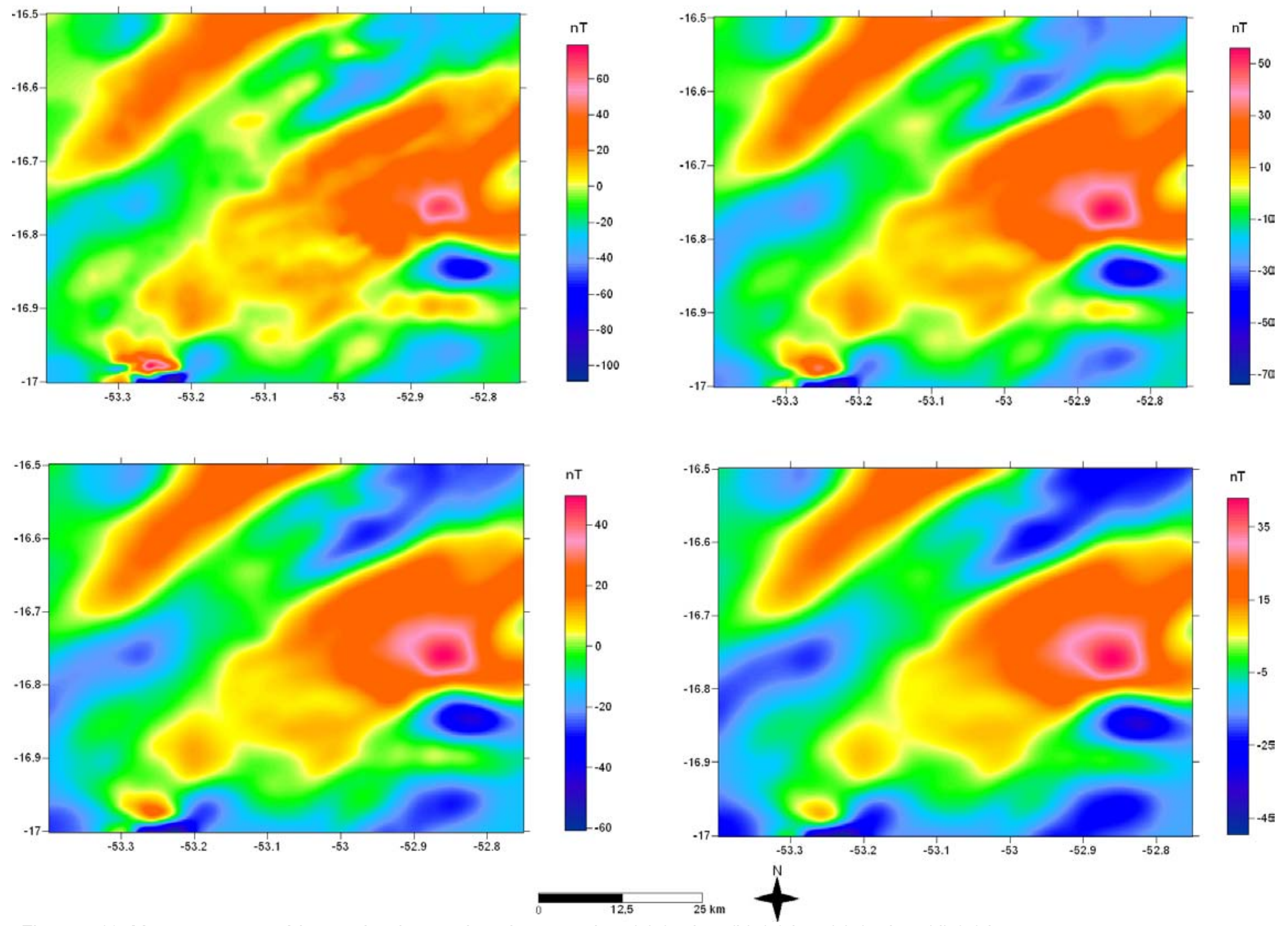

Figura 4.19. Mapas aeromagnéticos anômalos continuados para cima (a) 0,5 km, (b) 1,0 km, (c) 1,5 km, (d) 2,0 km. 


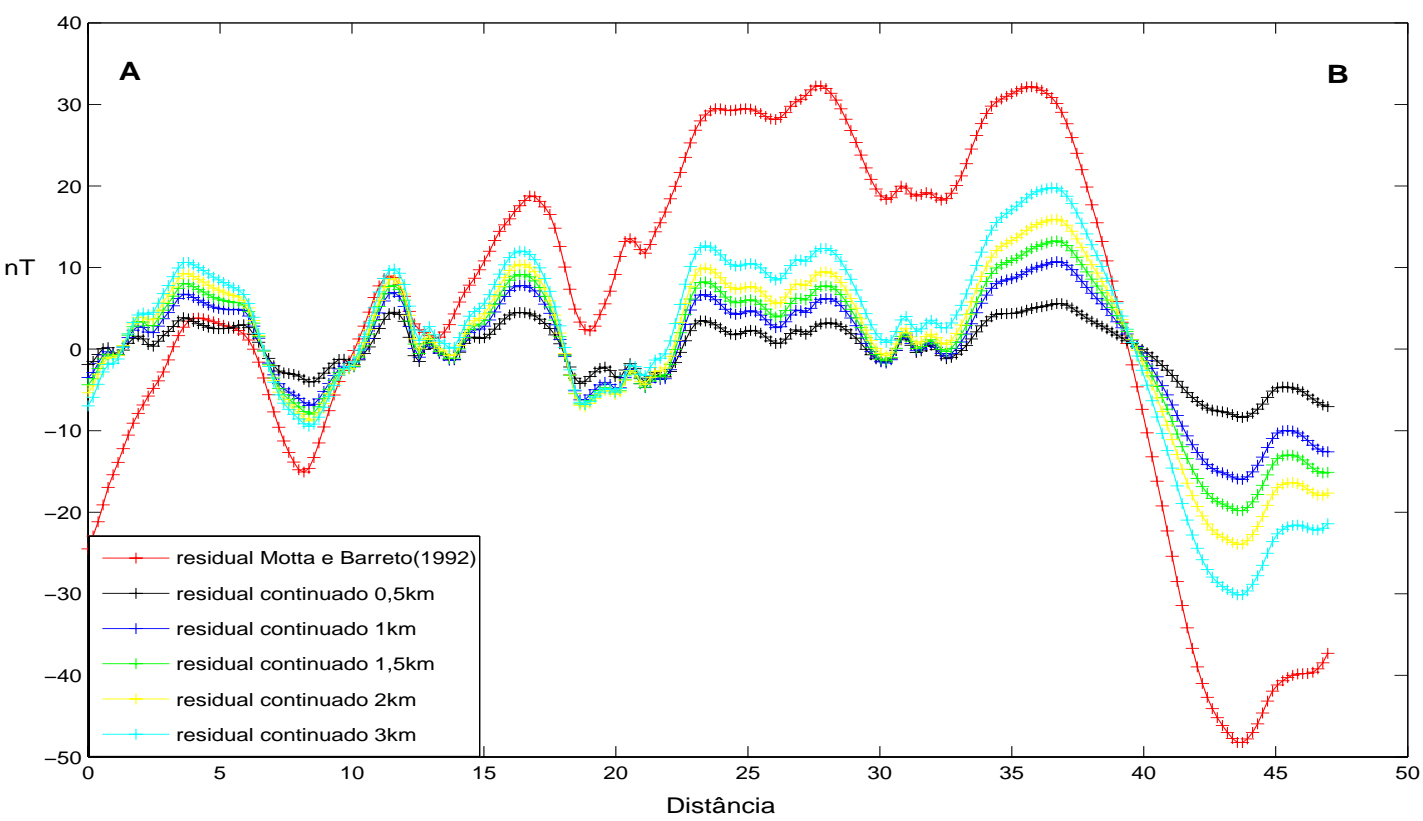

Figura 4.20. Perfil A-B comparativo entre o campo magnético anômalo obtido por meio do modelo de Motta e Barreto (1992) e os residuais do mesmo campo continuado para cima em 0,5 km, $1 \mathrm{~km}, 1,5 \mathrm{~km}, 2 \mathrm{~km}$ e 3 $\mathrm{km}$.

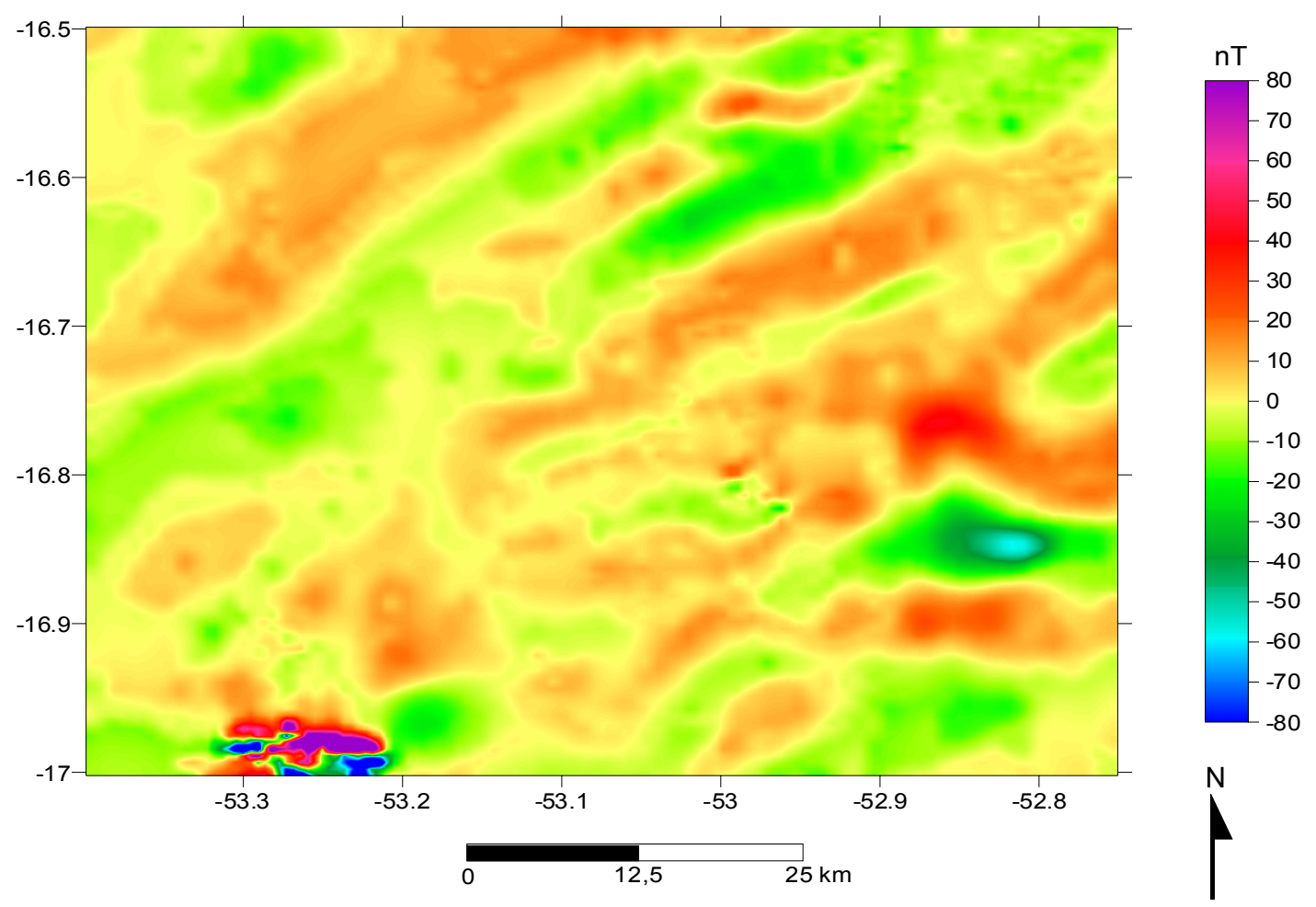

Figura 4.21. Mapa do campo magnético anômalo referente aos dados aeromagnéticos. A partir destes dados são extraídos os perfis para modelagem. 
Amplitude do sinal analítico

A importância do sinal analítico reside na interpretação dos dados, pois o mesmo é independente da direção de magnetização e da direção do campo da Terra. Isto significa que todos os corpos com mesma geometria têm o mesmo sinal analítico. Os picos da função são simétricos e ocorrem diretamente sobre as bordas de corpos alongados e centro de corpos estreitos, definindo a posição das fontes indiferentemente da existência de remanescência (Milligan e Gunn, 1997). A amplitude do sinal analítico pode ser expressa matematicamente por:

$$
|A(x, y)|=\left(\left(\frac{\partial m}{\partial x}\right)^{2}+\left(\frac{\partial m}{\partial y}\right)^{2}+\left(\frac{\partial m}{\partial z}\right)^{2}\right)^{1 / 2}
$$

onde $\mathrm{m}$ é a anomalia magnética.

A figura 4.22 mostra o mapa da amplitude do sinal analítico, na qual pode-se observar o contato do núcleo granítico bem definido nas coordenadas $-16,8^{\circ}$ e $-53,0^{\circ}$. Esta ferramenta de processamento, ao delimitar com precisão os contatos entre os corpos, mostra-se importante para o auxílio na escolha dos perfis a serem modelados, além de subsidiar a interpretação final das dimensões da estrutura de Araguainha.

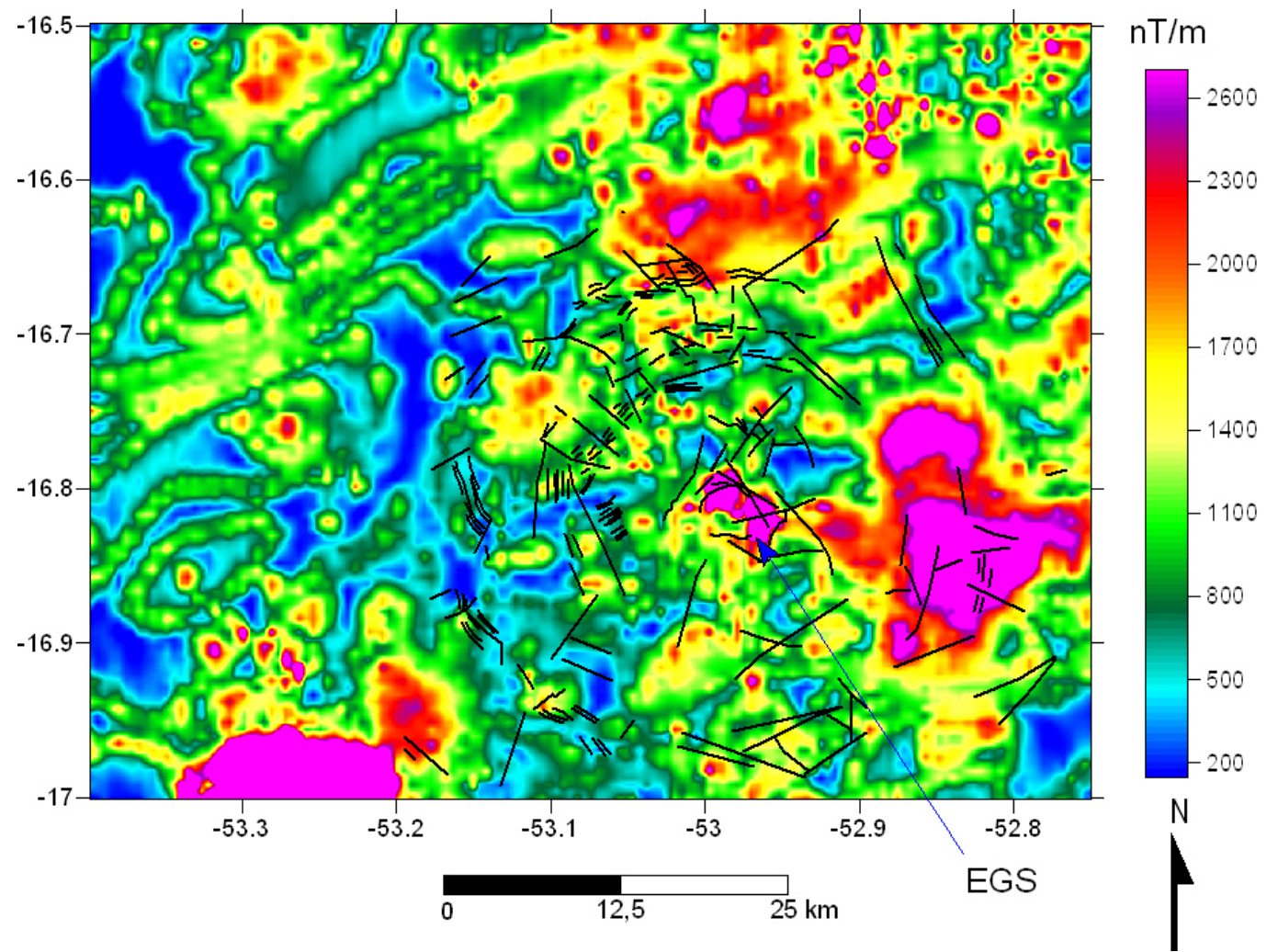

Figura 4.22. Mapa da amplitude do sinal analítico sobreposto por lineamentos estruturais. Observa-se o contorno do embasamento granítico soerguido (EGS) e a borda oeste da estrutura bem delimitados. 
Nota-se no mapa da amplitude do sinal analítico aproximadamente $5 \mathrm{~km}$ de diâmetro para o EGS. O contorno das bordas é tenuamente destacado com valores de $500 \mathrm{nT} / \mathrm{m}$ na porção oeste da estrutura, que é mascarado na borda leste por valores muito altos.

\section{Espectro de Potência}

O cálculo da profundidade média das fontes causadoras das anomalias magnéticas foi feito pelo método proposto por Spector \& Grant (1970).

Neste método, a crosta é considerada um conjunto de paralelepípedos retangulares verticais com profundidade $h$, largura a, comprimento $l$, espessura $t$ e magnetização $M$. Desta maneira, o campo magnético observado em qualquer área é considerado como resultante da superposição de um grande número de anomalias individuais, causadas por estes blocos com diversas dimensões e magnetizações.

O espectro de potência devido a um paralelepípedo com as características supracitadas, no domínio da freqüência, é dado por Bhattacharyya (1966) em coordenadas polares com a seguinte forma

$$
E(r, \theta)=|F(\Delta T)|^{2}=4 \pi^{2} k^{2} e^{-2 h r}\left(1-e^{-t r}\right)^{2} S^{2}(r, \theta) R_{T}^{2}(\theta) R_{K}^{2}(\theta)
$$

onde $S, R_{T}$ e $R_{k}$ são funções que dependem da largura e espessura dos das fontes, $k$ é o número de onda

Supondo que o espectro de potência de um perfil magnético seja produzido por um conjunto de paralelepípedos magnetizados, a expressão reduz-se para

$$
E(r)=|F(\Delta T)|^{2}=4 \pi^{2} k^{2} e^{-2 h r}
$$

Desta forma, com o auxilio do gráfico do logaritmo do espectro de potência dos dados aeromagnéticos versus o número de onda, pode-se calcular a profundidade média das fontes causadoras. O decaimento do logaritmo do espectro permite traçar retas as quais o coeficiente angular fornece $-2 \mathrm{~h}$, onde $\mathrm{h}$ é a profundidade média dos corpos causadores da anomalia. 
Esta técnica é aplicada nos dados aeromagnéticos de Araguainha em 78 perfis extraídos de sul para norte e espaçados de $4 \mathrm{~km}$ (Figura 4.23), que perfazem toda a área da cratera, a fim de vincular estas informações aos modelos gerados.

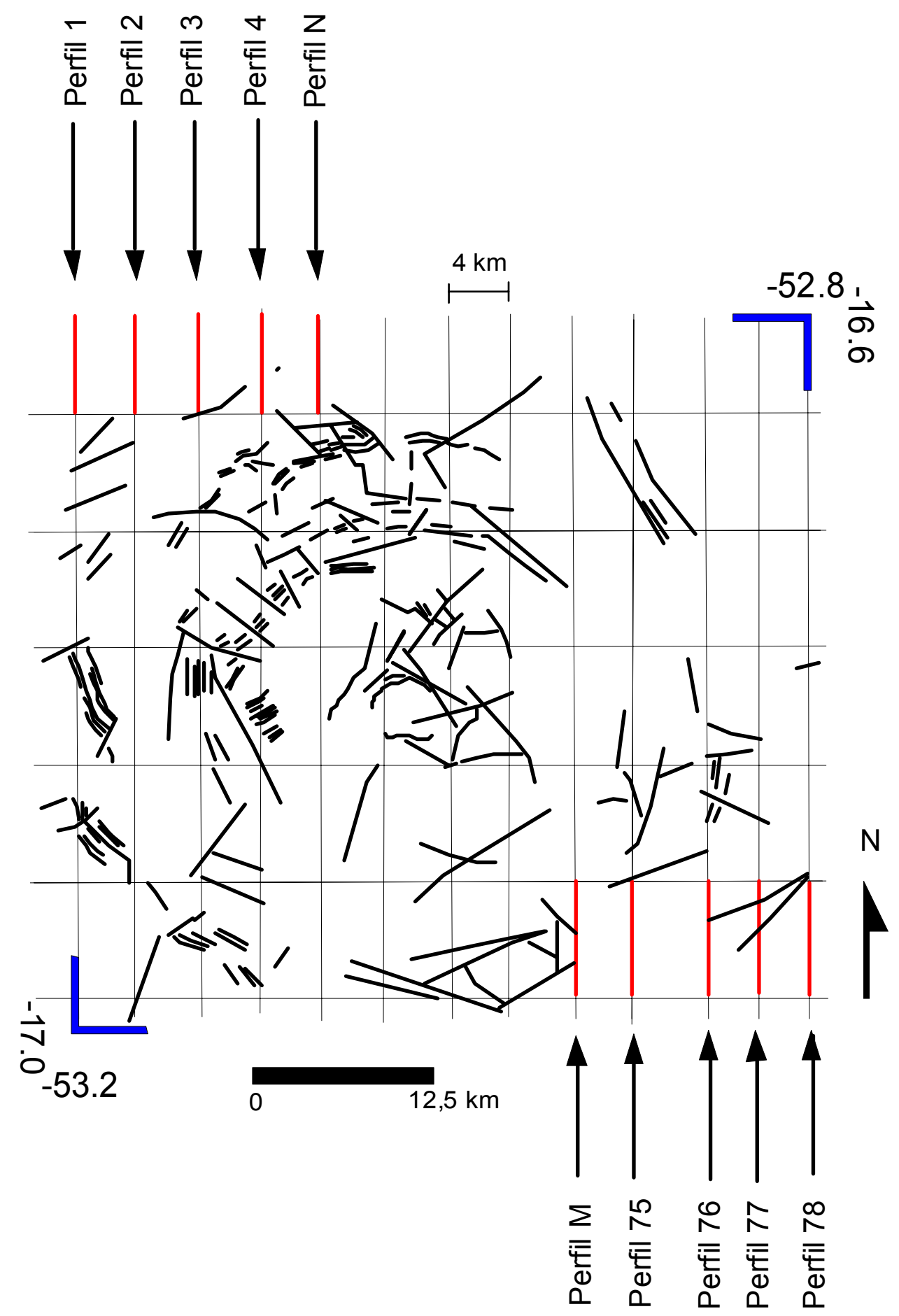

Figura 4.23. Mapa de lineamentos estruturais com localização dos perfis aeromagnéticos utilizados para o cálculo do espectro de potência. As linhas vermelhas marcam a posição onde os perfis foram extraídos. 
A grande maioria dos espectros obtidos mostra a existência de duas fontes: uma primeira mais rasa caracterizada por maior freqüência e menor coeficiente angular e uma segunda fonte mais profunda caracterizada por uma reta com maior coeficiente angular (Figura 4.24). A fonte mais rasa, com média de 0,5 km, pode estar relacionada à distância entre a aeronave e a superfície. Já a mais profunda apresenta média de $1 \mathrm{~km}$ e deve estar associada ao embasamento granítico da região.

O resultado dos perfis analisados são interpolados, para as segundas fontes, em uma malha de 2 por $2 \mathrm{~km}$ (Figura 4.25). O mapa gerado apresenta aparente homogeneidade para as profundidades em torno de $1 \mathrm{~km}$, o que favorece a afirmação de Masero et al. (1994), se estas estiverem de fato relacionadas ao embasamento. As regiões das bordas sul e leste apresentam profundidades em torno de 0,7 km e os valores mais altos estão dispersos. 

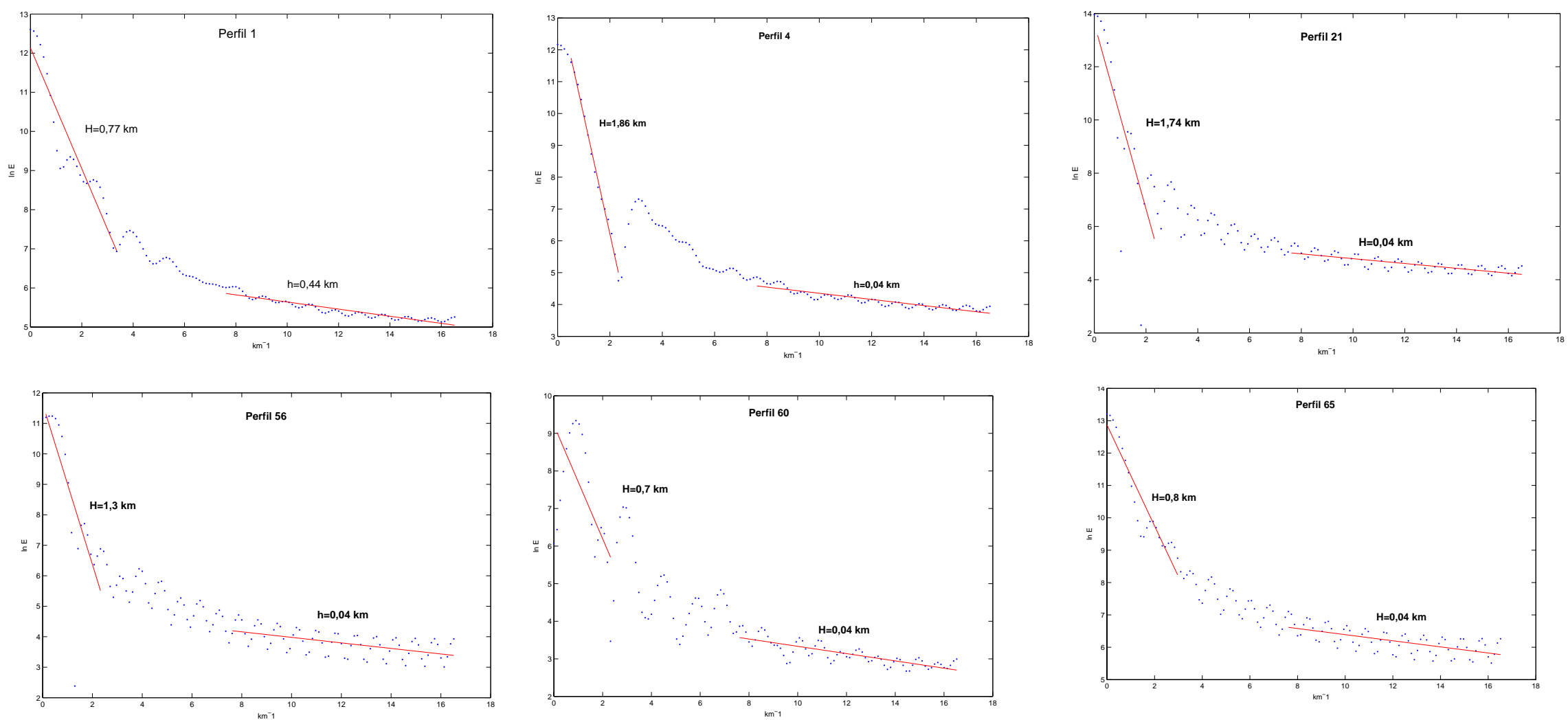

Figura 4.24. Espectros de potência da anomalia magnética em função da freqüência. A inclinação das retas determina a profundidade média das fontes ajustadas aos pontos $\mathrm{h}=$ profundidade da primeira fonte magnética, e $\mathrm{H}=$ profundidade da segunda fonte magnética, aqui relacionada ao embasamento. 


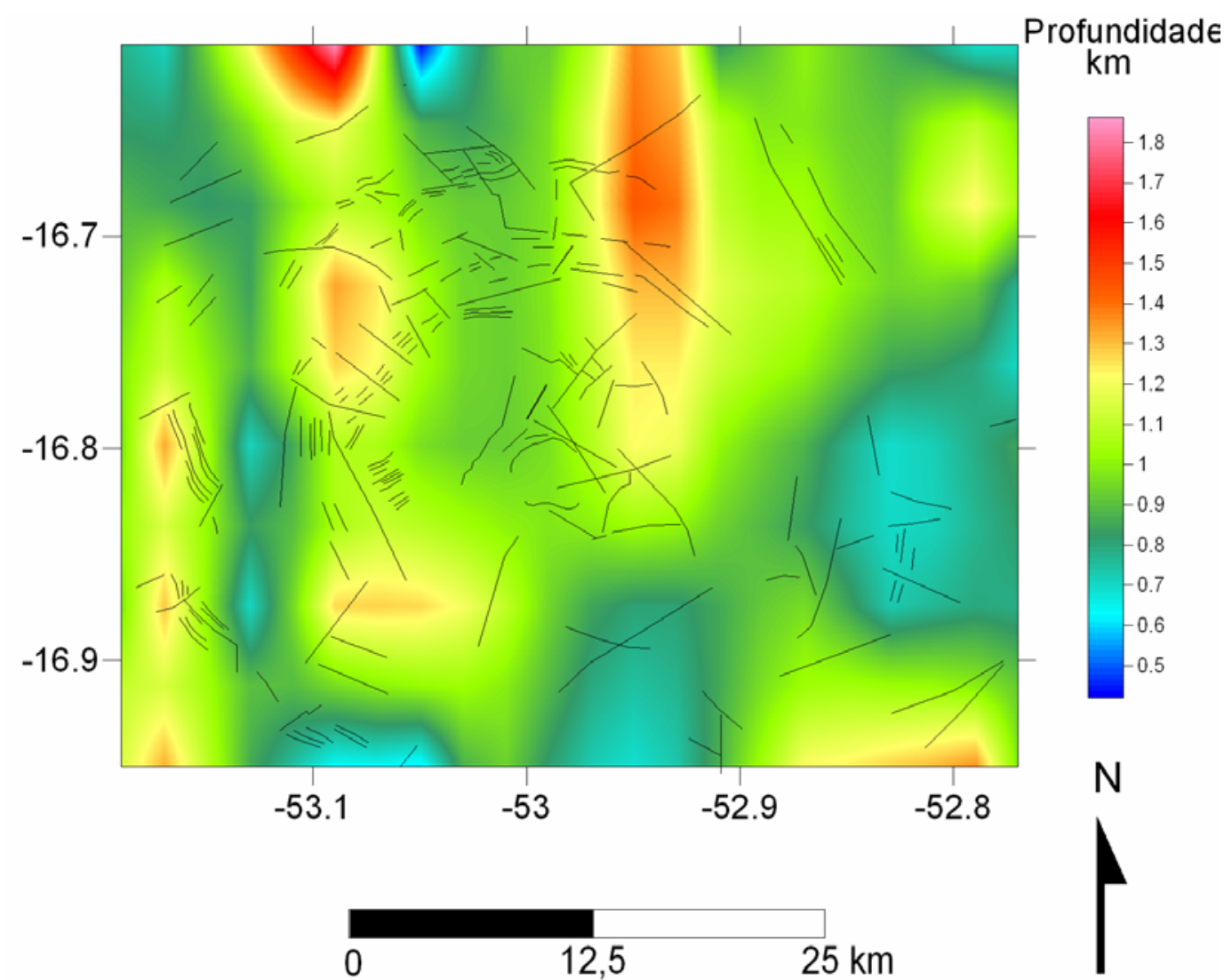

Figura 4.25. Mapa das profundidades das primeiras fontes magnéticas obtidas com o cálculo do espectro de potência dos dados aeromagnéticos correlacionado aos lineamentos estruturais.

\subsubsection{Dados magnéticos terrestres}

No trabalho de campo realizado para a coleta de dados magnéticos terrestres utilizou-se de dois magnetômetros de precessão de prótons (com sensibilidade de $1 \mathrm{nT}$ ), tipo overhouser, GSM-19 da GEM Systems, pertencentes ao Departamento de Geofísica do IAG/USP. Um dos magnetômetros foi utilizado como base para monitorar a variação diurna do campo magnético e o outro como itinerante para o mapeamento de anomalias locais, sempre orientados com a bobina na direção do norte magnético. O magnetômetro que permaneceu na base foi configurado com cycle time de 10 segundos.

A coleta de dados terrestres consiste em 11 perfis radiais localizados em regiões importantes da estrutura, como bordas, anéis e núcleo soerguido (Figura 4.26). Alguns perfis ultrapassam os limites da estrutura para que o sinal magnético desta fique caracterizado de forma precisa. O espaçamento entre as estações foi da 
ordem de 50 metros de forma que as pequenas alterações no campo magnético induzidas pelas rochas possam ser amostradas de forma confiável.

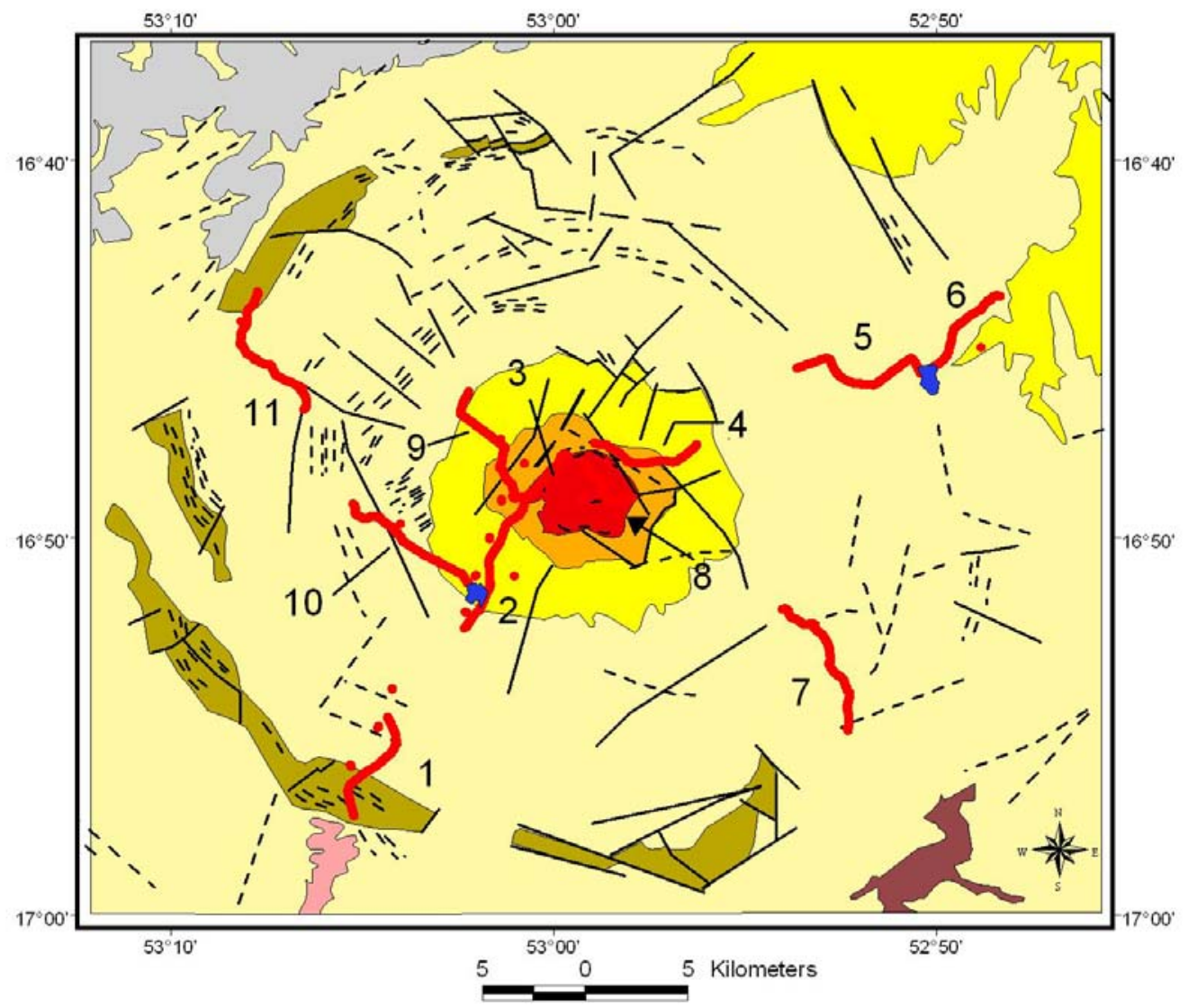

Figura 4.26. Articulação dos perfis magnéticos terrestres (pontos vermelhos) coletados até às 13 horas de cada dia com espaçamento de 50 metros.

Durante a realização do trabalho de campo um dos magnetômetros apresentou problemas na qualidade do sinal e a partir de então os dados foram adquiridos apenas com um magnetômetro (cerca de 66\% dos dados). Para realizar uma correção diurna confiável utilizou-se como base dados de uma estação fixa localizada em Palmas, que coletou dados no mesmo período do levantamento terrestre, cedidos pela AGP-LA, convênio ANP-Poli-USP (Andrade, 2006).

Compararam-se os dados de Palmas aos dados dos três dias nos quais a estação base de Araguainha operou sem problemas. Após a remoção de um shift de 1200 nT dos dados de Palmas, observa-se que a máxima diferença entre os dois conjuntos de dados é menor que $5 \mathrm{nT}$. Nota-se que ambos são coerentes para os pontos coletados na parte da manhã, sendo que no período da tarde surge uma pequena divergência (Figuras 4.27, 4.28 e 4.29). Assumiu-se, então, a estação de 
Palmas como base para realização da correção diurna, optando-se por trabalhar unicamente com os dados terrestres coletados até às 13 horas dos 11 dias de campo, o que não compromete a modelagem realizada.

Após a correção diurna foi subtraído dos dados o valor do IGRF correspondente a $23378,4 \mathrm{nT}$, valor médio para a região na data da aquisição. Desta forma obtém-se o campo magnético anômalo para os dados magnéticos terrestres, destinado à etapa de modelagem.

A magnetometria terrestre faz-se importante neste trabalho, pois permite que as anomalias magnéticas possam ser mais bem vinculadas às suas fontes.

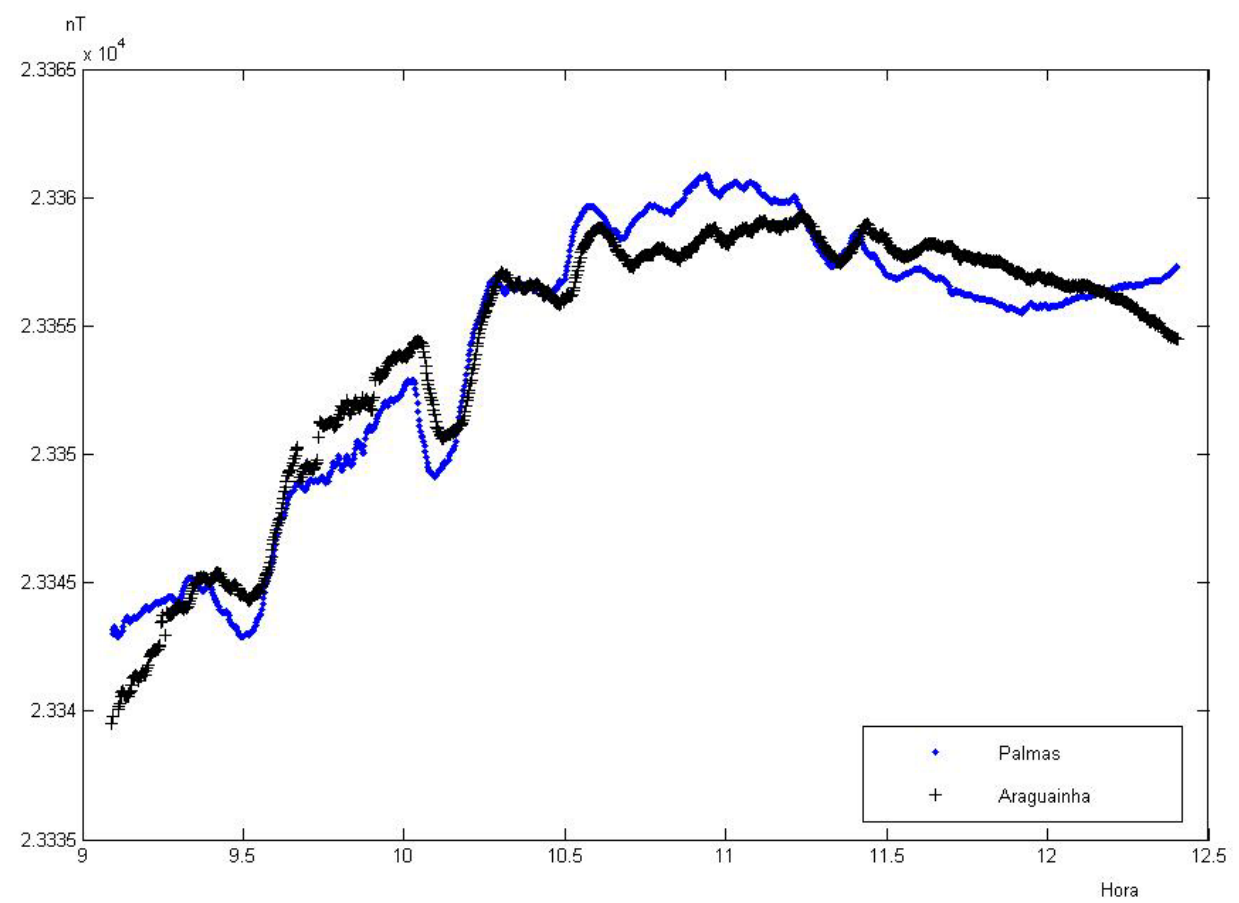

Figura 4.27. Comparação entre as estações de Palmas (pontos em azul) e Araguainha (cruzes em preto) para o dia 27.02. Há boa sobreposição dos dados, importante na utilização da estação de Palmas para correção da variação diurna. 


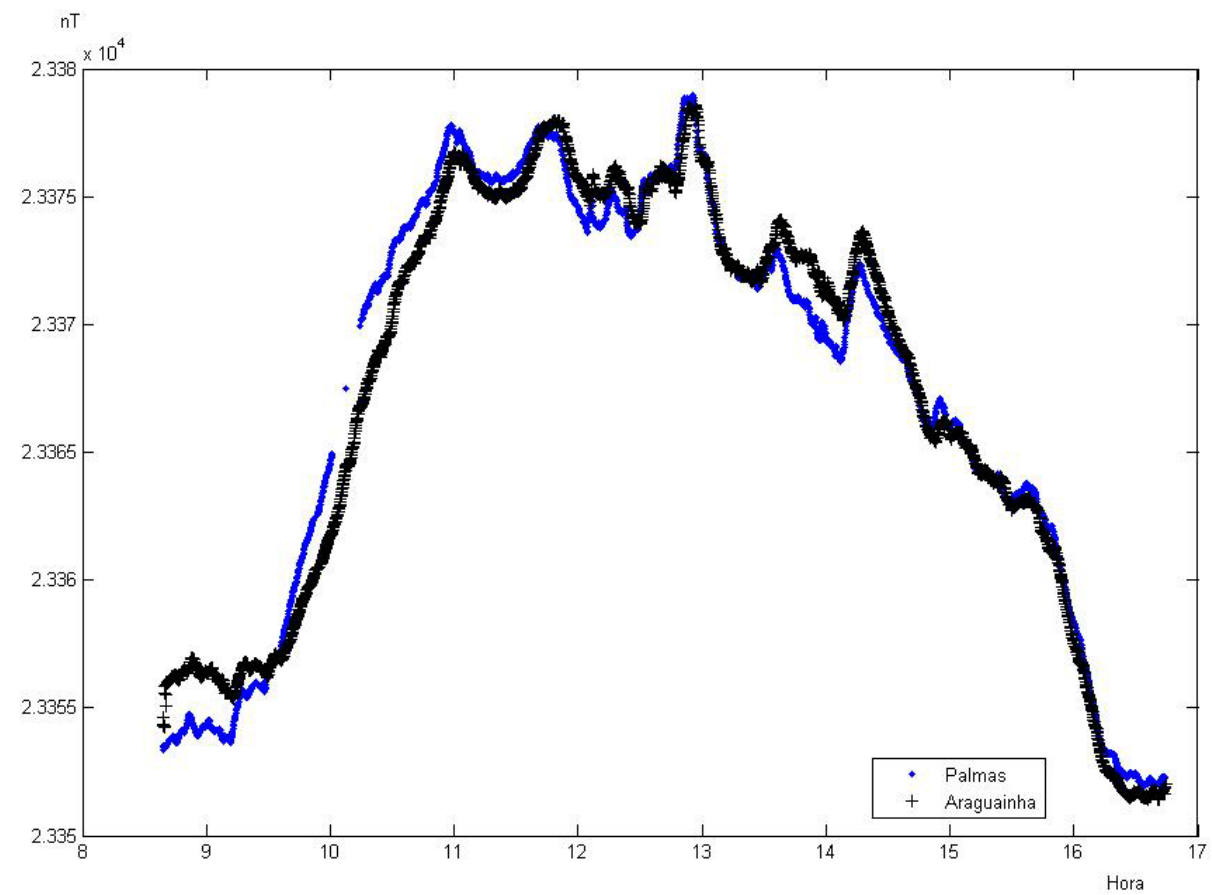

Figura 4.28. Comparação entre as estações de Palmas (pontos em azul) e Araguainha (cruzes em preto) coletadas no dia 28.02. Nota-se a boa sobreposição dos dados , importante para que a estação base de Palmas seja utilizada para correção da variação diurna dos dados.

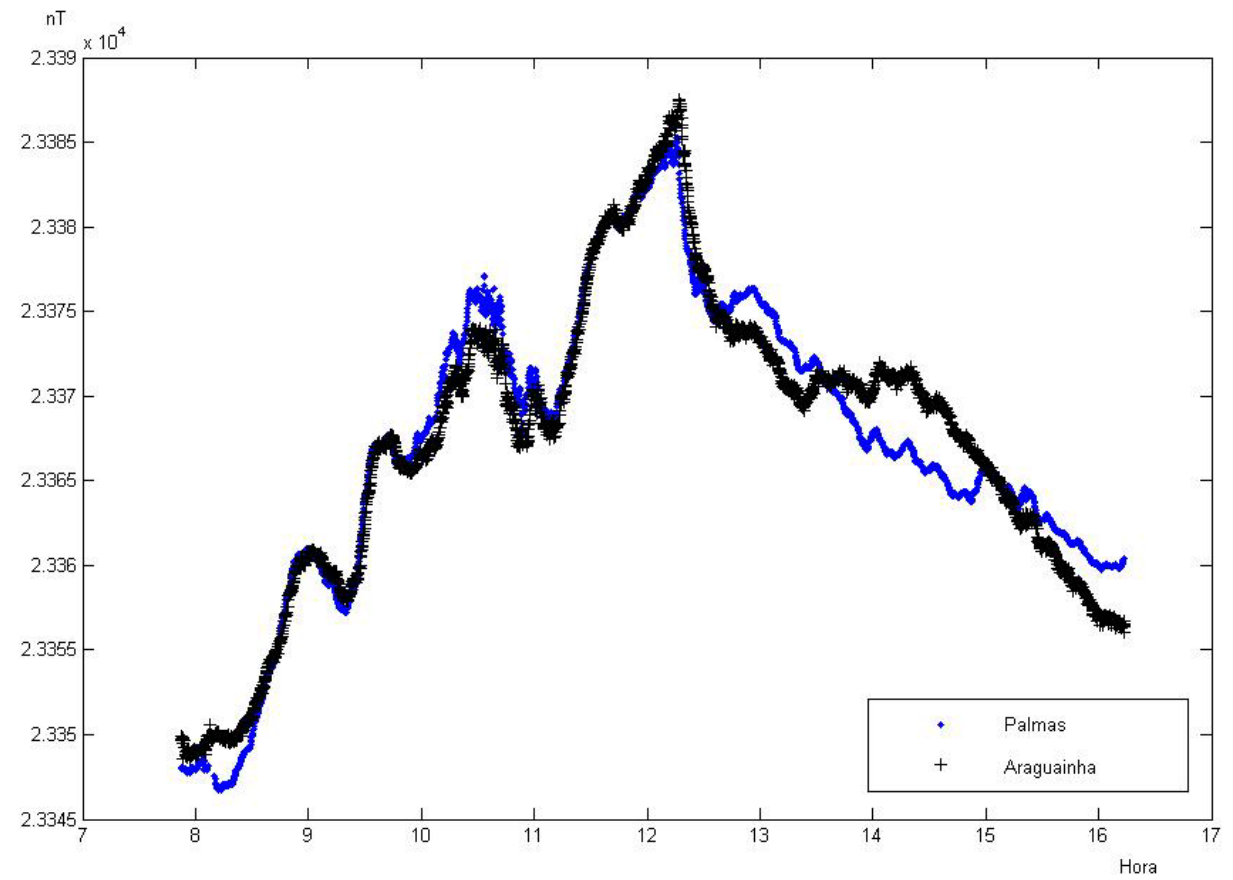

Figura 4.29. Comparação entre as estações de Palmas (pontos em azul) e Araguainha (cruzes em preto) coletadas no dia 01.03. Percebe-se boa sobreposição dos dados, com exceção para dados coletados na parte da tarde. 


\subsubsection{Propriedades físicas das amostras}

Para uma modelagem magnética coerente, exige-se a inserção de informações concernentes à susceptibilidade magnética $(k)$ e magnetização remanescente $\left(M_{R}\right)$ das rochas da região de estudo.

Diversos litotipos constituintes do centro da estrutura foram amostrados, incluindo brechas, produtos de fusão diretamente relacionados ao impacto, e o próprio granito representante do embasamento.

Como parte integrante dos dados de Yokoyama (2006), foram realizadas no Laboratório de Paleomagnetismo, IAG/USP, medidas de susceptibilidade em 528 amostras que são utilizadas neste trabalho. Destas, 48 referem-se às brechas do NCS, 110 aos pseudotaquilitos, 319 ao granito, 8 aos melts e 43 aos sedimentos da bacia. Os dados de remanescência foram obtidos em 44 amostras do granito.

Com os dados de susceptibilidade dos litotipos referentes à porção central elaboram-se histogramas (Figura 4.31) que mostram maior freqüência de $200 \times 10^{-5}$ (SI) para os granitos, $100 \times 10^{-5}$ a $400 \times 10^{-5}(\mathrm{SI})$ para os pseudotaquilitos e $100 \times 10^{-5}(\mathrm{SI})$ para as brechas e melts.

Tanto a localização quanto os valores de susceptibilidade de todos estes litotipos são muito próximos, o que torna difícil discriminá-los em modelagem. Por este motivo, para a maioria dos modelos adota-se, para alguns corpos da região central dos modelos, o valor de $250.10^{-3}(\mathrm{SI})$, que representa a melhor freqüência de susceptibilidades para a maioria das análises. 
a)

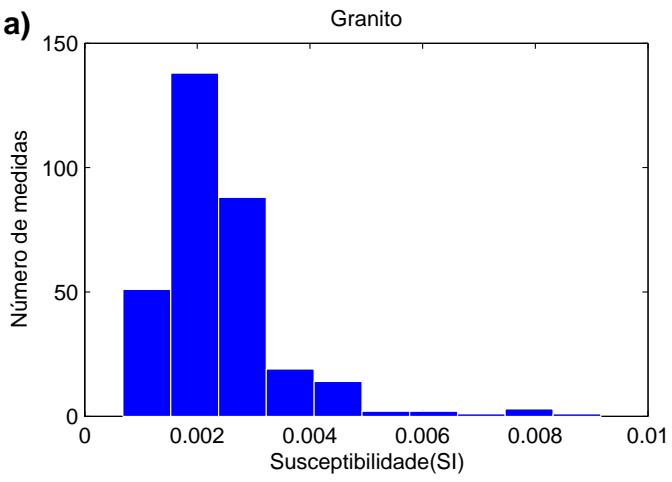

c)

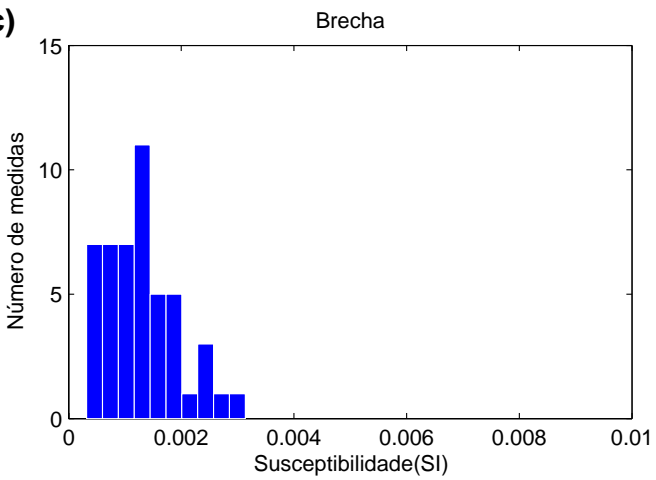

b)

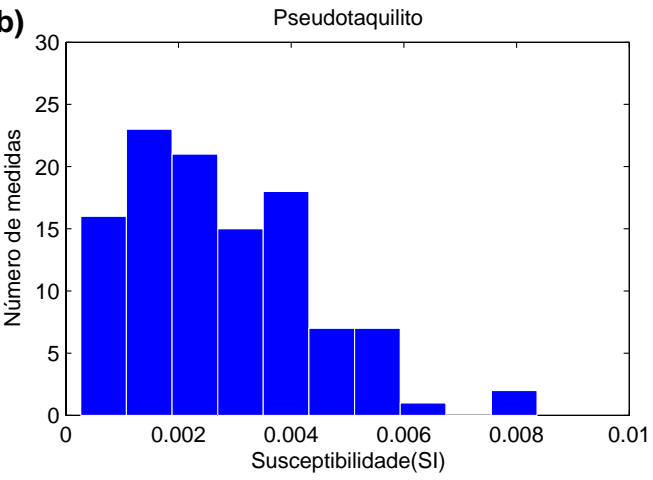

d)

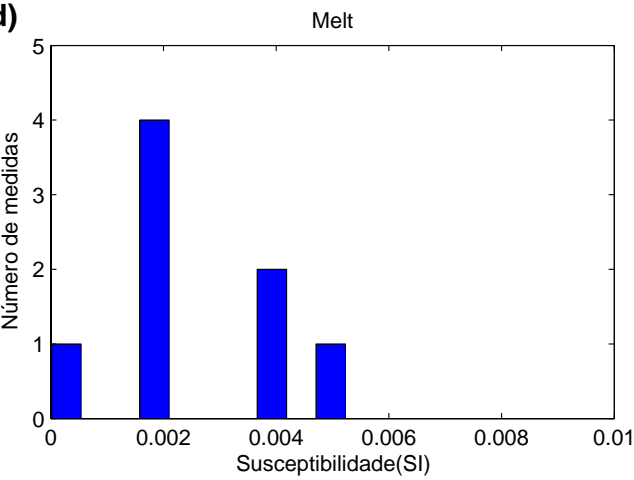

Figura 4.30. Distribuição das susceptibilidades (SI) dos diversos litotipos diferenciáveis na porção central do núcleo soerguido, (a) granitos, (b) pseudotaquilitos, (c) brechas e (d) melts. Dados cedidos por Yokoyama (2006).

\subsubsection{Magnetização remanescente}

O campo magnético terrestre (CMT) pode ser representado pelo campo B, referente ao vetor na superfície denominado indução magnética, e campo $\mathrm{H}$, representado quando há interações com materiais, designado campo magnético. $\mathrm{A}$ relação entre esses dois campos é dada por

$$
\vec{B}=\mu\left(\vec{H}+\vec{J}^{M}\right)
$$

onde $\vec{J}^{M}$ representa o somatório dos momentos elementares por unidade de volume.

O CMT exerce sobre alguns materiais um momento cuja magnitude é proporcional ao momento magnético total do material M. Do ponto de vista macroscópico este momento pode ser considerado

$$
\vec{M}=\int v \vec{J}^{M} d v
$$


A magnetização volumétrica é função da magnetização remanescente do material, e do campo magnético ambiente, que determina a magnetização induzida. Quando se trabalha com valores de susceptibilidades muito pequenos, considera-se a magnetização induzida $\vec{M}_{i}$ proporcional à susceptibilidade, e dada por

$$
\vec{M}_{i}=k \vec{H}
$$

na qual $\vec{H}=\vec{B} / \mu$, e $\mu$ é denominado permeabilidade magnética do material.

A equação 4.11 mostra que a magnitude da magnetização induzida, $\mathrm{M}_{\mathrm{i}}$, depende da susceptibilidade da rocha e a direção é paralela ao campo indutor (CMT). Quando a rocha possui uma magnetização remanescente $\left(M_{R}\right)$, a magnetização total é a soma vetorial das duas magnetizações.

Ainda na região do núcleo, 22 sítios foram destinados à análise de magnetização, inclinação e declinação remanescentes. $O$ histograma da magnetização remanescente das 45 amostras (Figura 4.31) mostra maior freqüência para valores em torno de $0,1 \mathrm{~A} / \mathrm{m}$. Já o histograma para as medidas de inclinação remanescente revela uma dispersão dos valores, apresentando maior freqüência de $35^{\circ}$ (Figura 4.32).

A declinação remanescente apresenta-se com valores muito variáveis, sem nenhuma direção preferencial (Tabela A.10), o que não torna possível seu emprego para a geração dos modelos 2,5D.

Algumas medidas de susceptibilidade foram obtidas para os sedimentos da bacia. No entanto, seus valores permanecem muito baixos, na ordem de $1 \times 10^{-5} \mathrm{SI}$ a $50 \times 10^{-5} \mathrm{SI}$ (Tabelas A.2, A.3 e A.4), desprezíveis para a presente aplicação. 


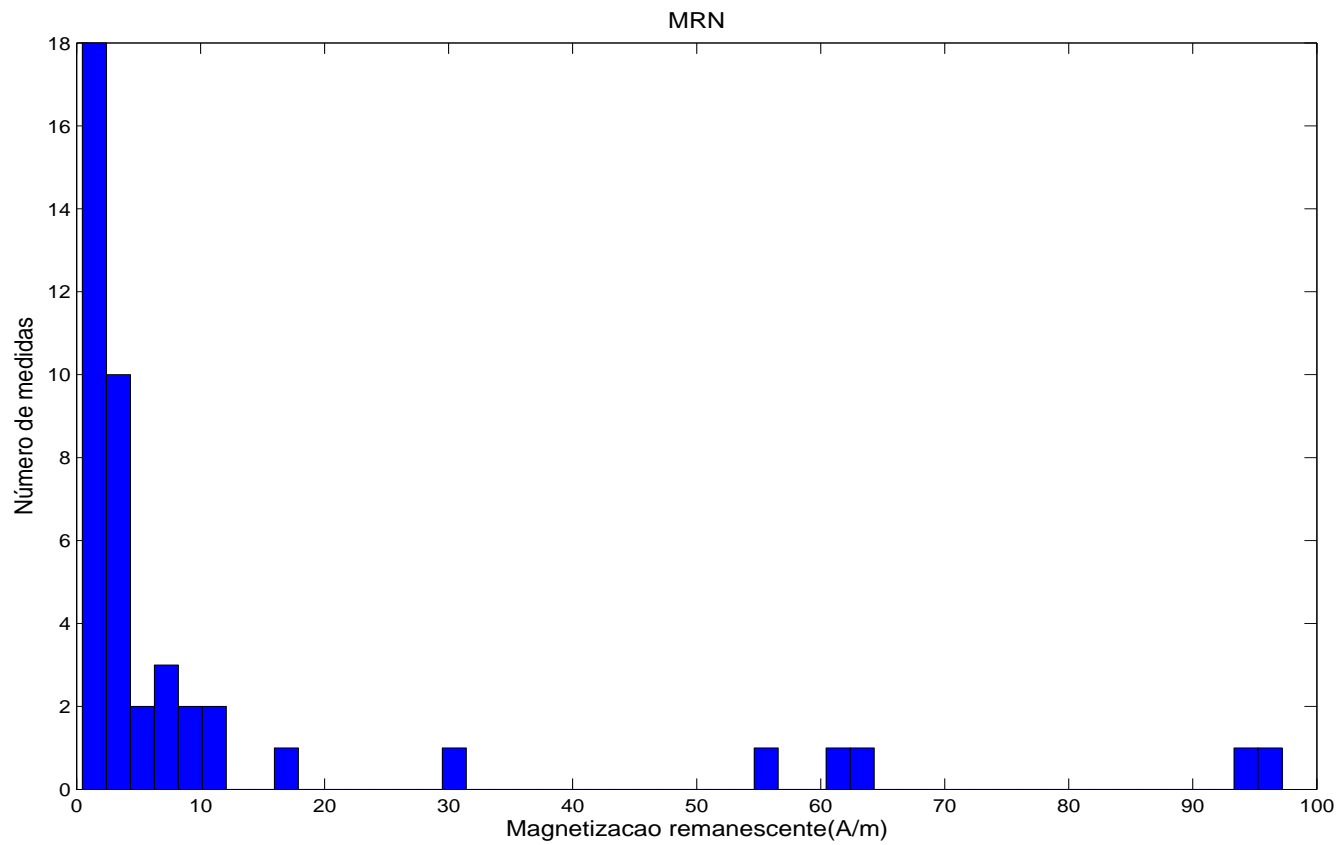

Figura 4.31. Distribuição das medidas de intensidade da magnetização remanescente realizadas em amostras de granito do EGS. Dados cedidos por Yokoyama (2006).

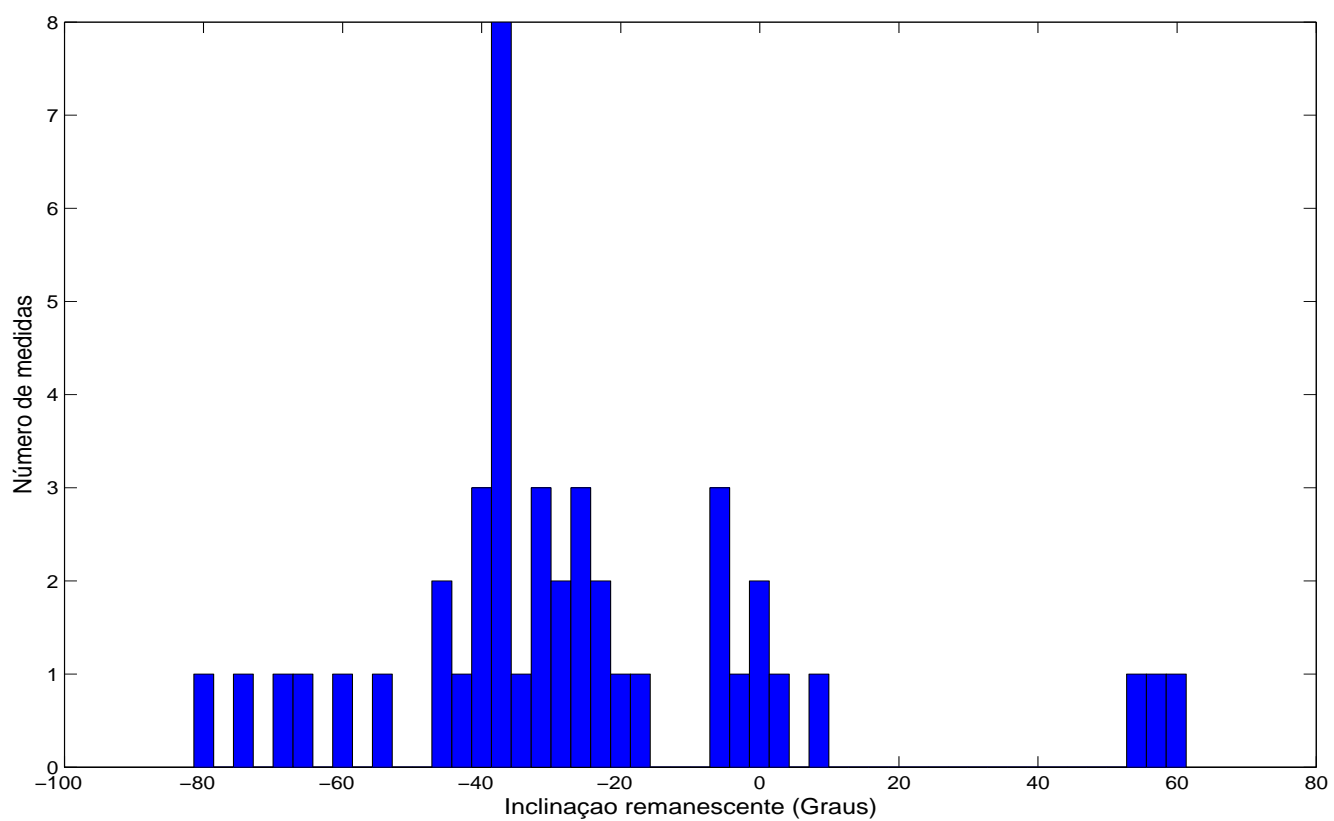

Figura 4.32. Distribuição das medidas de inclinação remanescente realizadas no granito do EGS. Dados cedidos por Yokoyama (2006). 
As medidas da magnetização remanescente das amostras (Tabela A.10) foram utilizadas no cálculo da medida da importância relativa da magnetização remanescente em relação à magnetização induzida, dada pela razão de Konigsberger

$$
Q=\frac{\vec{M}^{R}}{k \vec{H}}
$$

A razão de Konigsberger, $Q$, fornece uma idéia da importância de cada componente da magnetização $M_{R}$ e $M_{i}$, para a magnetização total $M_{t}$.

A aplicação da equação 4.10 revela que as amostras possuem uma contribuição muito maior da magnetização induzida que remanescente (Figura 4.33). Esta informação é de extrema importância para a obtenção de modelos mais precisos.

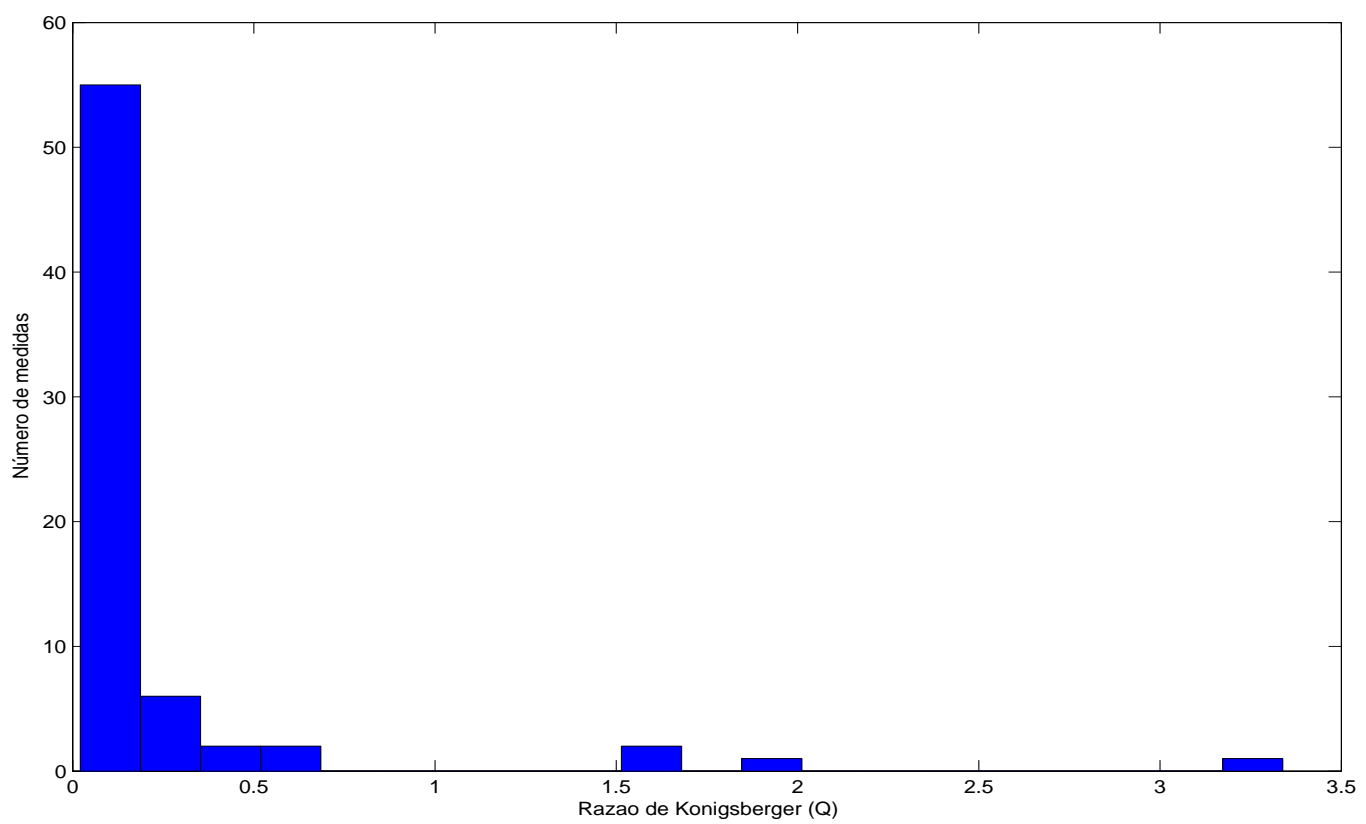

Figura 4.33. Distribuição dos valores da Razão de Koenigsberger (Q) para as amostras do NCS. Dados fornecidos por Yokoyama (2006). 


\subsubsection{Testes com modelos sintéticos}

Testes com modelos sintéticos são utilizados em métodos potenciais para definir a resposta de quaisquer estruturas em subsuperfície. No caso específico, nesta etapa inicial do modelamento pretende-se prever o comportamento do campo magnético para crateras simples e complexas. Analisando as semelhanças do dado real e dos dados sintéticos pode-se inferir o quanto o modelo representa a estrutura em subsuperfície. Esta comparação permite observar o comportamento do campo com parâmetros geométricos da fonte anômala mais definidos e complexos. O programa utilizado para estes resultados foi implementado a partir da rotina desenvolvida por Mendonça (2006).

Os testes com modelos sintéticos aqui realizados referem-se ao campo magnético, e consideram um corpo definido por vários polígonos justapostos, submetidos unicamente à magnetização induzida, com direção constante e isotrópica. A equação 4.12 resume o cálculo direto do campo potencial

$$
G \cdot \vec{p}=\vec{d}
$$

onde $\mathrm{G}$ é a matriz de sensibilidade que descreve a magnetização neste caso, $\vec{p}$ é o vetor de parâmetros relacionados à geometria do corpo, e $\vec{d}$ o vetor que descreve o campo potencial, que neste caso é o que se deseja encontrar.

Foram realizados dois principais testes para se obter a assinatura magnética geral para uma feição do tipo cratera simples e do tipo complexa, com $40 \mathrm{~km}$ de diâmetro e profundidade máxima de $1 \mathrm{~km}$. A forma de representação escolhida para os polígonos destina-se à representação da porção superior, que em Araguainha corresponderia aos sedimentos da bacia.

Os resultados mostram uma anomalia magnética simétrica com $120 \mathrm{nT}$ de contraste magnético entre o centro e as elevações de borda (Figura 4.34) para o modelo de cratera simples. O modelo de cratera complexa revela apresenta um alto magnético em seu centro com valor máximo próximo de $100 \mathrm{nT}$ envolto por dois baixos magnéticos de $-120 \mathrm{nT}$ (Figura 4.35). 

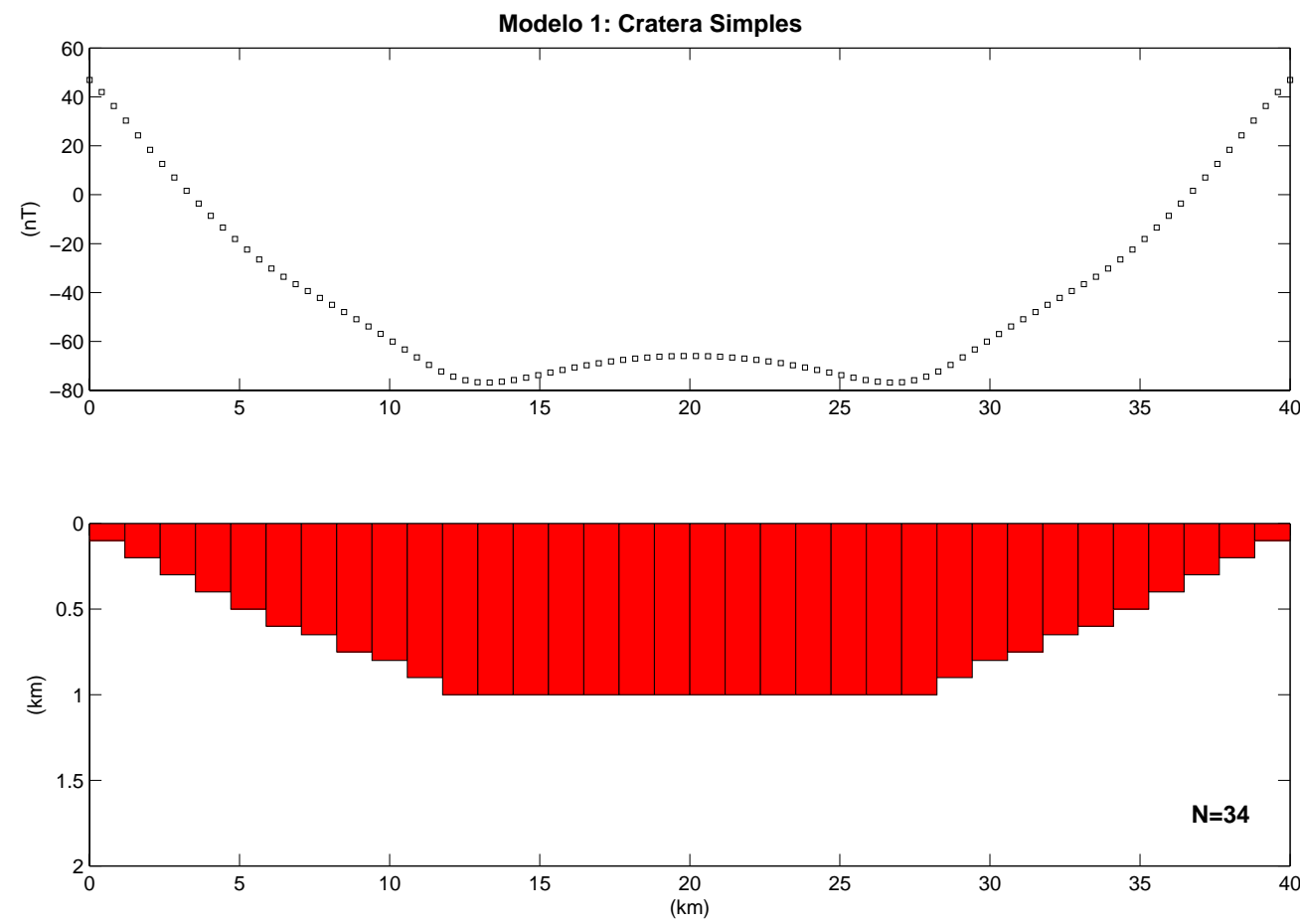

Figura 4.34. Teste com dados sintéticos simulando a estrutura de uma cratera de impacto do tipo simples através de polígonos justapostos homogêneos. $\mathrm{N}=$ número de polígonos.
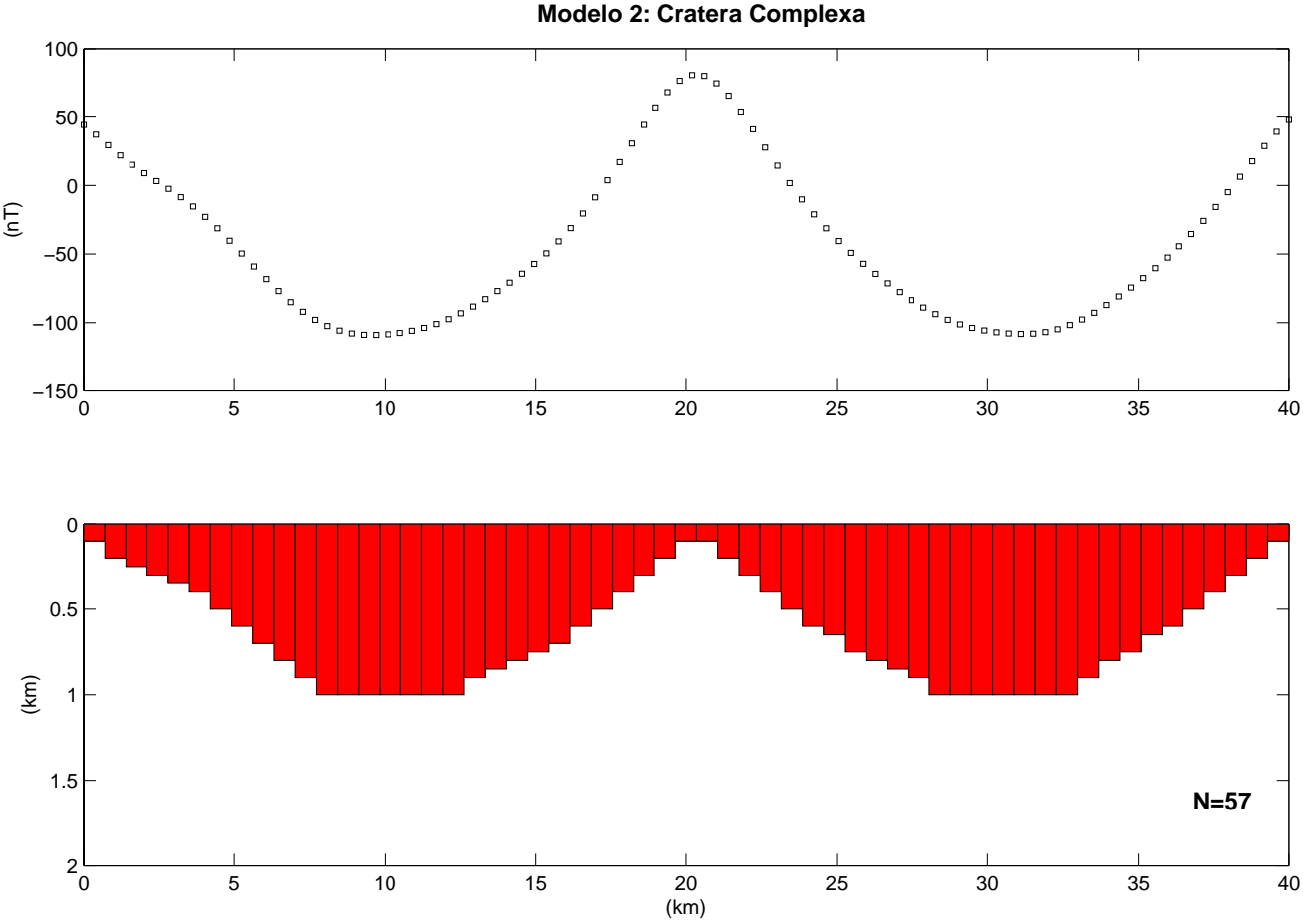

Figura 4.35. Teste com dados sintéticos simulando a estrutura de uma cratera de impacto do tipo complexa através de polígonos justapostos homogêneos. $\mathrm{N}=$ número de polígonos. 


\section{CAPÍTULO 5}

\section{Modelamento direto}

O modelamento é uma técnica matemática baseada na tentativa de se obter informação sobre o interior da Terra a partir de medições de entidades físicas na superfície. Consiste em exprimir um modelo geológico plausível que resulte em uma anomalia calculada mais ajustada possível à anomalia observada em campo, com o auxílio de informações geológicas preliminares. O modelo é calculado por sucessivas aproximações até obter-se a minimização da diferença entre a anomalia observada e a calculada.

O problema direto tem como objetivo calcular campos associados a um dado modelo físico, a partir da resolução de equações diferenciais ou integrais que regem o fenômeno físico associado. Este capítulo abrangerá a técnica do modelamento direto 2,5D utilizada para a obtenção dos resultados.

\subsection{MODELAMENTO DIRETO 2,5D}

O modelamento 2D geralmente é utilizado para estruturas que tendem apresentar tamanho muito maior que sua espessura, como fraturas, falhas, diques. Crateras de impacto são estruturas 3D que em geral não seriam apropriadamente bem representadas por este tipo de modelamento. Entretanto, pode-se determinar a estrutura tridimensional da fonte ao se realizar perfis de modelamentos em diversas direções de forma que a englobem.

No modelamento direto parâmetros do corpo anômalo tais como densidade, susceptibilidade e magnetização podem ser fornecidos, e outros como profundidade, e largura do corpo são estimados. Para tanto, as relações integrais entre os campos potenciais e os corpos causadores devem ser conhecidas.

A componente vertical de um campo gravitacional devido a um polígono é dada pela seguinte relação de volume, segundo Blakely (1995).

$$
g(P)=-G \int_{R} \rho(Q) \frac{z-z^{\prime}}{r^{3}} d v
$$


Similarmente são as relações para o cálculo do campo magnético

$$
\Delta T(P)=\int_{R} \frac{M(Q)}{r^{3}} \cdot[3(\hat{F} \cdot \hat{r}) \hat{r}-\hat{F}] d v
$$

onde $\mathrm{R}$ é o volume, $\mathrm{G}$ é a constante de atração gravitacional, $\rho(Q)$ refere-se à densidade nas três dimensões e $\mathrm{M}(\mathrm{Q})$ à magnetização do corpo.

Considerando um corpo submetido unicamente à magnetização induzida, com direção constante e isotrópica, pode-se sintetizar as duas equações acima da seguinte maneira

$$
f(P)=\int_{R} s(Q) \Psi(P, Q) d v
$$

onde $f(P)$ é o campo potencial em $P, s(Q)$ descreve a quantidade física (densidade ou magnetização) em $Q$ e $\Psi(P, Q)$ é uma função que depende da relação geométrica entre o ponto $P$ e um ponto $Q$ da fonte (Figura 5.1). A equação (5.3) tem a mesma forma da equação 4.12 apresentada no capítulo anterior e é conhecida como a equação de Fredholm do primeiro tipo, enquanto $\Psi(P, Q)$ é a função de Green do problema.

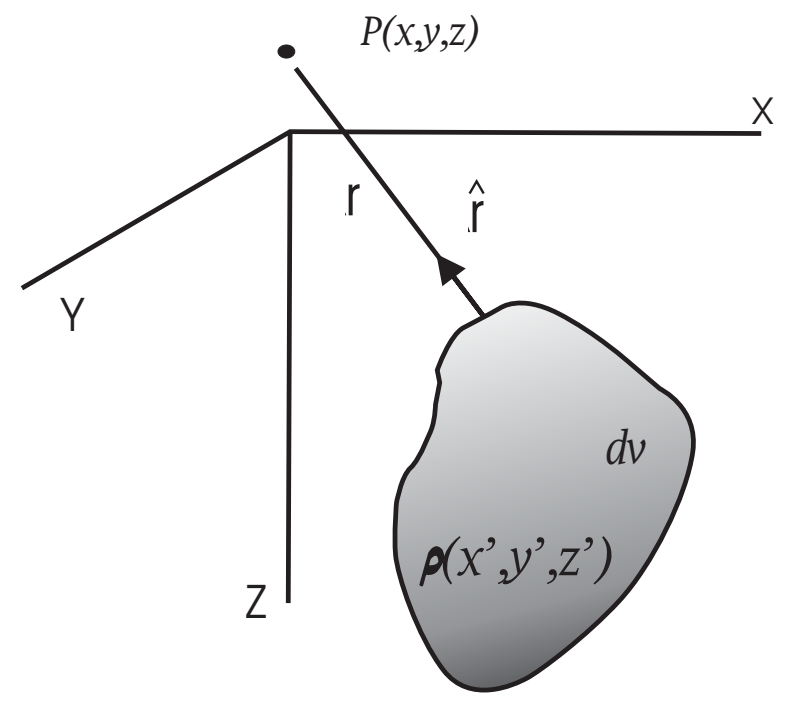

Figura 5.1. Corpo tridimensional com densidade $\rho\left(x^{\prime}, y^{\prime}, z^{\prime}\right)$ e forma arbitrária observada no ponto $P(x, y, z)$ (Modificado de Bakely, 1995). 
Ao se tentar modelar corpos tridimensionais através de seções deve-se realizar uma correção dos campos potenciais ao longo do eixo y (Figura 5.2). Este método calcula a componente do campo em um ponto $\mathrm{P}$ devido a um polígono de $n$ vértices para um polígono finito no eixo y. Desta maneira, o método de modelamento que se utiliza da aproximação da dimensão tridimensional do corpo para uma dimensão bidimensional é denominado modelamento 2,5D. O perfil ao longo do eixo $x$ é assumido como meio-caminho entre os dois extremos do corpo (Figura 5.2) e perpendicular à sua direção (Shuey \& Pasquale, 1973). As expressões analíticas empregadas no programa para correção de dados extraídos ao longo de perfis magnéticos foram desenvolvidas por Shuey \& Pasquale (1973). Os cálculos para a correção dos dados do campo gravimétrico foram desenvolvidos por Rasmussen \& Pedersen (1979).

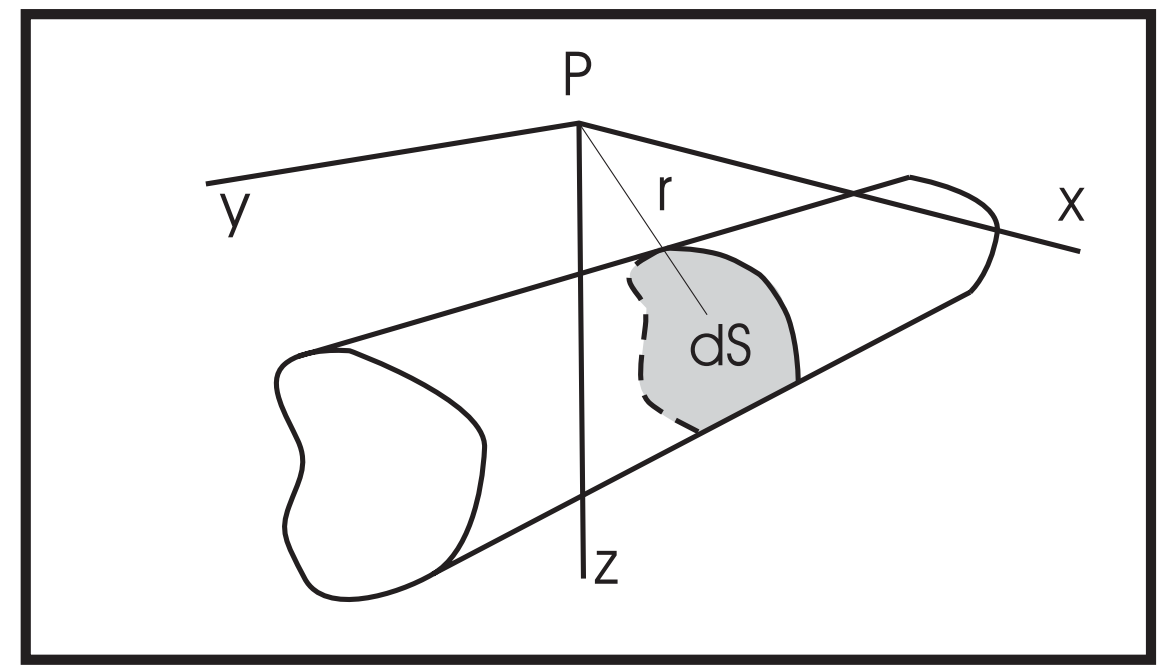

Figura 5.2. Aproximação de um corpo bidimensional por um polígono de $\mathrm{n}$ lados (Modificado de Blakely, 1995).

O cálculo da componente vertical gravitacional dado por Rasmussen \& Pedersen (1979) pode ser simplificado quando $\mathrm{y} \rightarrow \infty$ para a expressão definida por Talwani et al. (1959). Desta maneira, ao considerar um polígono de $n$ lados e densidade $\rho$, tem-se

$$
V=2 G \rho \sum_{i=1}^{n} Z i
$$

onde $\mathrm{G}$ é a constante gravitacional e $Z_{i}$ é dado pela seguinte relação 


$$
Z_{i}=a_{i} \operatorname{sen} \vartheta_{i} \cos \vartheta_{i}\left[-\theta_{i}-\theta_{i+1}+\tan \vartheta_{i} \ln \frac{\cos \theta_{i}\left(\tan \theta_{i}-\tan \vartheta_{i}\right)}{\cos \theta_{i+1}\left(\tan \theta_{i+1}-\tan \vartheta_{i}\right)}\right]
$$

onde

$$
\begin{aligned}
& \theta_{i}=\tan ^{-1} \frac{z_{i}}{x_{i}}, \\
& \vartheta_{i}=\tan ^{-1} \frac{z_{i+1}-z_{i}}{x_{i+1}-x_{i}}, \\
& \theta_{i+1}=\tan ^{-1} \frac{z_{i+1}}{x_{i+1}}, \\
& a_{i}=x_{i+1}+z_{i+1} \frac{x_{i+1}-x_{i}}{z_{i}-z_{i+1}} .
\end{aligned}
$$

Adota-se um sistema de coordenadas cartesianas com origem no ponto $\mathrm{P}$ do plano $X Z$ e o eixo-Z positivo apontando verticalmente para baixo. A intersecção entre o plano $X Z$ e a reta que une o ponto $\mathrm{P}$ ao ponto médio de cada lada do polígono define o ângulo $\theta$ (Figura 5.3).

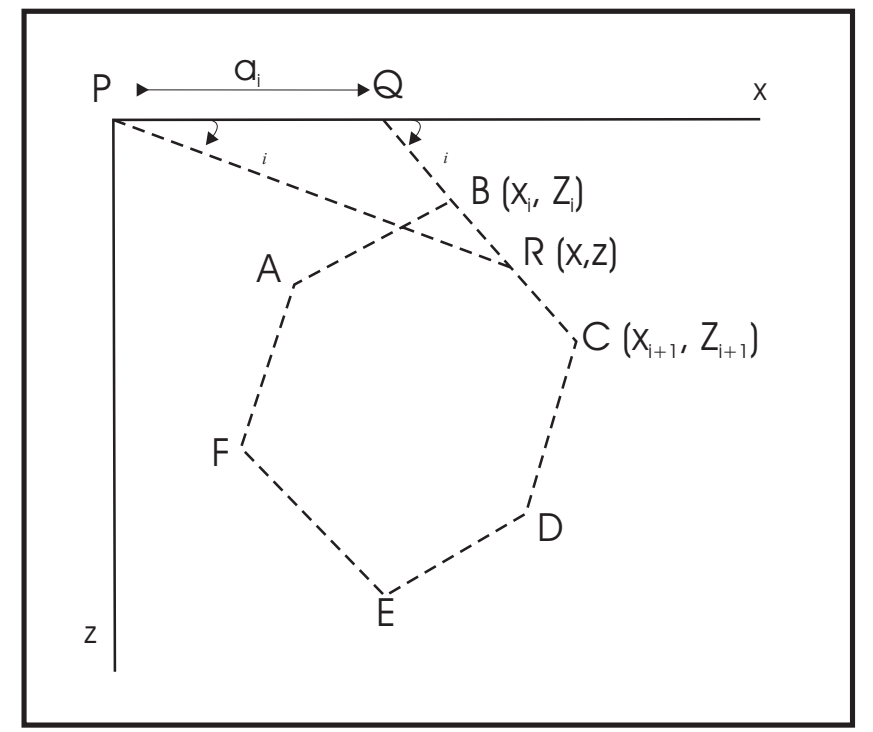

Figura 5.3. Elementos geométricos envolvidos na atração gravitacional de um polígono de $\mathrm{n}$ lados (Modificado de Talwani et al., 1959).

Os modelos são construídos com base em informações geológicas e geofísicas. Apesar do cálculo direto de $f(P)$ (equação 5.3) ser matematicamente único, um modelo para as fontes magnéticas ou gravimétricas obtidos através do método direto, é não único. Os resultados obtidos por esta técnica serão abordados no próximo capítulo. 


\section{CAPÍTULO 6}

\section{Resultados}

Este capítulo traz os resultados do modelamento direto 2,5D realizado com os dados magnéticos e gravimétricos. Os modelos visam obter estimativas de profundidade para a interface embasamento/rochas sedimentares e para as diversas dimensões da cratera, de forma a fornecer subsídios para a análise genética e deformacional da estrutura.

A forma circular das crateras de impacto permite inferir a geometria de sua fonte como tridimensional, com grande variação ao longo de sua dimensão. Ao avaliar a fonte anômala geradora com esta geometria e perceber que ambos os campos apresentam variações em cada parte da estrutura, deve-se procurar uma melhor maneira de pormenorizar estas variações para se entender a causa da fonte geradora. Portanto, a maneira escolhida para a amostragem dos dados é seccionar toda a estrutura de Araguainha com perfis de direção N-S, E-W, NE-SW e NW-SE.

Foram extraídos 14 perfis principais amostrados em 250 metros das malhas de anomalia aeromagnética e Bouguer, perfazendo $608 \mathrm{~km}$ de toda a estrutura (Figura 6.1). Esta escolha obedece a coincidência dos dados gravimétricos e magnéticos com os perfis aeromagnéticos utilizados no cálculo do espectro de potência, visando correlacioná-los (Figura 4.23). Alguns perfis selecionados ultrapassam os limites de Araguainha, para comparação da espessura das camadas e limite de estabilidade das rochas.

Deve-se notar que a complexidade dos campos potenciais atuantes na região de estudo pode dificultar a geração de modelos correlatos às informações disponíveis, e mesmo entre si. Esta correlação entre modelos magnéticos e gravimétricos que resulta na geração de modelamento conjunta pode não apresentar resultados satisfatórios porque uma fonte magnética não necessariamente coincide com a fonte gravimétrica. Por este motivo, a etapa inicial da modelagem consiste na geração de modelos magnéticos e gravimétricos individuais para avaliação dos mesmos e posterior modelamento conjunto. 


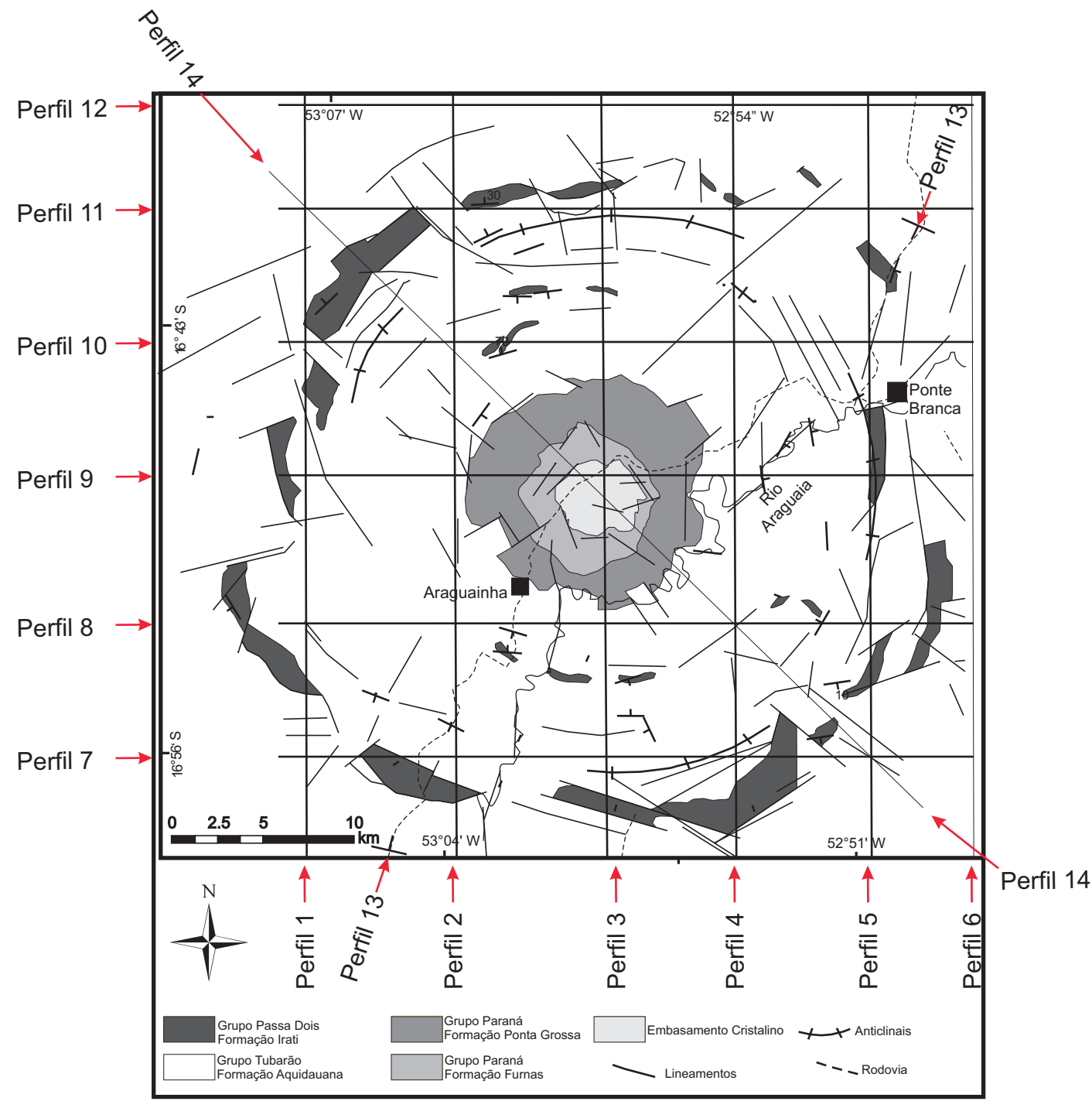

Figura 6.1. Articulação dos 14 perfis extraídos dos dados aeromagnéticos e gravimétricos para realização do modelamento $2,5 \mathrm{D}$.

Os resultados obtidos constam de 14 modelos aeromagnéticos, 14 modelos gravimétricos e 14 modelos conjuntos. Além destes, os dados magnéticos terrestres servem como apoio no detalhamento de feições importantes da cratera. Foram coletados em 11 perfis que da mesma forma geram 11 modelos individuais e mais 11 em conjunto com os dados gravimétricos. Desta maneira, os perfis extraídos totalizam 64 modelos que serão comparados entre si, analisados e interpretados. Dar-se-á maior destaque para os perfis de maior importância interpretativa, sendo que os demais são apresentados nos Apêndices B - modelos gravimétricos; C - modelos aeromagnéticos; D - magnéticos terrestres; $E$ - conjuntos: aeromagnéticos $e$ gravimétricos; e $\mathrm{F}$ - conjuntos: magnéticos terrestres e gravimétricos. 


\subsection{MODELAMENTO DIRETO 2,5D DE DADOS GRAVIMÉTRICOS E MAGNÉTICOS INDIVIDUAIS}

A construção dos modelos bidimensionais para a estrutura de Araguainha baseia-se em informações geológicas e geofísicas. As informações geológicas (Figura 6.2 e 6.3) são utilizadas para a delimitação dos contatos entre os sedimentos da bacia e para localização de estruturas como bordas, anéis e núcleo central soerguido (NCS). As principais informações geofísicas que provêm de Masero et al. (1994) e dos dados de espectro de potência ajudam na delimitação da profundidade média do embasamento. Estes vínculos indiretos ajudam a reduzir o caráter ambíguo dos modelos baseados apenas em dados de campos potenciais.

Os valores de densidade e susceptibilidades encontrados são atribuídos aos corpos de forma a considerá-los homogêneos. Assim, procura-se obter o melhor ajuste entre a anomalia calculada e observada. Os valores médios de densidade obtidos para as rochas sedimentares da bacia (Tabelas A.2 a A.5) permitem discretizá-las como corpos distintos no modelamento gravimétrico.

A assinatura gravimétrica negativa no centro de Araguainha a torna diferente de outras crateras modeladas até o presente momento. Este fato obriga a inserção de uma densidade de $2,15 \mathrm{~g} / \mathrm{cm}^{3}$, inferior às supracrustais que o circundam, para o polígono central. $\mathrm{O}$ valor considerado está abaixo da média de densidade de corpos graníticos disponíveis em literatura. No entanto, pode ser justificado pela presença de brechas, xenólitos e ao seu intenso fraturamento. Por este motivo, o valor médio de $2,45 \mathrm{~g} / \mathrm{cm}^{3}$ obtido para as amostras de granito (Tabela A.1) é arrogado ao embasamento localizado abaixo das rochas sedimentares (região branca dos modelos). 


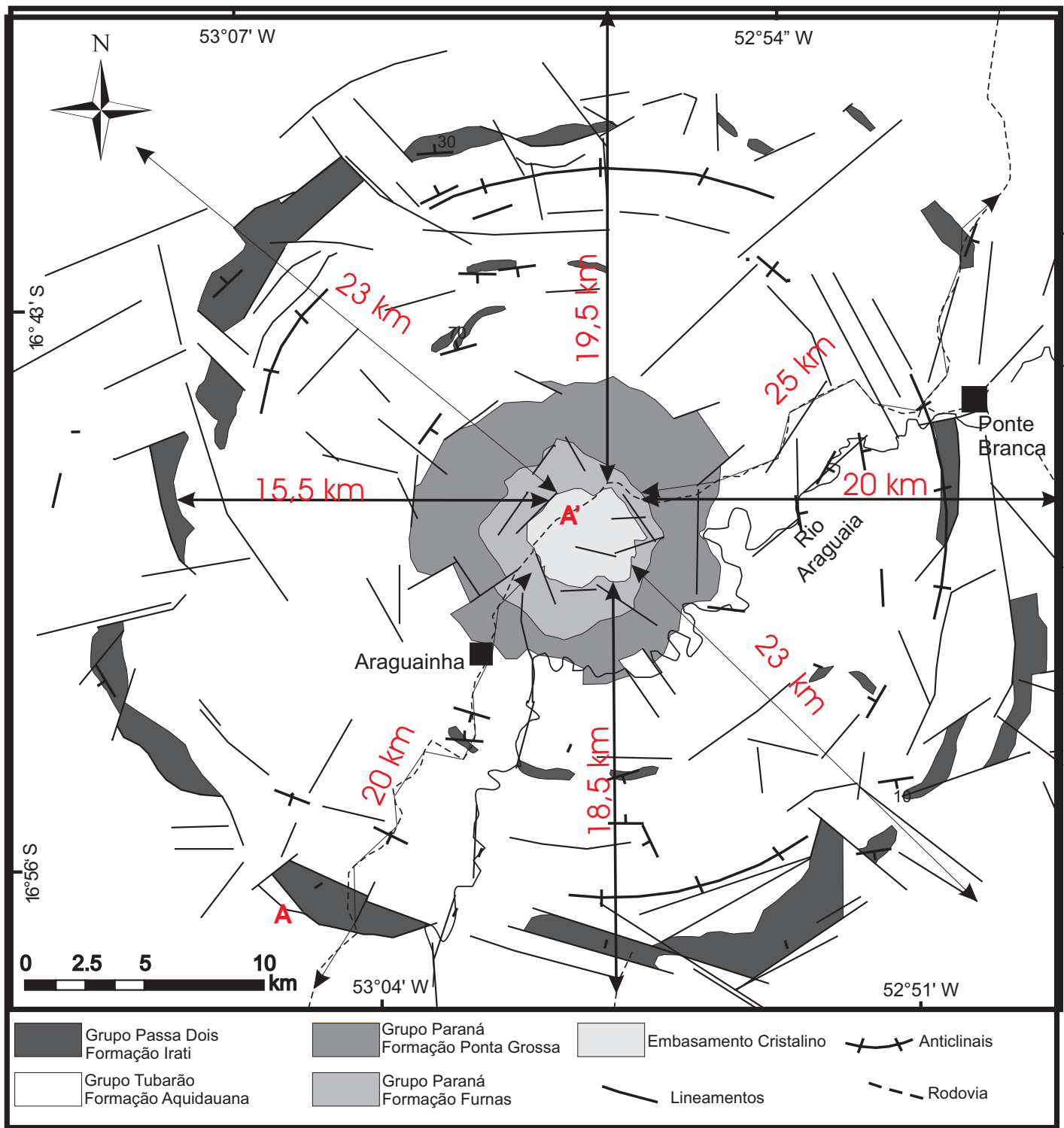

Figura 6.2. Mapa geológico da estrutura de Araguainha com distâncias dos principais perfis modelados (perfis 3,9,13 e 14) para o núcleo granítico. Estas e outras informações são utilizadas como medidas inseridas no modelamento (Modificado de Lana et al., 2006b).

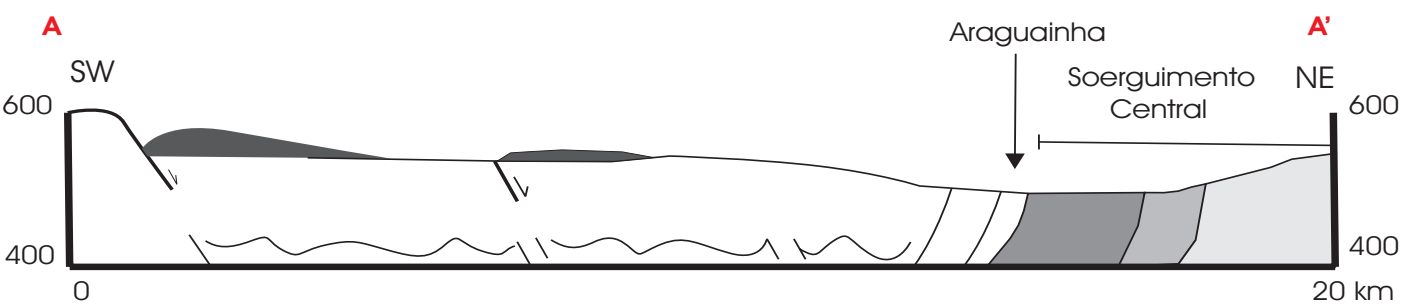

Figura 6.3. Perfil geológico confeccionado utilizado como base para a confecção dos modelos (Modificado de Lana et al., 2006a). 
Os valores médios de susceptibilidade magnética $(\mathrm{k})$ da ordem de $1 \times 10^{-5} \mathrm{SI}$ a $50 \times 10^{-5} \mathrm{SI}$ mensurados nos sedimentos da bacia são considerados desprezíveis para este estudo, de forma que a componente magnética da região possui o embasamento como fonte única, representado por um polígono com contraste de susceptibilidade magnética negativo. Para o corpo referente ao EGS é atribuído o valor obtido em laboratório correspondente a $150 \times 10^{-5} \mathrm{SI}$. O restante do embasamento é considerado homogêneo, com susceptibilidade magnética de $600.10^{-5} \mathrm{SI}$. Esta combinação de valores resulta em um contraste negativo de susceptibilidade do EGS em relação ao restante do embasamento, o que na verdade é o desejado para satisfazer o baixo magnético de Araguainha na região central.

\subsubsection{Modelos individuais}

Os modelos gravimétricos gerados apresentam bons ajustes entre dados calculados e observados. Para alguns é necessário a remoção de um shift de forma a melhorar o ajuste dos dados.

Os resultados mostram aproximadamente $0,5 \mathrm{~km}$ e 1,2 $\mathrm{km}$ de profundidades mínima e máxima do embasamento, respectivamente. (Figura 6.4).

Opta-se por um modelo de representação de domínio mais rúptil-dúctil, a exemplo do que se observa nos modelos gerados a partir de seções sísmicas de crateras (Juhlin \& Pedersen, 1987; Tsikalas et al., 1998). Desta maneira, o embasamento mostra-se acidentado, com contrastes de altos e baixos que em algumas localidades estão relacionados provavelmente a regiões de falhas.

Os ajustes obtidos nos modelamentos dos dados aeromagnéticos e gravimétricos são satisfatórios, com melhores resultados para o primeiro conjunto de informações (Figuras 6.4 e Figura 6.5). Ambos os modelos mostram-se semelhantes nas características deformacionais da estrutura de Araguainha. A descrição dos resultados será abordada partindo do centro da estrutura para as regiões de borda.

Inicia-se esta análise com a região do NCS. Os modelos gravimétricos demonstram-se melhores para representar uma elevação do embasamento de aproximadamente $0,8 \mathrm{~km}$ presente abaixo do polígono vermelho que representa o EGS (Figura 6.4). Esta elevação por vezes mostra-se com valores superiores às regiões da borda da cratera (Figura 6.5). Esse aspecto deve ser considerado ao se analisar o mapa de anomalia Bouguer (Figura 4.13) que ressalta para a região do NCS valores mais elevados que para algumas regiões de borda. No entanto, a mesma 
anomalia se estende para a borda sul da estrutura, o que dificulta o ajuste de alguns modelos. Ao apresentar valores em torno de $-2 \mathrm{mGal}$, esta anomalia foge aos padrões da anomalia da borda e da anomalia que circunda o NCS.

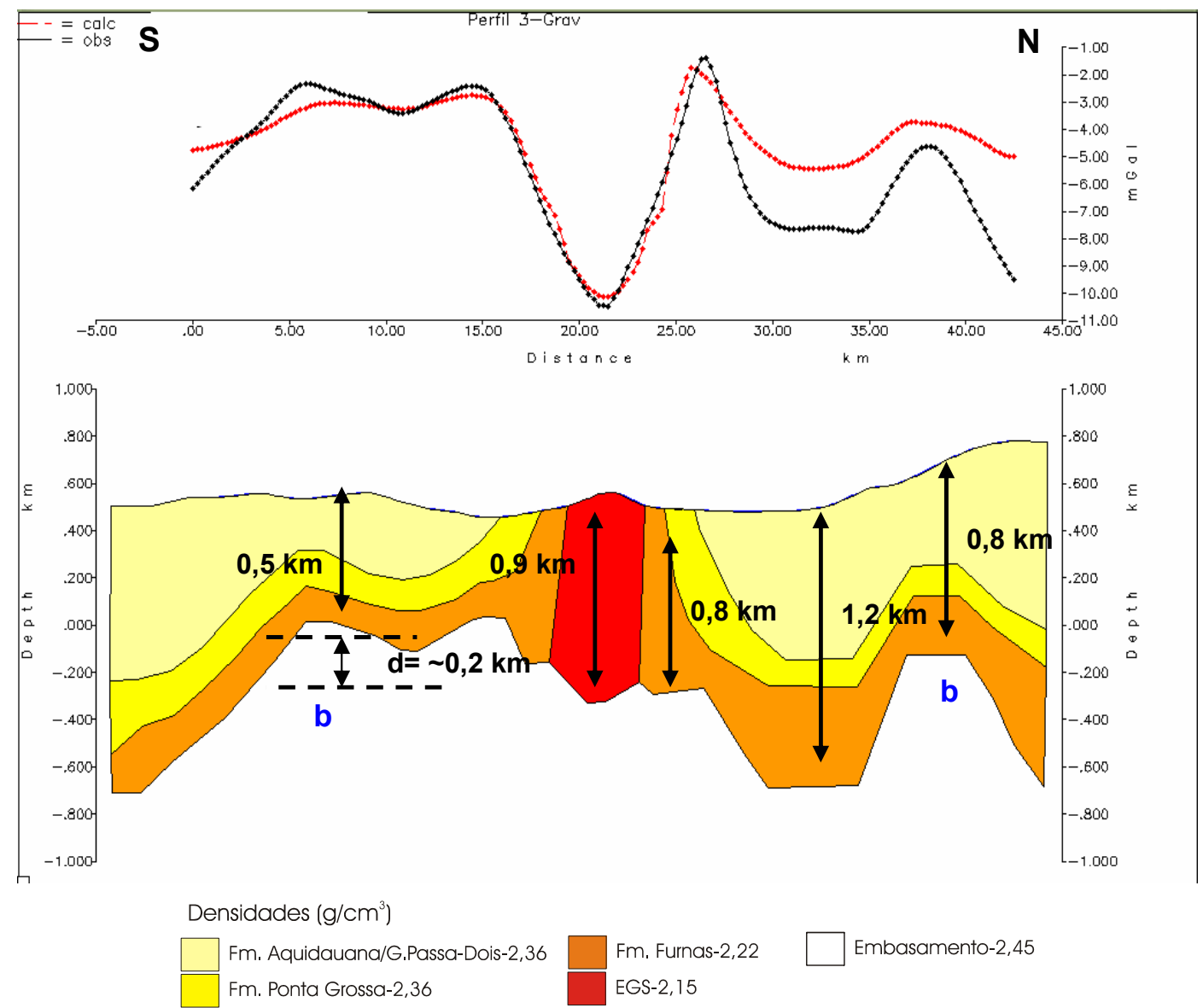

Figura 6.4. Modelo para a estrutura de Araguainha gerado a partir de dados gravimétricos extraídos ao longo do perfil 3. Nota-se um soerguimento maior do NCS e borda sul comparado às mesmas regiões a norte. As setas indicam os valores correspondentes a cada região, $d=$ diferença de soerguimento entre as bordas sul e norte; $b=$ região de borda da estrutura.

O modelo realizado ao longo do perfil 3 mostra ainda para esta região cerca de 0,2 km de soerguimento maior na porção sul em relação à norte (letra "d", figura 6.4), que se estende para a região de borda. $O$ modelo magnético (Figura 6.6) correspondente não demonstrou soerguimento nas bordas, talvez pelo ajuste dos dados não ter sido satisfatório.

O corpo representado pelo polígono vermelho apresenta de 0,8 a $0,9 \mathrm{~km}$ de profundidade tanto nos modelos gravimétricos (Figuras 6.4 e 6.5) quanto nos aeromagnéticos (Figura 6.6) que seccionam a região central. Há coerência entre os modelos gravimétricos no que diz respeito ao formato pontiagudo da base do EGS, necessário ao formato afinado da anomalia observada. No entanto, esta feição não é 
observada nos modelos aeromagnéticos homônimos, talvez em função do comprimento de onda representado.

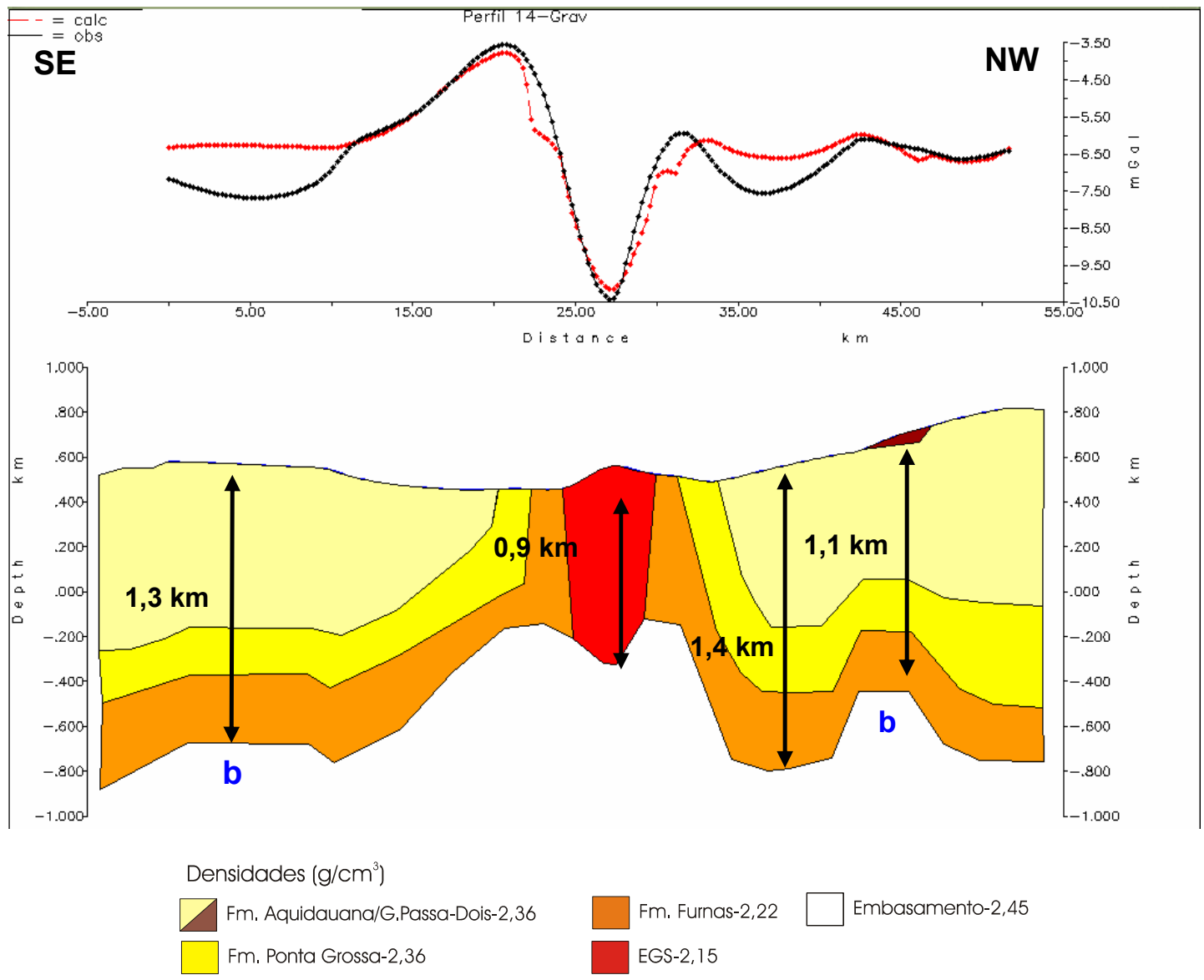

Figura 6.5. Modelo para a estrutura de Araguainha gerado a partir de dados gravimétricos extraídos ao longo do perfil 14.Nota-se estrutura praticamente simétrica ao longo da direção do perfil; $b=$ região de borda. Os valores correspondem às profundidades do embasamento em casa região ao longo do perfil.

$\mathrm{Na}$ tentativa de buscar alternativas de modelos que pudessem justificar o baixo gravimétrico central, foi gerado um modelo considerando um corpo para o qual é atribuída a densidade encontrada de $2,15 \mathrm{~g} / \mathrm{cm}^{3}$ abaixo do granito aflorante com densidade de $2,45 \mathrm{~g} / \mathrm{cm}^{3}$ (Figura 6.7). O ajuste entre as curvas seria ideal se não fosse o baixo gravimétrico que é gerado no contato deste corpo, o que o torna menos favorável comparado à proposta anterior.

Os modelos gravimétricos dos perfis 3 (Figura 6.4), 9 (Figura 6.8), 13 (Figura 6.9) e 14 (Figura 6.5), estão relativamente bem ajustados para a região central, e, com exceção do primeiro, enfatizam soerguimento praticamente simétrico para a região do NCS. O Perfil 3, com característica singular, apresenta maior soerguimento na porção sul do NCS. 


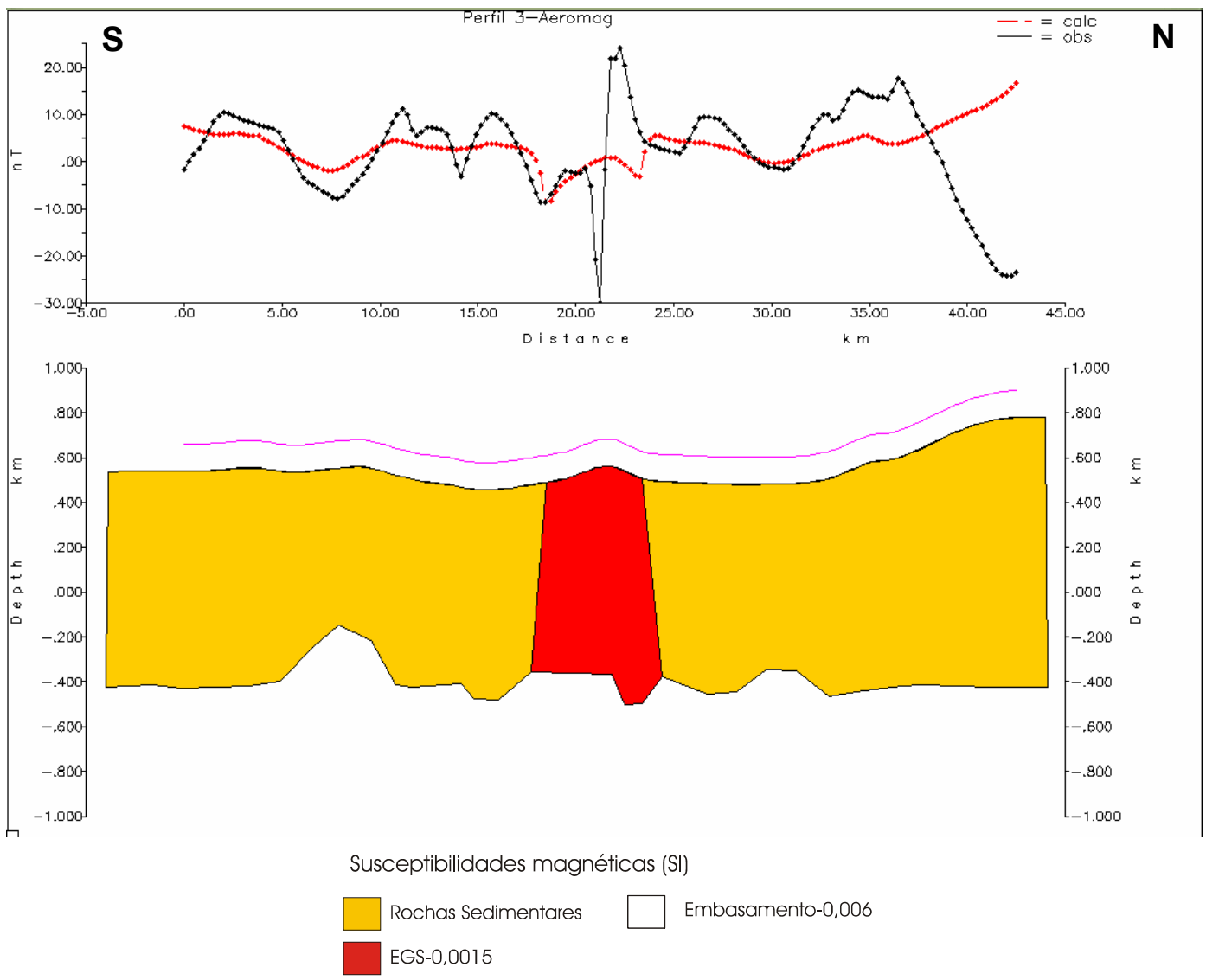

Figura 6.6. Modelo para a estrutura de Araguainha gerado a partir de dados aeromagnéticos extraídos ao longo do perfil 3.

A região que apresenta as maiores profundidades em todos os modelos está situada entre o NCS e as bordas. Esta se mostra com cerca 1,2 km de pacote sedimentar na parte norte do perfil 3 (Figura 6.4). No perfil 14 (Figura 6.5) seus valores na região nordeste são de aproximadamente 1,4 km. Esta profundidade é semelhante para os modelos dos perfis 9 (Figura 6.8) e 13 (Figura 6.9). Estes dois últimos modelos mostram-se muito semelhantes no comportamento do campo gravimétrico, e similarmente revelam uma estrutura praticamente simétrica nas direções E-W e NESW.

No que diz respeito à profundidade do embasamento nas regiões de borda, a borda sul de Araguainha demonstra menor profundidade, cerca de 0,5 km (Figura 6.4). Este mesmo perfil caracteriza a borda norte com $0,8 \mathrm{~km}$ de profundidade. Próximos a estes valores, as bordas nordeste e sudoeste, representadas pelo perfil 13 (Figura 6.9), e as bordas leste e oeste, representadas pelo perfil 9 (Figura 6.8) mostram cerca de $0,9 \mathrm{~km}$ de profundidade do embasamento. O modelo realizado ao longo do perfil 14 
(Figura 6.5) revela que o embasamento na borda noroeste está a $1,1 \mathrm{~km}$ de profundidade, apresentando cerca de $0,2 \mathrm{~km}$ de soerguimento a mais que a borda sudeste.

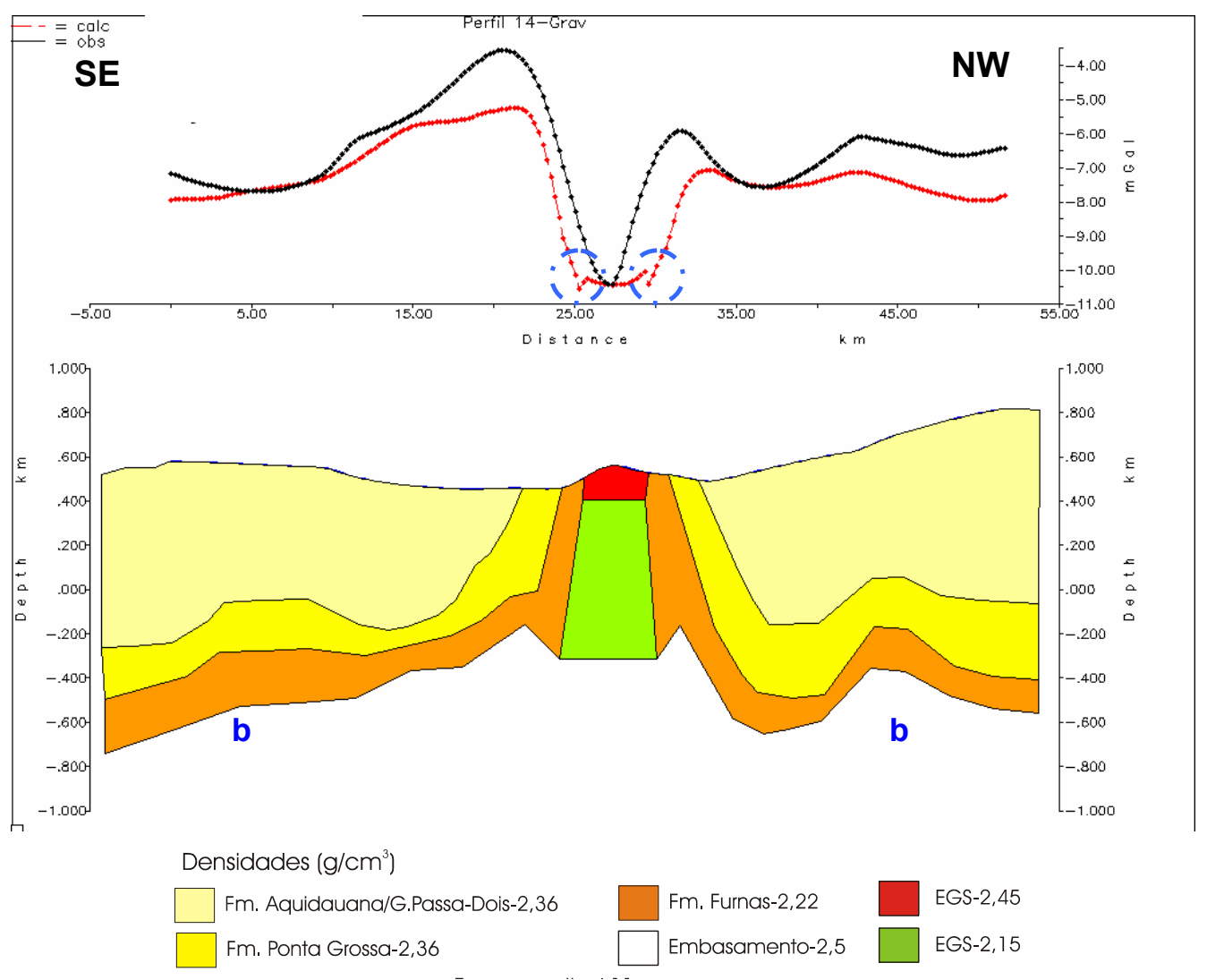

Figura 6.7. Outra proposta de modelo gravimétrico em comparação com o perfil 14 da figura 6.7 para a estrutura de Araguainha. Os círculos azuis mostram as anomalias incompatíveis geradas nas bordas da anomalia central negativa, a letra "b" marca as regiões de borda. 


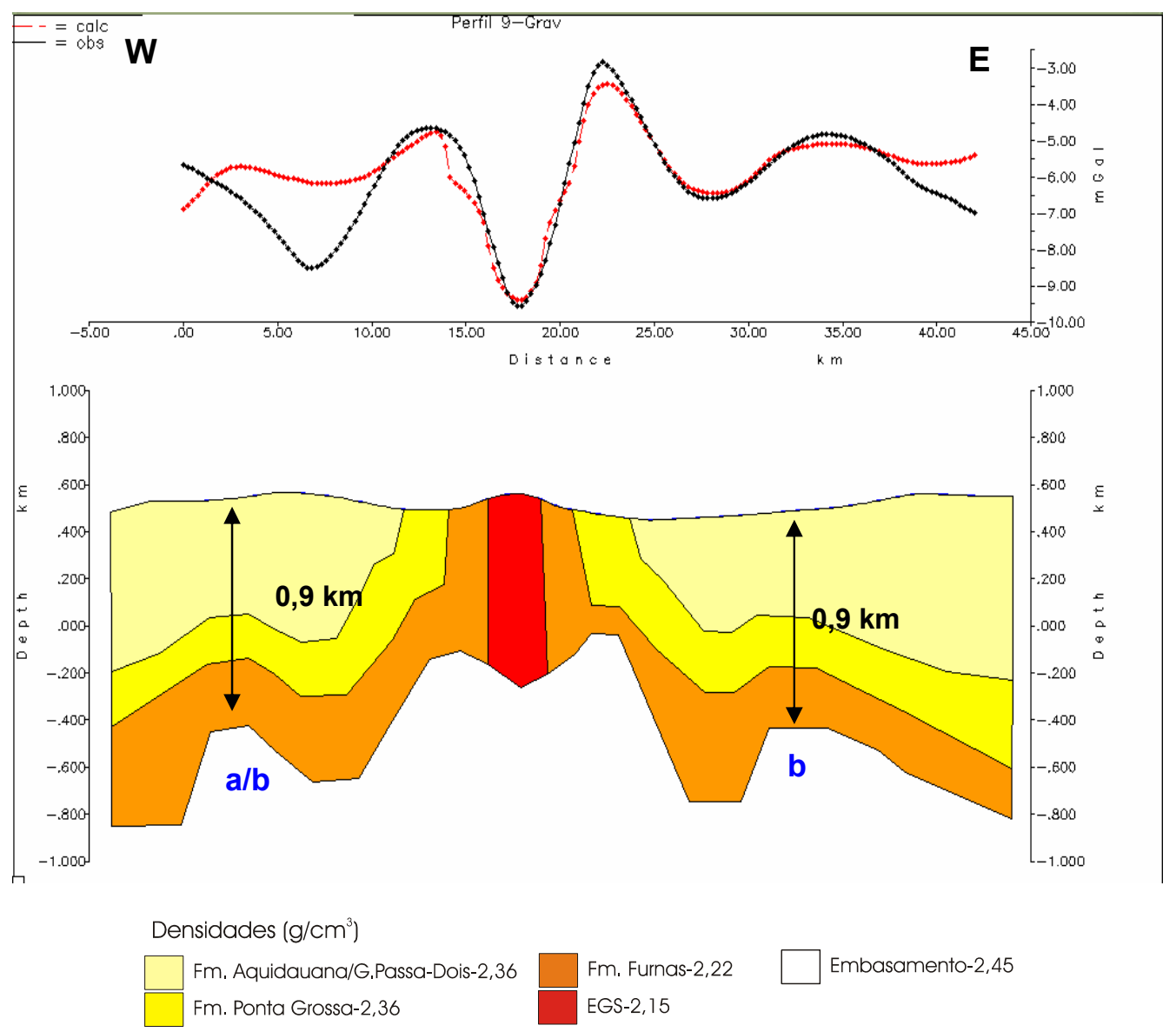

Figura 6.8. Modelo construído a partir de dados gravimétricos ao longo do perfil 9. As regiões das bordas leste e oeste marcadas pela letra "b"mostram soerguimento simétrico, com profundidades do embasamento de $0,9 \mathrm{~km} ; \mathrm{a} / \mathrm{b}=$ região de transição entre anéis e borda.

A Formação Aquidauana apresenta-se com espessura média de $0,8 \mathrm{~km}$, com espessura maior nas regiões de borda tendendo a diminuição em direção ao NCS. O Grupo Passa-Dois, presente nas elevações topográficas mostra-se, quando representado, com espessura máxima de $0,1 \mathrm{~km}$.

É notável em todos os modelos o espessamento das camadas sedimentares na região localizada entre a borda e o NCS. Pelo que se observa nos resultados as Formações Aquidauana, Ponta Grossa e Furnas adquirem tal espessamento, entretanto esta última é a que demonstra resultados mais notáveis de espessamento da camada. Uma discussão mais detalhada deste resultado será realizada no capítulo seguinte. 


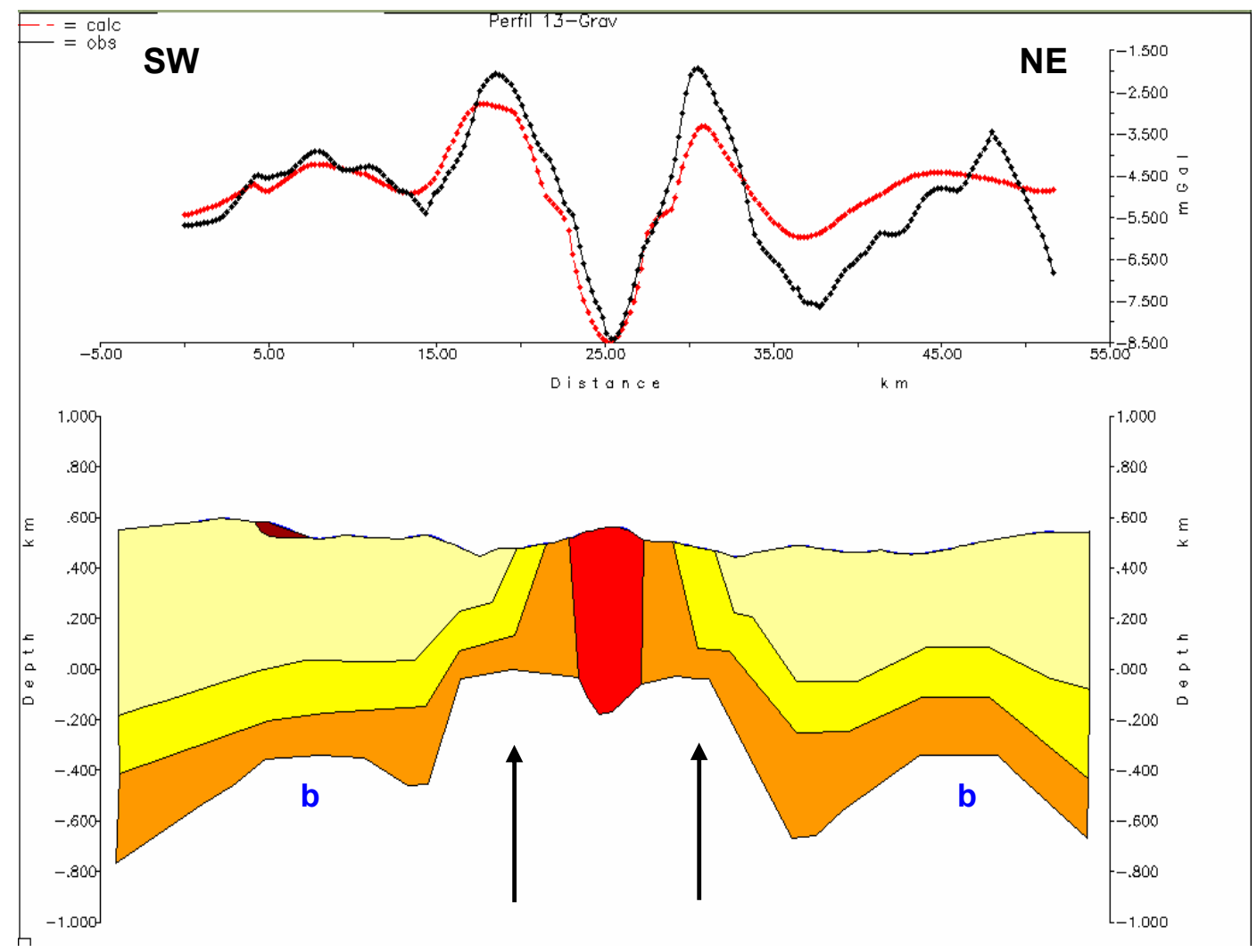

Densidades $\left(\mathrm{g} / \mathrm{cm}^{3}\right)$

Fm. Aquidauana/G.Passa-Dois-2,36 Fm. Ponta Grossa-2,36

Fm. Furnas-2,22

Embasamento-2,45

EGS-2,15

Figura 6.9. Modelo gravimétrico gerado a partir de dados gravimétricos extraídos ao longo do perfil 13. Destaca-se a simetria do soerguimento no NCS, mostrado nas setas e nas bordas, representadas pela letra 'b'.

O alto gravimétrico relativo de 3,4 mGal presente sobre a borda NW revela um embasamento com profundidade de 0,8 km nesta região, um pouco inferior ao valor encontrado com o modelamento ao longo do perfil 14 (Figura 6.5). Considerando a média de profundidade do embasamento, o soerguimento do embasamento seria de aproximadamente $0,4 \mathrm{~km}$. O que se observa na topografia é aproximadamente 0,2 km de expressão topográfica superior à média da região (Figura 6.10). Também se nota neste modelo um soerguimento de $0,3 \mathrm{~km}$ maior na região norte em relação à borda sul. Essas análises são importantes em que pese a caracterização do grau de erosão em Araguainha.

Todos os 14 modelos gravimétricos gerados são apresentados no Apêndice B e os modelos aeromagnéticos no Apêndice $\mathrm{C}$. 


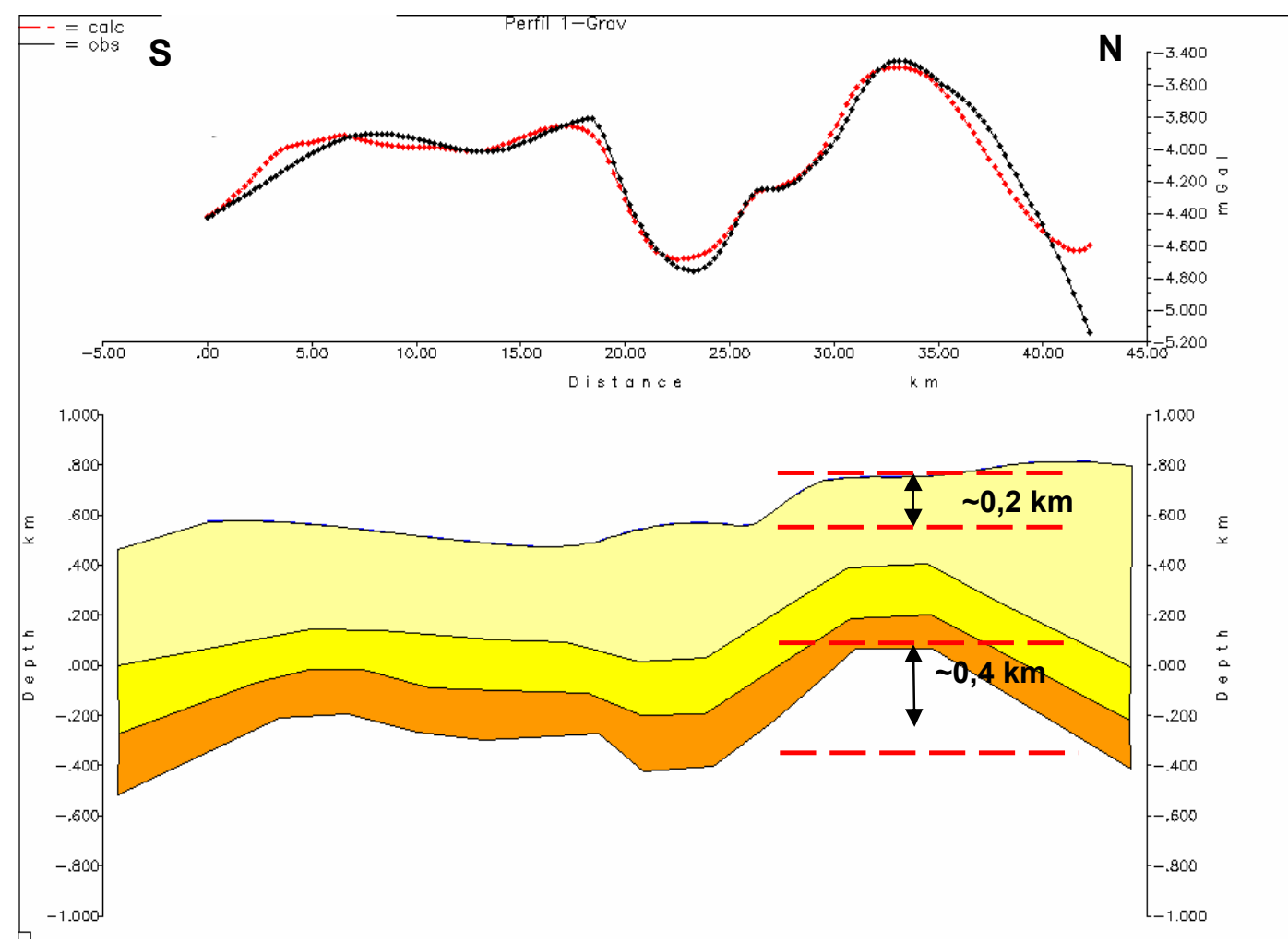

Densidades $\left(\mathrm{g} / \mathrm{cm}^{3}\right)$

Fm. Aquidauana/G.Passa-Dois-2,36

Fm. Furnas-2,22

Fm. Ponta Grossa-2,36

Embasamento-2,45

Figura 6.10. Modelo para a cratera de Araguainha gerado a partir de dados gravimétricos ao longo do perfil 1. Nota-se na porção norte soerguimento de aproximadamente $0,4 \mathrm{~km}$ com $0,2 \mathrm{~km}$ de expressão topográfica acima da média da região.

Em particular análise, os 11 perfis magnéticos terrestres são ajustados aos maiores comprimentos de onda da anomalia. Os resultados apresentam-se coerentes e pormenorizam a interação do embasamento com as supracrustais. Os maiores valores de profundidade estão concentrados na região ao redor do NCS e nos anéis da estrutura. A profundidade máxima modelada nestes dados é de cerca de 1,9 km, alcançando em níveis mais rasos cerca de $0,1 \mathrm{~km}$.

Os resultados alcançados nestes modelos marcam bem a transição da região dos anéis para a borda da estrutura. Este limite é observado na figura 6.11, que mostra uma diferença de $0,8 \mathrm{~km}$ entre o soerguimento do embasamento na borda noroeste e o piso da estrutura. 


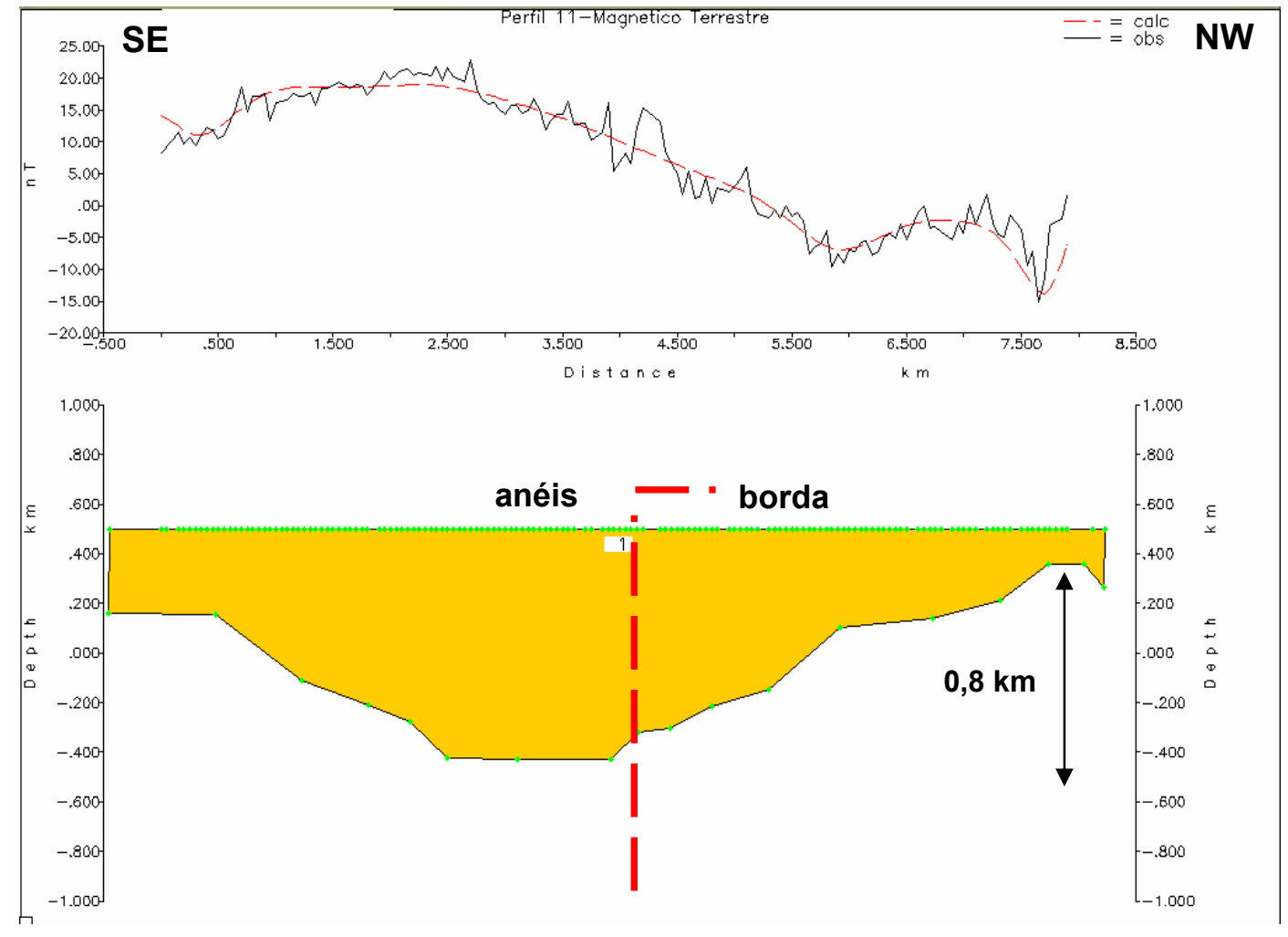

Susceptibilidades magnéticas (SI)

Rochas Sedimentares

Embasamento-0,006

Figura 6.11. Modelo para a estrutura de Araguainha gerado a partir dos dados magnéticos terrestres. A linha vermelha tracejada marca o limite do início das elevações de borda noroeste. O modelo apresenta cerca de $0,8 \mathrm{~km}$ de diferença entre o piso da cratera e o soerguimento da borda.

Os modelos magnéticos terrestres também são importantes no mapeamento da região do EGS. O resultado do perfil 8 associado às informações geológicas permitem estimar o contato entre o corpo brechado e o embasamento granítico. Neste caso específico, o modelo só se apresenta coerentemente modelável após a inserção das informações da magnetização remanescente no granito aflorante representado pelo polígono vermelho (Figura 6.12). Apesar de baixa razão de Konigsberger, a inserção de 0,5 A/m (Figura 4.31), além da inclinação de $-40^{\circ}$ (Figura 4.32) são essenciais para a caracterização do baixo magnético como o limite entre a brecha e o granito. Este contato é observado em campo e mostra-se coerente com a caracterização de brecha de impacto por matriz fundida realizada por Engelhardt et al. (1992)(Figura 6.13). O modelo mostra-se bem ajustado, principalmente na porção central, o que permite caracterizar o contato com mergulho do plano para leste. Além disso, caracteriza-o a uma profundidade de $0,3 \mathrm{~km}$ junto ao contato com o embasamento de mais alta susceptibilidade magnética (região branca do modelo). 
Os demais modelos magnéticos terrestres serão apresentados no Apêndice D.

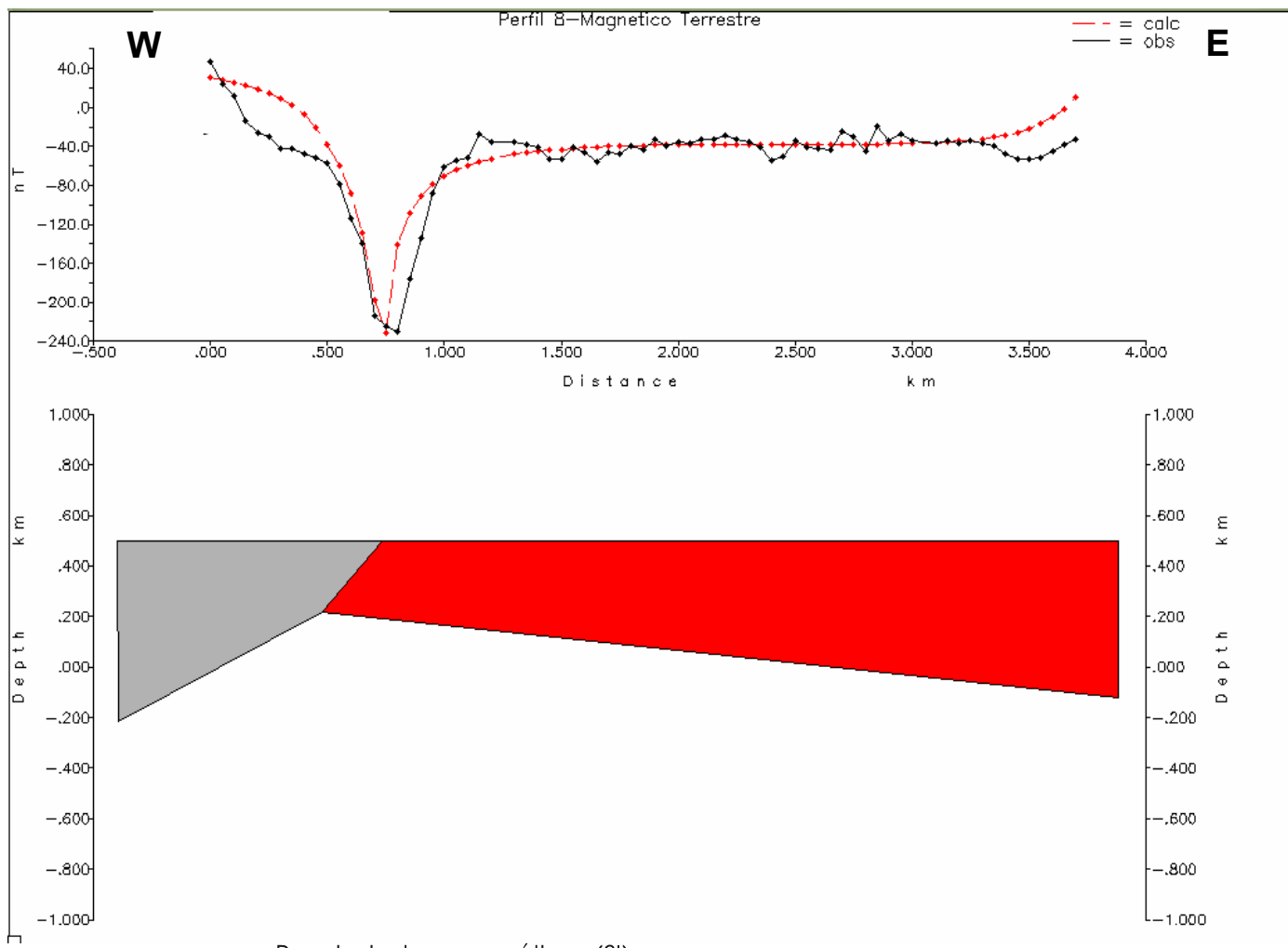

Propriedades magnéticas (SI)

Brechas- $k=0,0015$

Embasamento- $\mathrm{k}=0,006$

EGS- $k=0,0015 ; M_{R}=0,5 ;$ inc $=-40^{\circ}$

Figura 6.12. Modelo para a região do EGS gerado a partir dos dados magnéticos terrestres. Mostra o contato entre a brecha de impacto de matriz fundida e o granito. (SI); $\mathrm{k}=$ susceptibilidade magnética; $\mathrm{M}_{\mathrm{R}}=$ intensidade da magnetização remanescente $(\mathrm{A} / \mathrm{m})$; inc= inclinação remanescente

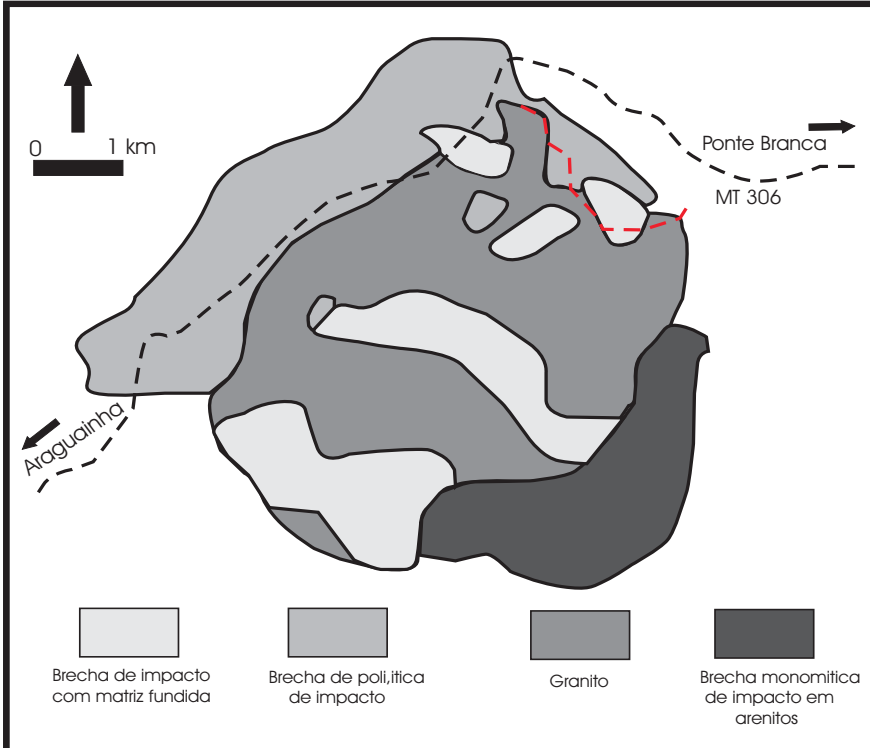

Figura 6.13. Mapa geológico da porção interna do núcleo soerguido. A linha vermelha tracejada mostra o caminho traçado pelo perfil magnético terrestre de número 8 que define o contato entre a brecha de impacto com matriz fundida do corpo granítico (Modificado de Engelhardt et al., 1992). 


\subsubsection{Modelos conjuntos}

O modelamento conjunto dos dados aeromagnéticos e gravimétricos mostra-se em boa parte pouco concordante, principalmente no que diz respeito às anomalias magnéticas de curto comprimento de onda. Somente a tendência geral dos dados aeromagnéticos demonstra razoável ajuste.

O ajuste de ambos os dados em conjunto com os dados gravimétricos da região do EGS também se mostra difícil. Esta limitação revela uma provável não correspondência entre as fontes gravimétrica e magnética.

Os resultados destas modelagens conjuntas indicam que a profundidade máxima do embasamento tem cerca de $1,8 \mathrm{~km}$. As maiores profundidades, assim como as obtidas nos modelos anteriores, estão concentradas nas regiões entre as bordas e o NCS (seta verde da Figura 6.14). Contrastando com esses valores, as menores profundidades estão associadas às regiões de borda, e à região do NCS, abaixo do NGS (setas azuis da Figura 6.14). Essas áreas atingem cerca de 0,6 km de profundidade para o embasamento (Figura Ec-Perfil 3 do Apêndice "E”). O perfil 1 reafirma maior soerguimento para porção norte do embasamento se comparado à borda sul (Figura Ea-Perfil 1 do Apêndice "E”).

As características do EGS reveladas nestes modelos corroboram as informações obtidas nos modelos supra-descritos, e expressam da mesma maneira uma média de $1 \mathrm{~km}$ para o EGS e formato pontiagudo em sua base.

A Formação Furnas e Ponta Grossa mostram-se ambas com espessura média de $0,2 \mathrm{~km}$ e um espessamento um pouco mais acentuado na região que circunda o NCS. Já a Formação Aquidauana apresenta-se com espessura entre 0,6 e 0,8 km. Suas maiores espessuras concentram-se nas regiões ao redor do NCS e após ultrapassar as bordas da estrutura. 


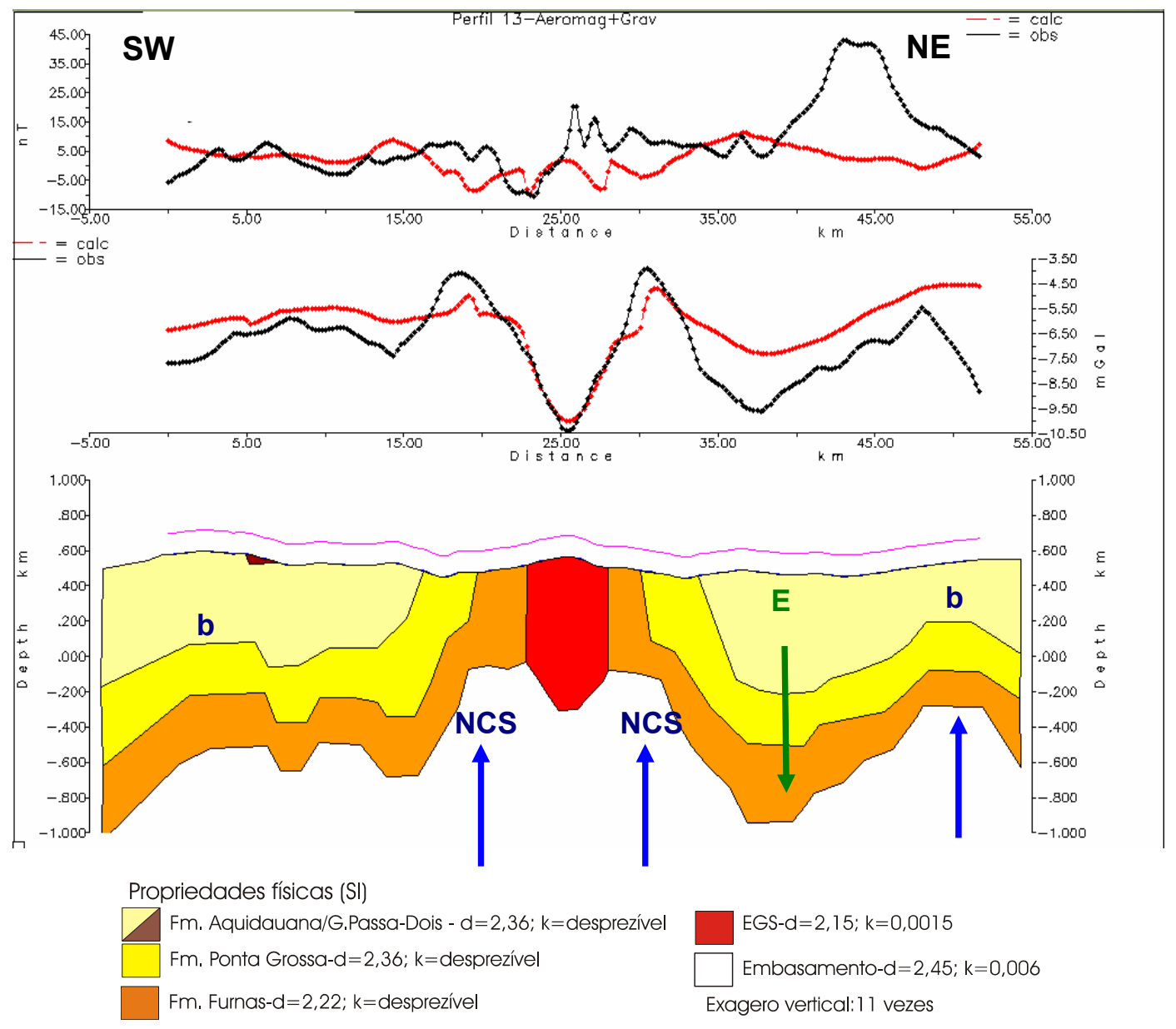

Figura 6.14. Modelamento conjunto dos dados aeromagnéticos e gravimétricos extraídos ao longo do perfil 13. As setas azuis conduzem à observação das regiões que em geral apresentam menores profundidades do embasamento; a seta verde conduz à observação das regiões que se mostram com maior espessamento; a letra "b" marca a região de borda; NCS= Núcleo Central Soerguido; E= Espessamento ao redor do NCS. $d=$ densidade $\left(\mathrm{g} / \mathrm{cm}^{3}\right) ; \mathrm{k}=$ susceptibilidade magnética $(\mathrm{SI})$.

Os modelos construídos ao longo dos perfis 5 (Figura E.e, Apêndice "E") e 6 Figura E.f, Apêndice "E") não apresentam bom ajuste para os dados aeromagnéticos. Não obstante isso, revelam que aproximadamente a $6 \mathrm{~km}$ leste do centro da estrutura a interação embasamento/ rochas sedimentares é praticamente horizontal, com poucos nuances estratigráficos. O sinal gravimétrico Bouguer desta região é praticamente horizontal, somente truncado por um baixo de cerca de $-20 \mathrm{mGal}$, que provavelmente não está relacionado ao impacto. Já na região norte, o modelo gerado a partir do perfil 11 (Figura E.I, Apêndice "E"), a cerca de 16,2 km do centro da estrutura, mostra maior estabilidade das camadas, tendendo a horizontalizar no perfil 12 (Figura E.m, Apêndice "E"). Esta observação é importante para caracterização deformacional de Araguainha a partir da região central do impacto. No entanto, isso não coincide com os modelos aeromagnéticos homônimos (Apêndice C), já que os 
altos magnéticos nos dados estão superpostos pela tendência regional que não foi totalmente removida. O restante dos modelos conjuntos consta no Apêndice " $E$ ".

Os últimos modelos gerados correspondem ao modelamento conjunto de informações gravimétricas e magnéticas terrestres para a cratera. Este modelamento conjunto apresenta boa confiabilidade devido à componente regional que foi bem removida, pela qualidade nos ajustes e pela correlação entre as duas fontes.

Os dados modelados ao longo destes perfis estão dispostos de forma a pormenorizar as feições das bordas sul, sudeste, nordeste e noroeste, e mostram aproximadamente $0,7 \mathrm{~km}$ de profundidade do embasamento para estas regiões de borda (Figuras F.a.-Perfil 1, F.g.-Perfil 7, F.h-Perfil 11, do Apêndice F). O modelo gerado ao longo do perfil 6 (Figura 6.14) é importante para o entendimento da borda nordeste da cratera, e revela uma dimensão de aproximadamente 1,5 km para a borda com o embasamento à profundidade de $0,5 \mathrm{~km}$ abaixo desta região. Ainda com respeito a esta localidade, pode-se dizer que há uma considerável redução na espessura dos estratos sedimentares, principalmente da Formação Ponta Grossa. Após esta elevação os estratos tendem a apresentar mergulhos mais acentuados, com camadas de espessura mais real, que transitam para a região estável com horizontalidade das camadas, a cerca de $3 \mathrm{~km}$ da borda. A diferença estimada entre o soerguimento da borda e o embasamento para além dos limites da estrutura é de aproximadamente $1,5 \mathrm{~km}$.

Outra observação importante é o afinamento das camadas sedimentares nas regiões de borda que pode estar relacionado à remobilização destes para as regiões do centro da estrutura e fora das bordas. 


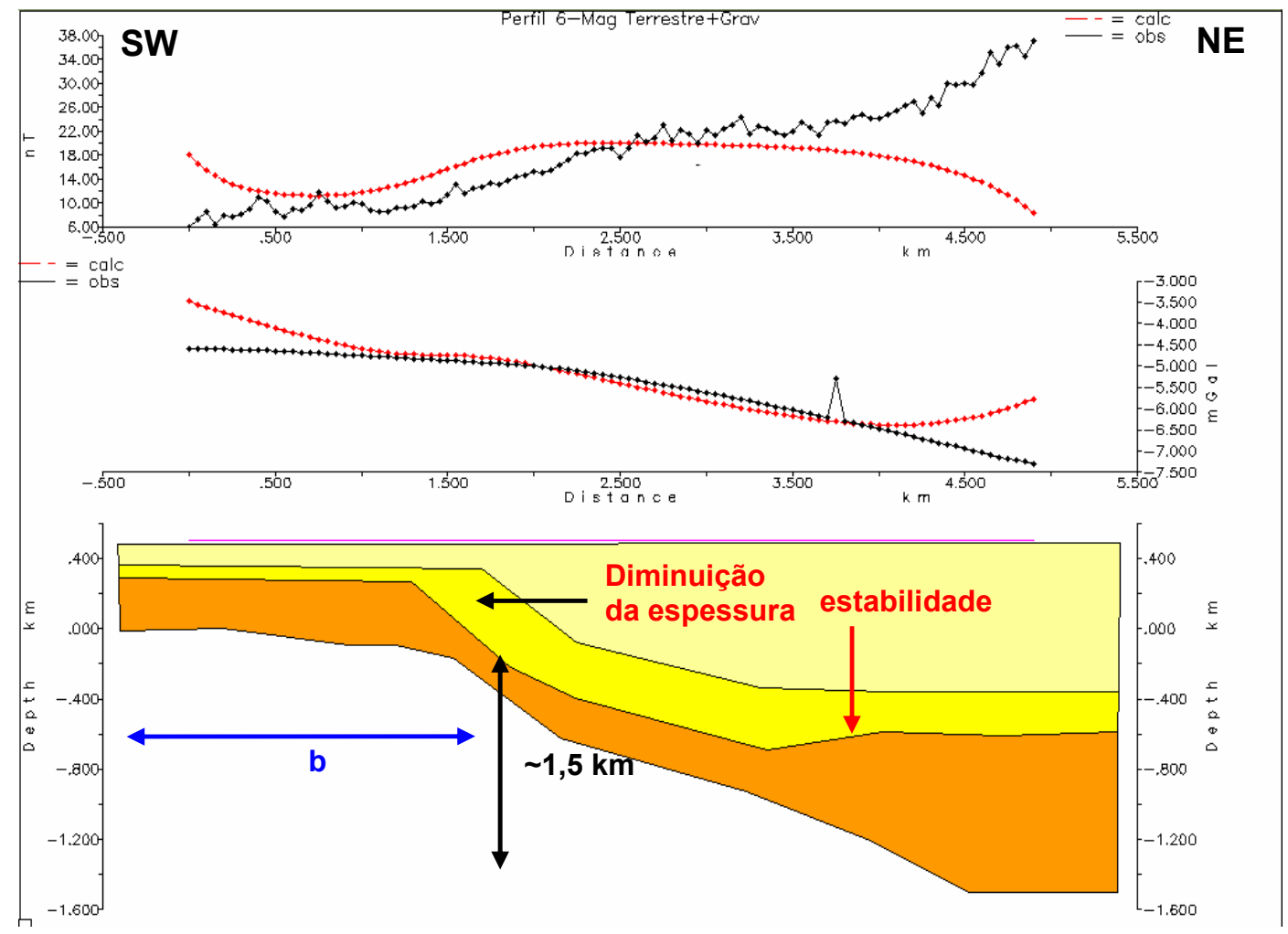

Propriedades físicas (SI)

Fm. Aquidauana- $\mathrm{d}=2,36 ; \mathrm{k}=$ desprezível $\square$ Fm. Furnas- $\mathrm{d}=2,22 ; \mathrm{k}=$ desprezível
Fm. Ponta Grossa-d=2,36; $\mathrm{k}=$ desprezível $\quad \square$ Embasamento- $\mathrm{d}=2,45 ; \mathrm{k}=0,006$

Figura 6.15. Modelo conjunto baseado nos dados gravimétrico e magnéticos terrestres extraídos ao longo do perfil 6. A seta vermelha marcada pela letra "b" indica a região da borda nordeste da cratera; a seta vermelha indica o ponto a partir do qual os sedimentos tendem apresentar horizontalidade dos estratos com maior estabilidade e fora da área deformacional do impacto. Os estratos sedimentares tendem a diminuir sua espessura na região da borda. $d=$ densidade $\left(\mathrm{g} / \mathrm{cm}^{3}\right)$; $\mathrm{k}=$ susceptibilidade magnética $(\mathrm{SI})$.

O modelo gerado a partir dos dados extraídos do perfil 8 (Figura 6.16) se assemelha ao resultado gerado pelo modelo gravimétrico (Figura 6.12). Por meio deste perfil consegue-se validar o contato entre as brechas e o EGS, limite marcado por um baixo magnético de $170 \mathrm{nT}$. Nota-se ainda espessura de cerca de $0,3 \mathrm{~km}$ para a camada brechada (corpo cinza da Figura 6.16) e profundidade máxima de 0,9 km para o EGS. 


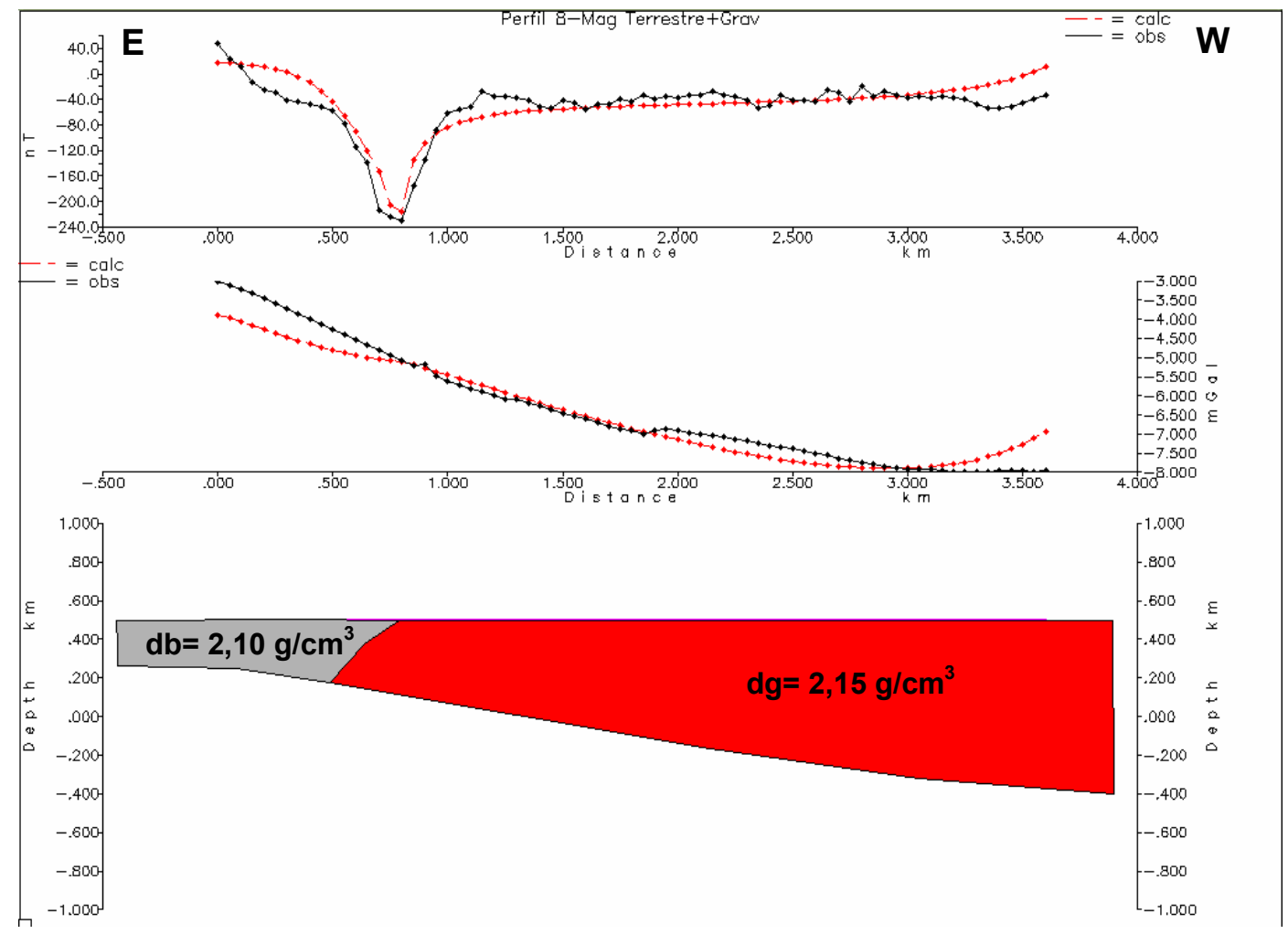

Propriedades magnéticas (SI)

Brechas-k=0,0015

Embasamento-k=0,006

EGS $-\mathrm{k}=0,0015 ; \mathrm{M}_{\mathrm{R}}=0,5 ;$ inc $=-40^{\circ}$

Figura 6.16. Modelo conjunto baseado nos dados gravimétrico e magnéticos terrestres extraídos ao longo do perfil 8. O limite entre o corpo vermelho (granito) e o corpo cinza (brecha) marca a região contato entre ambos. $K=$ susceptibilidade magnética; $M_{R}=$ Intensidade da magnetização remanescente $(A / m)$; inc= inclinação remanescente; $d g=$ densidade do granito; $d b=$ densidade da brecha.

O modelo gerado ao longo do perfil 9 (Figura 6.17) é importante para a caracterização da região de transição entre o NCS e a bacia anelar, e mostra 0,7 km de profundidade do embasamento em estratos horizontais, que se acentua à medida que se direciona para NE. O modelo mostra cerca de $0,8 \mathrm{~km}$ de diferença entre a elevação do NCS e o piso da cratera.

Os demais modelos conjuntos são apresentados no Apêndice F.

A partir das informações extraídas dos modelos com melhores ajustes dentre os 64 será apresentada uma proposta de modelo tridimensional para a estrutura de Araguainha no capítulo ulterior. 


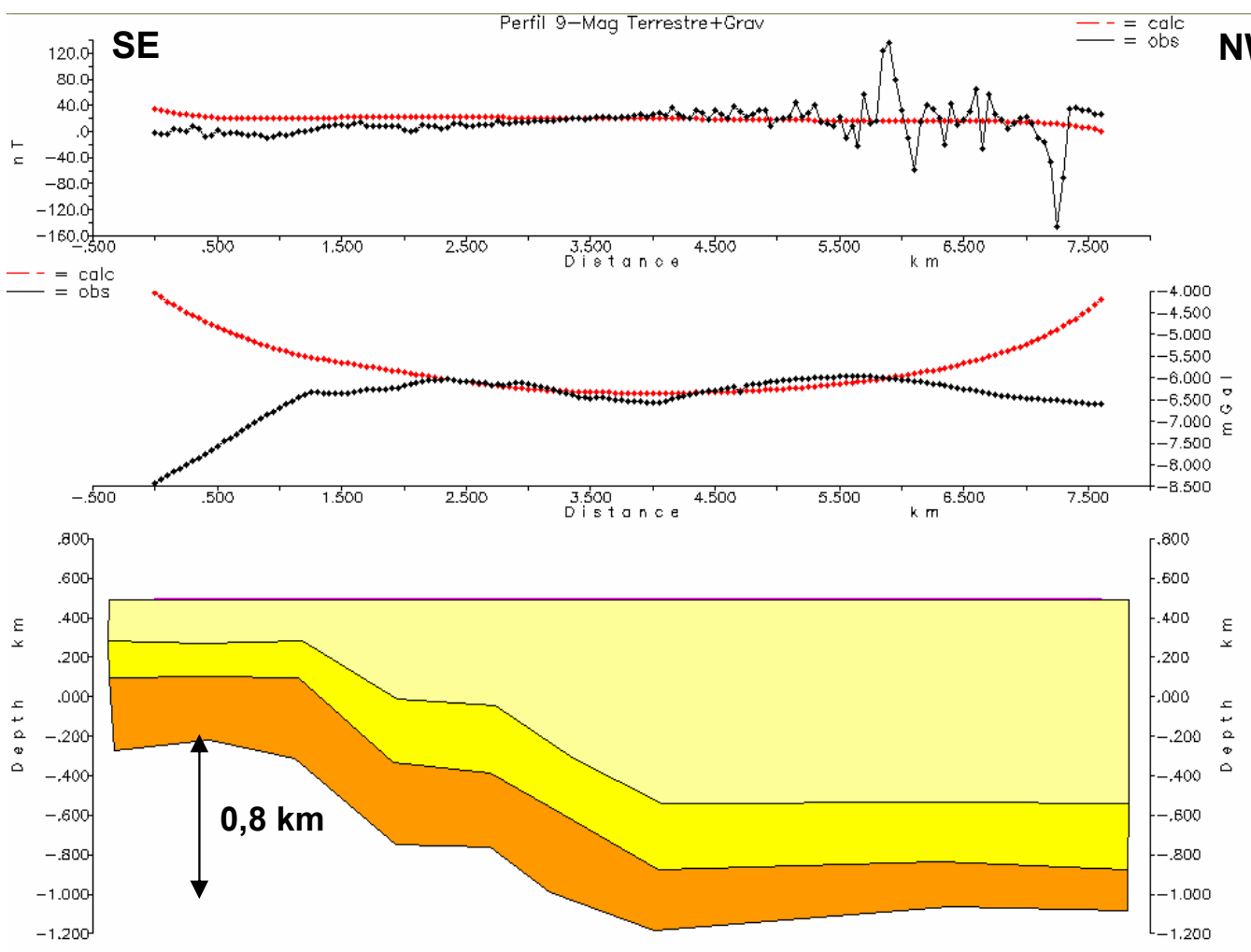

Propriedades físicas (SI)

Fm. Aquidauana- $d=2,36 ; k=$ desprezível Fm. Ponta Grossa-d=2,36; k= desprezíve

Fm. Furnas- $d=2,22 ; \mathrm{k}=$ desprezível Embasamento- $d=2,45 ; k=0,006$

Figura 6.17. Modelo conjunto baseado nos dados gravimétrico e magnéticos terrestres extraídos ao longo do perfil 9. O modelo revela cerca de $0,8 \mathrm{~km}$ de diferença entre o soerguimento do NCS e o piso da cratera. $d=$ densidade $\left(\mathrm{g} / \mathrm{cm}^{3}\right) ; \mathrm{k}=$ susceptibilidade magnética $(\mathrm{SI})$. 


\section{CAPÍTULO 7}

\section{Discussão e interpretação dos dados}

A análise dos resultados do modelamento direto obtidos permite extrair informações da profundidade média do embasamento e sua forma de interação com as supracrustais, da dimensão do EGS, da espessura média dos estratos sedimentares, da estimativa da erosão na região, dos regimes de deformação vigentes, das dimensões, e apresenta uma proposta de evolução para a estrutura. Para tais interpretações são utilizados os modelos que apresentam melhores ajustes e coerência. Como resultado final são propostos modelos geológicos para os principais perfis que caracterizam a estrutura e a reunião de suas informações permite a geração de um modelo 3D para a mesma.

\subsection{ANÁLISE DOS AJUSTES DOS MODELOS}

Como observado em alguns modelos aeromagnéticos e nos modelos conjuntos, a obtenção de ajustes dos dados magnéticos aéreos nem sempre se mostra possível. Isto pode ser justificado por duas hipóteses: i) os dados aeromagnéticos foram suavizados pela digitalização das cartas magnéticas e conseqüentemente perdem informações; ii) algumas fontes magnéticas e gravimétricas podem não ser correlatas geográfica e geometricamente.

Outra hipótese para o não ajuste dos dados aeromagnéticos em algumas regiões dos perfis é a superposição de uma forte tendência regional de direção NESW, já descrita nos capítulos anteriores. Apesar de todo o processamento realizado para sua remoção, esta componente oriunda de fontes profundas ainda permanece perceptível nos dados do campo magnético anômalo (Figura 4.21). A direção desta componente pode ser atribuída regionalmente à direção do expressivo Lineamento Transbrasiliano. Esta feição é definida e descrita como um conjunto de falhas regionais, transcorrentes, de direção geral N30E (Schobbenhaus, 1975), geradas na fase de deformação final do Ciclo Brasiliano. Nota-se a continuidade desta estrutura para a região da Bacia do Paraná passando pelos limites de Araguainha (Figura 7.1), o que de fato se adequa à origem levantada em questão. 


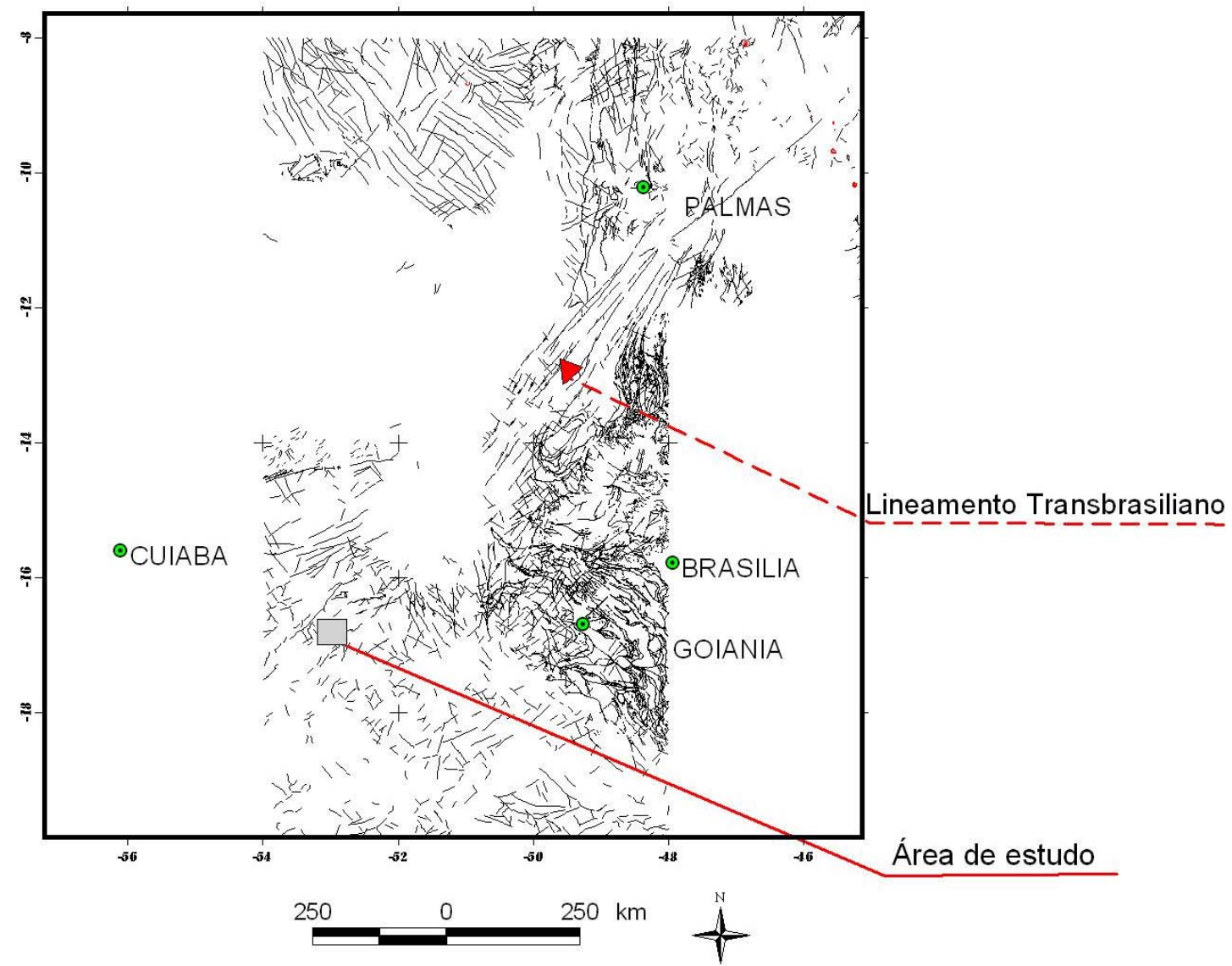

Figura 7.1. Mapa regional de lineamentos mostrando a continuidade expressiva do Lineamento Transbrasiliano.

\subsection{ANÁLISE DA ASSINATURA GRAVIMÉTRICA E MAGNÉTICA DE ARAGUAINHA}

Investigações geofísicas em estruturas de impacto revelam que uma variedade de assinaturas pode resultar das mudanças de propriedade física nas rochas-alvo (Pilkington \& Grieve, 1992).

Os mapas dos campos gravimétrico e magnético residuais aliados ao perfil magnético terrestre expõem claramente valores mais baixos para a região do EGS comparado às suas adjacências. Entretanto, a co-existência de altos ou baixos magnético e gravimétrico não precisa necessariamente existir (Pilkington \& Grieve, 1992).

O baixo gravimétrico de -9 mGal observado nos perfis se contrapõe à maioria das assinaturas das crateras complexas estudadas até o presente, como por exemplo Chicxulub (Espindola et al.,1995), Vredefort (Henkel \& Reimold, 1998), além de outras. 
Pilkington \& Griveve (1992) associam a causa deste baixo a mudanças litológicas e físicas associadas com o processo de crateramento. No caso do estudo, o baixo pode estar relacionado ao fraturamento e brechação das rochas-alvo, além da presença de xenólitos de arenitos arcóseos e biotita-muscovita-xistos descritos por Lana et al. (2006b). Esta análise concorda com Theilen-Willige (1981), que já havia relacionado a origem do baixo magnético provavelmente à presença de suevito, fraturas e brechas.

O baixo magnético de cerca de $-10 \mathrm{nT}$ para o núcleo de Araguainha também diverge das anomalias magnéticas descritas em outras crateras do mundo (Morokweng - Henkel et al., 2002; Lonar - Rajasekhar e Mishra, 2005). Em geral, crateras de impacto com diâmetro maior que $40 \mathrm{~km}$ possuem anomalias centrais de alta amplitude (Pilkington \& Griveve, 1992). Este fato também não está em consonância com a assinatura magnética obtida nos testes com dados sintéticos (Figura 4.34). A redução da susceptibilidade magnética central é atribuída por Kumar e Ward (1963, apud Pilkington \& Grieve,1992) como derivada da uma pressão maior que $10 \mathrm{GPa}$, processo que é descrito em locais de explosão nuclear (Short, 1965, apud Pilkington \& Grieve,1992).

Esta provável diferença nas propriedades físicas do EGS em relação ao restante do embasamento permite inferir um limite de propriedade cerca de $1 \mathrm{~km}$ de profundidade (Figura 7.2).

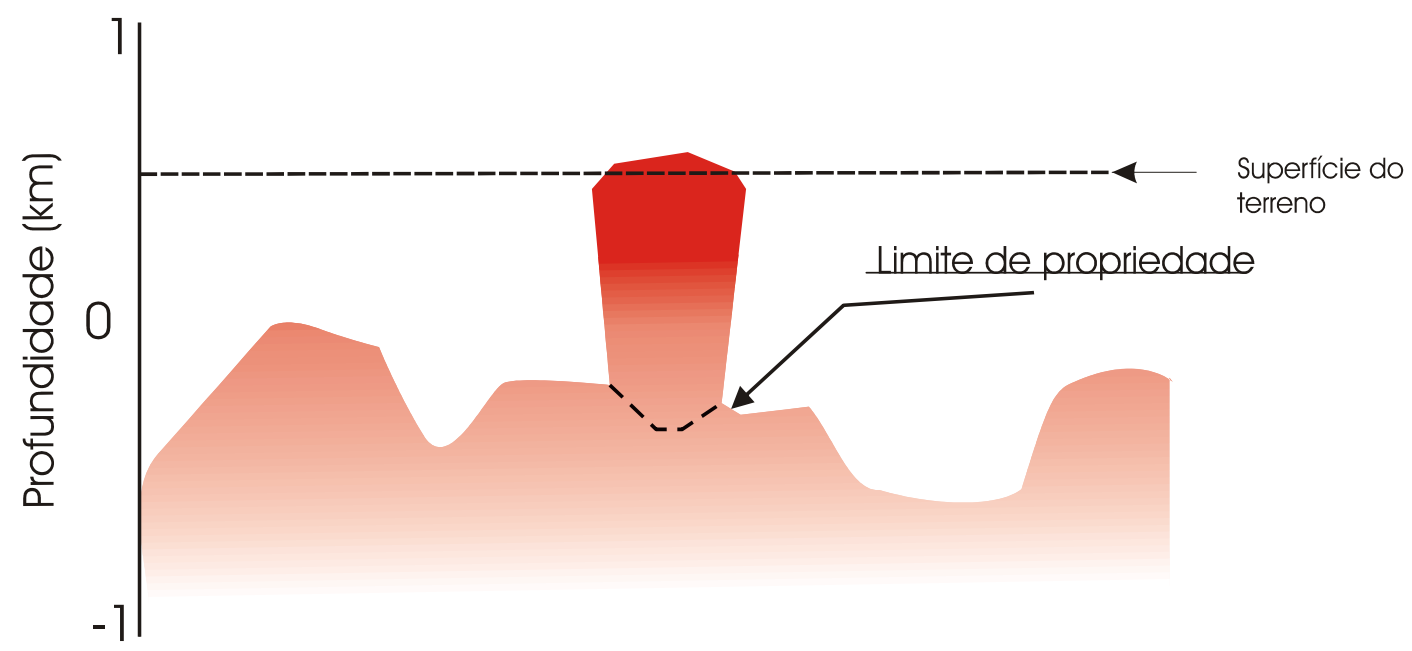

Figura 7.2. Interpretação para o limite de propriedade física que separa o embasamento abaixo das supracrustais do EGS, traçado a partir da necessidade de explicar baixos gravimétrico e magnético do centro de Araguainha. 
As demais anomalias gravimétricas estão principalmente relacionadas ao contraste topográfico das diversas regiões do embasamento, já que os valores de susceptibilidade e densidade associados a ele são maiores que dos corpos sobrepostos. Pode-se, desta forma, considerar a feição geral das anomalias gravimétricas como bem semelhante à disposição do embasamento em profundidade.

Como resposta à assimetria gravimétrica observada nos perfis que seccionam a região no núcleo (perfis 3, 9, 13 e 14) (exemplificado na figura 7.3) e no alongamento da anomalia ao redor do NCS para as bordas (Figura 4.15), os modelos gerados apresentam soerguimento e/ou abatimento diferenciado do embasamento. Esta observação pode auxiliar no entendimento deformacional da estrutura com relação ao ângulo de impacto do projétil. Metade de todas as direções dos alvos estão entre $30^{\circ} \mathrm{e}$ $60^{\circ}$ (Pierazzo \& Melosh, 2000 apud Scherler et al. 2006). O desenvolvimento de assimetrias estruturais no soerguimento central ou na área da borda da cratera pode estar associado a ângulos de impacto baixos (Scherler et al., op. cit.). Entretanto, esta afirmação ainda é frágil diante da quantidade de informações que se tem em Araguainha, e deve ser suportada por outros argumentos geológicos e geofísicos. A distribuição assimétrica de ejecta auxilia na interpretação desta hipótese (Schultz \& D'Hondt, 1996); no entanto, estes foram erodidos em Araguainha. O que se defende é que a dimensão do diâmetro do pico central, neste caso o EGS, não teria relação com a diminuição do ângulo de impacto (Ekholm \& Melosh, 2001).

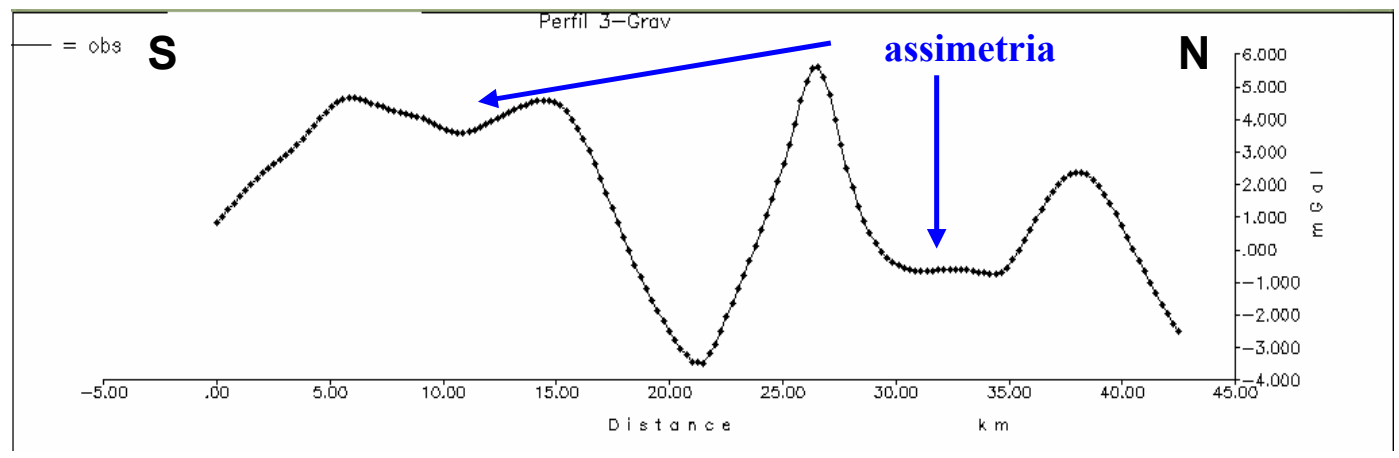

Figura 7.3. Assimetria da assinatura gravimétrica observada no perfil 3. Destaca-se uma anomalia de -1 mGal para a região norte contrastante com uma anomalia de aproximadamente $4 \mathrm{mGal}$ na região sul, ambas localizadas na bacia anelar. 


\subsection{PROFUNDIDADE MÉDIA DO EMBASAMENTO DE ARAGUAINHA}

Os modelos que apresentam dados gravimétricos mostram-se importantes para a identificação dos limites destas fontes após a aplicação da derivada de segunda ordem. A partir destas informações, os contatos são fixados lateralmente, diminuindo a ambigüidade lateral dos modelos. A informação da profundidade média obtida dos espectros de potência é importante para limitar a profundidade da camada sedimentar. Partindo-se destas premissas, pode-se analisar de maneira mais confiável a profundidade do embasamento de Araguainha ao longo de toda sua estrutura.

Os modelos são unívocos na profundidade média de $1 \mathrm{~km}$ encontrada para o EGS. As regiões adjacentes ao EGS mostram profundidade média de aproximadamente $0,8 \mathrm{~km}$ para ambos os lados. Entretanto, a qualidade do ajuste da anomalia gravimétrica do perfil 3 (Figura 7.4) a sul do EGS permite avaliar uma assimetria deste em relação ao lado norte. De modo geral, os modelos gerados para o perfil 3 mostram embasamento cerca de $0,2 \mathrm{~km}$ mais raso na porção sul que norte. $O$ resultado nada mais é que a expressão do alto gravimétrico alongado para sul presente nos dados.

Considerando a média de profundidade do embasamento na região de $1 \mathrm{~km}$ (Zalan, 1986 apud Molina et al. (1989) e Masero et al., 1994), pode-se dizer que o soerguimento abaixo das Formações Furnas e Ponta Grossa varia entre 0,1 e 0,4 km (Figura 7.4). Este soerguimento seria o responsável pelos altos gravimétricos que contrastam com o baixo no EGS (Figura 7.5). 


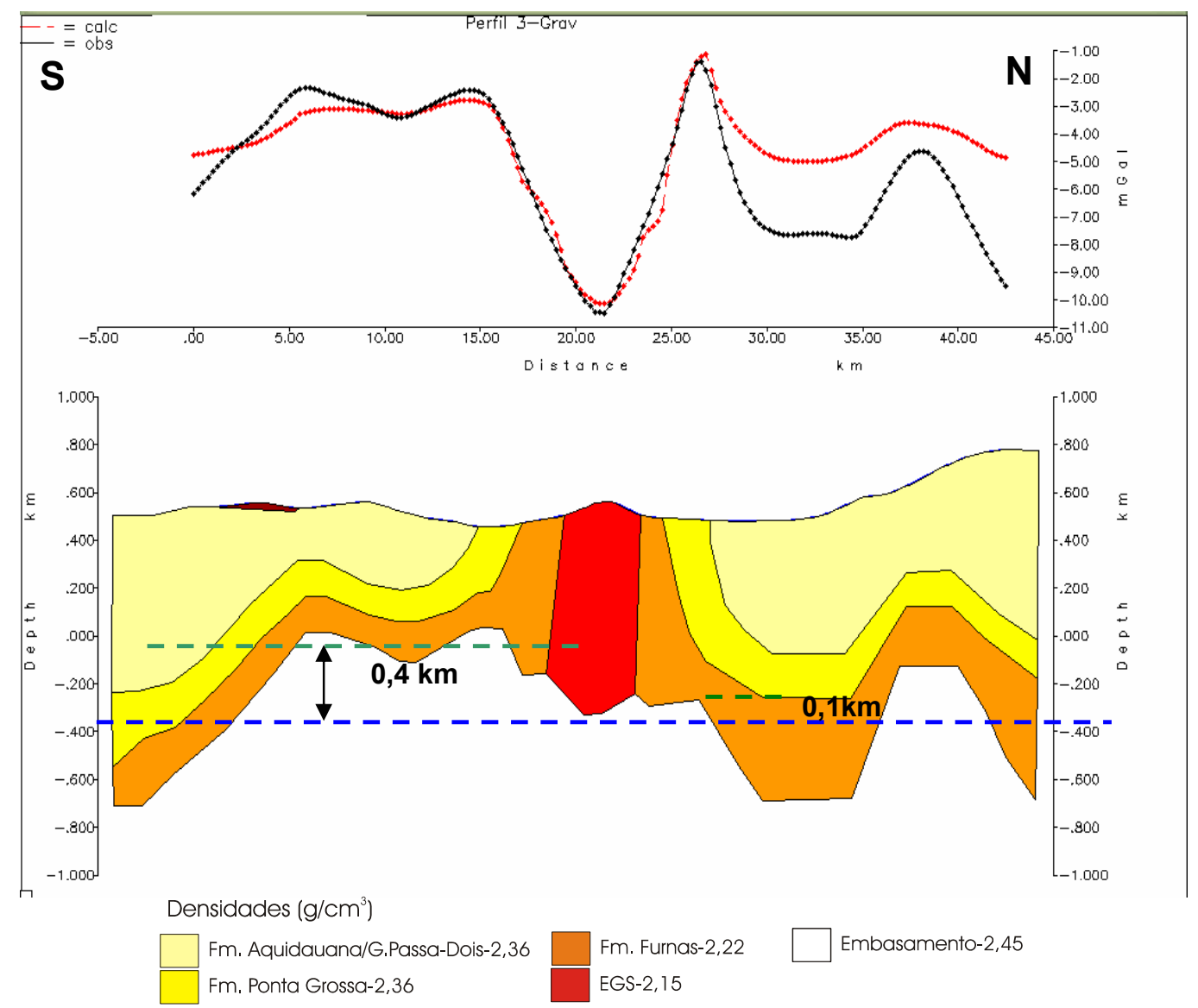

Figura 7.4. Modelo gravimétrico gerado ao longo do perfil 1 mostrando soerguimento do NCS $0,3 \mathrm{~km}$ maior na porção sul se comparado à região norte (linhas tracejadas em verde). A linha tracejada azul mostra a profundidade média do embasamento na região, que serve como parâmetro inicial para comparação.

a)

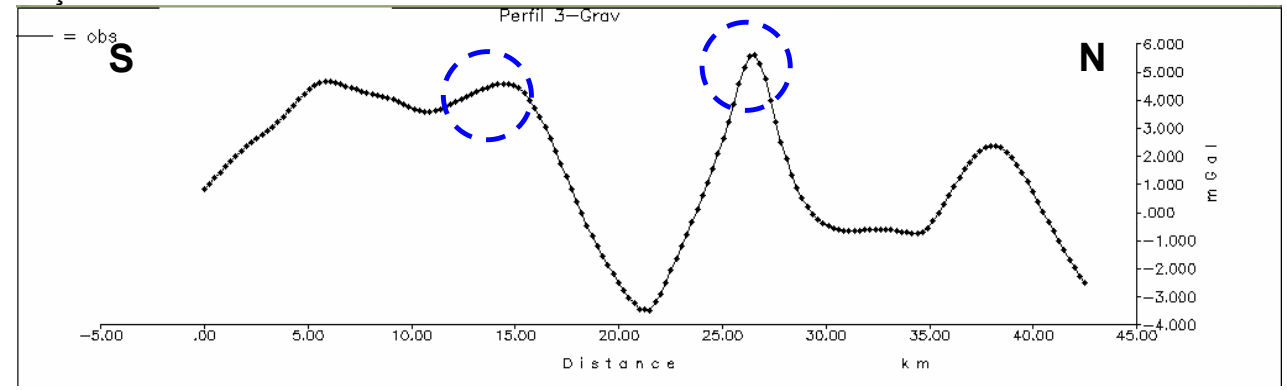

b)

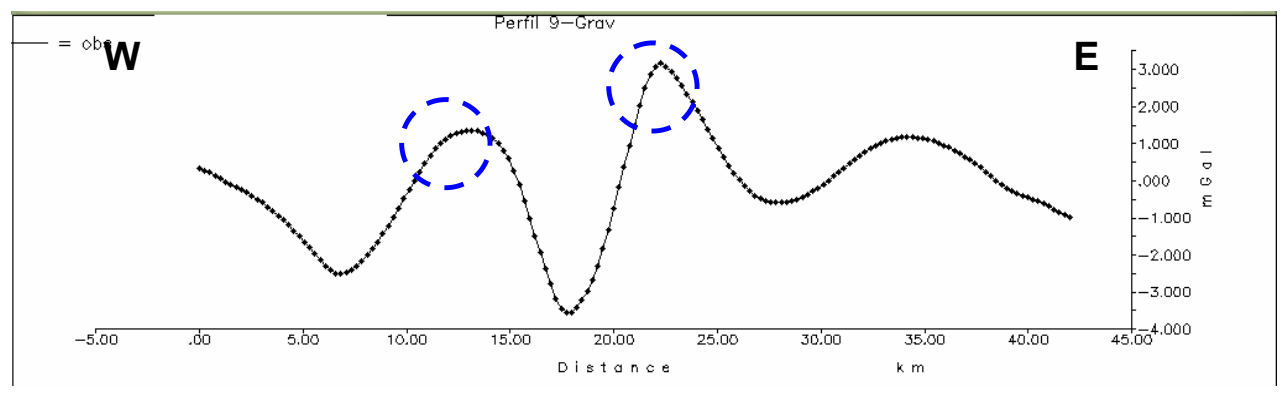

Figura 7.5. Anomalias gravimétricas relacionadas aos perfis 3 (a), e 9 (b), nos quais se observa altos gravimétricos marcados pelos círculos em azul, que são interpretados como resultantes do soerguimento do embasamento abaixo das Formações Furnas e Ponta Grossa. 
A partir do soerguimento diferenciado do embasamento de Araguainha, propõe-se um modelo genético para região no núcleo soerguido (Figura 7.6). Este modelo é uma tentativa de explicar os $0,4 \mathrm{~km}$ de soerguimento abaixo das Formações Furnas e Ponta Grossa, e trata de diferenciar o EGS do NCS, já que estes por si demonstram divergência nas propriedades físicas. O soerguimento responde ao alto gravimétrico que circunda o baixo do EGS e de certa forma também auxilia na explicação da verticalidade destes estratos sedimentares. A proposta mostra que o soerguimento na região central, iniciado no estágio de escavação (Melosh, 1989), é maior devido à atuação vetorial que nesta região seria mais intensa, diminuindo radialmente para as adjacências. Isto estaria ligado ao grau de pressão de 20 a 25 GPa atuante na região central proposto por Engelhardt et al. (1992) através da observação de clastos de brechas polimíticas e do granito porfirítico. A atuação compressional mais intensa na região central conduziria a um rebote elástico maior, não eximindo as adjacências de também apresentarem certo grau de soerguimento. $O$ rebote elástico é uma resposta das rochas à aplicação de forças, e explica a tendência das rochas-alvo retornarem ao estado inicial pré-evento, considerado como um estágio reversível (Melosh \& Ivanov, 1999).

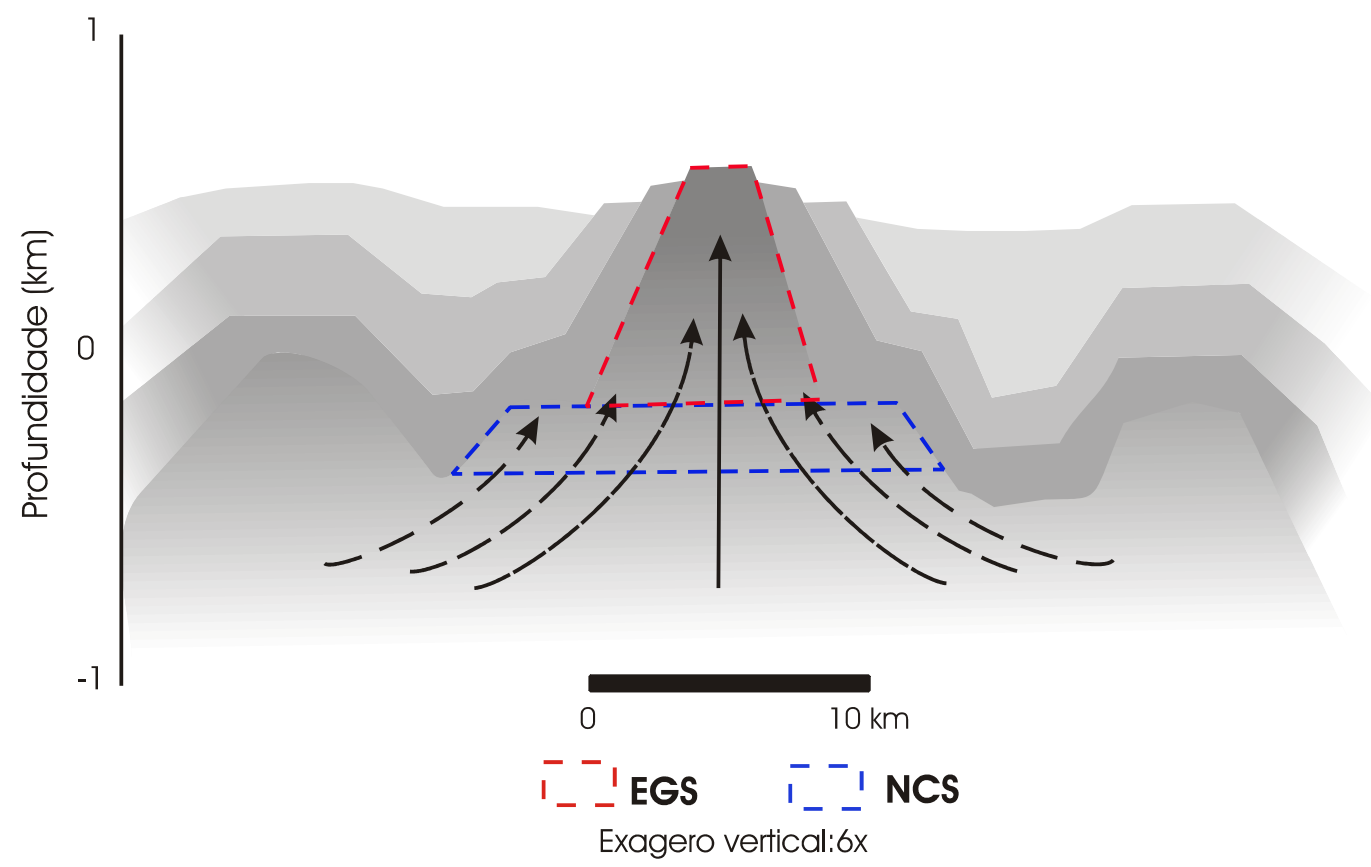

Figura 7.6. Proposta de modelo genético para o soerguimento central da estrutura de impacto de Araguainha. Há um maior soerguimento na região central correspondente ao EGS em relação ao NCS. O tamanho dos vetores resulta em região de maior soerguimento. 
A relação dada por Grieve et al. (1981) na equação 7.1 atribuiria um soerguimento central de 3,5 km para Araguainha. Entretanto, com os resultados dos modelos, o máximo soerguimento atribuído ao núcleo de Araguainha seria de 1,4 km, como somatória do soerguimento de $1 \mathrm{~km}$ do EGS (Figuras 6.4, 6.5, 6.8 e 6.9) e 0,4 km do NCS (Figura 7.4).

$$
S C=0,06 D^{1,1}=3,5 \mathrm{~km}
$$

onde $\mathrm{D}$ é o diâmetro da estrutura.

Considerando o diâmetro de Araguainha, o soerguimento total do núcleo estimado nos modelos é proporcionalmente inferior, se comparado aos $13 \mathrm{~km}$ encontrados para a estrutura de Vredefort (Henkel \& Reimold, 1998), com $250 \mathrm{~km}$ de diâmetro, e aos $30 \mathrm{~km}$ para Subdury (Grieve \& Therriault, 2000) com 200-280 de diâmetro (Grieve et al., 1991, Deutsch et al., 1995).

A estrutura mostra-se com profundidades do embasamento entre 0,8 e 1,1 km para as bordas leste, oeste, norte, nordeste, noroeste e sudoeste. Já a região da borda sudeste apresenta-se com profundidade em torno de 1,3 km (Perfil 14 gravimétrico da figura 6.5). A profundidade do embasamento da borda sul é a mais discrepante das demais, mostrando $0,5 \mathrm{~km}$ de pacote sedimentar e um soerguimento mais acentuado nesta região.

A região da bacia anelar comporta as maiores profundidades em todos os modelos (Figuras 6.4, 6.5, 6.8, 6.9 e 6.14). Trata-se de aproximadamente $1,4 \mathrm{~km}$ de pacote sedimentar acima do embasamento que revela um espessamento dos estratos sedimentares nesta região.

Considerando $1 \mathrm{~km}$ e 0,6 km como profundidade média do embasamento e altitude da região, respectivamente, a relação do soerguimento da borda norte com a expressão topográfica assinalada na figura 6.10 revela cerca de $0,2 \mathrm{~km}$ de expressão topográfica. A análise permite inferir erosão de cerca de $0,1 \mathrm{~km}$ dos estratos sedimentares ao menos nesta região, isto se a topografia estiver unicamente relacionada ao impacto. Esta medida está subestimada em relação ao máximo de 0,32 $\mathrm{km}$ mencionado por Lana et al. (2006b), que associa grau mais acentuado nas regiões de rebaixamento topográfico. Entretanto, a estimativa se aproxima desta ao realizar a mesma análise para o perfil 1 aeromagnético (Figura 7.7) . 


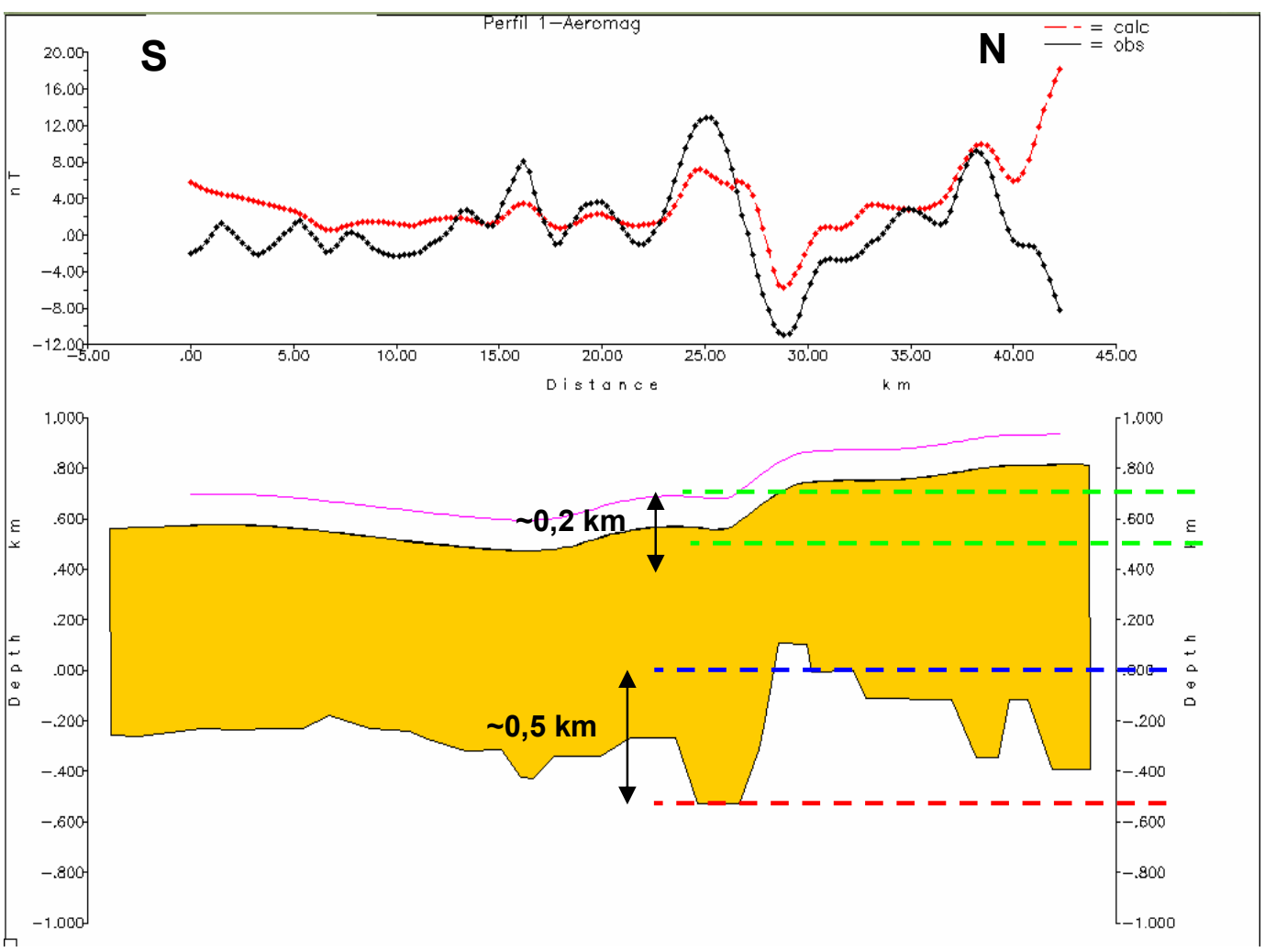

Susceptibilidades magnéticas (SI)

Rochas Sedimentares

Embasamento-0,006

Figura 7.7. Modelo representativo dos sedimentos da bacia gerado ao longo do perfil $11 \mathrm{com}$ base em informações aeromagnéticas. O valor de aproximadamente $0,5 \mathrm{~km}$ refere-se à diferença da profundidade média do embasamento na região (linha tracejada vermelha), e o soerguimento da borda (linha tracejada azul). O soerguimento estaria refletindo em cerca de 0,2 km de expressão topográfica, o que resultaria em aproximadamente $0,3 \mathrm{~km}$ de erosão estimada na borda NW de Araguainha.

Em análise geral, Araguainha apresenta uma estrutura praticamente simétrica na direção E-W e NE-SW, e levemente assimétrica nas demais regiões, com destaque para a porção sul/sudeste que apresenta soerguimento mais acentuado, bem representado pelos perfis gravimétricos 3 e 14, respectivamente. Entretanto, o rebaixamento topográfico na região sudeste da estrutura denota o grau de erosão mais acentuado (Lana et al., 2006b), o que em princípio dificulta esta interpretação.

Em suma, tem-se que ao pacote geral dos sedimentos possui espessura média de $1 \mathrm{~km}$, alcançando cerca de $1,4 \mathrm{~km}$ nas regiões da bacia anelar e 0,5 km nas regiões de borda. Destes, aproximadamente $0,2 \mathrm{~km}$ é atribuído à Formação Furnas, 0,25 km à Formação Ponta Grossa, 0,7 km à Formação Aquidauana, e 0,1km à Formação Irati. As medidas das formações Furnas e Ponta Grossa mostram-se subestimadas em relação às observações de Lana et al. (2006b). Entretanto, vale ressaltar que as 
mesmas foram realizadas pelos autores principalmente nos estratos localizados fora da estrutura.

\subsection{MODELOS GEOLÓGICOS}

A partir da análise dos modelos diretos 2,5D aliados às informações dos mapas geológicos, magnético residual e amplitude do sinal analítico podem-se inferir modelos geológicos plausíveis para Araguainha.

Estudos sísmicos na estrutura complexa de Mjolnir (Tsikalas et al., 2002) atribuem a esta estrutura um regime essencialmente rúptil, com maior concentração de falhas nas regiões de borda e dobras de pequeno porte localizadas. As interpretações geológicas para os modelos de Araguainha seguem este mesmo padrão, associando as regiões de falha mostradas em mapa (Figura 6.2) às descontinuidades dos modelos.

A sinuosidade da interface embasamento/rochas sedimentares observada nos modelos propõe uma relação bem acidentada entre estes dois litotipos seccionados por falhas de colapso gravitacional quilométricas (Figura 7.8 a 7.11). Estas falhas normais tendem a se concentrar nas regiões de borda e anéis da estrutura convergindo para a região da bacia anelar, indo de encontro a outras falhas de grande porte que surgem especularmente do centro em direção às bordas. De forma geral, estas estruturas rúpteis estão concentricamente arranjadas rodeando a região anelar e por vezes limitando blocos das formações Aquidauana e Irati (Lana et al., 2006b). Estas estruturas são provavelmente as responsáveis pelo espessamento dos estratos sedimentares unanimemente modelados na região da bacia anelar, feição esta mais bem observada na Formação Furnas.

O modelo apresentado na figura 7.8 mostra esta relação de espessura/falhamento para a região norte, na qual as falhas de colapso gravitacional de fato estão marcadas em mapa e o restante surge como necessidade de resposta das anteriores. Já a porção desprovida do espessamento é marcada somente por falhas de colapso gravitacional. Nos lados leste e oeste de Araguainha observa-se o espessamento dos sedimentos (Figura 7.9). As bordas nordeste e sudoeste de Araguainha também se mostram marcadas por falhas (Figura 7.10). A borda nordeste mostra na assinatura gravimétrica comprimentos de ondas menores que, apesar de não terem sido bem ajustados, indicam contraste de densidade entre blocos aqui interpretados como falhas, que são justificadas por lineamentos quilométricos observados em mapas nesta mesma região. As falhas com direção de mergulho do 
centro para as bordas são interpretadas a partir da análise dos demais modelos com a necessidade de explicar o espessamento e constricção dos sedimentos.

A falha marcada no extremo noroeste de Araguainha (Figura 7.11) limita as formações Aquidauana e Irati, conforme observação de Lana et al. (2006b), mostra-se representada no mapa geológico coincidindo com um baixo magnético. Além disso, é ressaltada nos mapas de amplitude do sinal analítico (Figura 4.21) como um lineamento de direção NE-SW.

A idéia de espessamento da região localizada entre os anéis e o soerguimento central parece consistente ao se comparar os modelos com os resultados obtidos em modelamentos numéricos de estruturas complexas realizados por Morgan et al. (2000), Collins et al. (2002) e Ivanov (2005). De acordo com a análise de Collins et al. (op. cit.) para a cratera de Chicxulub, a região de espessamento teria sido formada a partir do colapso da cratera transiente por meio de falhas normais. Este colapso estaria ligado a um regime de fluxo da borda da cratera que se destinaria ao centro da estrutura, caracterizando uma movimentação lateral e vertical dos estratos (Figura 7.12). 


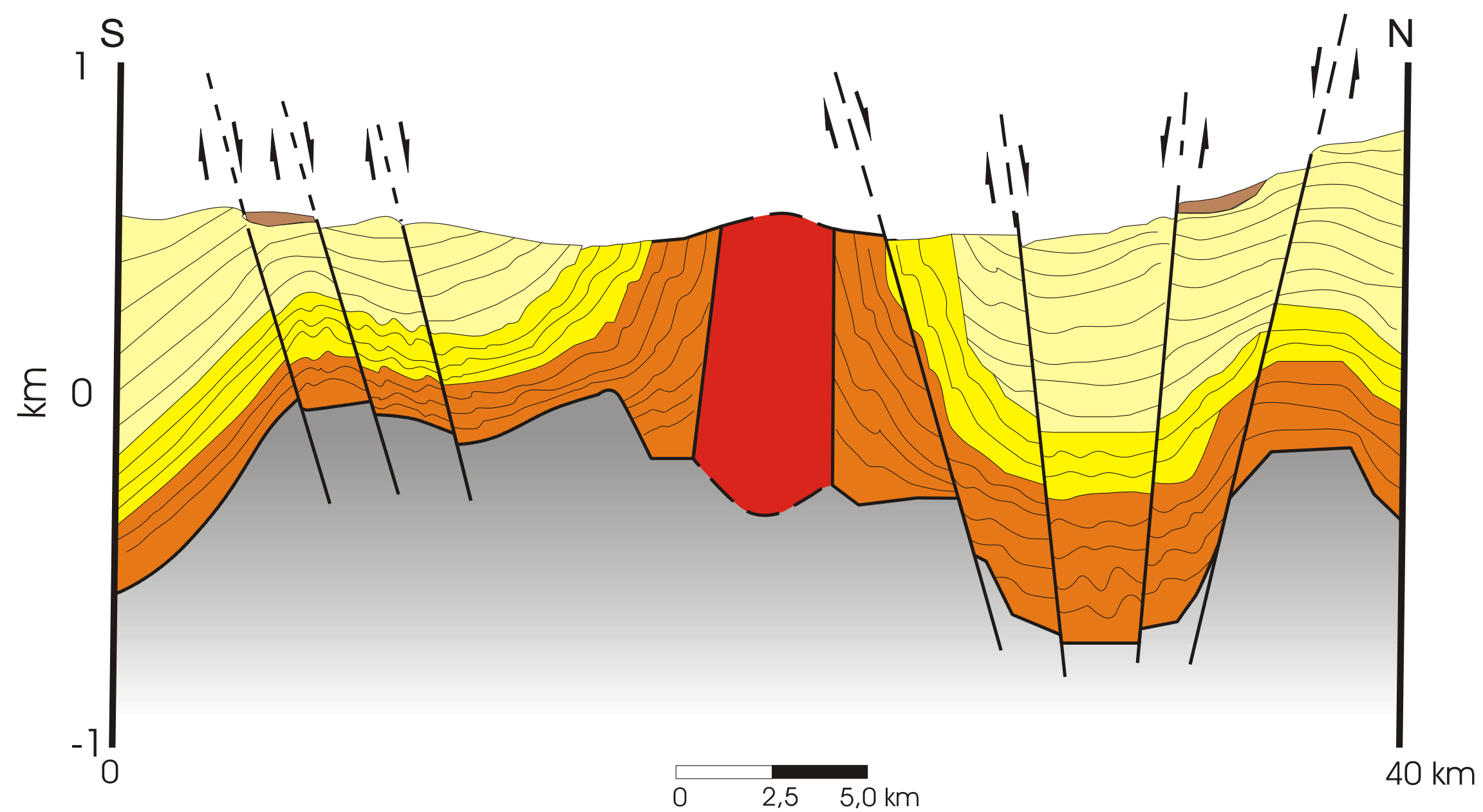

7.8. Seção geológica esquemática gerada através das informações obtidas do modelamento do perfil 3. Nota-se a região da borda sul mais soerguida em relação à borda norte. Na borda norte há espessamento dos estratos sedimentares a partir da atuação de falhas que convergem para a região da bacia anelar. Exagero vertical $=9$ vezes. 


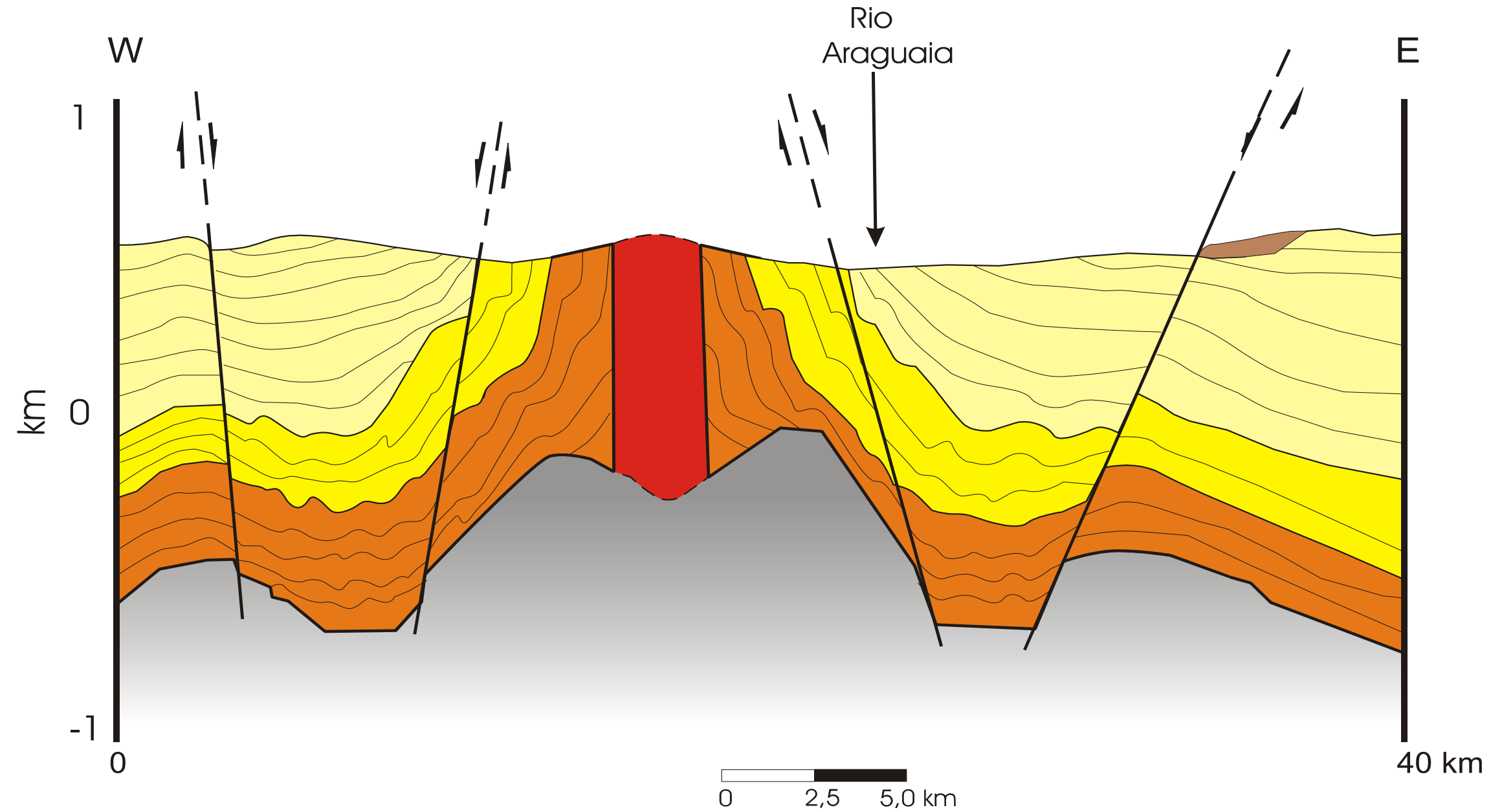

7.9. Seção geológica esquemática com base nos resultados obtidos para o perfil 9 gravimétrico e aeromagnético. Observam-se as bordas marcadas por falhas de colapso gravitacional que convergem para a região da bacia anelar. Esta por sua vez é deformada e espessa. Exagero vertical $=9$ vezes. 


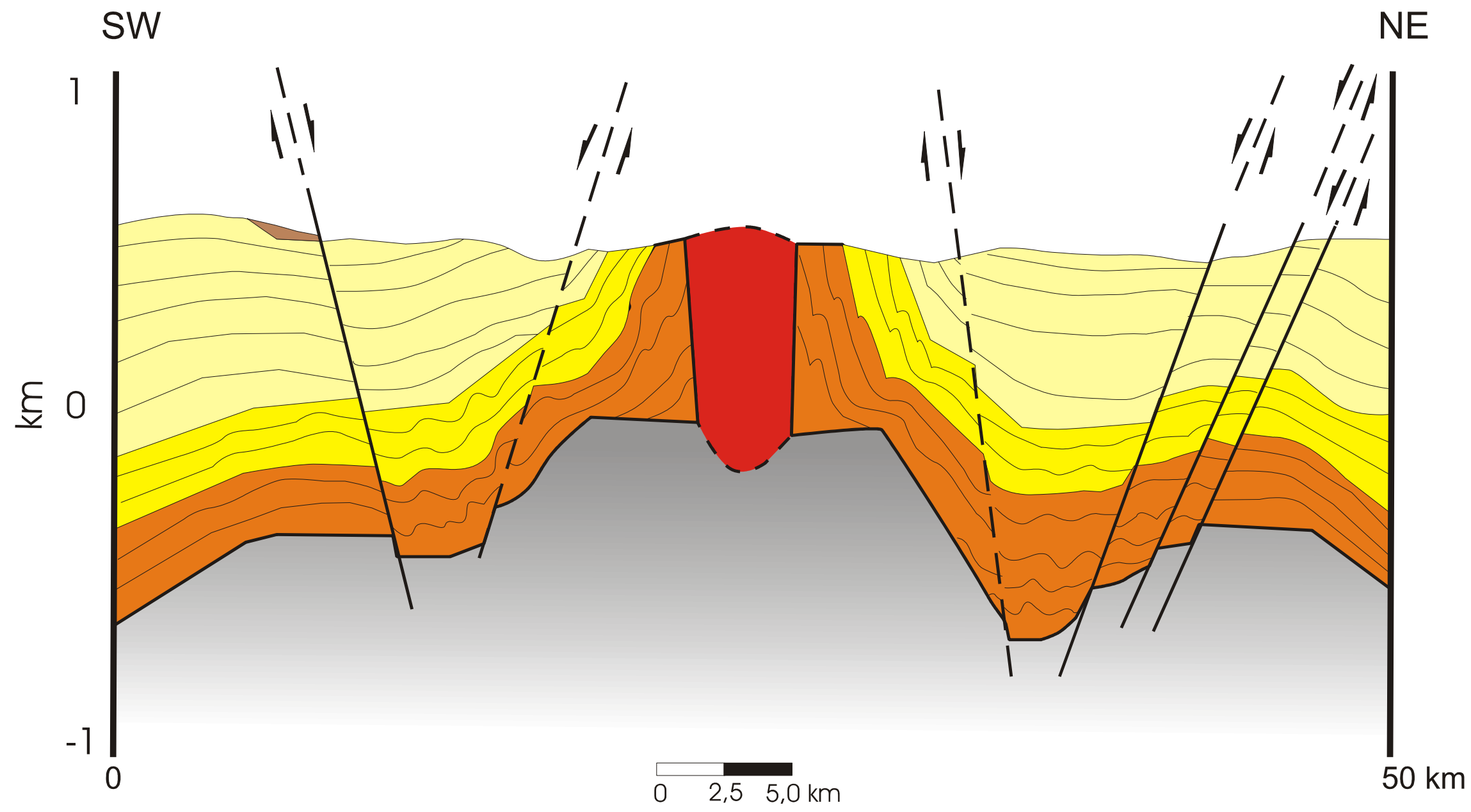

Figura 7.10. Seção geológica esquemática com base em interpretação dos resultados do modelamento $2,5 \mathrm{D}$ ao longo do perfil 13 . Ressalta-se o espessamento e constricção dos sedimentos na região da bacia anelar causados pelas falhas normais. Exagero vertical $=11$ vezes. 


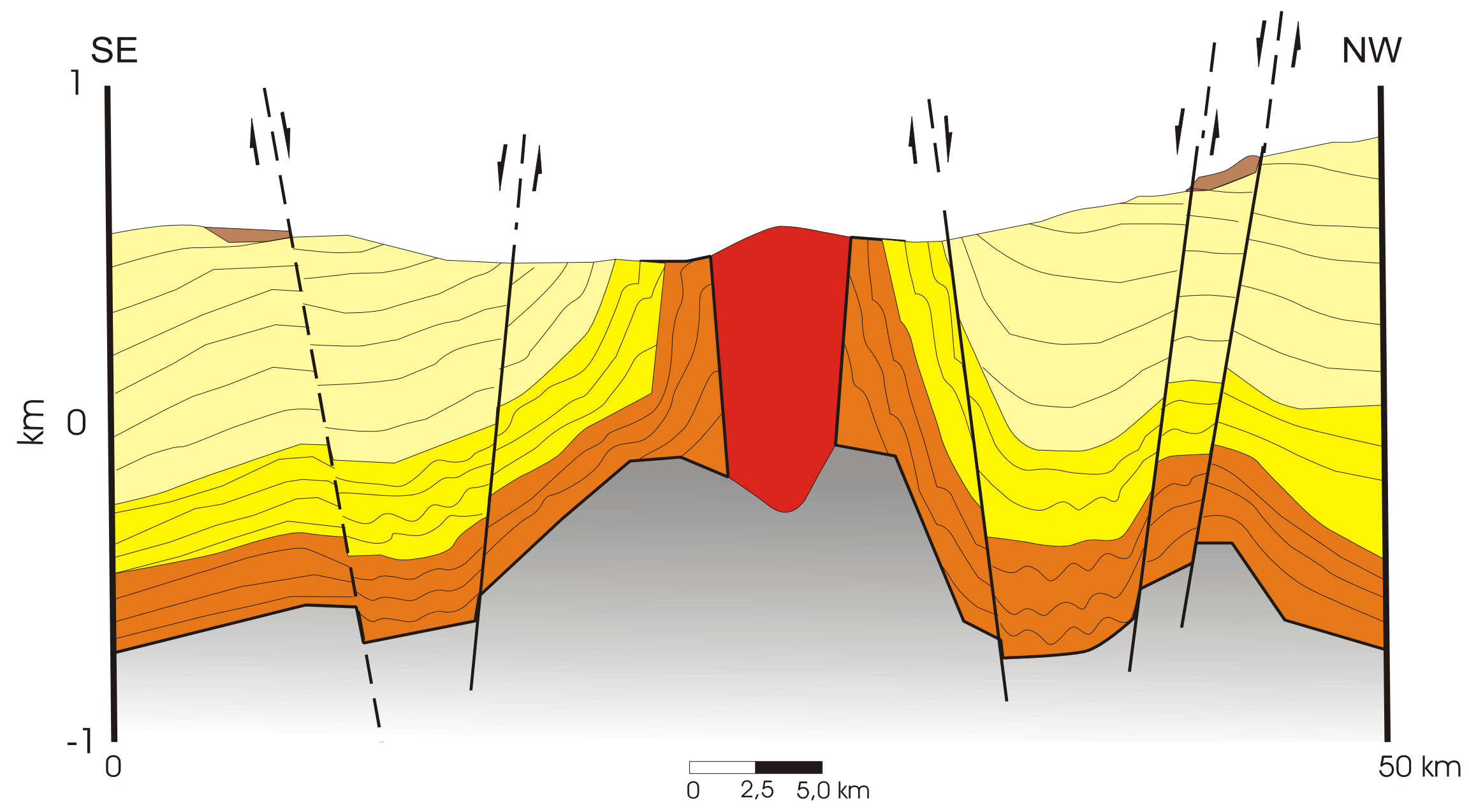

Figura 7.11. Seção geológica esquemática confeccionada com base no perfil 14. Nota-se a região da bacia anelar intensamente dobrada e com maior espessamento devido à atuação de falhas normais. Exagero vertical = 11 vezes. 


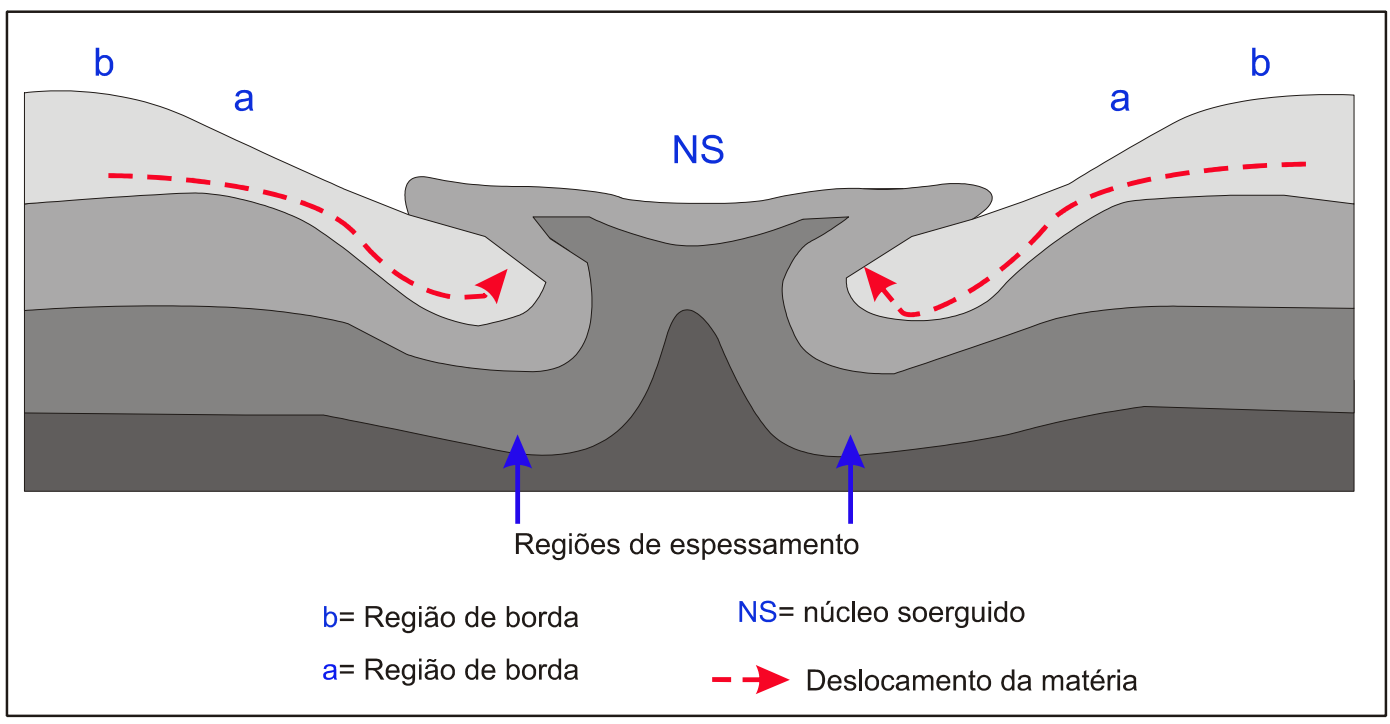

Figura 7.12. Modelos de formação do núcleo soerguido a partir de modelagem numérica. Destacam-se as regiões de espessamento assinaladas pela seta azul, que são concordantes com o espessamento observado na bacia anelar dos modelos 2,5D gerados (Modificada de Collins et al., 2002).

O soerguimento das regiões de borda da cratera promove uma compressão vertical nesta região, e o conseqüente fluxo descrito por Collins et al. (2002). Este fluxo refere-se ao estiramento dos sedimentos ali localizados, que migram em direção ao centro da estrutura e para fora de seus limites no estágio de modificação da cratera. Esta hipótese é sustentada a partir da análise dos modelos que envolvem dados magnéticos terrestres, que se mostram relativamente bem ajustados (Figura 7.13). Nota-se que os estratos sedimentares diminuem sua espessura na região delimitada pela borda tendendo ao retorno da espessura a uma distância de aproximadamente 2 km para a borda nordeste.

Com o mesmo nível de detalhe, as bordas sudoeste e noroeste demonstram esta diminuição na espessura dos estratos. Ainda podem-se observar falhas de colapso precedentes às regiões de borda, que marcam os dois modelos geológicos (Figuras 7.13a e 7.13d). 
(a) SW

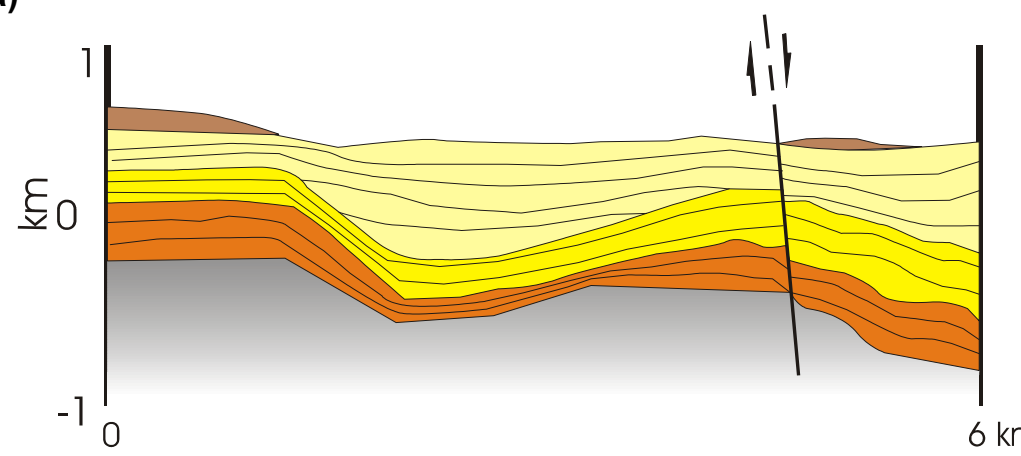

(b) SW

NE

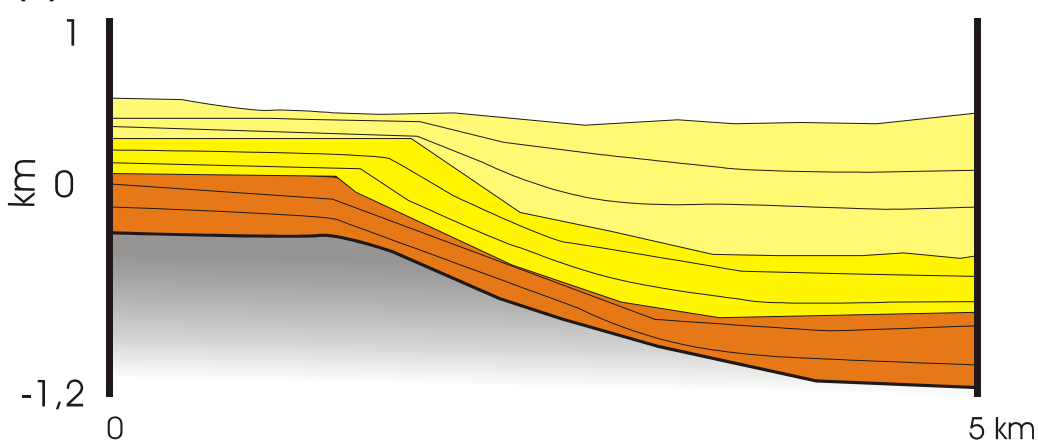

(d) NNW

(d)

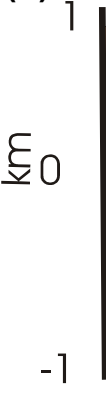

0
SE

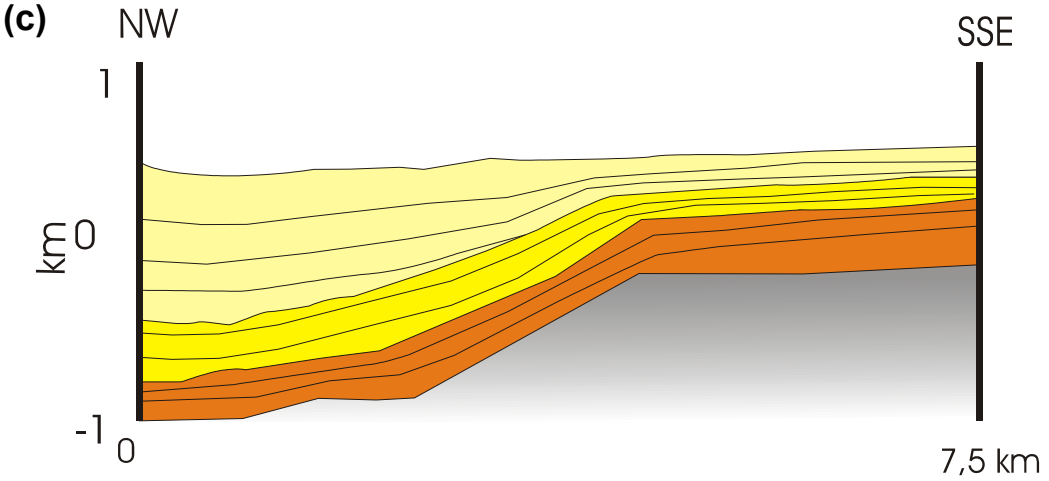

7.13. Seções geológicas esquemáticas das principais estruturas de Araguainha com base em modelamento conjunto de dados gravimétricos e magnéticos terrestres (a) perfil 1, borda sudoeste, (b) perfil 6, borda nordeste, (c) perfil 7, borda sudeste e (d) perfil 11, borda noroeste. 
Com a formação dos dois conjuntos de falhas, dispostos em direções opostas, os sedimentos localizados na região da bacia anelar e proximidades tendem a ser comprimidos. De fato, dobras abertas em grande escala estão expostas nos arenitos da Formação Furnas, conforme observações de campo de Lana et al. (2006b). Segundo os autores, a análise da orientação dos eixos destas dobras indicaria compressão substancial E-W. Entretanto, considerando que a compressão teria se iniciado com a formação do núcleo soerguido e prosseguido ao estágio de modificação, o mais provável seria a atuação de tensores radialmente dispostos. A direção desta deformação na verdade é esperada ao se relembrar a disposição de falhas e fraturas em forma radial.

Segundo Lana et al. (2006b), esta fase de deformação dúctil também teria promovido encurtamento de um fator de 3 a 4 dos sedimentos da Formação Furnas. Já os arenitos da Formação Aquidauana tendem a apresentar acamamento mais horizontal com menor encurtamento observado. Estas observações são ilustradas nos modelos das figuras $7.13 \mathrm{a}$ até $7.13 \mathrm{~d}$.

Após esta análise, pode-se dizer, sinteticamente, que a disposição estrutural final de Araguainha é interpretada como resultado da combinação de um encurtamento horizontal durante o colapso das bordas da estrutura com o soerguimento do embasamento na porção central.

Enquanto a formação de dobras indica deformação em regime dúctil o desenvolvimento de zonas brechadas indica deformação rúptil (Wieland et al., 2005). Em escala de lâmina, Engelhardt et al. (1992) associam fraturas e deformação planar observados em grãos de quartzo do granito como resultados de um fraturamento rúptil. Além disso, Crósta et al. (1981) descreveram estruturas de deformação intragranular como kink bands em cristais de mica e plagioclásio do granito.

A partir destas considerações, entende-se que na estrutura de Araguainha vigora um regime de deformação rúptil-dúctil, de forma que o segundo decorre principalmente da necessidade de acomodação do primeiro, quando se trata das falhas de grande porte e dobras. Esta interpretação se dá com base na necessidade de se explicar os modelos ajustados, e é suportada pelas observações em campo somadas às informações de Lana (2007).

Pode-se, então, delimitar regiões de predomínio dos estados de deformação e sentido do tensor deformação para cada uma das regiões de Araguainha (Figura 7.14). Esta análise não exclui o outro tipo de deformação em cada região, somente diz respeito ao principal regime de deformação atuante, e é baseada na análise conjunta dos modelos geofísicos e informações geológicas. 
A direção e sentido dos principais tensores apresentados para Araguainha são válidas para o estágio de modificação da cratera. Estes vetores apontam para uma expansão da matéria na região de borda adjacente à região da bacia anelar, onde predomina uma compressão horizontal.

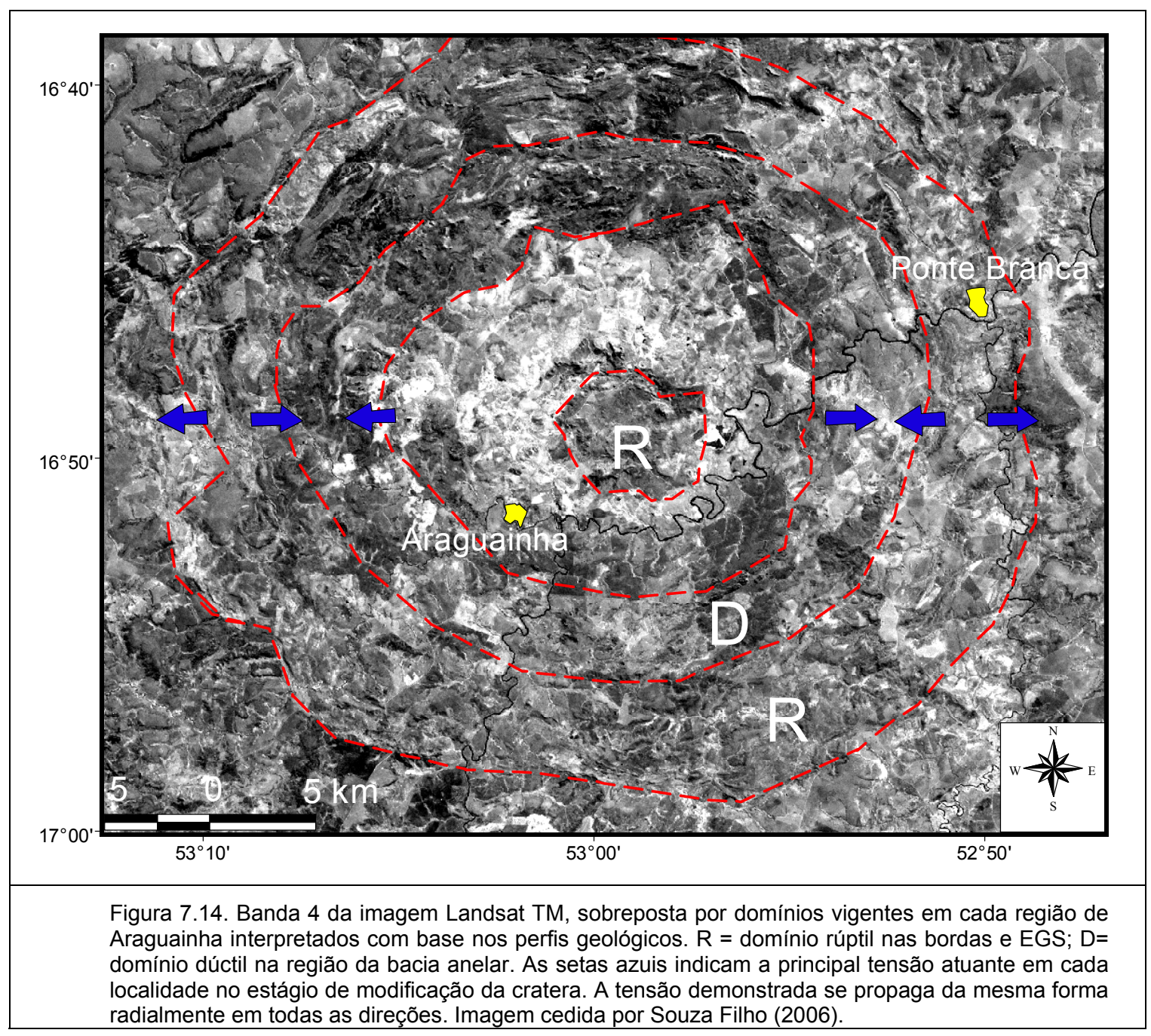




\subsection{PROPOSTA DE EVOLUÇÃO PARA ARAGUAINHA}

Após a apresentação das estruturas formadas nos domínios rúptil e dúctil de Araguainha, devem-se posicioná-las dentro de uma proposta evolutiva. Uma síntese dos estágios de formação da estrutura complexa de Araguainha é mostrada na figura 7.15 com base nos modelos de French (1998), Melosh (1989) e nas informações obtidas dos modelos.

O estágio de compressão abre o sistema deformacional no momento em que o projétil entra em contato com a superfície promovendo a propagação das ondas de choque e completa vaporização do projétil. No estágio de escavação (momento 1 da figura 7.15) a cratera expande-se formando a cratera transiente. À medida que a expansão progride, suas bordas se elevam, tornando-se cada vez mais abruptas, e funcionam como uma rampa de lançamento para o material que continua sendo ejetado para fora da região de impacto. O rebote elástico proporciona a formação de uma região de descompressão na parte central que dá início à formação do EGS (momento 2 da figura 7.15). Após esta etapa inicia-se então o estágio de modificação que dá continuidade ao soerguimento central diferenciando o NCS do EGS através de uma descompressão maior no ponto central (momento 3.1 da figura 7.15). Este soerguimento inicia a verticalização das formações Furnas e Ponta Grossa na região central em contato com o EGS. Sincronicamente a esta modificação inicia-se o soerguimento da borda que promove tensão vertical nesta região e conseqüente estiramento dos estratos sedimentares acima localizados. Estes então migram para o interior da estrutura e para fora dos limites da mesma. Concomitante a estas deformações inicia-se a formação das falhas de colapso gravitacional nas regiões de borda e anéis (momento 3.2 da figura 7.15). Como resposta à continuidade do soerguimento central surgem as falhas antitéticas às anteriores, que juntas tratam por espessar os estratos sedimentares da bacia anelar. O deslocamento dos blocos pelos pares de falhas geram uma tensão horizontal e conseqüente constricção dos sedimentos nesta interface.

Após a compressão e a escavação os estratos se acomodam em níveis gravitacionalmente estáveis e tem-se então a estrutura deformacional final de Araguainha (momento 4 da figura 7.15 ). 


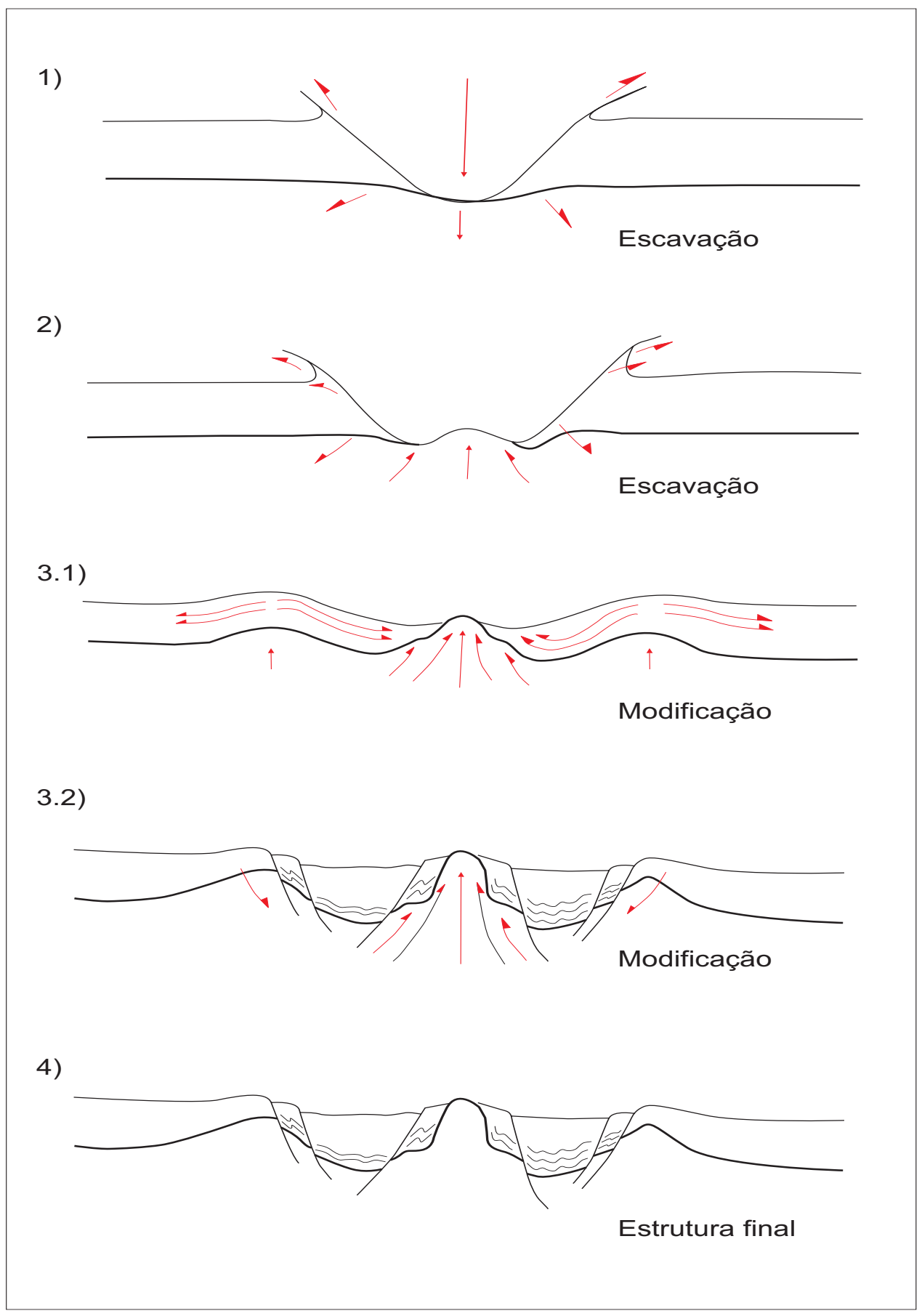

Figura 7.15. Proposta de evolução para a estrutura de impacto de Araguainha com base nas interpretações dos modelos geológicos e partir dos modelos French (1998) e Melosh (1989). As setas vermelhas indicam a principal tensão atuante na região. As dimensões estão fora de escala. 


\subsection{DIMENSÕES DE ARAGUAINHA}

As informações obtidas da etapa de processamento e dos modelos gerados permitem inferir algumas das principais dimensões para a estrutura de Araguainha.

O mapa de amplitude de sinal analítico (Figura 4.22) demonstra boa delimitação das fontes oriundas das bordas leste e sul, estando as demais sobrepostas por outras fontes. Ao unir esta informação com os lineamentos dos mapas geológicos à disposição, tem-se um diâmetro de aproximados $40 \mathrm{~km}$ na direção E-W e $38 \mathrm{~km}$ na direção N-S. Para o EGS estima-se $5 \mathrm{~km}$ de diâmetro, conferindo com informações de Engelhardt et al. (1992) e Lana et al. (2006a). Esta observação também se aproxima do resultado obtido para os modelos que seccionam a região central.

Engelhard et al. (1992) notaram que as brechas polimíticas possuem clastos de granito e hornfels, ambos derivados do embasamento, permitindo atribuir cerca de 2,4 km de escavação dos sedimentos da bacia pelo meteorito. Lana et al. (2006a) atribuem cerca de 2,0-2,5 km com base nas equações apresentadas por Melosh (1989), medida que se aproxima da estimada por Engelhard et al. (op. cit.). De fato, as sugestões dos autores parecem coerentes; entretanto, o que se observa nos modelos é uma profundidade máxima do embasamento a 1,4 km (Figura 7.16), o que pode significar que grande parte do estrato original tenha sido vaporizado e/ou ejetado da cavidade transiente.

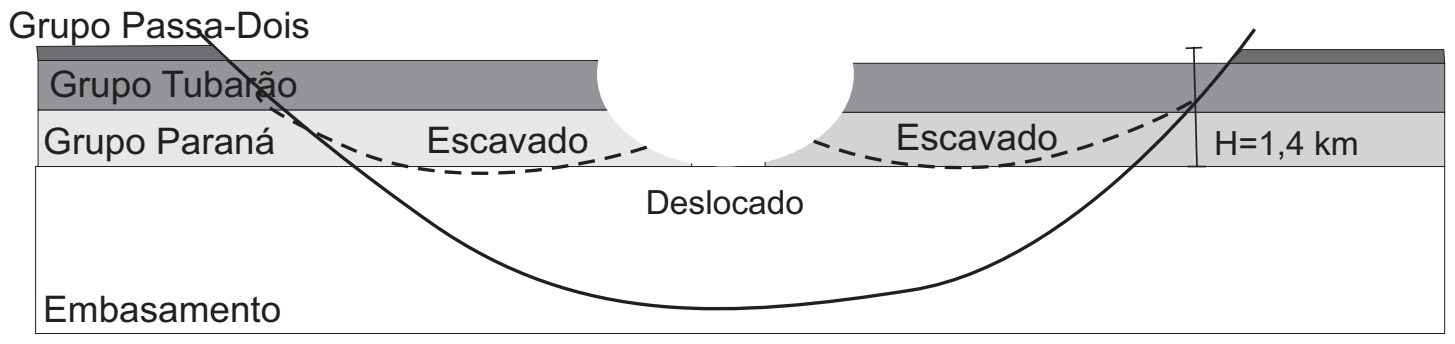

Figura 7.16. Estimativa da profundidade de escavação obtida com base nas informações dos modelos 2,5D gerados (Modificado de Lana et al., 2006a).

Com base nos modelos gerados ao longo dos perfis gravimétrico 3, 9 e 13, podese afirmar que o diâmetro da cavidade transiente $\left(D_{t}\right)$ varia entre $23 \mathrm{~km}$ na direção NWSE e $28 \mathrm{~km}$ na direção E-W, atingindo cerca de $30 \mathrm{~km}$ na direção N-S. Essas estimativas se aproximam às citadas por Lana et al. (2006a) de 20-25 km, equacionadas por Melosh (1989). Já a região da bacia anelar apresenta valores em torno de $10 \mathrm{~km}$ de raio. Para o 
soerguimento central, que envolve o EGS somado às formações Furnas e Ponta Grossa, o valor encontrado varia entre 9 e $13 \mathrm{~km}$.

Um perfil é apresentado na figura 7.17 com as principais dimensões encontradas com base nos resultados dos modelamentos.

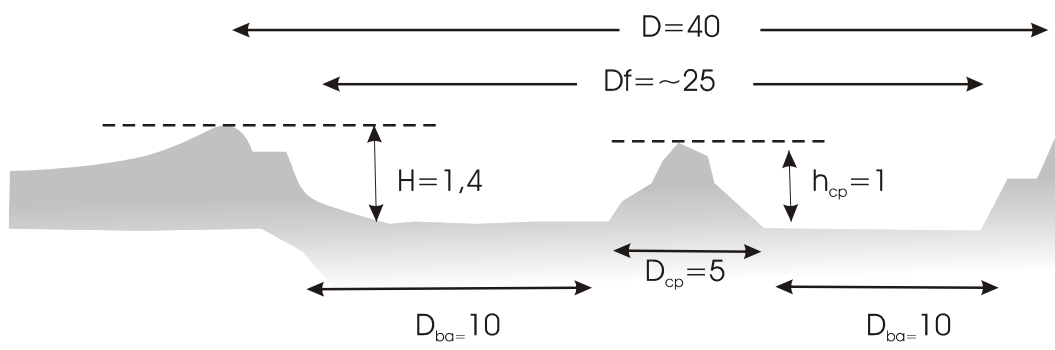

Figura 7.17. Dimensões estimadas para as principais medidas da cratera de Araguainha com base nos modelos gerados. Os valores são apresentados em quilômetros.

\subsection{ESTRUTURA TRIDIMENSIONAL DE ARAGUAINHA}

Como último resultado reuniram-se as informações de diversos perfis de modelamento 2,5D para a confecção de um modelo final 3D de profundidade do embasamento (Figura 7.18). Foram selecionados os perfis mais coerentes nos valores de profundidade e que apresentaram os melhores ajustes dos dados. $O$ intuito deste modelo tridimensional para a estrutura de Araguainha é fomentar uma melhor noção da profundidade do embasamento da estrutura como um todo.

O modelo foi confeccionado a partir das coordenadas e profundidades obtidas de 2,5 em 2,5 km ao longo das linhas modeladas. Para a seleção dos valores de profundidade foram utilizados os seguintes perfis: Perfil 1 conjunto aeromagnético e gravimétrico; Perfil 2 gravimétrico; Perfis 3 e 4 gravimétricos; Perfil 5 conjunto aeromagnético e gravimétrico; Perfis 6 e 7 gravimétricos; Perfil 8 conjunto aeromagnético e gravimétrico; Perfis 9, 10, 11, 13 e 14 gravimétricos.

Com este modelo a simetria de Araguainha é mais realçada e nota-se a região de maior soerguimento da porção centro-sul. Nota-se também a região da bacia anelar, que como citado nas análises anteriores, é a que apresenta maiores profundidades, com valores de cerca de $1,4 \mathrm{~km}$. O soerguimento do NCS também é mais realçado neste modelo. 


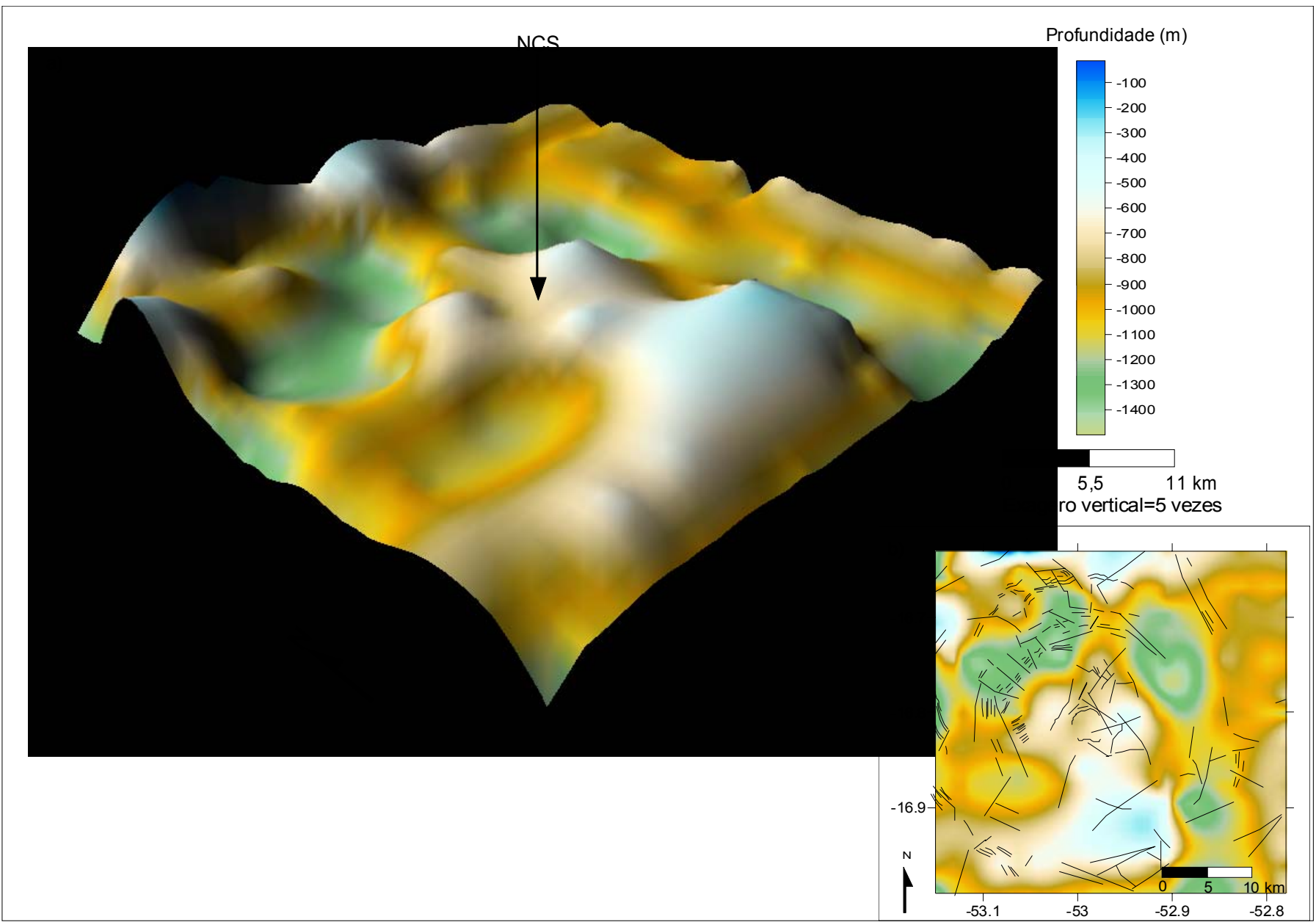

Figura 7.18. (a) Modelo 3D de profundidades do embasamento da estrutura de impacto de Araguainha confeccionado com base nos modelamentos 2,5D. Para obtenção deste resultado utilizaram-se os seguintes perfis: Perfil 1 conjunto aeromagnético e gravimétrico; Perfil 2 gravimétrico; Perfis 3 e 4 gravimétricos: Perfil 5 conjunto aeromagnético e gravimétrico; Perfis 6 e 7 gravimétricos: Perfil 8 conjunto aeromagnético e gravimétrico; Perfis 9 , 10, 11, 13 e 14 gravimétricos. (b) Mapa 2D de profundidades do embasamento sobreposto por lineamentos estruturais. Destaca-se a região do núcleo central soerguido (NCS). As maiores profundidades se apresentam na região da bacia anelar, com cerca de 1,4 km. 


\section{CAPÍTULO 8}

\section{Conclusões}

A maioria dos resultados do modelamento 2,5D mostra-se com ajustes confiáveis e coerentes geologicamente. Os modelos que envolvem dados aeromagnéticos (simples ou conjuntos) não resultaram em bons ajustes para os menores comprimentos de onda. O não ajuste destes menores comprimentos de onda pode estar tanto relacionado à componente regional NE-SW que não foi totalmente removida, como à não correlação entre as fontes gravimétricas e magnéticas, no caso do modelamento conjunto. A primeira hipótese é válida em que pese a região de Araguainha estar na direção dos Lineamentos Transbrasilianos. Para a segunda conjectura deve-se realizar uma análise mais precisa a partir da técnica da Razão de Poisson entre dados magnéticos terrestres e gravimétricos.

Os modelos gravimétricos mostram-se razoavelmente bem ajustados após a remoção da componente regional com o método do polinômio robusto. A partir do cálculo de suas derivadas de segunda ordem delimita-se o contato lateral entre as rochas sedimentares da bacia e o embasamento granítico. Isto confere a estes modelos, ou mesmo aos demais conjuntos que se aproveitam da informação gravimétrica, caráter de alta confiabilidade, pelo menos no que diz respeito à ambigüidade em $x$. A ambigüidade em $z$ é relativamente contornada a partir de vínculos indiretos associados aos modelos. Dentre eles, a informação de modelagem magnetotelúrica de Masero et al. (1994) e o cálculo do espectro de potência realizado neste trabalho ao longo de 78 perfis, que inferem uma profundidade média de $1 \mathrm{~km}$ para o embasamento da região.

Os problemas ocorridos nos magnetômetros de base referente aos dados magnéticos terrestres de forma alguma afetam a obtenção de resultados confiáveis. A correção diurna foi realizada com a transposição de base de outra localidade que mostra alta similaridade aos dias de funcionamento de Araguainha. Os 11 perfis magnéticos terrestres mostram-se muito importantes do ponto de vista da caracterização das regiões de bordas, anéis e núcleo da estrutura, e permitem delimitar o contato entre a brecha polimítica e o EGS. A razão de Konigsberger para amostras do EGS revela pouca influência da componente remanescente. Apesar disso, sua inserção no modelamento mostra-se extremamente importante de forma a delimitar este contato. 
Sugere-se o adensamento dos dados magnéticos terrestres na região central, além de um maior detalhe para a borda sudeste e noroeste, desprovidas destas informações.

A forma das anomalias gravimétricas reflete praticamente a disposição topográfica do embasamento. Este interage com as supracrustais com contatos acidentados e lineares, quando não seccionados por falhas iniciadas no estágio de escavação com continuidade ao estágio de modificação da cratera.

As falhas de colapso gravitacional são observadas em mapa e distintas nos modelos pelas faces lineares dos polígonos. Além destas informações, alguns lineamentos proeminentes são bem marcados nos mapas de derivada e amplitude do sinal analítico. Estas estruturas rúpteis estão dispostas em forma anelar, em pares espelhados nas regiões de borda e bacia anelar, e demonstram provável responsabilidade pelo espessamento dos estratos sedimentares que atingem 1,4 km de profundidade. Resultados de modelamento numérico de Collins et al. (2002) mostram-se similares aos modelos obtidos neste trabalho no que diz respeito a esta região de espessamento. Os autores também a associam a um fluxo de matéria e a regiões de falhas gravitacionais.

Como resposta a esta fase de regime rúptil os sedimentos das regiões de borda são estirados e migrados em direção ao centro e para fora dos limites da cratera. Os sedimentos direcionados para o centro são encurtados por uma tensão horizontal formando as dobras que podem ser observadas nas formações Furnas e Ponta Grossa, e próximos ao núcleo soerguido são verticalizados.

O acervo destas e outras estruturas permite caracterizar Araguainha como portadora de uma deformação rúptil-dúctil, podendo-se diferenciar a principal atuação de cada domínio nas diversas regiões da cratera.

Os resultados também permitem caracterizar Araguainha como uma estrutura concêntrica, e praticamente simétrica no que diz respeito à profundidade do embasamento. Com exceção da borda sul, que se mostra $0,3 \mathrm{~km}$ mais rasa comparada ao restante das regiões, as demais apresentam similaridade em seus valores. Esta assimetria pode auxiliar em posterior entendimento do ângulo de impacto do meteorito, mas necessita-se de informações mais consistentes para esta análise. Não fosse o alto estágio de erosão de Araguainha, a distribuição de ejecta poderia auxiliar nesta argumentação.

Estima-se cerca de 0,3 km de erosão para as regiões mais afetadas da estrutura. Esta informação é inferida de alguns modelos gerados e está dentro do intervalo medido em campo por Lana et al. (2006b). 
Os baixos gravimétrico e magnético de Araguainha são destoantes se comparados a outras crateras complexas do mundo. Modelos magnéticos sintéticos para os dois tipos de crateras assinalam uma assinatura positiva na região soerguida que servem como parâmetro para a aplicação e comparação aos dados reais. O baixo gravimétrico pode ser reflexo do intenso fraturamento, brechação e pela presença de xenólitos de arenitos arcóseos e biotita-muscovita-xistos. Já o baixo magnético é atribuído por Kumar \& Ward (1963) à redução de susceptibilidade devido à uma pressão de choque maior que $10 \mathrm{GPa}$. Já Theilen-Willige (1981) associa este baixo magnético à presença de suevito, fraturas e brechas. Esta característica permite diferenciar duas fácies principais do embasamento com base nas mudanças de propriedades físicas. Sendo assim, o embasamento abaixo dos sedimentos demonstra possuir densidade e susceptibilidade maiores que o embasamento da parte soerguida.

A assinatura gravimétrica permite diferenciar $\mathrm{o}$ soerguimento central de Araguainha em duas regiões complementares. A primeira (NCS - Núcleo Central Soerguido), com soerguimento estimado de $0,4 \mathrm{~km}$, ocorre abaixo das formações Furnas e Ponta Grossa como resposta ao alto gravimétrico circundante ao baixo central. A segunda (EGS - Embasamento Granítico Soerguido), associada ao baixo gravimétrico central, é marcada nos modelos por $1 \mathrm{~km}$ do embasamento junto às brechas, fraturas e xenólitos supracitados. Desta maneira, o soerguimento central total de Araguainha somaria aproximadamente $1,4 \mathrm{~km}$. Esse soerguimento se inicia no estágio de escavação com continuidade ao estágio de modificação da cratera (Melosh, 1989).

Os modelos confirmam cerca de $40 \mathrm{~km}$ para o diâmetro de Araguainha em profundidade, e permitem estimar de 23 a $30 \mathrm{~km}$ para a região da cavidade transiente e $10 \mathrm{~km}$ para a bacia anelar

Dados de susceptibilidade magnética revelam que os sedimentos da bacia não foram magnetizados com o impacto (piezomagnetismo) ou apresentam magnetização de impacto muito fraca. As mesmas amostras foram destinadas às medidas de densidade, que mostram pouca diferença entre os pacotes sedimentares. Entretanto, uma amostragem mais representativa dos sedimentos da bacia deve ser realizada na estrutura.

Os dados gravimétricos também devem ser adensados no interior da estrutura e cerca de $100 \mathrm{~km}$ de distância do núcleo, a fim de se estimar o campo gravimétrico regional com maior confiabilidade. Os modelamentos realizados nas regiões de entorno da estrutura também permitiriam caracterizar o limite de deformação das rochas com o impacto. Informações obtidas de furos de sondagem nas principais regiões da estrutura 
auxiliariam na inserção de vínculos mais confiáveis, diminuindo a ambigüidade dos modelos. Sugere-se também o estudo de métodos de inversão favoráveis ao problema apresentado a fim de corroborar as informações apresentadas.

Ressalta-se que os modelos gerados não são considerados a última palavra na análise de Araguainha; na verdade, muito se tem a fazer ainda nesta estrutura. Para se obter um modelo estrutural com maior acurácia sugere-se a realização de sísmica de reflexão, demonstrado por Pilkington \& Grieve (1992) como método mais eficaz para estruturas de impacto.

Com base nos principais resultados obtidos via modelamento, apresenta-se uma síntese para a estrutura de Araguainha no Apêndice G. 


\section{Referências Bibliográficas}

ANDRADE, F. 2006. Dados magnéticos terrestres cedidos pela AGP-LA, convênio ANP-PoliUSP. Comunicação pessoal.

BHATTACHARYYA, B.K. 1966. Continuous spectrum of the total-magnetic-field anomaly due to a rectangular prismatic body. Geophysics, 31:97-121.

BELTRÃO, J.F., SILVA, J.B.C., COSTA, J.C. 1991. Robust polynomial fitting method for regional gravity estimation. Geophysics, vol. 56 (1): 80-89.

BLAKELY, R.J. 1995. Potential theory in gravity and magnetic applications. Cambridge University Press.

COLLINS, G.S., MELOSH, H., MORGAN, J, AND WARNER, M. 2002. Hydrocode simulations of Chicxulub Crater collapse and peak ring formation: Icarus, v. 157: 24-33.

CORDANI, U.G., BRITO NEVES B.B., FUCK R.A., PORTO R., FILHO A.T., CUNHA F.M. BEZERRA. 1984. Estudo preliminar de integração do Pré-Cambriano com os eventos tectônicos das bacias sedimentares brasileiras. Bol. Ciênc. Técn. Petról.,15:1-70.

COWAN, D.R., COOPER, G.R.J. 2005. Enhancement of magnetic signatures of impact structures. Geological Society of America, special papeer 384, 51-65.

CRÓSTA, A.P., GASPAR; J.C. \& CANDIA, M.A.F. 1981. Feições de metamorfismo de impacto no Domo de Araguainha. Rev. Bras. Geoc., 11: 139-146.

CRÓSTA, A.P. 1999. Domo de Araguainha - O maior astroblema da América do Sul.In: Schobbenhaus, C., Campos, D.A., Queiroz, E.T., Winge, M., Berbert-Born, M.(Edit.). Sítios geológicos e paleontológicos do Brasil. Publicado na Internet no endereço: http://www.unb.br/ig/sigep/sitio001/sitio001.htm.

CRÓSTA, A.P. 2004. Geology and impact features of the Araguainha Astrobleme, states of Mato Grosso and Goiás, Brazil. $67^{\text {th }}$ annual meeting the meteoritical Society.Rio de Janeiro, $21 \mathrm{pp}$.

DEUTSCH, A., GRIEVE, R.A.F., AVERMANN, M., BISCHOFF, L., BROCKMEYER, P. et al. 1995. The Subdury structure ( Ontario, Canada): a tectonically deformed multi-ring basin. Geol. Rundsch. 84: 697-709. 
DOBRIN, M.B. 1960. Introduction to geophysical prospecting, $2^{\text {nd }}$ edition.446pp.

DUARTE, O. 2003. Dicionário eciclopédico Inglês-Português de geologia e geofísica. Sociedade Brasileira de Geofísica, SBGf.

EARTH IMPACT DATABASE (2005): www.unb.ca/passc/lmpactDatabase/index.html

EBBING, J., JANLE, P., K., JANNIS, MILKEREIT, B. 2001. 3D gravity modelling of the Chicxulub impact structure. Planetary and space science 49: 599-609.

EKHOLM, A.G., MELOSH, H.J. 2001. Crater features diagnostic of oblique impacts: The size and position of the central peak. Geophysical research letters., vol 28.4 : 623-636.

ESPINDOLA, J.M., MENA, M., LA FUENTE M. , CAMPOS-ENRIQUEZ, J.O. 1995. A model of the Chicxulub impact structure (Yucatan, México) based on its gravity and magnetic signatures. Physics of the earth and planetary interiors 92: 272-278.

ENGELHARDT, W.VON, MATTHÄI, S.K. \& WALZEBUCK, J. 1992. Araguainha impact crater, Brazil. 1. The interior part of the uplift. Meteoritics, 27: 442-457.

FEATHERSTONE, W.E. \& DENTITH, M.C. 1997. A geodetic approach to gravity data reduction for geophysics. Computers \& Geosc., 23 (10): 1063-1070.

FILHO C.V.P., FERREIRA F. J.F., FILHO E.F.R., ROSTIROLLA S.P. 1995. Compartimentação magnética-estrutural do sistema aqüífero Geral e sua conectividade com o sistema aqüífero Guarani na região central do arco de Ponta Grossa (Bacia do Paraná).Revista brasileira de Geociências. 35 (3): 369-381.

FRENCH, B. M., 1998. Traces of Catastrophe: a Handbook of Shock-metamorphic Effects in Terrestrial Meteorite Impact Structures. Lunar and Planetary Institute, Houston. 130 pp.

GRIEVE, R.A.F., ROBERTSON, P.B., AND DENCE, M. 1981. Constraints on the formation of ring impact structures, based on terrestrial data, in Schultz P. H. and Merrill R. B., eds, Mult-Ring Basins: Formation and Evolution: New York, Pergamon, Lunar and Planetary Science, 791- 814 .

GRIEVE, R.A.F., STÖFFER, D., DEUTSCH, A. 1991. The Subdury structure: controversial or misunderstood. J. Geophys. Res. 96: 22,753-22,764. 
GRIEVE, R., THERRIAULT, A. 2000. Vredefort, Subdury, Chicxulub: Three of a kind?. Annu. Rev. Earth Planet. Sci, 28: 305-38.

HAMMERSCHIMIDT, K. \& ENGELHARDT, W.VON, 1995. ${ }^{40} \mathrm{Ar} /{ }^{39} \mathrm{Ar}$ dating of the Araguainha impact structure, Mato Grosso, Brazil. Meteoritics, 30: 227-233.

HART, R.J., CONELL, S.H. , CLOETE, M. , MARE, L., DRUNY,M. , TREDOUX, M. 2000. Super magnetic rocks generated by shock metamorphism from the centre of the vrefort impact structure, South Africa. S.Afr.J.Geol., 103(2): 151-155.

HENKEL, H., REIMOLD, W.U. 1998. Integrated geophysical modelling of a giant, complex impact structure:anatomy of the Vrefort Structure, South Africa.Tectonophysics 287:b1-20.

HENKEL, H., REIMOLD, W.U. 2002. Magnetic model of the central uplift of the Vrefort impact structure, South Africa. Journal of Applied Geophysics 51: 43-62.

HENKEL, H., REIMOLD, W.U. , KOEBERL, C. 2002. Magnetic and gravity model of the Morokweng impact structure. Journal of Applied Geophysics 49: 129-147.

HIPPERT, J. \& LANA, C. 1998. Aerial crystallization of hematite in impact bombs from the Araguainha astrobleme, Mato Grosso, central Brazil. Meteoritics \& Planetary Science, 33: 1303-1309.

Ivanov, B.A.. Numerical Modeling of the Largest terrestrial meteorite craters. Solar System Research, 39, n 5, pp.381-409.

JUHLIN, C., PEDERSEN, L.B. 1987. Reflection seismic investigations of the Siljan impact structure, Sweden. Journal of geophysical research. vol. 92: 14,113-14,122.

LANA, C. 2007. Informações acerca das estruturas existentes em Araguainha. University of Stellenbosch. Comunicação pessoal.

LANA, C., ROMANO, R., REIMOLD, UWE, HIPPERTT, J. 2006a. Collapse of large complex impact craters: Implications from the Araguainha impact structure, central Brazil. Geology, vol. 34;1: 9-12.

LANA, C., SOUZA FILHO, C.R., MARANGONI, Y.R., YOKOYAMA, E., TRINDADE, R.I.F., TOHVER, E., REIMOLD, W.U. 2006b. The Araguainha impact structure, central Brazil: a shallowly eroded peak-ring structure. Submeted in GSA Bulletin. 
MANTESSO NETO, V., et al. 2004. Geologia do continente sul-americano: evolução da obra de Fernando Marques de Almeida. Ed. Beca. São Paulo/SP. 647p.

MASERO, W., SCHENEGG, P.A. \& FONTES, S.L. 1994. A magnetotelluric investigation of the Araguainha impact structure in Mato Grosso-Goiás, central Brazil. Geophys. J. Int., 116: 366-376.

MASERO, W., FISCHER, G. \& SCHNEGG, PA. 1997. Electrical condutivity and crustal deformation from magnetotelluric results in the region of the Araguainha impact, Brazil. Phys. Earth Planet. Inter., 101: 271-289.

MELFI A.F., PICCIRILLO E.M., NARDY A.J.R. 1988 in:The Mesozoic food volcanism od the Paraná basin: petrogenetic and geophysical aspects. E.M. Piccirillo, A.L. Melfi. Sao Paulo. Univesidade de Sao Paulo, Instituto Astronômico e Geofísico: 1-13.

MELOSH, H. J., 1989. Impact cratering: A geologic process. Oxford University Press, New York.

MELOSH, H. J., IVANOV, B.A.1999. IMPACT CRATER COLLAPSE. Annu Rev. Earth Planet. Sci, 385-415.

MENDONÇA, C.A., 2066. IAG/USP. Rotina para o cálculo de anomalias magnéticas associadas a dados sintéticos. Comunicação pessoal.

MILANI, E.J. 1997. Evolução tectono-estratigráfica da Bacia do Paraná e seu relacionamento com a geodinâmica fanerozóica do Gondwana sul-ocidental. Instituto de Geociênicias, Universidade Federal do Rio Grande do Sul. Tese de doutoramento, 255p.

MILANI, E. J., ZALAN, P. V. 1999. An outline of the geologyand petroleum systems of the Paleozoic interior basins of South America: Episodes, v. 22: 199-205.

MILLIGAN, P.R., GUNN, P.J. 1997. Enhancement and presentation of airbone geophysical data. Journal of Australian Geology 7. Geophysics, 17(2): 63-75.

MOLINA, E.C., USSAMI, N., SÁ, N.C., BLITZKOW, D. 1989. Interpretação dos dados gravimétricos da parte norte da Bacia do Parná. RBG 19 (2): 187-196. 
MORGAN, J. V., WARNER, M. R., COLLINS, G. S., MELOSH, H. J., AND CHRISTESON, G. L. 2000. Peak ring formation in large impact craters: Earth and Planetary Science Letters, vol. 183: 347-354.

MORITZ, H. 1984. Geodetic Reference System 1980. In: C.C. Tscherning (ed.). The Geodesist's Handbook 1984 - Bull. Géod. 58: 388-398.

MOTTA, C.M. \& BARRETO, L.M. 1992. Campo geomagnético normal e sua variação secular no Brasil em 1985.CNPq-Observatório Nacional (ON), Rio de Janeiro, 48p.

O'KEEFE, J.D. \& AHRENS, T.J. 1999. Complex craters: Relationships of stratigraphy and rings to impact conditions. J. Geophys. Res., 104(E11): 27,091-27,104.

PILKINGTON, M. \& GRIEVE, R.A.F. 1992. The geophysical signature of terrestrial impact craters. Rev. Geophys., 30(2): 161-181.

PILKINGTON, M., HILDEBRAND, A.R. 2000. Three-dimensional magnetic imaging of the Chicxulub crater. Journal of geophysical research, 105: 23,479-23,491

PILKINGTON, M. \& HILDEBRAND, A.R. 2003. Transient and disruption cavity dimensions of complex terrestrial impact structures derived from magnetic data. Geophys. Res. Lett., 30(21): art. 2087.

POHL, J., U., B., HORNEMANN, U. 1975. Shock magnetization and demagnetization of basalt by transient stress up to 10 kbar. J. Geophys., 41: 23-41.

PROSPEC S.A. Projeto Alto Garças: Levantamento Aerogeofísico. 1972. Ministério das Minas e Energia, Comissão Nacional de Energia Nuclear-CNEN, Departamento Nacional de Produção Mineral_DNPM, Companhia de Pesquisa de Recursos Minerais-CPRM, convênio CNEN/DNPM/CPRM. Relatório Final, Rio de Janeiro.

RAJASEKHAR R.P., MISHRA D. C. 2005. Analysis of gravity and magnetic anomalies over Lonar Lake, Índia: Na impact crater in a basalt province. Current Science, vol 88, $\mathrm{n}^{\circ} 11$.

RASMUSSEN, R., PEDERSEN, L.B. 1979. End Corrections in potential field modeling. Geophysical Prospecting, 27: 749-760. 
SÁ, N.C. de. 2004. O campo de gravidade, o geóide e a estrutura crustal na América do Sul. Tese de livre-docência, IAG-USP, São Paulo, 121 pp.

SCHERLER, D., KENKMANN, T. , JAHN, A. 2006. Structural record of an oblique impact. Earth and planetary science letters 248:43-53.

SCHNEGG, P-A., FONTES, S.L., 2002. Feasibility study of the geoelectric structure of the Araguainha impact, Brazil. Earth Planets Space, 54: 597-606.

SCHOBBENHAUS C. 1975. Carta Geológica do Brasil ao Milionésimo.Brasília, DNPM

SCHULTZ, P.H., D'HONDT, S. 1996. Cretaceous-Tertiary (Chicxulub) impact angle and its consequences. Geology. vol. 24 (11): 963-967.

SHUEY, R.T., PASQUALE, A.S. 1973. End corrections ins magnetic profile interpretation. Geophysics, vol 38 (3): 507-512.

SHUKOWSKY, W. 2000. IAG/USP. Rotina desenvolvida em Matlab com base na teoria de ajuste polinomial Robusto. Comunicação pessoal.

SHUKOWSKY, W. 2006. IAG/USP. Rotina desenvolvida em Matlab para o cálculo de derivadas verticais e limitação de fontes anômalas. Comunicação pessoal.

SOUZA FILHO, C.A. 2006. Imagem do satélite Landsat TM com bandas 4, 5 e 7 fundidas à banda 8. Comunicação pessoal.

SPECTOR, A., GRANT, F.S. 1970. Statistical models for interpreting aeromagnetic data. Geophysics, vol. 35 (2): 293-302.

TAWANI, M. WORZEL, J.L. , LANDISMAN, M. 1959. Rapid gravity computations for twodimensional bodies with application to the Mendocino submarine fracture zone. Journal of Geophysical Research, 64: 49-59.

TELFORD, W.M., GELDART, L.P, SHERIFF, R.E., KEYS, D.A. 1990. Applied Geophysics, Cambridge University Press. 860pp.

THEILEN-WILLIGE, B. 1981. The Araguainha impact structure, Central Brazil. Rev. Bras. Geociências, 11: 91-97. 
TSIKALAS, F., GUDLAUGSSON, S.T., ELDHOLM, O., FALEIDE, J.I. 1998. Integrated geophysical analysis supporting the impact origin of the Mjolnir structure, Barents Sea. Tectonophysics 289:257-280.

TSIKALAS, F., GUDLAUGSSON, S.T., FALEIDE, J.I., ELDHOLM, O. 2002. The Mjolnir marine impact crater porosity anomaly. Deep-sea research vol 49: 1103-1120.

TUMA, S.L. 2006. Inversão por etapas de anomalias magnéticas bi-dimensionais.Tese de doutoramento, Instituto de Astronomia, Geofísica e Ciências atmosféricas, Universidade ed São Paulo, IAG/USP.

WIELAND, F., GIBSON, R.L., AND REIMOLD, W.U. 2005, Structural analysis of the collar of the Vredefort Dome, South Africa-Significance for impact-related deformation and central uplift formation: Meteoritics \& Planetary Science, vol. 40: 1537-1554.

YOKOYAMA, E. 2006.Informações cedidas via comunicação pessoal integrantes da dissertação de mestrado em andamento:Magnetismo da estrutura de impacto de Araguainha, MT/GO, IAG/USP.Comunicação pessoal. 


\section{Lista de Apêndices}

\begin{tabular}{|c|c|c|}
\hline Apêndice A - & 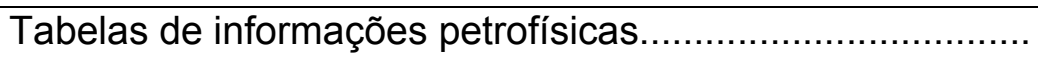 & 125 \\
\hline Apêndice B - & Modelos gravimétricos.. & 143 \\
\hline Apêndice C - & Modelos aeromagnéticos... & 146 \\
\hline Apêndice D - & 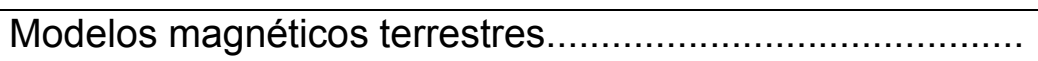 & 149 \\
\hline Apêndice E - & 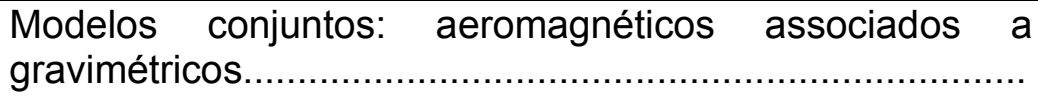 & 152 \\
\hline Apêndice F - & $\begin{array}{l}\text { Modelos conjuntos: magnéticos terrestres associados a } \\
\text { gravimétricos.. }\end{array}$ & 155 \\
\hline Apêndice G - & $\begin{array}{l}\text { Mapa síntese dos modelos geológicos finais propostos } \\
\text { para Araguainha... }\end{array}$ & 158 \\
\hline
\end{tabular}




\section{UNIVERSIDADE DE SÃO PAULO \\ INSTITUTO DE ASTRONOMIA, GEOFÍSICA E CIÊNCIAS \\ ATMOSFÉRICAS-IAG.}

\section{APÊNDICE A \\ TABELAS DE INFORMAÇÕES PETROFÍSICAS}

São Paulo

2007 
Tabela A.1- Valores de densidade para amostras do embasamento granítico soerguido - EGS.

\begin{tabular}{|c|c|c|}
\hline Amostra & Densidade $\left(\mathrm{g} / \mathrm{cm}^{3}\right)$ & Litotipo \\
\hline AE 24 B3 & 2,451 & G \\
\hline $\mathrm{AE} 11 \mathrm{C} 4$ & 2,457 & G \\
\hline $\mathrm{AE} 10 \mathrm{~A}$ & 2,475 & G \\
\hline $\mathrm{AE} 19 \mathrm{~A} 1$ & 2,478 & G \\
\hline $\mathrm{AE} 13$ & 2,456 & G \\
\hline $\mathrm{AE} 16$ & 2,343 & $\mathrm{G}$ \\
\hline AE $26 \mathrm{C} 3$ & 2,482 & G \\
\hline $\mathrm{AE} 17$ & 2,426 & G \\
\hline $\mathrm{AE} 13$ & 2,410 & G \\
\hline AE 20 & 2,474 & G \\
\hline$A E 9 A 3$ & 2,425 & G \\
\hline AE 23 & 2,480 & $\mathrm{G}$ \\
\hline $\mathrm{AE} 18 \mathrm{C} 4$ & 2,439 & G \\
\hline AE 23 & 2,473 & G \\
\hline $\mathrm{AE} 11 \mathrm{~A} 3$ & 2,442 & G \\
\hline AE 25 & 2,432 & $\mathrm{G}$ \\
\hline$A E 18$ A3 & 2,512 & G \\
\hline AE 22 A2 & 2,492 & G \\
\hline $\mathrm{AE} 22 \mathrm{C} 3$ & 2,477 & G \\
\hline $\mathrm{AE} 24$ & 2,408 & G \\
\hline AE 26 A3 & 2,486 & G \\
\hline$A E 15 A 3$ & 2,439 & $\mathrm{G}$ \\
\hline AE $19 \mathrm{D} 3$ & 2,428 & G \\
\hline AE 9 D4 & 2,478 & G \\
\hline AE 10 & 2,466 & G \\
\hline $\mathrm{AE} 12 \mathrm{D} 4$ & 2,480 & G \\
\hline $\mathrm{AE} 21 \mathrm{C} 2$ & 2,448 & Pst \\
\hline$A E 21 A 3$ & 2,389 & Pst \\
\hline AE 14 D3 & 2,361 & G \\
\hline $\mathrm{AE} 13 \mathrm{~A} 3$ & 2,447 & Pst \\
\hline $\mathrm{AE} 15$ & 2,448 & G \\
\hline$A E 12 A 2$ & 2,363 & Pst \\
\hline
\end{tabular}

G: Granito; Pst: Pseudotaquilito;

Valor de densidade média: $(2,450 \pm 0,007) \mathrm{g} / \mathrm{cm}^{3}$.

$\left.{ }^{1}\right)$ Amostras cedidas pelo mestrando Elder Yokoyama, IAG/USP. 
Tabela A. $\mathbf{2}^{1}$ - Valores de densidade e susceptibilidade magnética na fácies ferruginosa da Formação Ponta Grossa.

\begin{tabular}{|c|c|c|}
\hline Amostra & Densidade $\left(\mathrm{g} / \mathrm{cm}^{3}\right)$ & $\mathrm{K}(\mathrm{SI}) \cdot 10^{-5}$ \\
\hline AE 65 IV1 & 3,085 & 25,16 \\
\hline AE 65 IV2 & 3,158 & 45,96 \\
\hline AE 65 IV3 & 3,152 & 28,92 \\
\hline AE 65 IV 4 & 3,021 & 43,4 \\
\hline AE 65 IV5 & 3,161 & 26,50 \\
\hline AE 65 IV 6 & 3,118 & 25,90 \\
\hline AE 65 IV7 & 3,186 & 50,75 \\
\hline AE 65 IV8 & 3,183 & 37,46 \\
\hline
\end{tabular}

K: susceptibilidade magnética

Valor de densidade média: $(3,133 \pm 0,056) \mathrm{g} / \mathrm{cm}^{3}$.

$\left({ }^{1}\right)$ Amostras cedidas pelo mestrando Elder Yokoyama, IAG/USP.

Tabela A. $3^{1}$ - Valores de densidade e susceptibilidade magnética em arenitos da Formação Furnas.

\begin{tabular}{lcc}
\hline Amostra & Densidade $\left(\mathbf{g} / \mathbf{c m}^{\mathbf{3}}\right)$ & $\mathbf{K} \mathbf{( S I )} \cdot \mathbf{1 0 ^ { - 5 }}$ \\
\hline AE 70 A1 & --- & 4,4 \\
AE 70 A2 & --- & 4,7 \\
AE 70 A3 & --- & 4,2 \\
AE 70 A4 & 2,180 & 5,2 \\
AE 70 B1 & 2,214 & 3,7 \\
AE 70 B2 & --- & 5,7 \\
AE 70 B3 & --- & 6,0 \\
AE 70 B4 & 2,194 & 5,1 \\
AE 70 C1 & 2,163 & 4,1 \\
AE 70 C2 & --- & 4,6 \\
AE 70 D1 & 2,325 & 3,3 \\
AE 70 D2 & --- & 10,6 \\
AE 70 D3 & --- & 7,8 \\
\hline
\end{tabular}

K:susceptibilidade magnética

Valor de densidade média: $(2,215 \pm 0,028) \mathrm{g} / \mathrm{cm}^{3}$.

( ${ }^{1}$ ) Amostras cedidas pelo mestrando Elder Yokoyama, IAG/USP. 
Tabela A.4 ${ }^{1}$ - Valores de densidade e susceptibilidade magnética em arenitos da Formação Aquidauana.

\begin{tabular}{ccc}
\hline Amostra & Densidade $\left(\mathbf{g} / \mathbf{c m}^{\mathbf{3}}\right)$ & $\mathbf{K}(\mathbf{S I}) \cdot \mathbf{1 0 ^ { - 5 }}$ \\
\hline AE 49 A 1 & 2,419 & 1,8 \\
AE 49 A 2 & 2,445 & 1,4 \\
AE 49 A 3 & 2,452 & 1,2 \\
AE 49 A 4 & --- & 1,4 \\
AE 49 B 1 & 2,474 & 1,3 \\
AE 49 B 2 & 2,433 & 0,7 \\
AE 49 C 1 & 2,362 & 1,2 \\
AE 49 C 2 & --- & 1,8 \\
AE 49 C 3 & 2,412 & 1,2 \\
AE 49 C 4 & --- & 1,2 \\
AE 49 D 1 & 2,270 & 1,1 \\
AE 49 D 2 & 2,307 & 1,3 \\
AE 49 D 3 & --- & 0,9 \\
AE 49 D 4 & 2,322 & 1,0 \\
AE 49 E 1 & 2,312 & 1,0 \\
AE 49 E 2 & --- & 1,2 \\
AE 49 E 3 & 2,308 & 1,4 \\
AE 49 E 4 & --- & 1,0 \\
AE 49 F 1 & --- & 2,6 \\
AE 49 F 2 & 2,274 & 2,1 \\
AE 49 F 3 & --- & 1,6 \\
AE 49 F 4 & -- & 1,1 \\
AE51F & 2,277 & --- \\
\hline
\end{tabular}


Tabela A. $5^{1}$ - Valores de densidade dos siltitos carbonáticos da Formação Irati.

\begin{tabular}{cc}
\hline Amostra & Densidade $\left(\mathbf{g} / \mathbf{c m}^{3}\right)$ \\
\hline AE 66 C1 & ${ }^{*} 2,157$ \\
AE 66 C2 & ${ }^{*} 2,150$ \\
AE 66 C3 & 2,223 \\
AE 66 C4 & 2,190 \\
AE 66 F1 & 2,214 \\
AE 66 F2 & 2,225 \\
AE 66 F3 & 2,230 \\
AE 66 F4 & 2,215 \\
\hline K: susceptibilidade magnética; .( $\left.{ }^{*}\right)$ valores desconsiderados \\
para cálculos da média e desvio padrão \\
Valor de densidade média: $(2,216 \pm 0,005)$ g/cm ${ }^{3}$. \\
${ }^{1}{ }^{1}$ Amostras cedidas pelo mestrando Elder Yokoyama, \\
IAG/USP. \\
\hline
\end{tabular}

Tabela A.6 ${ }^{1}$ - Valores de susceptibilidades magnéticas de amostras do granito (embasamento granítico soerguido - EGS).

\begin{tabular}{lc}
\hline Amostra & $\mathbf{K}(\mathbf{S I})$ \\
\hline AE-6A2 & 0,001658 \\
AE-2A1 & 0,001374 \\
AE-2A2 & 0,001566 \\
AE-2A3 & 0,001374 \\
AE-2A4 & 0,001519 \\
AE-2B1 & 0,001501 \\
AE-2B2 & 0,001703 \\
AE-2B3 & 0,001458 \\
AE-2B4 & 0,001901 \\
AE-2C1 & 0,001588 \\
AE-2C2 & 0,001765 \\
AE-2C3 & 0,00176 \\
AE-2C4 & 0,001729 \\
AE-3A1 & 0,002635 \\
AE-3A2 & 0,002875 \\
AE-3A3 & 0,002461 \\
AE-3A4 & 0,002245 \\
AE-3B1 & 0,001952 \\
AE-3B2 & 0,002203 \\
AE-3B3 & 0,002061 \\
\hline
\end{tabular}




\section{Continuação}

Tabela A.6 ${ }^{1}$ - Valores de susceptibilidades magnéticas de amostras do granito (embasamento granítico soerguido - EGS).

$\begin{array}{lc}\text { AE-3B4 } & 0,001794 \\ \text { AE-3C1 } & 0,002713 \\ \text { AE-3C2 } & 0,002543 \\ \text { AE-3C3 } & 0,002748 \\ \text { AE-3C4 } & 0,002421 \\ \text { AE-4A1 } & 0,002688 \\ \text { AE-4A2 } & 0,002484 \\ \text { AE-4A3 } & 0,00244 \\ \text { AE-4B1 } & 0,002235 \\ \text { AE-4B2 } & 0,002352 \\ \text { AE-5A1 } & 0,002722 \\ \text { AE-5A2 } & 0,002402 \\ \text { AE-5A3 } & 0,001855 \\ \text { AE-5A4 } & 0,002394 \\ \text { AE-5B1 } & 0,001887 \\ \text { AE-5B2 } & 0,002136 \\ \text { AE-5B3 } & 0,001666 \\ \text { AE-5C1 } & 0,002408 \\ \text { AE-5C2 } & 0,00258 \\ \text { AE-5C3 } & 0,002164 \\ \text { AE-6A1 } & 0,002054 \\ \text { AE-6B } & 0,0006806 \\ \text { AE-6G1 } & 0,002098 \\ \text { AE-6G2 } & 0,002263 \\ \text { AE-6G3 } & 0,001466 \\ \text { AE-7A1 } & 0,001899 \\ \text { AE-7A2 } & 0,001967 \\ \text { AE-7A3 } & 0,001511 \\ \text { AE-7B1 } & 0,002233 \\ \text { AE-7B2 } & 0,002441 \\ \text { AE-7B3 } & 0,002406 \\ \text { AE-7B4 } & 0,002501 \\ \text { AE-7C1 } & 0,002488 \\ \text { AE-7C2 } & 0,002821 \\ \text { AE-7C3 } & 0,002512 \\ \text { AE-7C4 } & 0,002464 \\ \text { AE-7D1 } & 0,002829 \\ \text { AE-7D2 } & 0,003039 \\ \text { AE-7D3 } & 0,002211 \\ \text { AE-9A1 } & 0,00324 \\ \text { AE-9A2 } & 003503 \\ \text { AE-9A3 } & \\ \text { AE-9A4 } & \end{array}$




\section{Continuação}

Tabela A.6 ${ }^{1}$ - Valores de susceptibilidades magnéticas de amostras do granito (embasamento granítico soerguido - EGS).

$\begin{array}{lc}\text { AE-9A5 } & 0,003803 \\ \text { AE-9C1 } & 0,00312 \\ \text { AE-9C2 } & 0,004596 \\ \text { AE-9C3 } & 0,004251 \\ \text { AE-9C4 } & 0,004071 \\ \text { AE-9D1 } & 0,002299 \\ \text { AE-9D2 } & 0,00319 \\ \text { AE-9D3 } & 0,002795 \\ \text { AE-9D4 } & 0,003752 \\ \text { AE-9E1 } & 0,002626 \\ \text { AE-9E2 } & 0,002710 \\ \text { AE-9E3 } & 0,00259 \\ \text { AE-9E4 } & 0,001807 \\ \text { AE-10A1 } & 0,002012 \\ \text { AE-10A2 } & 0,001635 \\ \text { AE-10A3 } & 0,001743 \\ \text { AE-10A4 } & 0,001293 \\ \text { AE-10A5 } & 0,001216 \\ \text { AE-10B1 } & 0,001485 \\ \text { AE-10B2 } & 0,001759 \\ \text { AE-10B3 } & 0,002003 \\ \text { AE-10C1 } & 0,001509 \\ \text { AE-10C2 } & 0,00165 \\ \text { AE-10C3 } & 0,001727 \\ \text { AE-10C4 } & 0,001434 \\ \text { AE-10C5 } & 0,001556 \\ \text { AE-11A1 } & 0,002227 \\ \text { AE-11A2 } & 0,001945 \\ \text { AE-11A3 } & 0,001731 \\ \text { AE-11A4 } & 0,002184 \\ \text { AE-11B1 } & 0,002100 \\ \text { AE-11B2 } & 0,002187 \\ \text { AE-11B3 } & 0,003295 \\ \text { AE-11B4 } & 0,002675 \\ \text { AE-11C1 } & 0,002092 \\ \text { AE-11C2 } & 0,001651 \\ \text { AE-11C3 } & 0,001256 \\ \text { AE-11C4 } & 0,001308 \\ \text { AE-12B1 } & 0,003412 \\ \text { AE-12B2 } & 0,004224 \\ \text { AE-12B3 } & 0,003701 \\ \text { AE-12C1 } & 0,004678 \\ \text { AE-12C2 } & \\ & 0,0454\end{array}$




\section{Continuação}

Tabela A.6 ${ }^{1}$ - Valores de susceptibilidades magnéticas de amostras do granito (embasamento granítico soerguido - EGS).

$\begin{array}{lc}\text { AE-12D1 } & 0,004721 \\ \text { AE-12D2 } & 0,003956 \\ \text { AE-12D3 } & 0,003592 \\ \text { AE-12D4 } & 0,004713 \\ \text { AE-13B1 } & 0,002695 \\ \text { AE-13B2 } & 0,002543 \\ \text { AE-13B3 } & 0,002457 \\ \text { AE-13C1 } & 0,002322 \\ \text { AE-13C2 } & 0,003003 \\ \text { AE-13C3 } & 0,002191 \\ \text { AE-14B1 } & 0,003197 \\ \text { AE-14B2 } & 0,002405 \\ \text { AE-14B3 } & 0,002459 \\ \text { AE-14D1 } & 0,004341 \\ \text { AE-14D2 } & 0,004737 \\ \text { AE-14D3 } & 0,004931 \\ \text { AE-15A1 } & 0,001957 \\ \text { AE-15A2 } & 0,002269 \\ \text { AE-15A3 } & 0,002302 \\ \text { AE-15B1 } & 0,002216 \\ \text { AE-15B2 } & 0,001938 \\ \text { AE-15B3 } & 0,001835 \\ \text { AE-15C1 } & 0,00211 \\ \text { AE-15C2 } & 0,002516 \\ \text { AE-16A1 } & 0,001857 \\ \text { AE-16A2 } & 0,002738 \\ \text { AE-16B1 } & 0,002849 \\ \text { AE-16B2 } & 0,002508 \\ \text { AE-16C1 } & 0,0027 \\ \text { AE-16C2 } & 0,002291 \\ \text { AE-16C3 } & 0,002284 \\ \text { AE-16C4 } & 0,002686 \\ \text { AE-17A1 } & 0,002611 \\ \text { AE-17A2 } & 0,002511 \\ \text { AE-17A3 } & 0,00244 \\ \text { AE-17B1 } & 0,002393 \\ \text { AE-17B2 } & 0,002255 \\ \text { AE-17B3 } & 0,002013 \\ \text { AE-17B4 } & 0,003364 \\ \text { AE-17C1 } & 0,002689 \\ \text { AE-17C2 } & 0,00249 \\ \text { AE-17C3 } & 0,0210 \\ \text { AE-17C4 } & \end{array}$




\section{Continuação}

Tabela A.6 ${ }^{1}$ - Valores de susceptibilidades magnéticas de amostras do granito (embasamento granítico soerguido - EGS).

$\begin{array}{lc}\text { AE-18A1 } & 0,002454 \\ \text { AE-18A2 } & 0,001951 \\ \text { AE-18A3 } & 0,002706 \\ \text { AE-18B1 } & 0,002707 \\ \text { AE-18B2 } & 0,002059 \\ \text { AE-18B3 } & 0,002422 \\ \text { AE-18B4 } & 0,002624 \\ \text { AE-18C1 } & 0,00159 \\ \text { AE-18C2 } & 0,002151 \\ \text { AE-18C3 } & 0,002657 \\ \text { AE-18C4 } & 0,002143 \\ \text { AE-19A1 } & 0,003019 \\ \text { AE-19A2 } & 0,00309 \\ \text { AE-19A3 } & 0,002823 \\ \text { AE-19A4 } & 0,002462 \\ \text { AE-19B1 } & 0,002607 \\ \text { AE-19B2 } & 0,002583 \\ \text { AE-19E1 } & 0,002467 \\ \text { AE-19E2 } & 0,002684 \\ \text { AE-19E3 } & 0,002643 \\ \text { AE-19E4 } & 0,002597 \\ \text { AE-20A1 } & 0,002362 \\ \text { AE-20A2 } & 0,002591 \\ \text { AE-20A3 } & 0,002905 \\ \text { AE-20B1 } & 0,002476 \\ \text { AE-20B2 } & 0,002553 \\ \text { AE-20B3 } & 0,002695 \\ \text { AE-20C1 } & 0,00245 \\ \text { AE-20C2 } & 0,002639 \\ \text { AE-20C3 } & 0,002525 \\ \text { AE-22A1 } & 0,00415 \\ \text { AE-22B1 } & 0,00432 \\ \text { AE-22B2 } & 0,003636 \\ \text { AE-22C1 } & 0,005346 \\ \text { AE-22C2 } & 0,008289 \\ \text { AE-22C3 } & 0,005816 \\ \text { AE-23A1 } & 0,00206 \\ \text { AE-23A2 } & 0,002186 \\ \text { AE-23A3 } & 0,001961 \\ \text { AE-23B1 } & 0,001754 \\ \text { AE-23B2 } & 0,002096 \\ \text { AE-23B3 } & 0,01758 \\ \text { AE-23C1 } & \\ & \end{array}$




\section{Continuação}

Tabela A.6 ${ }^{1}$ - Valores de susceptibilidades magnéticas de amostras do granito (embasamento granítico soerguido - EGS).

$\begin{array}{lc}\text { AE-23C2 } & 0,002594 \\ \text { AE-23C3 } & 0,002292 \\ \text { AE-24A1 } & 0,001848 \\ \text { AE-24A2 } & 0,002134 \\ \text { AE-24A3 } & 0,001906 \\ \text { AE-24B1 } & 0,001918 \\ \text { AE-24B2 } & 0,002105 \\ \text { AE-24B3 } & 0,002072 \\ \text { AE-24C1 } & 0,001837 \\ \text { AE-24C2 } & 0,001774 \\ \text { AE-25C1 } & 0,002283 \\ \text { AE-25C2 } & 0,002319 \\ \text { AE-25C3 } & 0,002718 \\ \text { AE-25D1 } & 0,003885 \\ \text { AE-25D2 } & 0,002378 \\ \text { AE-25D3 } & 0,002448 \\ \text { AE-25E1 } & 0,002178 \\ \text { AE-25E2 } & 0,002288 \\ \text { AE-25E3 } & 0,001639 \\ \text { AE-25E4 } & 0,001728 \\ \text { AE-26A1 } & 0,001584 \\ \text { AE-26A2 } & 0,00157 \\ \text { AE-26A3 } & 0,00167 \\ \text { AE-26B1 } & 0,001693 \\ \text { AE-26B2 } & 0,001501 \\ \text { AE-26B3 } & 0,001717 \\ \text { AE-27A2 } & 0,003175 \\ \text { AE-27A3 } & 0,003537 \\ \text { AE-27B1 } & 0,002067 \\ \text { AE-27B2 } & 0,002931 \\ \text { AE-27B3 } & 0,002653 \\ \text { AE-29A1 } & 0,004612 \\ \text { AE-29A2 } & 0,00394 \\ \text { AE-29A3 } & 0,004069 \\ \text { AE-29B1 } & 0,00158 \\ \text { AE-29B2 } & 0,001189 \\ \text { AE-29B3 } & 0,001874 \\ \text { AE-29B4 } & 0,002282 \\ \text { AE-29C1 } & 0,004116 \\ \text { AE-29C2 } & 0,003058 \\ \text { AE-29C3 } & 0,00337 \\ \text { AE-29C4 } & \text { AE-30C1 } \\ & 00413 \\ & \end{array}$




\section{Continuação}

Tabela A.6 ${ }^{1}$ - Valores de susceptibilidades magnéticas de amostras do granito (embasamento granítico soerguido - EGS).

$\begin{array}{lc}\text { AE-30C2 } & 0,002057 \\ \text { AE-30C4 } & 0,001844 \\ \text { AE-30D1 } & 0,002654 \\ \text { AE-30D2 } & 0,002252 \\ \text { AE-30D3 } & 0,001761 \\ \text { AE-30D4 } & 0,001707 \\ \text { AE-30E1 } & 0,002037 \\ \text { AE-30E2 } & 0,001971 \\ \text { AE-30E3 } & 0,001436 \\ \text { AE-31A1 } & 0,002193 \\ \text { AE-31A2 } & 0,00164 \\ \text { AE-31A3 } & 0,001736 \\ \text { AE-31B1 } & 0,002191 \\ \text { AE-31B2 } & 0,001788 \\ \text { AE-31B3 } & 0,001863 \\ \text { AE-31B4 } & 0,00172 \\ \text { AE-31C1 } & 0,001107 \\ \text { AE-31C2 } & 0,001517 \\ \text { AE-31C3 } & 0,001883 \\ \text { AE-32A1 } & 0,001141 \\ \text { AE-32A2 } & 0,001219 \\ \text { AE-32A3 } & 0,001307 \\ \text { AE-32A4 } & 0,001302 \\ \text { AE-32B1 } & 0,00138 \\ \text { AE-32B2 } & 0,001272 \\ \text { AE-32B3 } & 0,001345 \\ \text { AE-32B4 } & 0,001121 \\ \text { AE-32C1 } & 0,001377 \\ \text { AE-32C2 } & 0,001152 \\ \text { AE-33B1 } & 0,001808 \\ \text { AE-33B2 } & 0,001557 \\ \text { AE-33B3 } & 0,001421 \\ \text { AE-33B4 } & 0,001955 \\ \text { AE-33C1 } & 0,001876 \\ \text { AE-33C2 } & 0,001684 \\ \text { AE-33C3 } & 0,001740 \\ \text { AE-34C1 } & 0,0009614 \\ \text { AE-34C2 } & 0,001307 \\ \text { AE-34C3 } & 0,001296 \\ \text { AE-34D1 } & 001957 \\ \text { AE-34D2 } & \text { AE-34D3 } \\ \text { AE-34D4 } & \end{array}$




\section{Continuação}

Tabela A.6 ${ }^{1}$ - Valores de susceptibilidades magnéticas de amostras do granito (embasamento granítico soerguido - EGS).

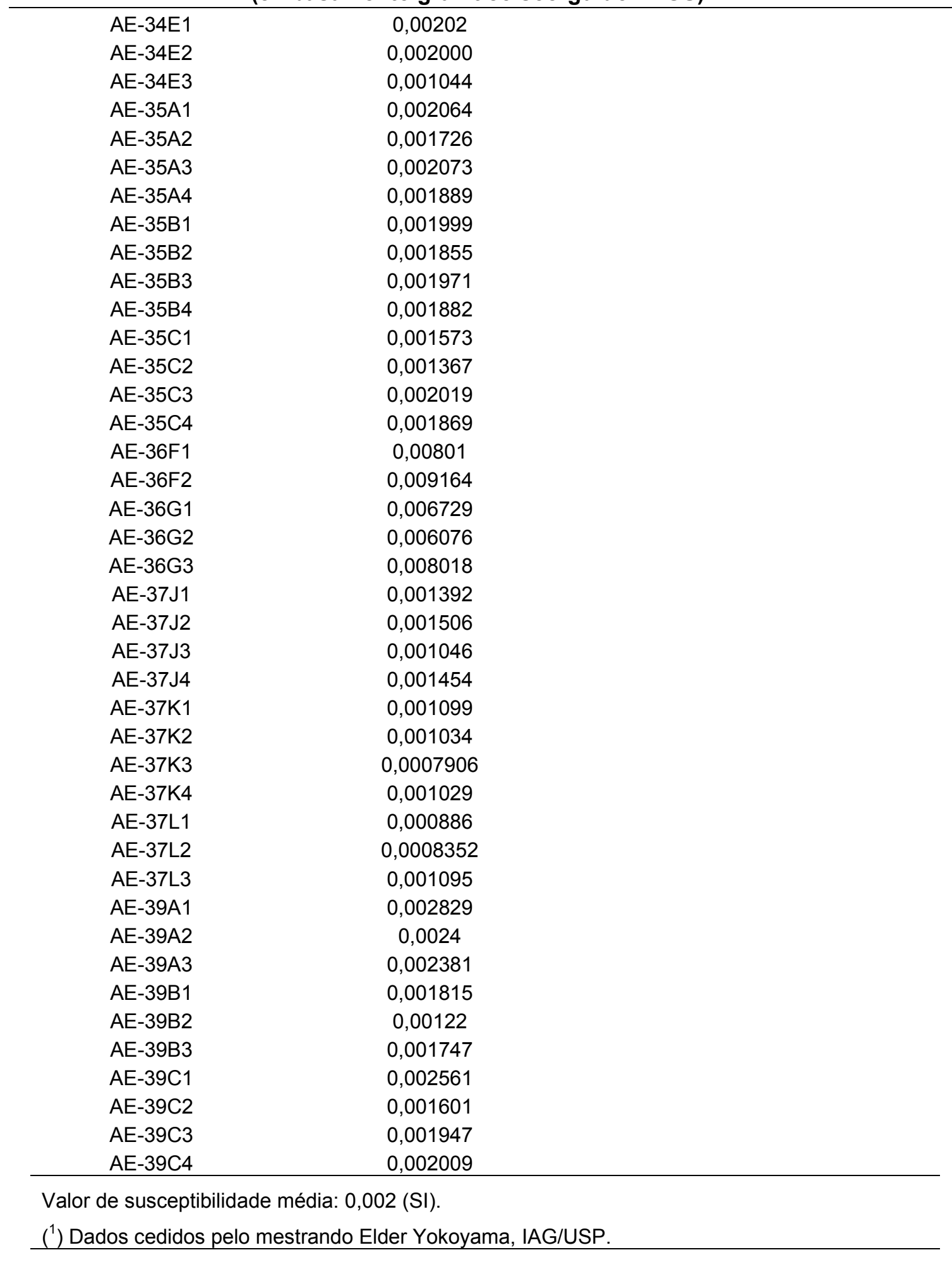


Tabela A. $7^{1}$ - Valores de susceptibilidades magnéticas de amostras do Pseudotaquilito (embasamento granítico soerguido - EGS).

\begin{tabular}{|c|c|}
\hline Amostra & $\begin{array}{l}\text { Susceptibilidade } \\
\text { (SI) }\end{array}$ \\
\hline $\mathrm{AE}-4 \mathrm{C} 1$ & 0,00192 \\
\hline $\mathrm{AE}-4 \mathrm{C} 2$ & 0,002007 \\
\hline$A E-4 C 3$ & 0,001833 \\
\hline $\mathrm{AE}-6 \mathrm{C} 1$ & 0,001131 \\
\hline $\mathrm{AE}-6 \mathrm{C} 2$ & 0,001335 \\
\hline$A E-6 D$ & 0,000366 \\
\hline AE-6E1 & 0,000622 \\
\hline $\mathrm{AE}-6 \mathrm{E} 2$ & 0,000929 \\
\hline AE-6E3 & 0,001081 \\
\hline $\mathrm{AE}-6 \mathrm{E} 4$ & 0,001026 \\
\hline $\mathrm{AE}-6 \mathrm{~F} 1$ & 0,001064 \\
\hline AE-6F2 & 0,001068 \\
\hline AE-6F3 & 0,001131 \\
\hline AE-6F4 & 0,001119 \\
\hline$A E-8 A 1$ & 0,00344 \\
\hline $\mathrm{AE}-8 \mathrm{~A} 2$ & 0,003235 \\
\hline AE-8A3 & 0,003437 \\
\hline $\mathrm{AE}-8 \mathrm{~A} 4$ & 0,003557 \\
\hline $\mathrm{AE}-8 \mathrm{~B} 1$ & 0,004186 \\
\hline AE-8B2 & 0,004388 \\
\hline AE-8B3 & 0,005065 \\
\hline AE-8B4 & 0,004682 \\
\hline $\mathrm{AE}-8 \mathrm{C} 1$ & 0,004688 \\
\hline $\mathrm{AE}-8 \mathrm{C} 2$ & 0,004459 \\
\hline $\mathrm{AE}-8 \mathrm{C} 3$ & 0,005455 \\
\hline $\mathrm{AE}-8 \mathrm{C} 4$ & 0,005875 \\
\hline AE-8C5 & 0,005897 \\
\hline AE-8D1 & 0,005195 \\
\hline $\mathrm{AE}-8 \mathrm{D} 2$ & 0,00437 \\
\hline AE-8D3 & 0,00322 \\
\hline $\mathrm{AE}-8 \mathrm{D} 4$ & 0,002421 \\
\hline $\mathrm{AE}-8 \mathrm{E} 1$ & 0,002075 \\
\hline $\mathrm{AE}-8 \mathrm{E} 3$ & 0,002426 \\
\hline $\mathrm{AE}-8 \mathrm{E} 4$ & 0,002441 \\
\hline $\mathrm{AE}-8 \mathrm{~F} 1$ & 0,004011 \\
\hline AE-8F2 & 0,003689 \\
\hline AE-8G1 & 0,003582 \\
\hline$A E-8 G 2$ & 0,003794 \\
\hline $\mathrm{AE}-8 \mathrm{G} 3$ & 0,004387 \\
\hline $\mathrm{AE}-8 \mathrm{H} 1$ & 0,003676 \\
\hline $\mathrm{AE}-8 \mathrm{H} 2$ & 0,003364 \\
\hline
\end{tabular}




\section{Continuação}

Tabela A. $7^{1}$ - Valores de susceptibilidades magnéticas de amostras do Pseudotaquilito (embasamento granítico soerguido - EGS).

\begin{tabular}{|c|c|}
\hline $\mathrm{AE}-8 \mathrm{H} 3$ & 0,003984 \\
\hline $\mathrm{AE}-8 \mathrm{H} 4$ & 0,003182 \\
\hline AE-8I1 & 0,005818 \\
\hline AE-8I2 & 0,005403 \\
\hline AE-9B1 & 0,007578 \\
\hline AE-9B2 & 0,008365 \\
\hline AE-9B3 & 0,005757 \\
\hline$A E-12 A 1$ & 0,002921 \\
\hline$A E-12 A 2$ & 0,002554 \\
\hline$A E-12 A 3$ & 0,003046 \\
\hline$A E-13 A 1$ & 0,001886 \\
\hline$A E-13 A 2$ & 0,001903 \\
\hline$A E-13 A 3$ & 0,001607 \\
\hline $\mathrm{AE}-14 \mathrm{~A} 1$ & 0,000705 \\
\hline$A E-14 A 2$ & 0,000963 \\
\hline$A E-14 A 3$ & 0,000906 \\
\hline$A E-14 C 1$ & 0,001859 \\
\hline$A E-14 C 2$ & 0,001655 \\
\hline$A E-14 C 3$ & 0,001457 \\
\hline AE-14C4 & 0,001481 \\
\hline$A E-19 C 1$ & 0,0024 \\
\hline$A E-19 C 2$ & 0,002215 \\
\hline AE-19C3 & 0,002262 \\
\hline AE-19D1 & 0,003525 \\
\hline AE-19D2 & 0,002057 \\
\hline AE-19D3 & 0,002173 \\
\hline AE-19D4 & 0,003069 \\
\hline AE-25A1 & 0,002212 \\
\hline$A E-25 A 2$ & 0,00252 \\
\hline$A E-25 A 3$ & 0,002291 \\
\hline AE-25B1 & 0,000265 \\
\hline AE-25B2 & 0,002574 \\
\hline AE-25B3 & 0,002422 \\
\hline$A E-26 C 1$ & 0,001474 \\
\hline$A E-26 C 2$ & 0,001725 \\
\hline$A E-26 C 3$ & 0,00175 \\
\hline$A E-26 D$ & 0,003666 \\
\hline AE-26E & 0,002984 \\
\hline$A E-27 C 1$ & 0,001779 \\
\hline AE-27C2 & 0,002607 \\
\hline$A E-27 C 3$ & 0,003188 \\
\hline $\mathrm{AE}-27 \mathrm{C} 4$ & 0,006617 \\
\hline AE-28A1 & 0,001533 \\
\hline
\end{tabular}




\section{Conclusão}

Tabela A. $7^{1}$ - Valores de susceptibilidades magnéticas de amostras do Pseudotaquilito (embasamento granítico soerguido - EGS).

\begin{tabular}{cc}
\hline AE-28A2 & 0,001445 \\
AE-28A3 & 0,002439 \\
AE-29D1 & 0,003855 \\
AE-29D2 & 0,003761 \\
AE-29D3 & 0,003318 \\
AE-29E1 & 0,003556 \\
AE-29E2 & 0,003463 \\
AE-29E3 & 0,00357 \\
AE-29E4 & 0,003907 \\
AE-30A1 & 0,003481 \\
AE-30A2 & 0,003857 \\
AE-30A3 & 0,00396 \\
AE-30A4 & 0,00336 \\
AE-30A5 & 0,00366 \\
AE-30B1 & 0,001809 \\
AE-30B3 & 0,001607 \\
AE-33A1 & 0,001838 \\
AE-33A2 & 0,001841 \\
AE-33A3 & 0,001822 \\
AE-34A1 & 0,000327 \\
AE-34A2 & 0,000416 \\
AE-34A3 & 0,000427 \\
AE-34A4 & 0,000423 \\
AE-34B1 & 0,000988 \\
AE-34B2 & 0,001181 \\
AE-34B3 & 0,000914 \\
\hline Valor de susceptibilidade média: $0,003(\mathrm{SI})$ \\
\hline Dados cedidos pelo mestrando Elder Yokoyama, IAG/USP.
\end{tabular}


Tabela A. $8^{1}$ - Valores de susceptibilidades magnéticas de amostras do melt (embasamento granítico soerguido - EGS).

\begin{tabular}{cc}
\hline Amostra & Susceptibilidade (SI) \\
\hline AE-21A1 & 0,001805 \\
AE-21A2 & 0,002002 \\
AE-21A3 & 0,001831 \\
AE-21B1 & 0,004091 \\
AE-21B2 & 0,003739 \\
AE-21B3 & 0,001804 \\
AE-21C1 & 0,000015 \\
AE-21C2 & 0,005227 \\
\hline
\end{tabular}

Valor de susceptibilidade média: 0,003 (SI).

( $\left.{ }^{1}\right)$ Dados cedidos pelo mestrando Elder Yokoyama, IAG/USP.

Tabela A.9 $9^{1}$ - Valores de susceptibilidades magnéticas de amostras da brecha (embasamento granítico soerguido - EGS).

\begin{tabular}{cc}
\hline Amostra & Susceptibilidade (SI) \\
\hline AE-37A1 & 0,000683 \\
AE-37A2 & 0,000762 \\
AE-37B1 & 0,000889 \\
AE-37B2 & 0,000406 \\
AE-37B3 & 0,000831 \\
AE-37C1 & 0,001433 \\
AE-37C2 & 0,001744 \\
AE-37C3 & 0,001554 \\
AE-37D1 & 0,001935 \\
AE-37D2 & 0,002289 \\
AE-37D3 & 0,002351 \\
AE-37E1 & 0,002390 \\
AE-37E2 & 0,001509 \\
AE-37E3 & 0,001474 \\
AE-37F1 & 0,003137 \\
AE-37F2 & 0,002739 \\
AE-37F3 & 0,002508 \\
AE-37G1 & 0,000569 \\
AE-37G2 & 0,001101 \\
AE-37G3 & 0,001427 \\
AE-37H2 & 0,001055 \\
AE-37H3 & 0,000972 \\
\hline
\end{tabular}




\section{Conclusão}

Tabela A. $9^{1}$ - Valores de susceptibilidades magnéticas de amostras da brecha (embasamento granítico soerguido - EGS).

\begin{tabular}{ll} 
AE-37I1 & 0,001395 \\
AE-37I2 & 0,001453 \\
AE-38A1 & 0,000320 \\
AE-38A2 & 0,000455 \\
AE-38A3 & 0,000325 \\
AE-38A4 & 0,000331 \\
AE-38B1 & 0,000560 \\
AE-38B2 & 0,000781 \\
AE-38B3 & 0,000885 \\
AE-38C1 & 0,001400 \\
AE-38C2 & 0,000682 \\
AE-38C3 & 0,000686 \\
AE-38C4 & 0,000841 \\
AE-38D1 & 0,000973 \\
AE-38D2 & 0,001131 \\
AE-38D3 & 0,001324 \\
AE-40A1 & 0,001439 \\
AE-40A2 & 0,001421 \\
AE-40A3 & 0,001245 \\
AE-40A4 & 0,001598 \\
AE-40B1 & 0,001272 \\
AE-40B2 & 0,001974 \\
AE-40B3 & 0,001441 \\
AE-40C1 & 0,001857 \\
AE-40C2 & 0,001751 \\
AE-40C3 & 0,001411 \\
\hline &
\end{tabular}

Valor de susceptibilidade média: 0,001306 (SI).

( $\left.^{1}\right)$ Dados cedidos pelo mestrando Elder Yokoyama, IAG/USP.

Tabela A.10 ${ }^{1}$ - Valores de magnetização remanescente e razão de Koenigsberger (embasamento granítico soerguido - EGS).

\begin{tabular}{cccccc}
\hline Amostra & $\mathbf{M}_{\mathbf{R}}(\mathbf{S I})$ & $\mathbf{D e c}\left({ }^{\circ}\right)$ & $\mathbf{I n c}\left(^{\circ}\right)$ & $\mathbf{Q}$ & Litotipo \\
\hline AE-1A2 & 3,21 & 358,5 & $-39,9$ & 0,080197 & X.S. \\
AE-1C1 & 6,99 & 348,9 & $-65,4$ & 0,215343 & X.S. \\
AE-2A2 & 97,2 & 119,3 & 54,4 & 3,338657 & $\mathrm{G}$ \\
AE-2C3 & 62,1 & 236,3 & $-73,4$ & 1,897912 & $\mathrm{G}$ \\
AE-3A2 & 4,26 & 353,5 & $-32,9$ & 0,079702 & $\mathrm{G}$ \\
AE-4A2 & 2,09 & 18,2 & $-36,4$ & 0,045258 & $\mathrm{G}$ \\
AE-4C3 & 2,17 & 12,6 & $-26,2$ & 0,063679 & Pst \\
& & & & & continua
\end{tabular}




\begin{tabular}{|c|c|c|c|c|c|}
\hline $\begin{array}{c}\text { Conclusã } \\
\text { Tabela }\end{array}$ & $\begin{array}{r}\text { lores } \\
\text { (em }\end{array}$ & $\begin{array}{l}\text { etizaç } \\
\text { to gra }\end{array}$ & $\begin{array}{l}\text { hanes } \\
\text { soerg }\end{array}$ & $\begin{array}{l}\text { e razão o } \\
\text { - EGS). }\end{array}$ & sberger \\
\hline AE-5A3 & 2,79 & 7,9 & $-31,1$ & 0,080902 & G \\
\hline AE-5B3 & 2,38 & 143,1 & $-59,3$ & 0,076842 & $\mathrm{G}$ \\
\hline AE-6B & 0,815 & 4,1 & $-23,5$ & 0,064411 & G \\
\hline AE6-C1 & 1,29 & 356,2 & $-27,7$ & 0,061351 & Pst \\
\hline AE6-E4 & 9,01 & 290,8 & -3 & 0,472362 & Pst \\
\hline AE7-A3 & 0,605 & 217,5 & $-81,4$ & 0,021537 & G \\
\hline AE7-D3 & 2,01 & 10,5 & $-37,1$ & 0,0489 & G \\
\hline AE8-A4 & 10,3 & 99,9 & $-6,5$ & 0,155758 & Pst \\
\hline AE8-B4 & 56,1 & 109,7 & $-18,4$ & 0,644509 & Pst \\
\hline AE9-A3 & 4,59 & 5,2 & $-37,3$ & 0,069961 & G \\
\hline AE9-D4 & 3,88 & 1,8 & $-37,3$ & 0,055625 & G \\
\hline AE10-A5 & 0,965 & 32,8 & $-26,3$ & 0,042687 & $\mathrm{G}$ \\
\hline AE10-C5 & 1,63 & 29,7 & $-36,4$ & 0,056348 & G \\
\hline AE11-A3 & 2,1 & 1 & $-32,6$ & 0,065256 & G \\
\hline $\mathrm{AE} 11-\mathrm{C} 4$ & 1,45 & 10,8 & $-30,1$ & 0,059629 & $\mathrm{G}$ \\
\hline $\mathrm{AE} 12-\mathrm{A} 2$ & 10,4 & 350,6 & $-24,3$ & 0,219033 & Pst \\
\hline AE12-D4 & 9,7 & 317,5 & $-4,6$ & 0,110706 & Pst \\
\hline$A E 13-A 3$ & 2,36 & 224,1 & 61,3 & 0,078994 & Pst \\
\hline$A E 13-C 3$ & 1,9 & 34,3 & 8,3 & 0,046645 & G \\
\hline AE13-C3 & 0,475 & 359,4 & $-40,8$ & 0,388496 & Pst \\
\hline AE14-A3 & 6,54 & 256,9 & 0,8 & 0,19417 & G \\
\hline AE14-D3 & 17,8 & 8,3 & $-29,8$ & 0,06379 & G \\
\hline$A E 15-A 3$ & 6,54 & 256,9 & 0,8 & 0,081783 & G \\
\hline AE15-A3 & 2,73 & 7,8 & $-41,3$ & 0,0398 & $\mathrm{G}$ \\
\hline AE15-B3 & 2,79 & 6,8 & $-41,8$ & 0,654732 & G \\
\hline$A E 16-C 3$ & 1,69 & 344,8 & $-38,5$ & 1,621368 & G \\
\hline AE 17-A3 & 29,7 & 177,3 & 56,8 & 0,024251 & $\mathrm{G}$ \\
\hline AE17-C3 & 63,3 & 59,4 & $-25,6$ & 0,026355 & G \\
\hline$A E 18-A 3$ & 1,22 & 18 & $-38,5$ & 1,673015 & $\mathrm{G}$ \\
\hline AE18-C4 & 1,05 & 5,3 & $-19,9$ & 0,130451 & Pst \\
\hline AE19-A1 & 93,9 & 286,7 & $-6,1$ & 0,070547 & G \\
\hline AE19-D3 & 5,27 & 296,8 & 4,2 & 0,046014 & $G$ \\
\hline AE20-A3 & 3,81 & 0 & $-67,3$ & 0,108401 & $\mathrm{M}$ \\
\hline AE20-C3 & 2,16 & 20,9 & $-53,4$ & 0,03046 & $\mathrm{M}$ \\
\hline AE21-A3 & 3,69 & 9,8 & $-44,9$ & 0,032533 & G \\
\hline AE21-C2 & 2,96 & 18,2 & -47 & 0,04578 & G \\
\hline AE22-A2 & 2,51 & 4,3 & $-36,9$ & 0,034836 & $\mathrm{G}$ \\
\hline $\begin{array}{l}M_{R}: \text { intensid } \\
\text { inclinação m } \\
\text { granito; Pst: }\end{array}$ & quilito & Razã & $\begin{array}{l}\text { :declin } \\
\text { enigsb }\end{array}$ & $\begin{array}{l}\text { nagnética } r \\
\text { X.S: xenól }\end{array}$ & $\begin{array}{l}\text { ente; Inc: } \\
\text { ito; G: }\end{array}$ \\
\hline Valor de ma & to reme & médio: & & & \\
\hline Valor da Raz & Jenigsb & lio: 0,2 & & & \\
\hline$\left({ }^{1}\right)$ Dados ce & o mest & Yoko & $A G / U S$ & & \\
\hline
\end{tabular}




\title{
UNIVERSIDADE DE SÃO PAULO \\ INSTITUTO DE ASTRONOMIA, GEOFÍSICA E CIÊNCIAS ATMOSFÉRICAS-IAG.
}

\author{
APÊNDICE B \\ MODELOS GRAVIMÉTRICOS
}

São Paulo

2007 
a)

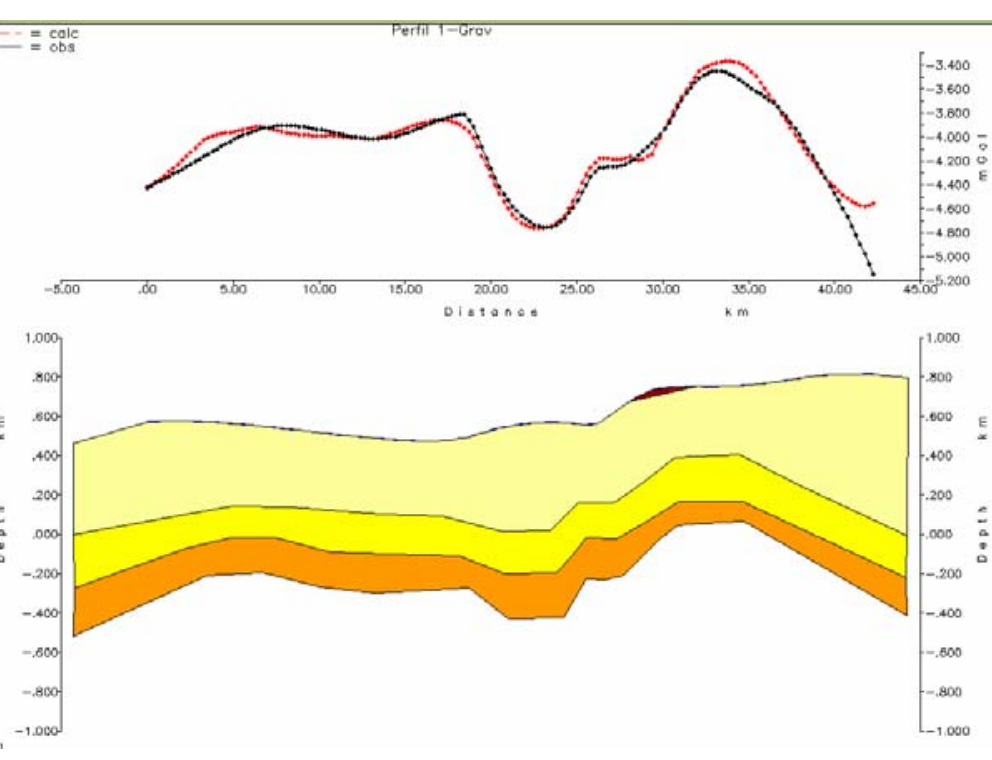

d)
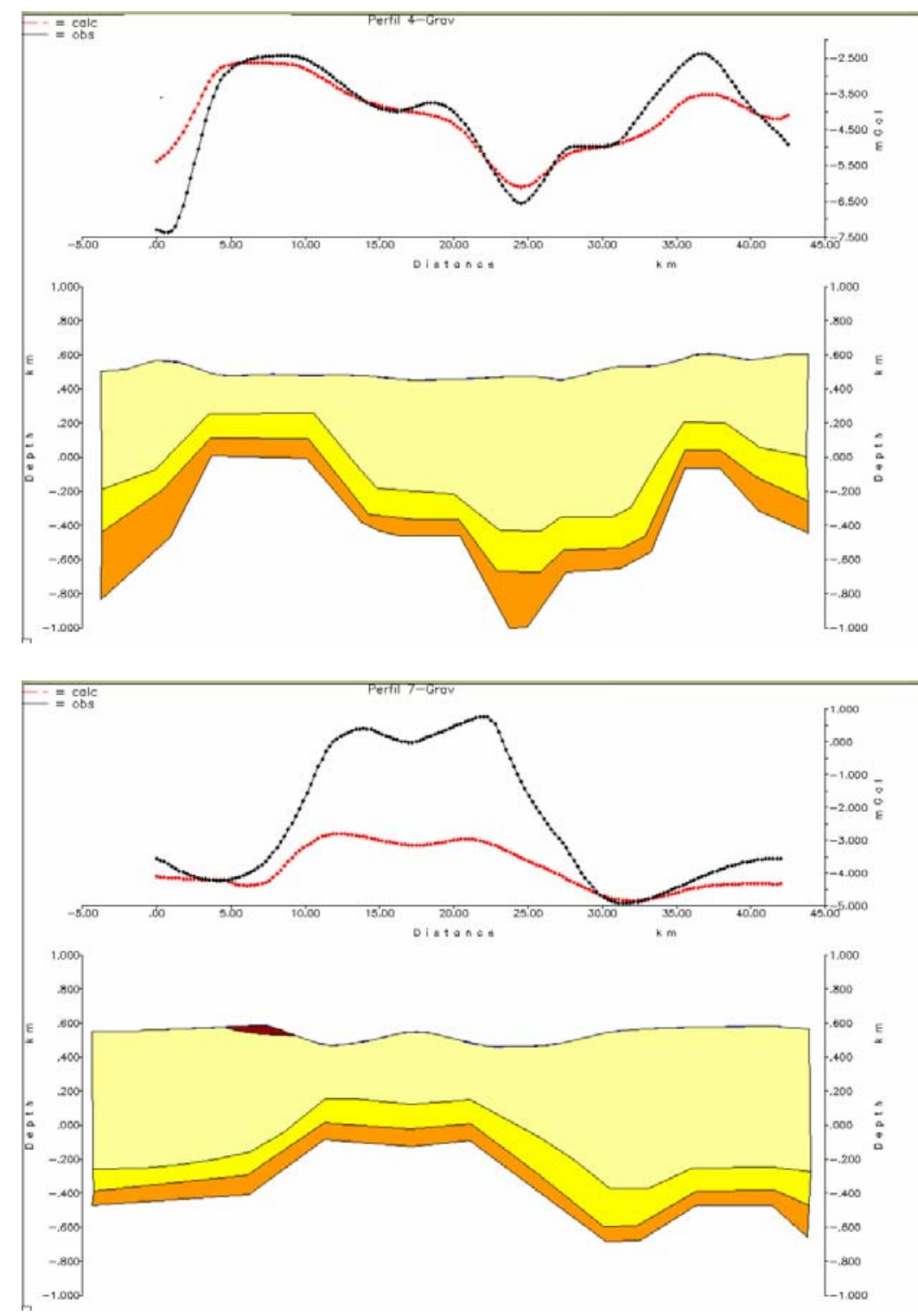

b)
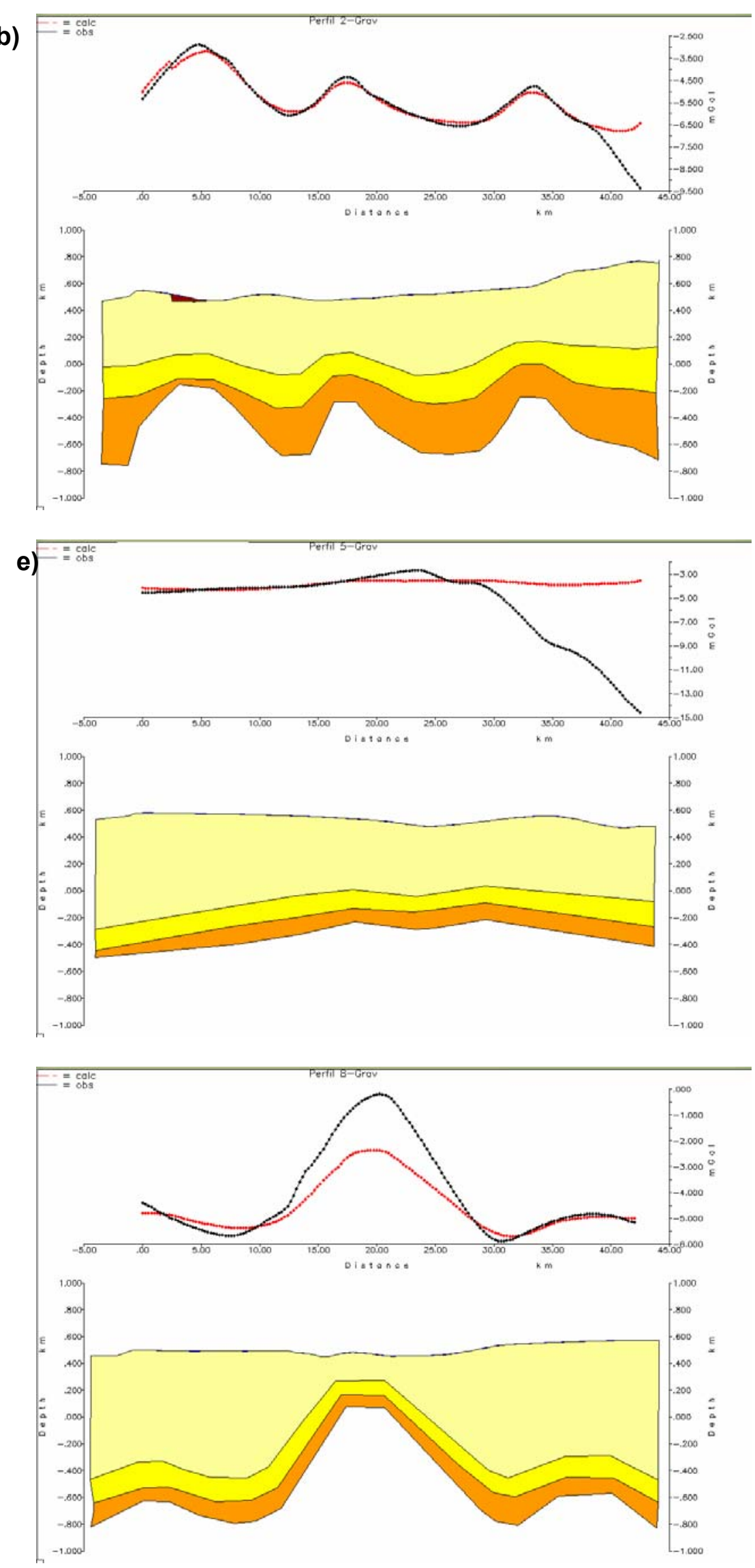

c)
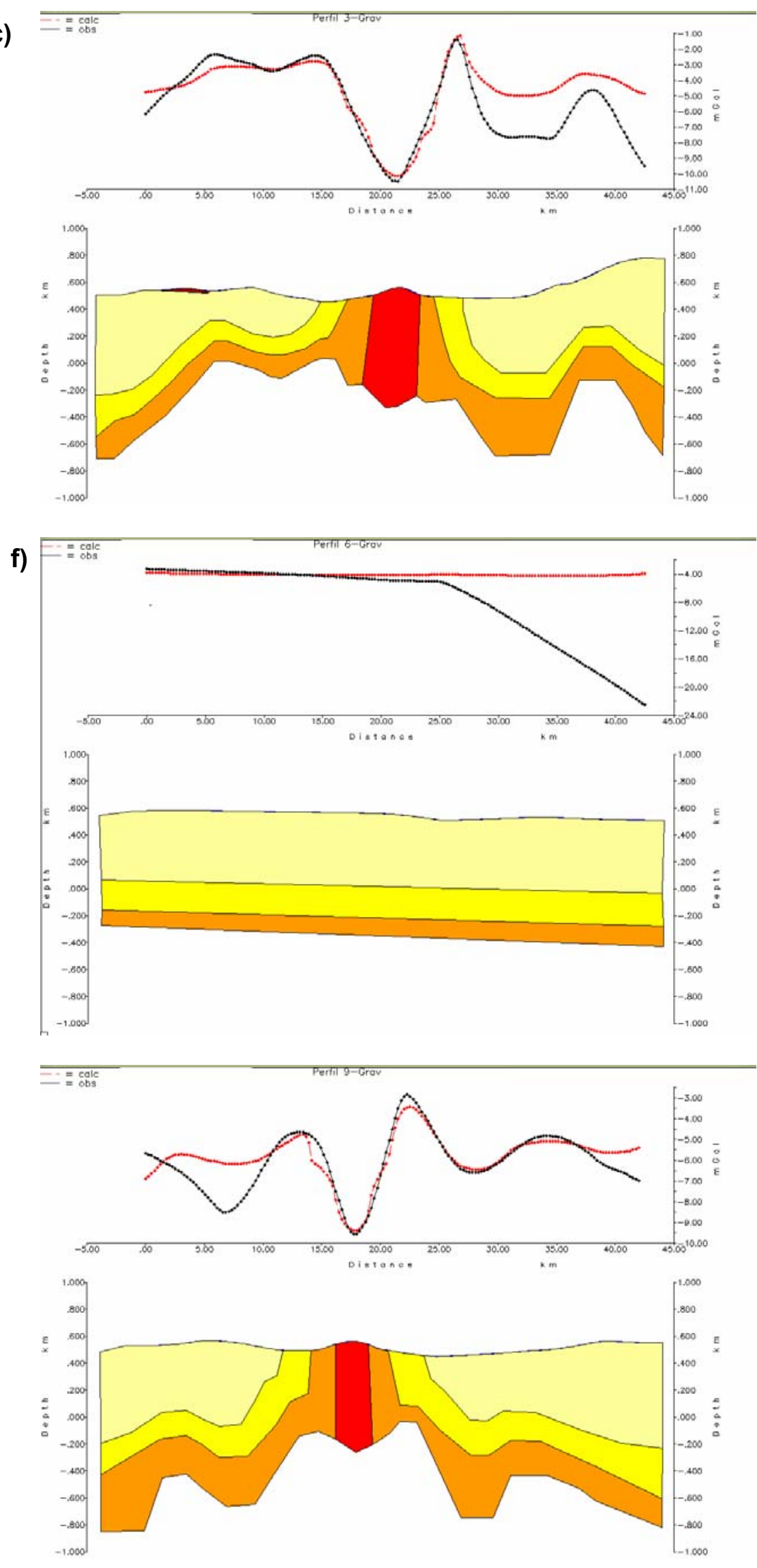

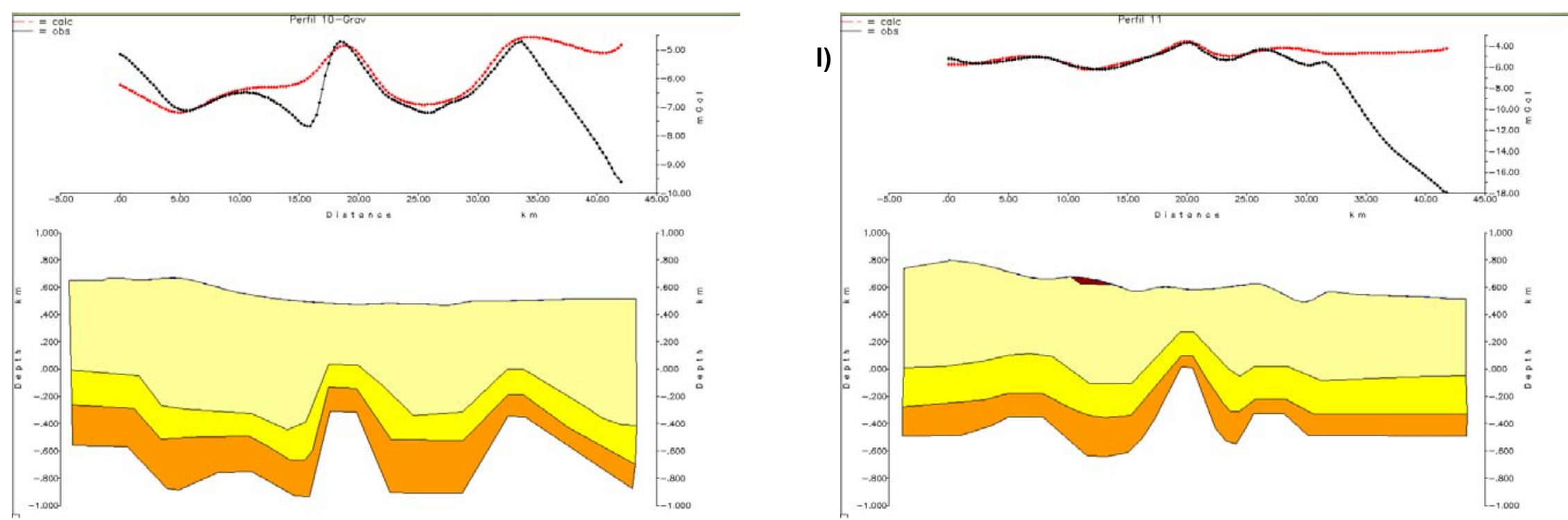

m)

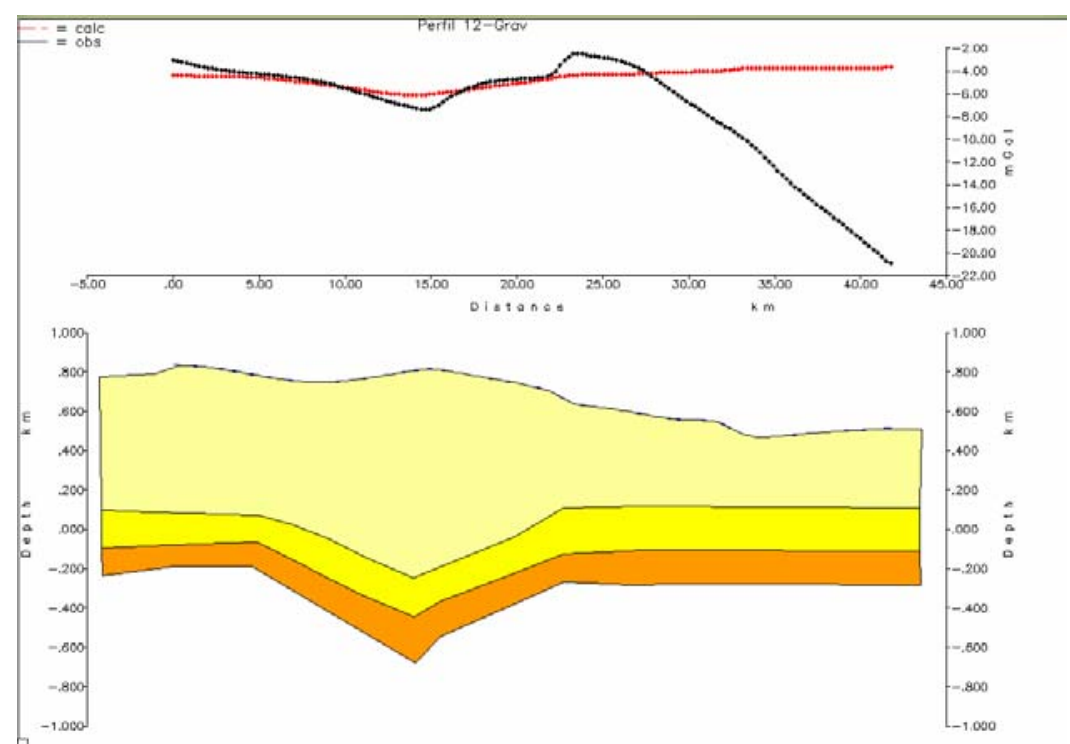

n)
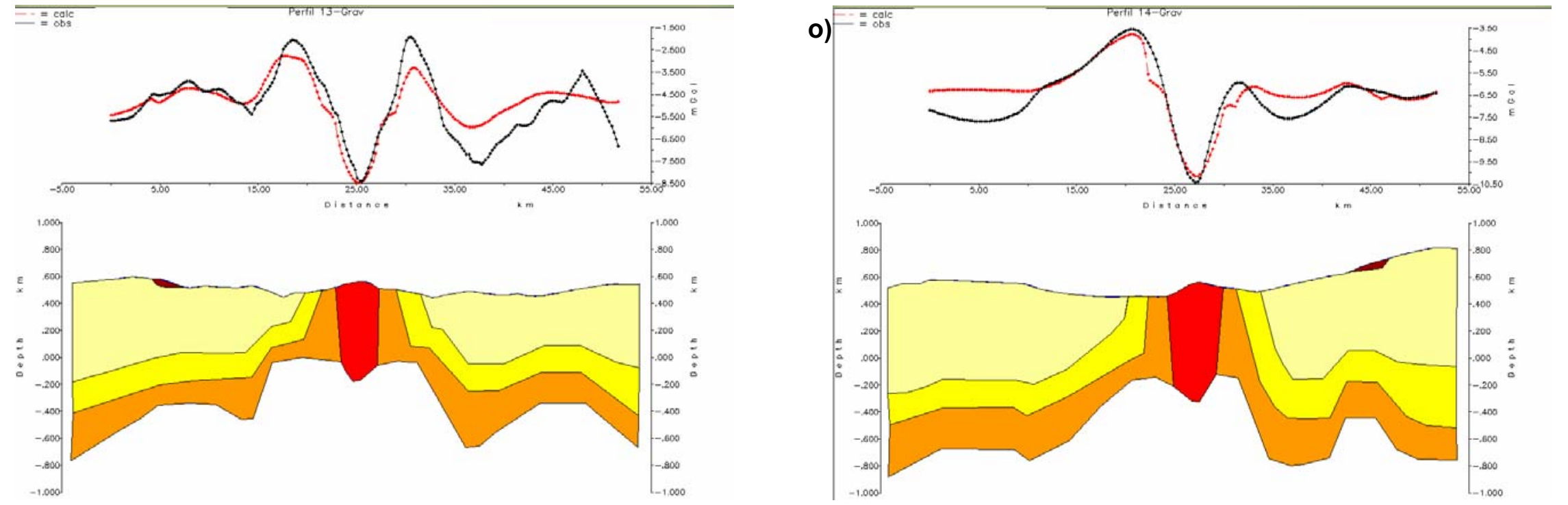

Figura B- Resultados dos modelamentos diretos realizados com os dados gravimétricos. De "a" até "o" modelos gerados ao longo dos perfis 1 a 14, respectivamente. A localização dos perfis é mostrada na Figura 6.1.

\begin{tabular}{|l|l|}
\hline Densidades $\left(\mathrm{g} / \mathrm{cm}^{3}\right)$ \\
\begin{tabular}{|l|l|}
\hline & Fm. Aquidauana/G.Passa-Dois-2,36 \\
\hline & Fm. Ponta Grossa-2,36 \\
\hline \hline & Fm. Furnas-2,22 \\
& EGS-2,15 \\
\hline & Embasamento-2,45 \\
\hline
\end{tabular}
\end{tabular}




\section{UNIVERSIDADE DE SÃO PAULO \\ INSTITUTO DE ASTRONOMIA, GEOFÍSICA E CIÊNCIAS \\ ATMOSFÉRICAS-IAG.}

\section{APÊNDICE C \\ MODELOS AEROMAGNÉTICOS}

São Paulo

2007 

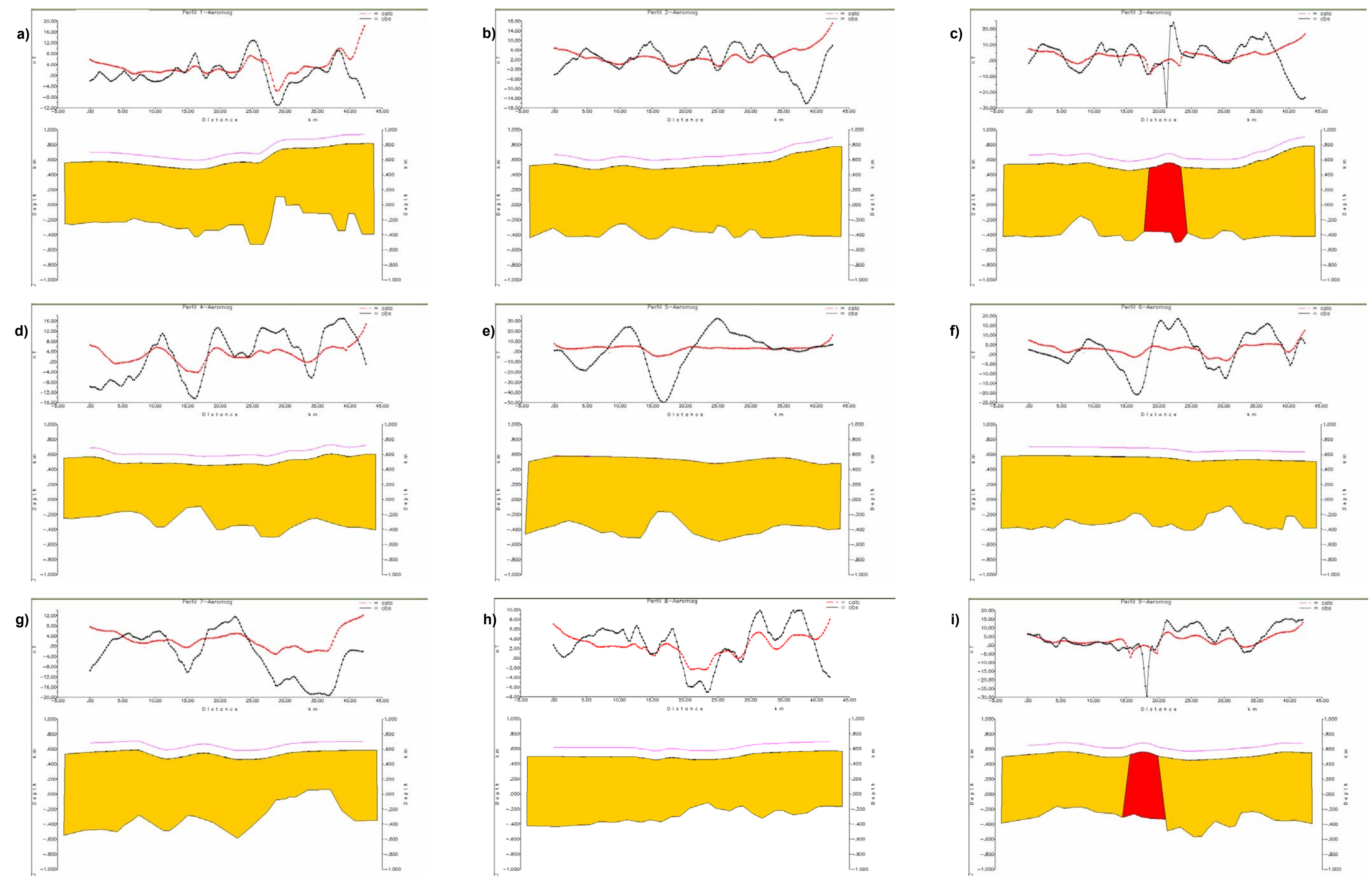
j)

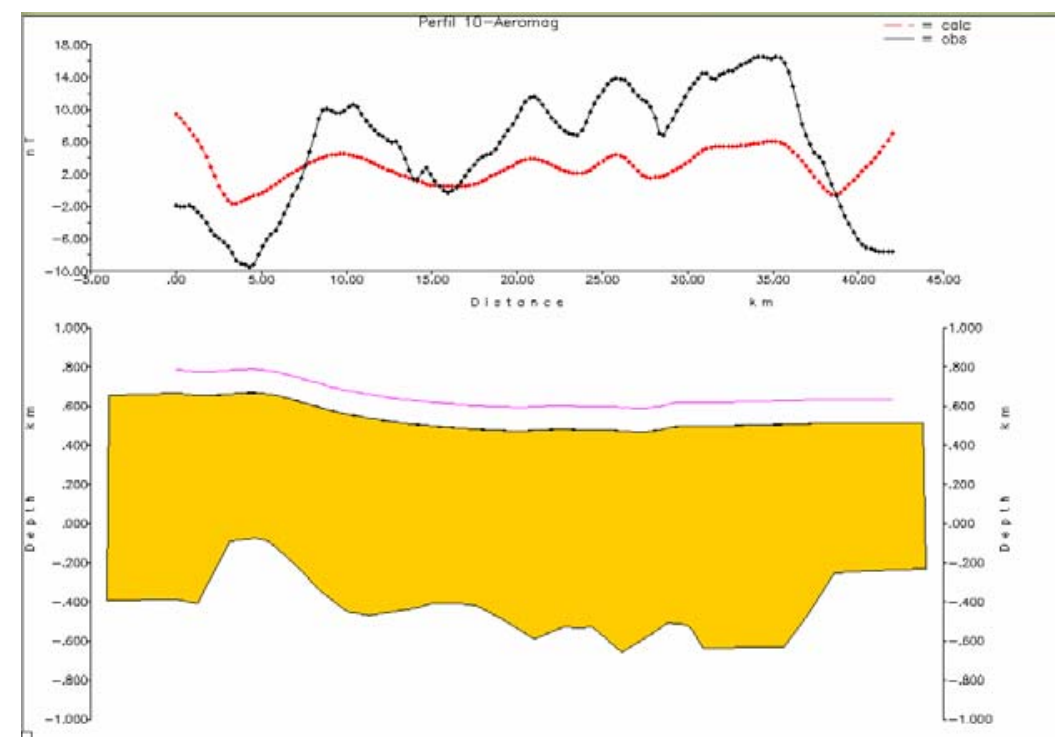

n)

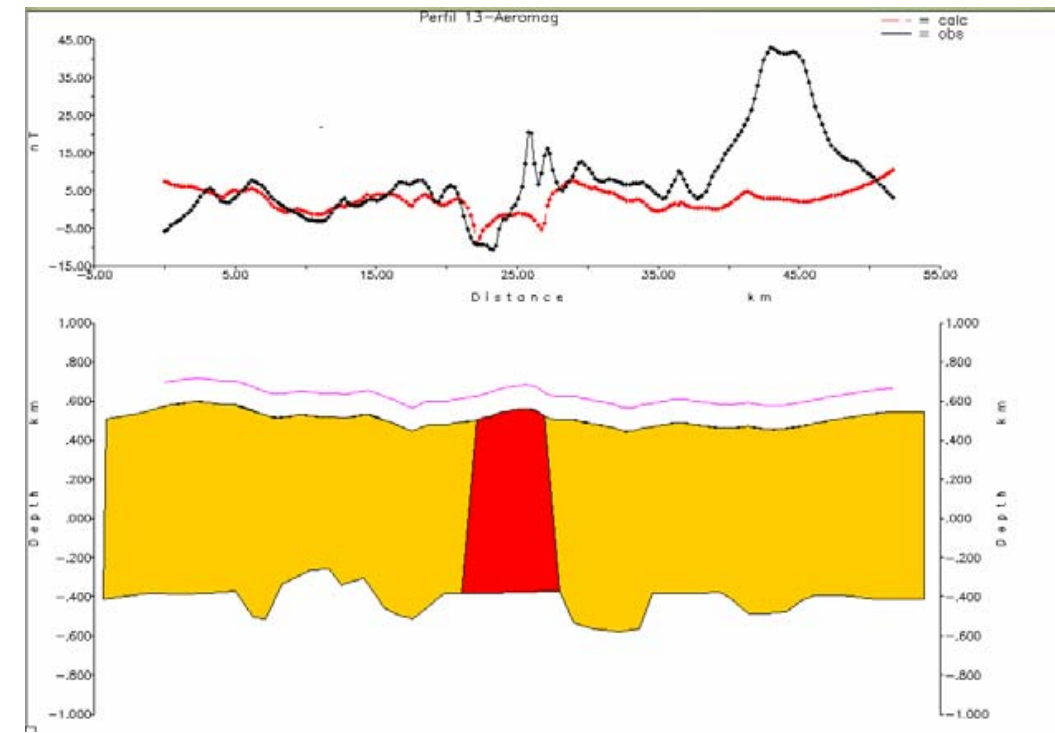

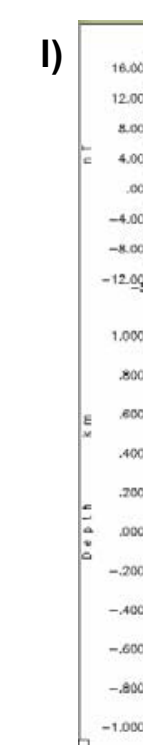
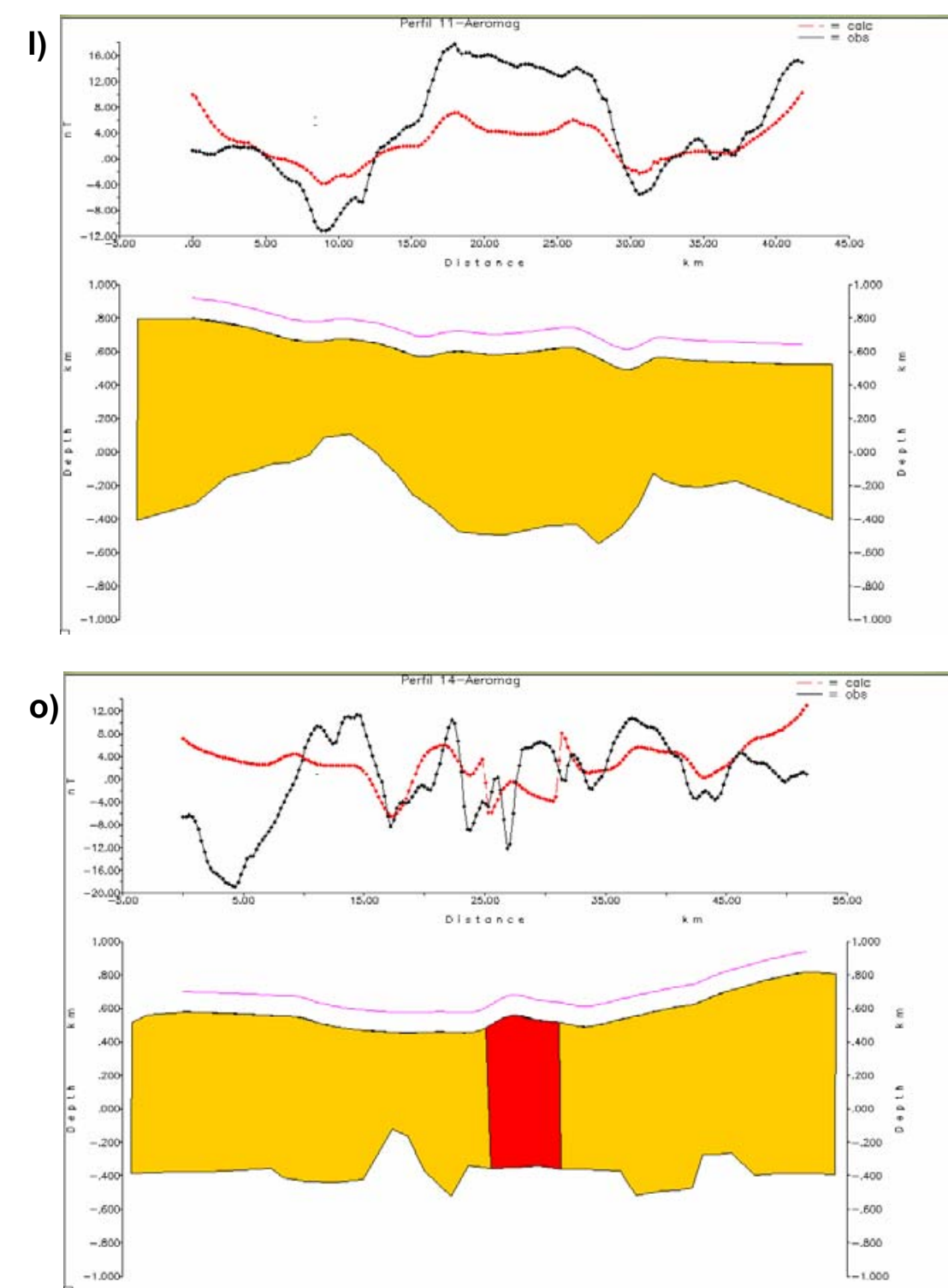

m)

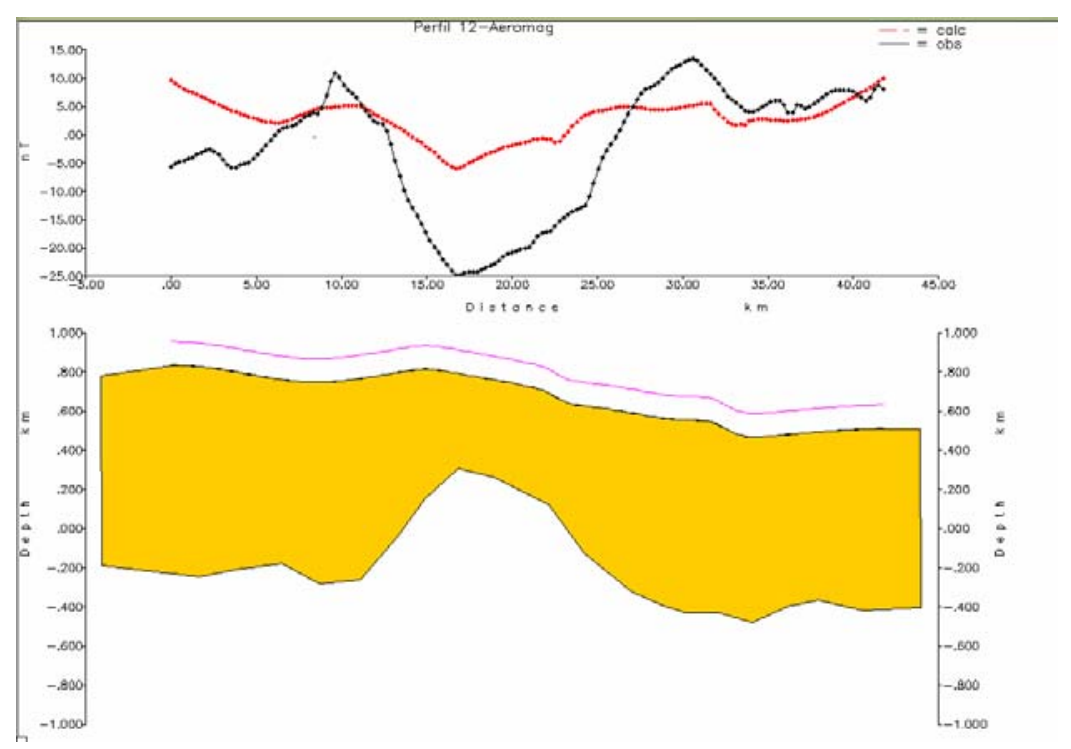

Figura C - Resultados dos modelamentos diretos realizados com dados aeromagnéticos. De "a"até "o" modelos gerados ao longo dos perfis 1 a 14, respectivamente. A localização dos perfis é mostrada na Figura 6.1.

Susceptibilidades magnéticas-k (SI)
$\square$ Rochas Sedimentares- desprezível
EGS-0,0015
$\square$ Embasamento-0,006




\section{UNIVERSIDADE DE SÃO PAULO \\ INSTITUTO DE ASTRONOMIA, GEOFÍSICA E CIÊNCIAS \\ ATMOSFÉRICAS-IAG.}

\section{APÊNDICE D \\ MODELOS MAGNÉTICOS TERRESTRES}

São Paulo

2007 
a)
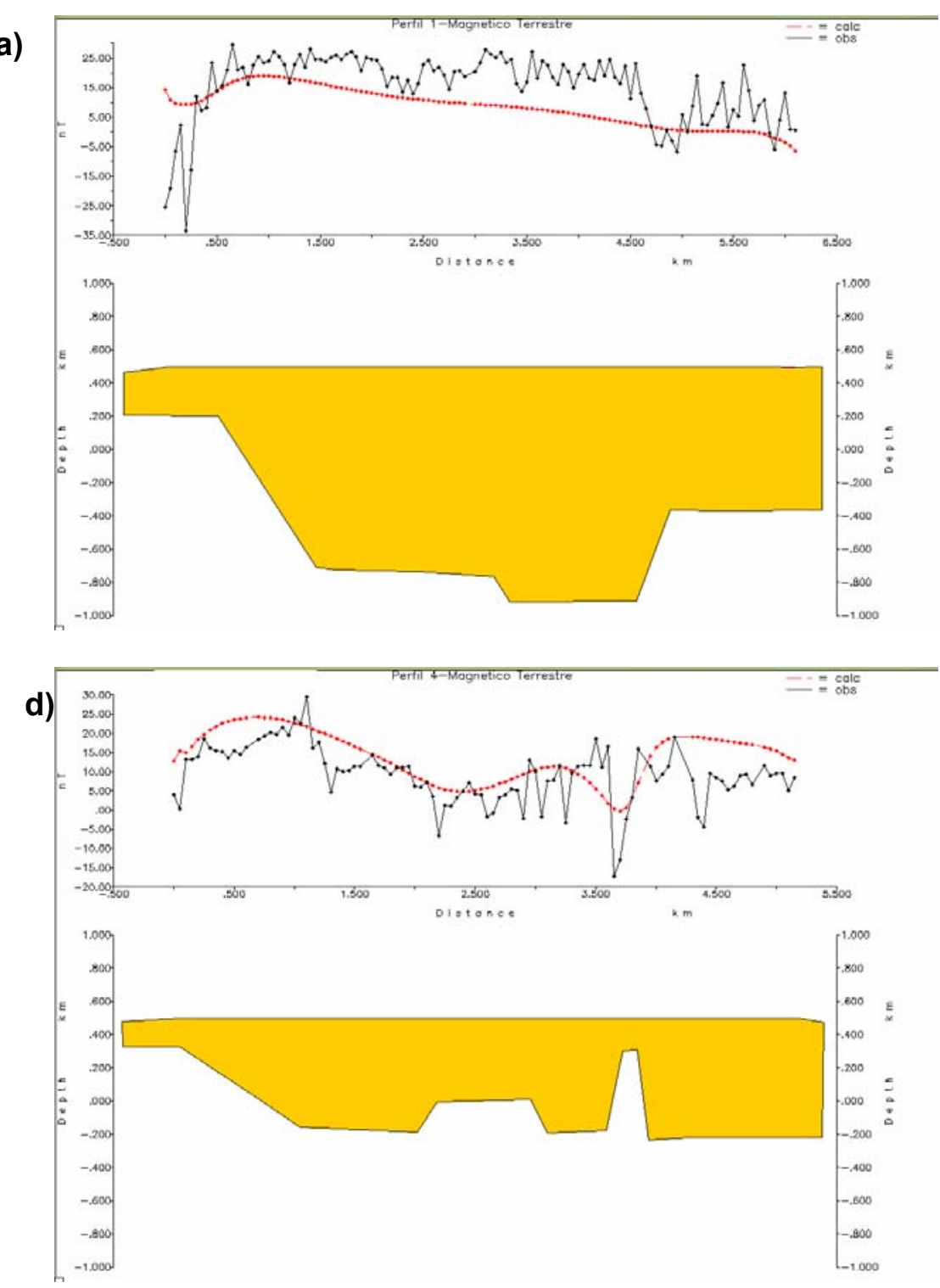

b)
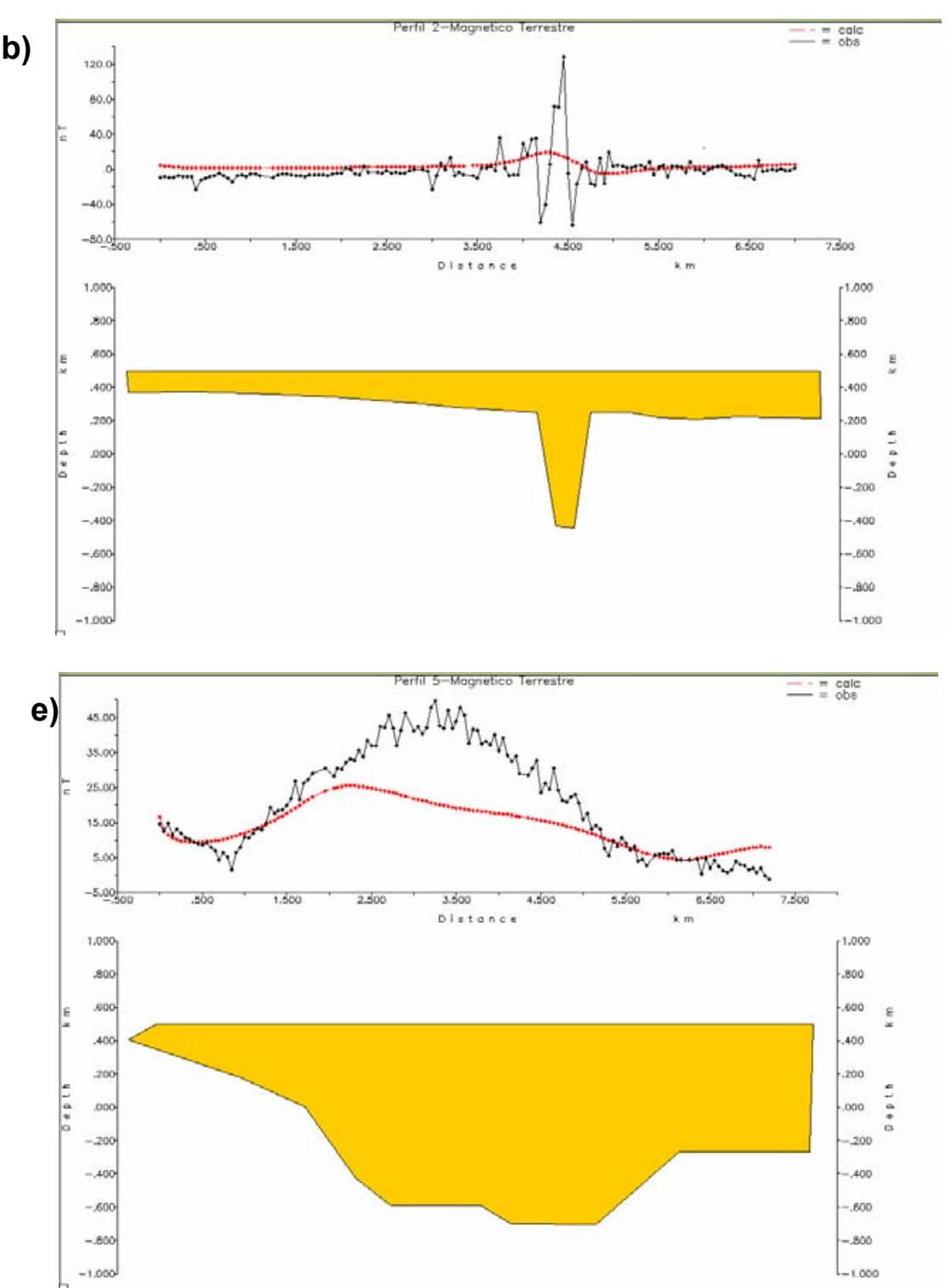

c)
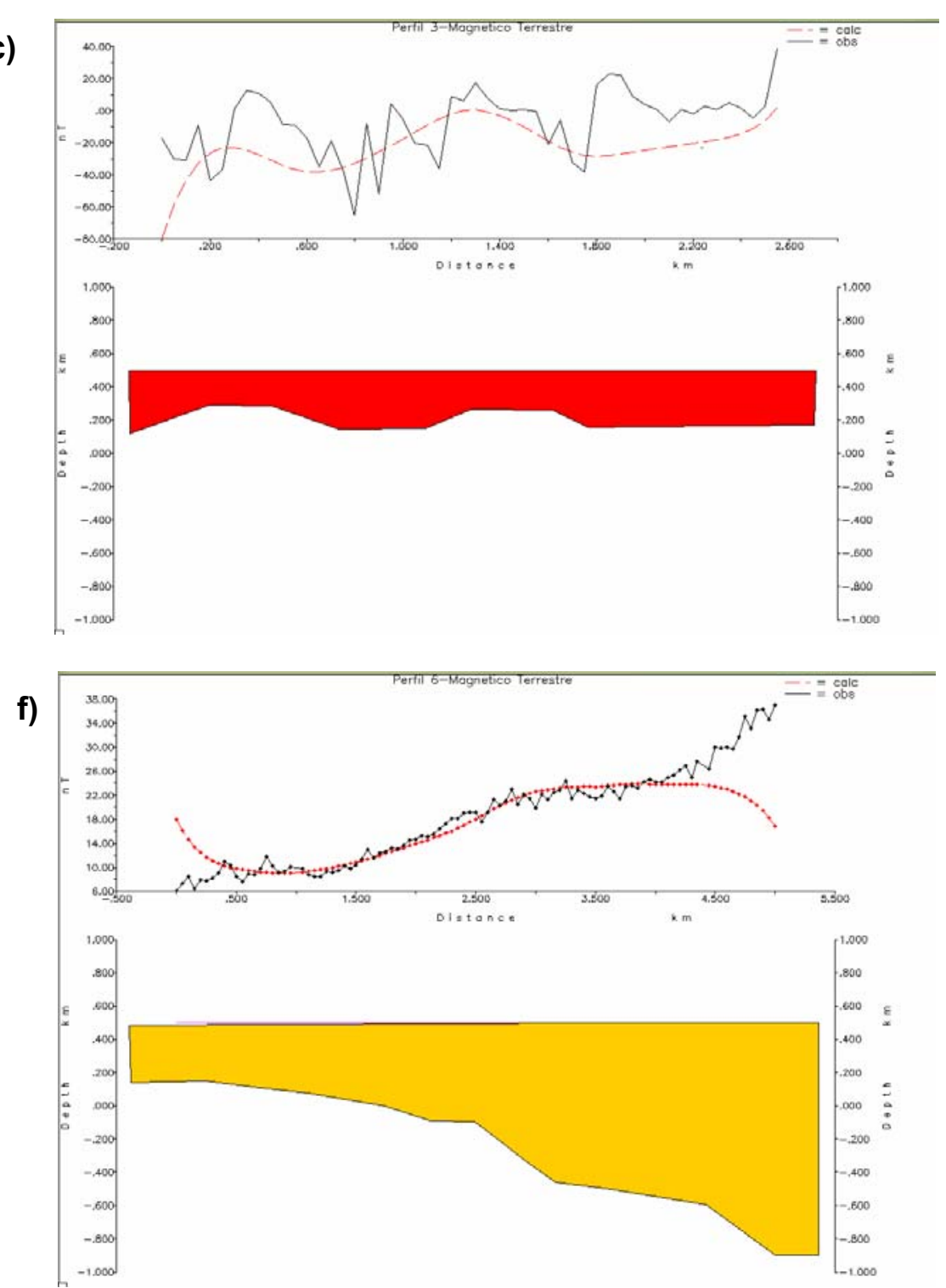
g)

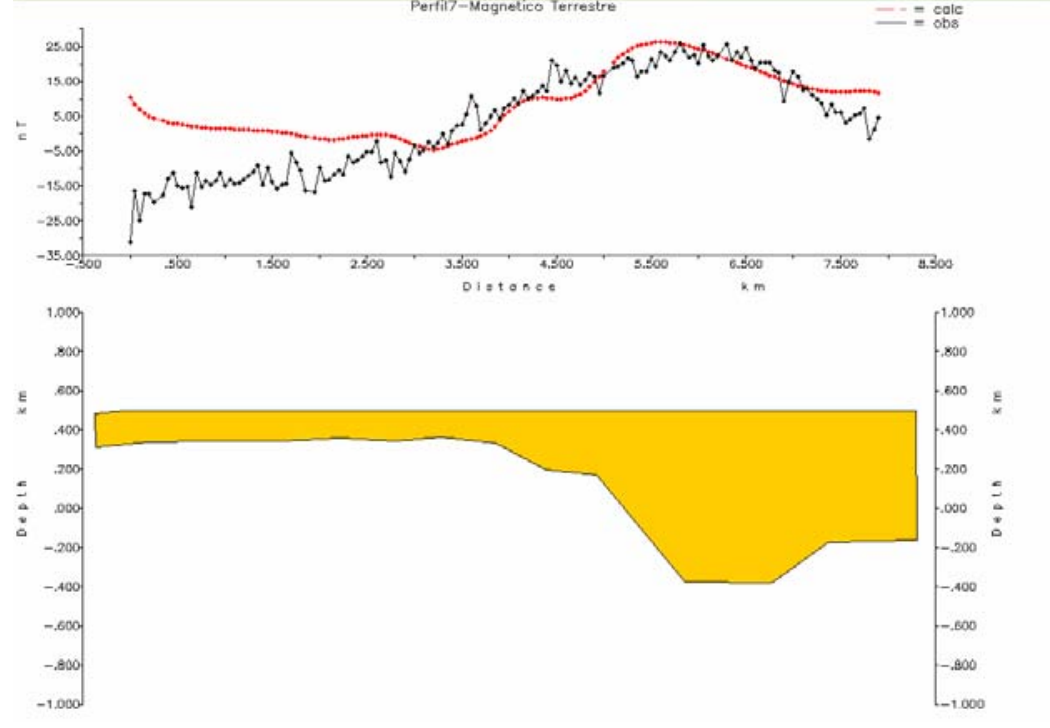

j)

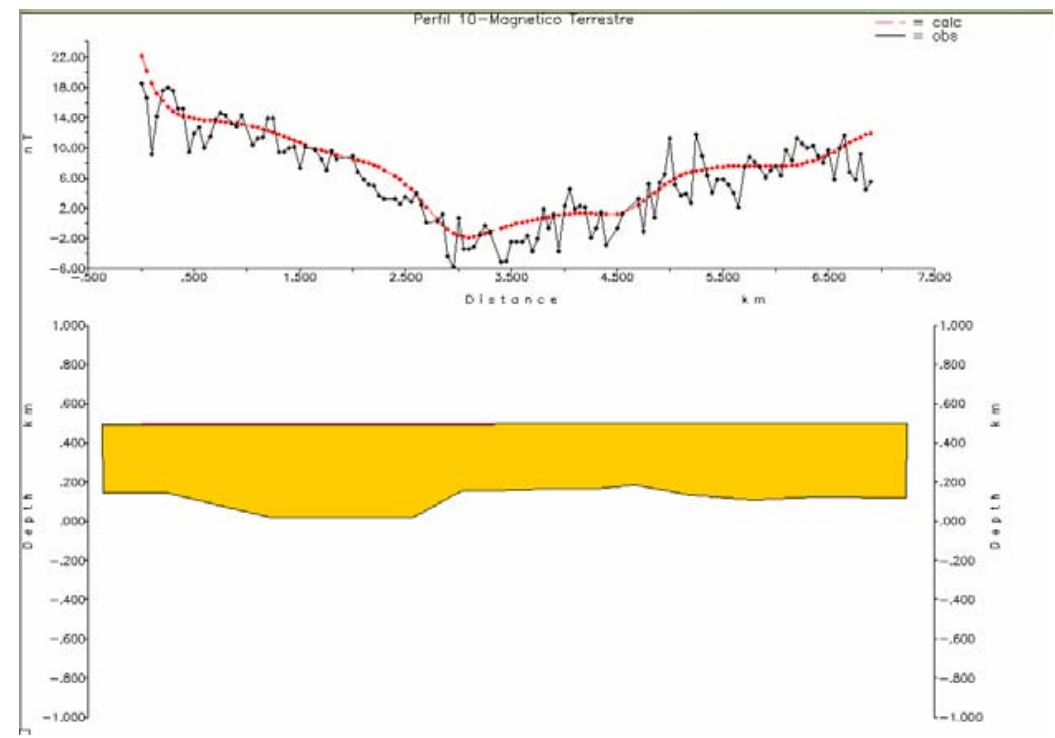

h)
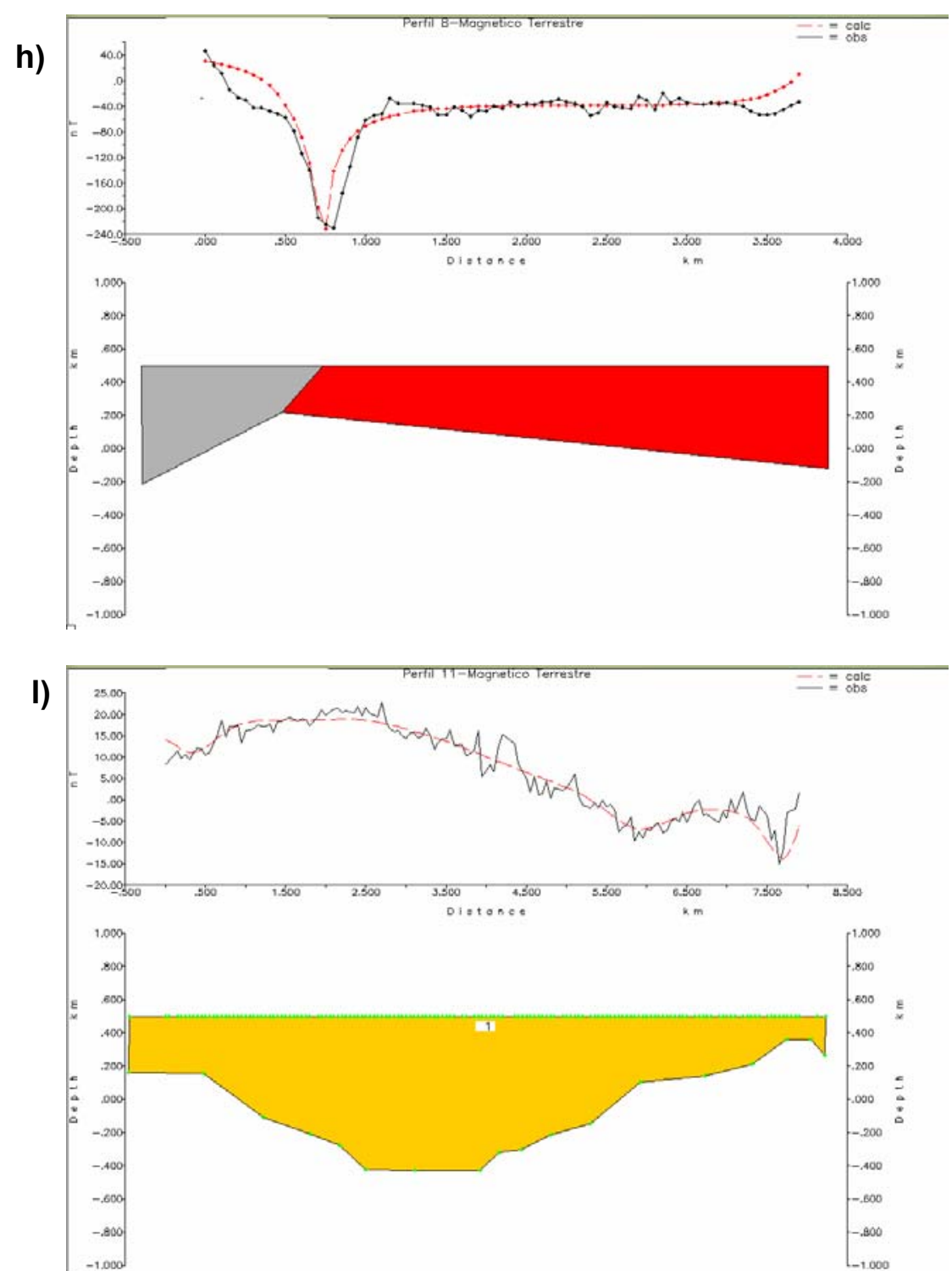

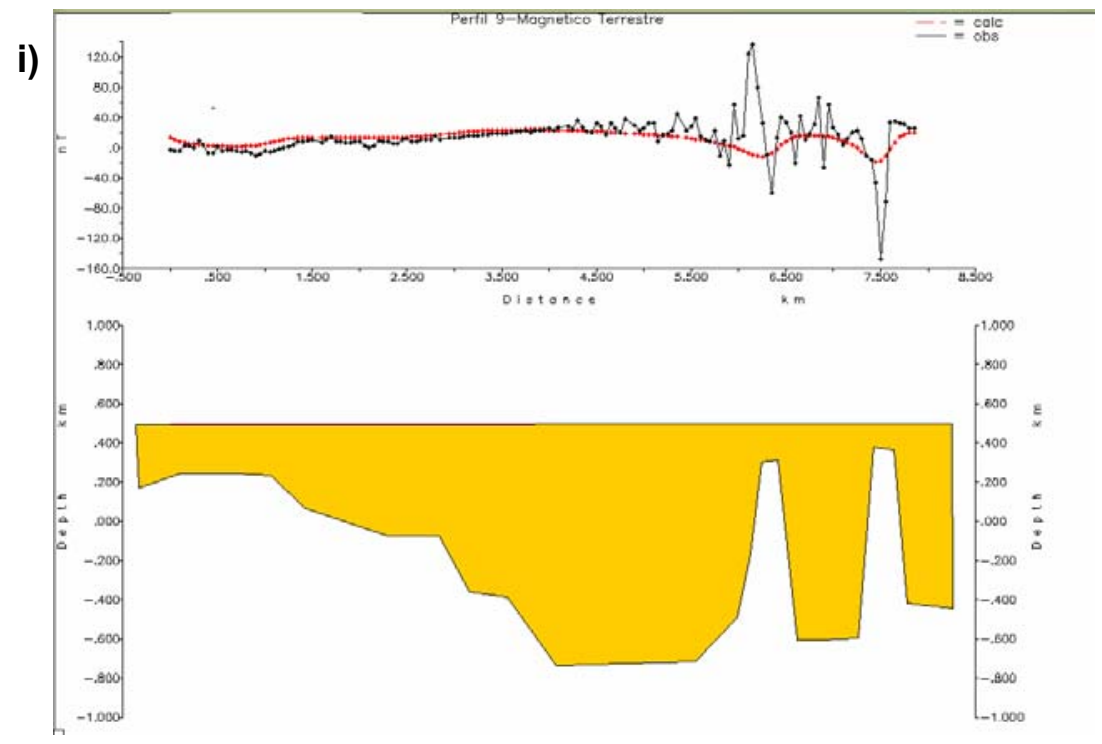

4.26 .

\begin{tabular}{|l}
\hline Propriedades magnéticas (SI) \\
$\square$ Rochas Sedimentares- $\mathrm{k}=$ desprezivel \\
$\square$ Brechas-k $\mathrm{k}=0,0015$ \\
EGS- $\mathrm{k}=0,0015 ; \mathrm{M}_{\mathrm{R}}=0,5 ;$ inc $=-40^{\circ}$ \\
$\square$ Embasamento- $\mathrm{k}=0,006$ \\
$\mathrm{k}=$ susceptibilidade magnética \\
$\mathrm{M}_{\mathrm{R}}=$ intensiddade da magnetização remanescente \\
inc =inclinação remanescente
\end{tabular}




\title{
UNIVERSIDADE DE SÃO PAULO \\ INSTITUTO DE ASTRONOMIA, GEOFÍSICA E CIÊNCIAS \\ ATMOSFÉRICAS-IAG.
}

\author{
APÊNDICE E \\ MODELOS CONJUNTOS \\ AEROMAGNÉTICOS ASSOCIADOS A GRAVIMÉTRICOS
}

São Paulo

2007 
a)

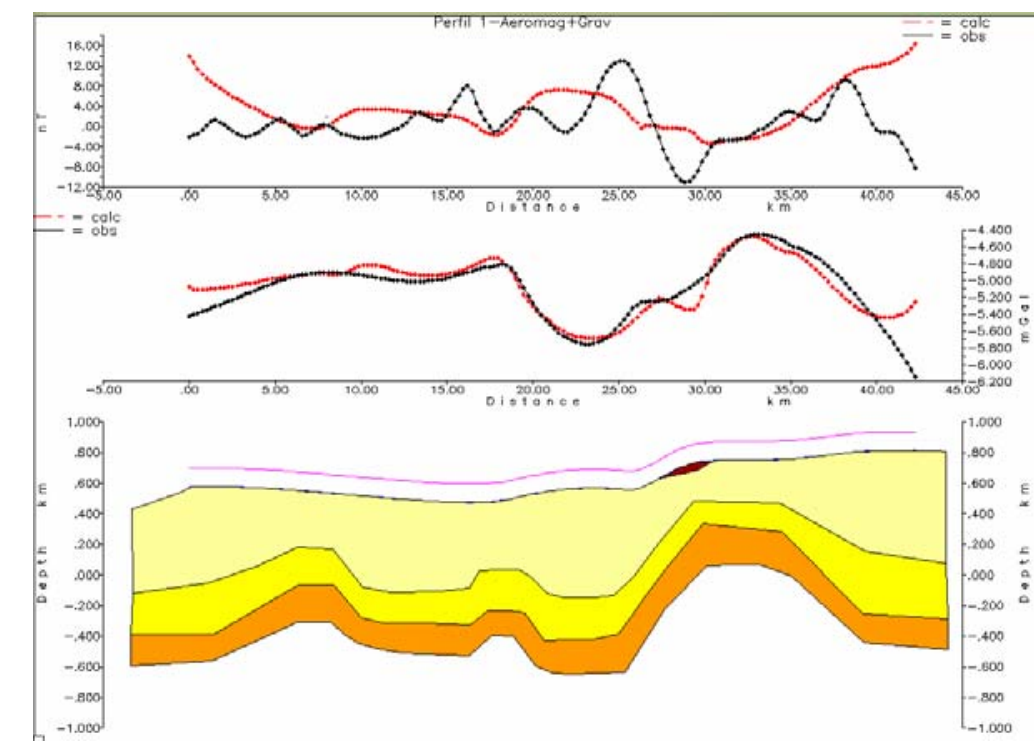

d)
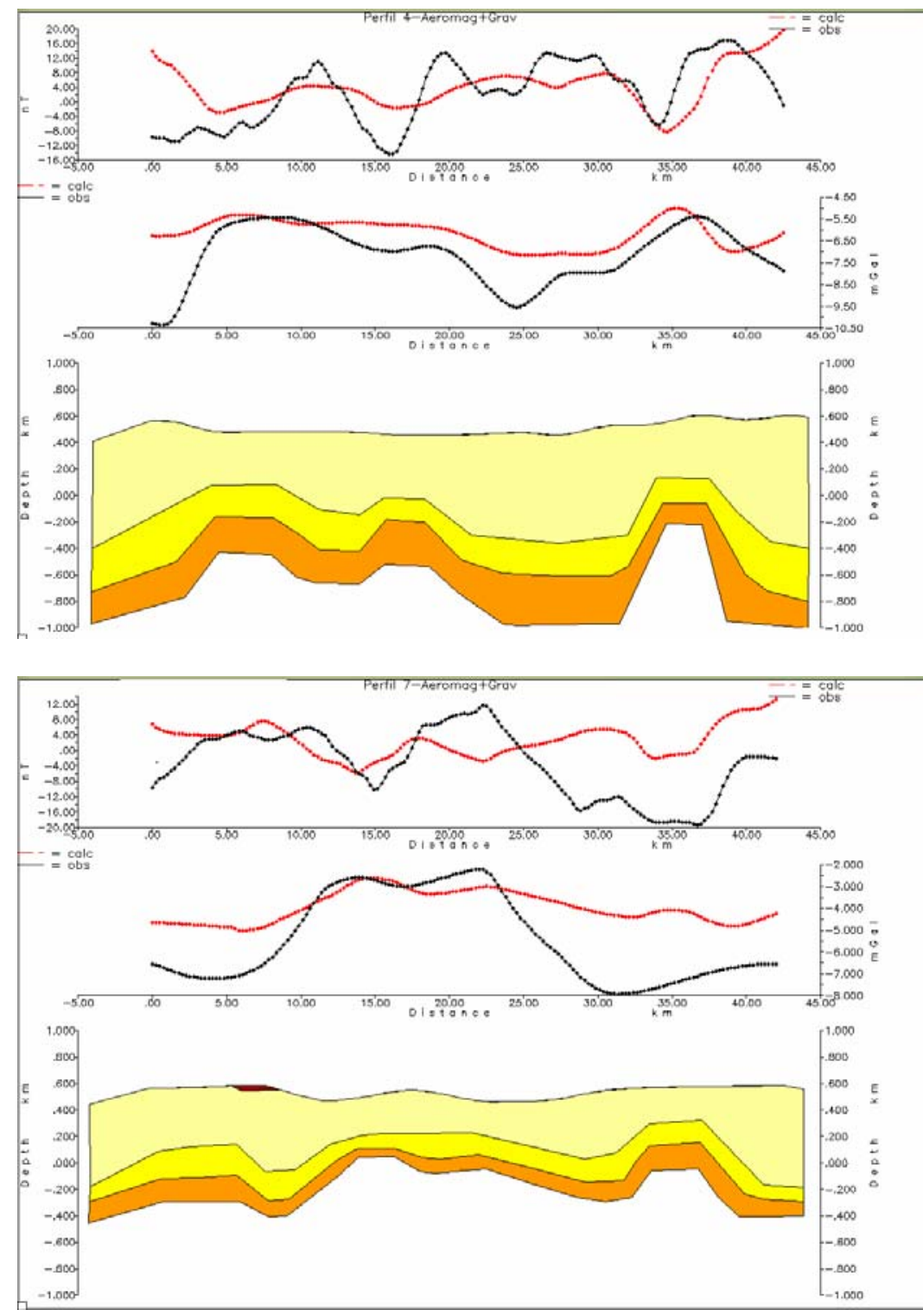

b)
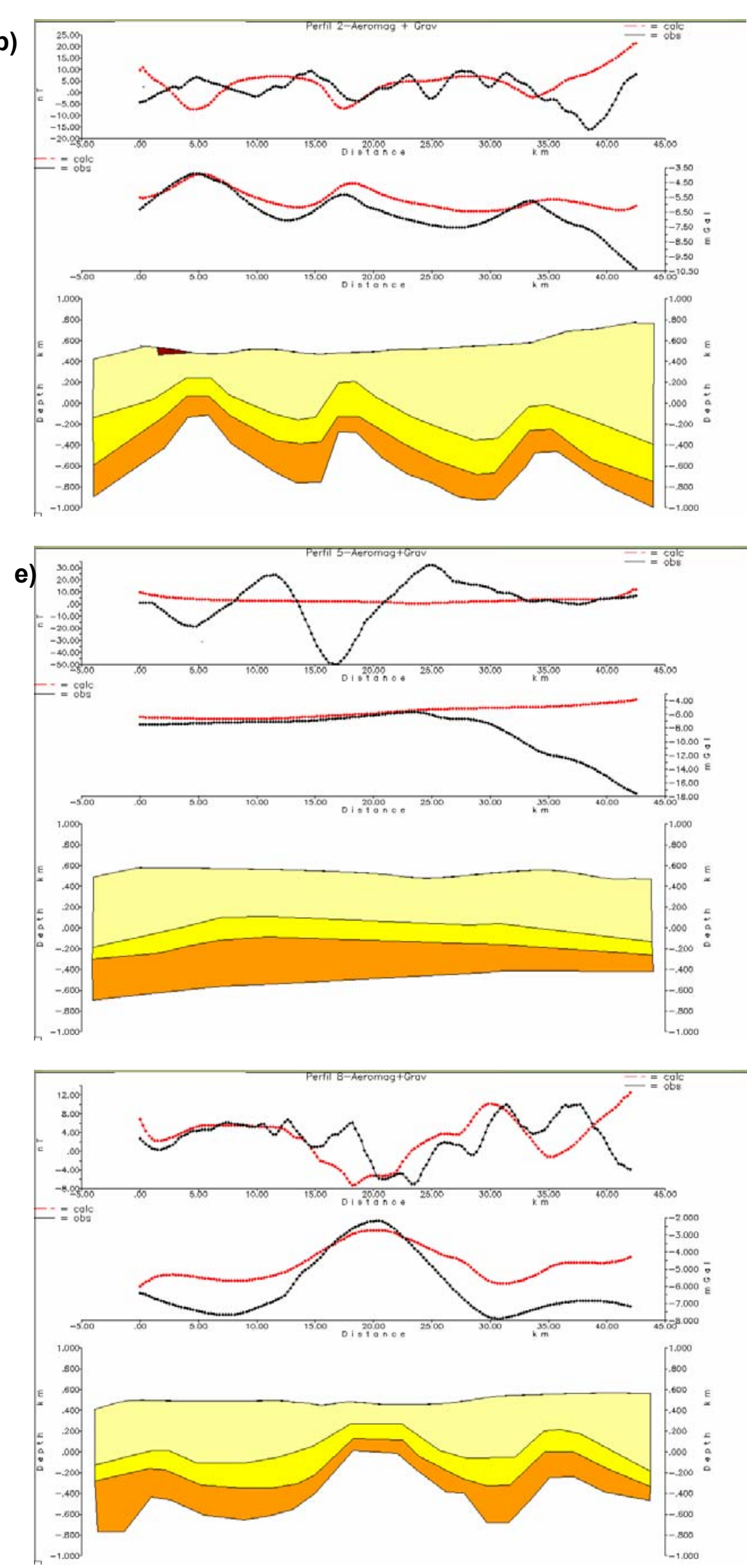

c)

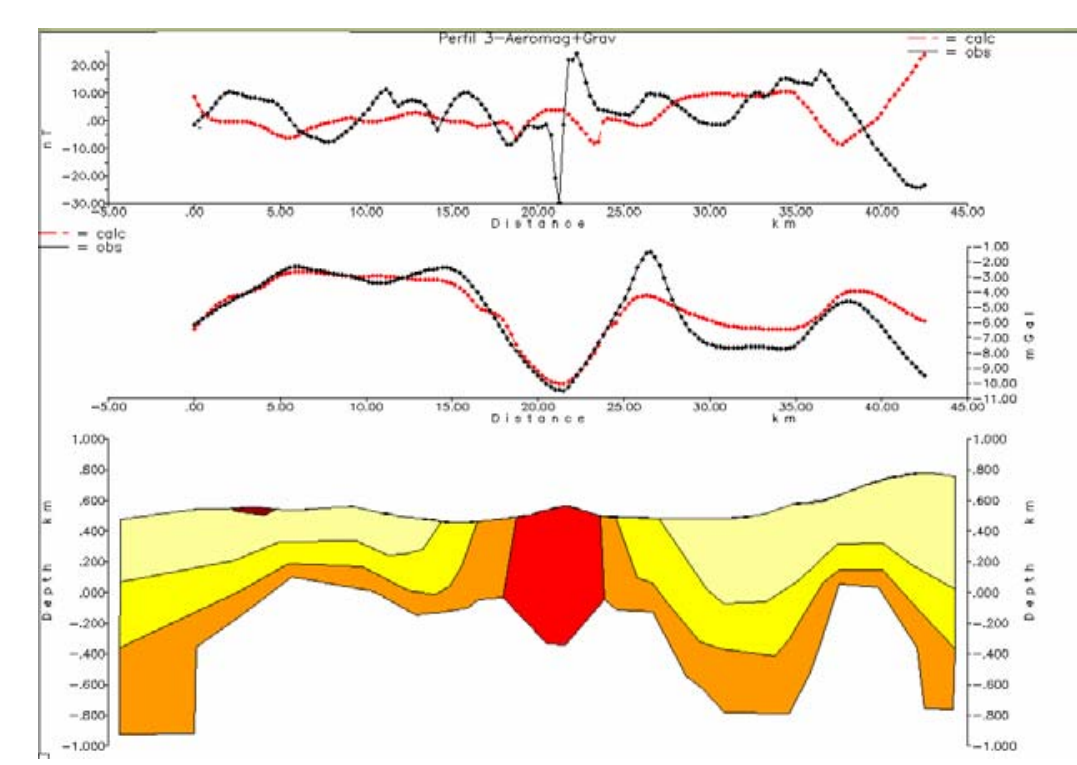

f)
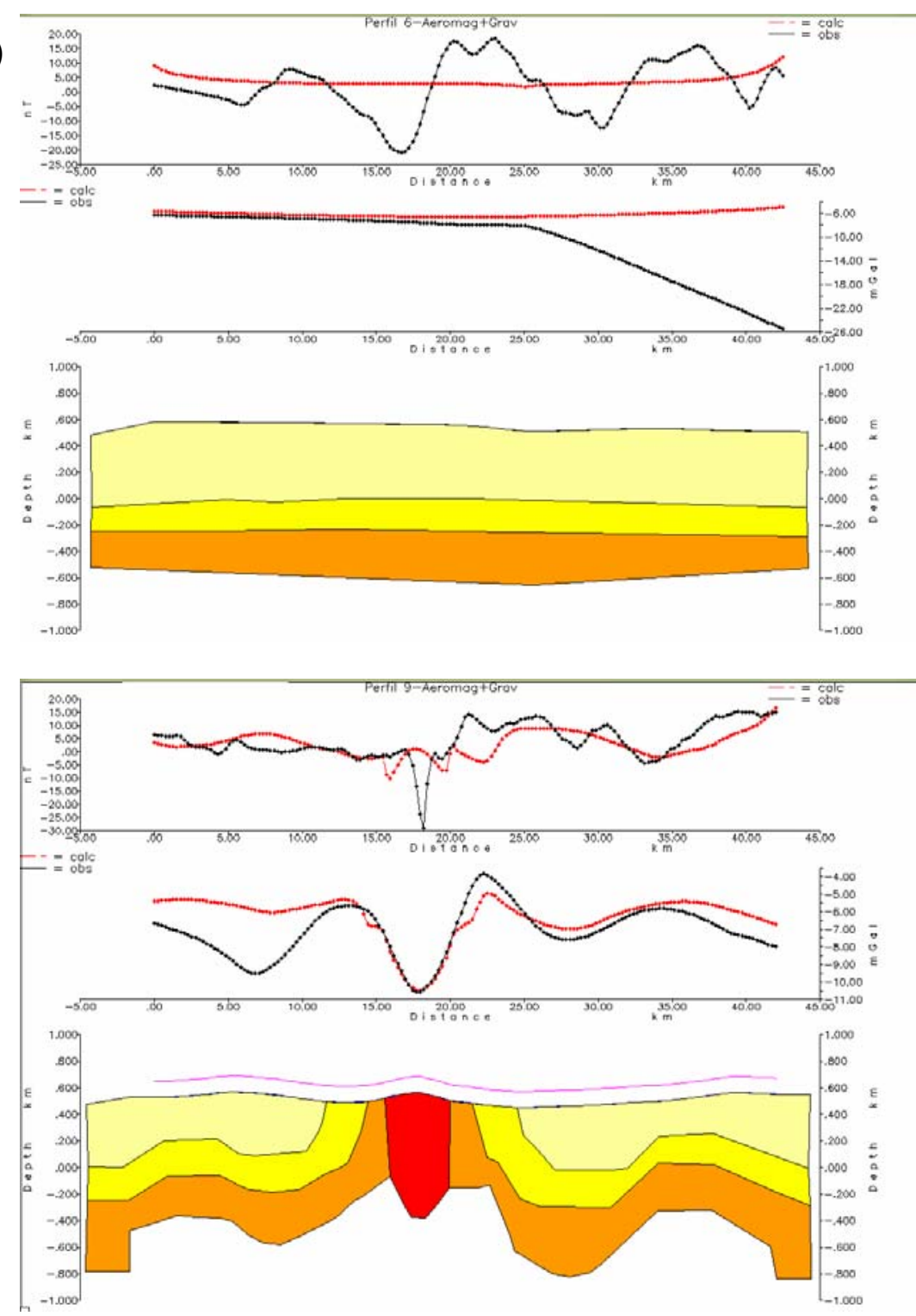


\title{
UNIVERSIDADE DE SÃO PAULO \\ INSTITUTO DE ASTRONOMIA, GEOFÍSICA E CIÊNCIAS \\ ATMOSFÉRICAS-IAG.
}

\author{
APÊNDICE F \\ MODELOS CONJUNTOS \\ MAGNÉTICOS TERRESTRES ASSOCIADOS A \\ GRAVIMÉTRICOS
}

São Paulo

2007 
a)

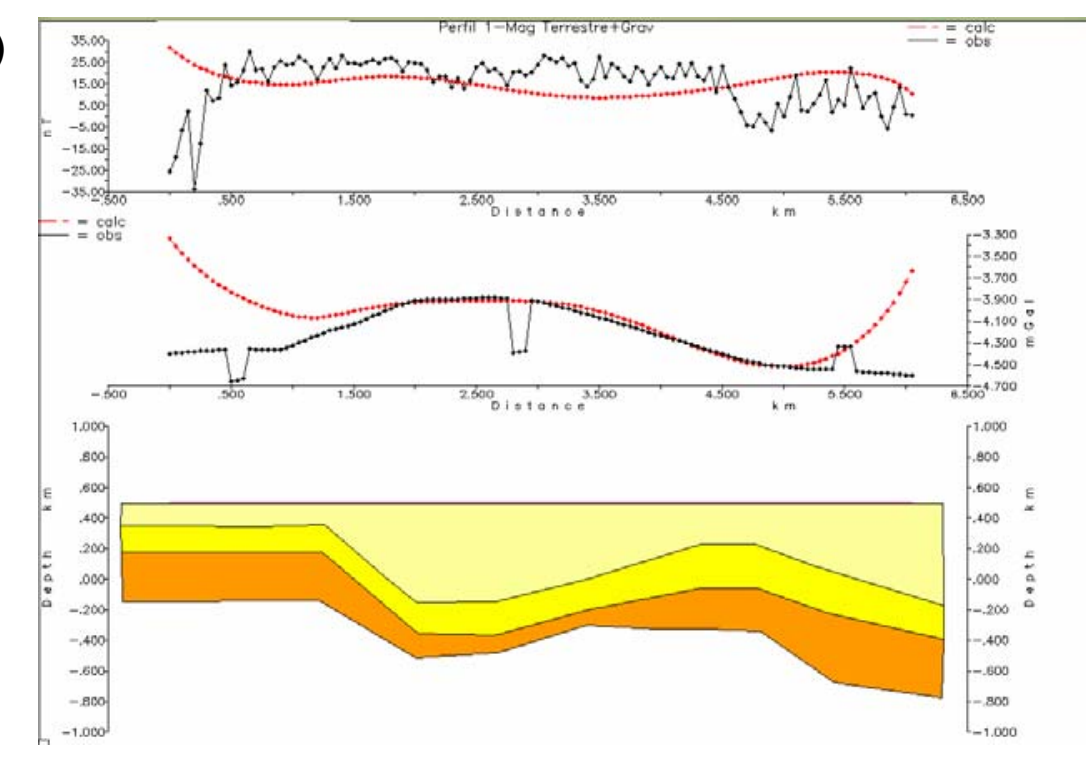

d)

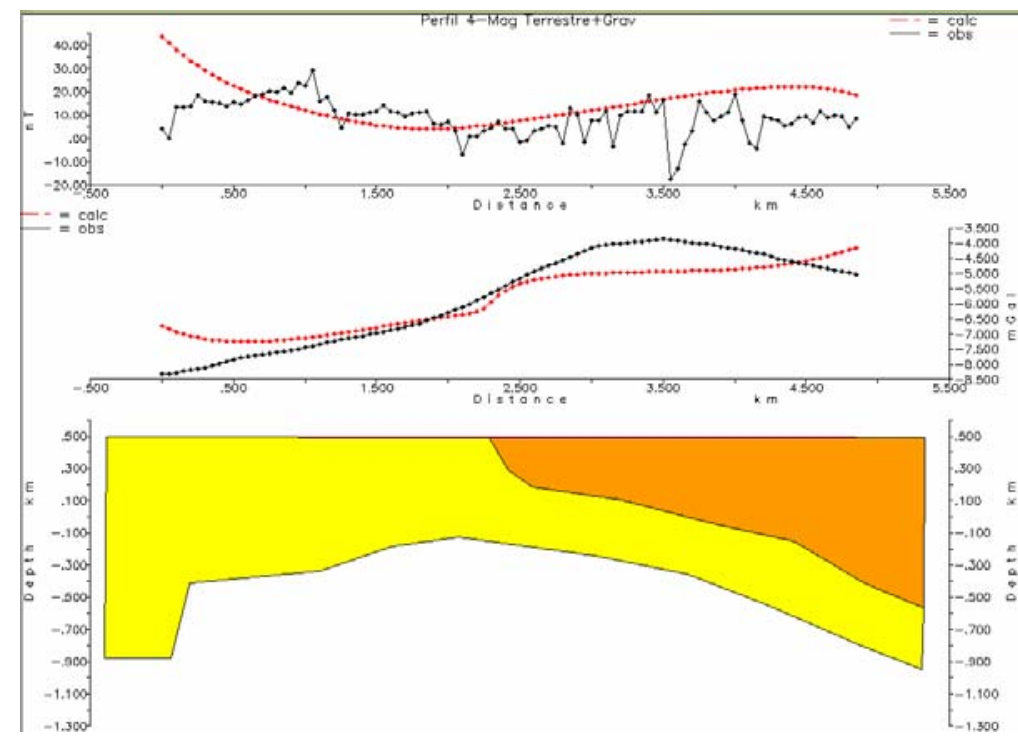

b)

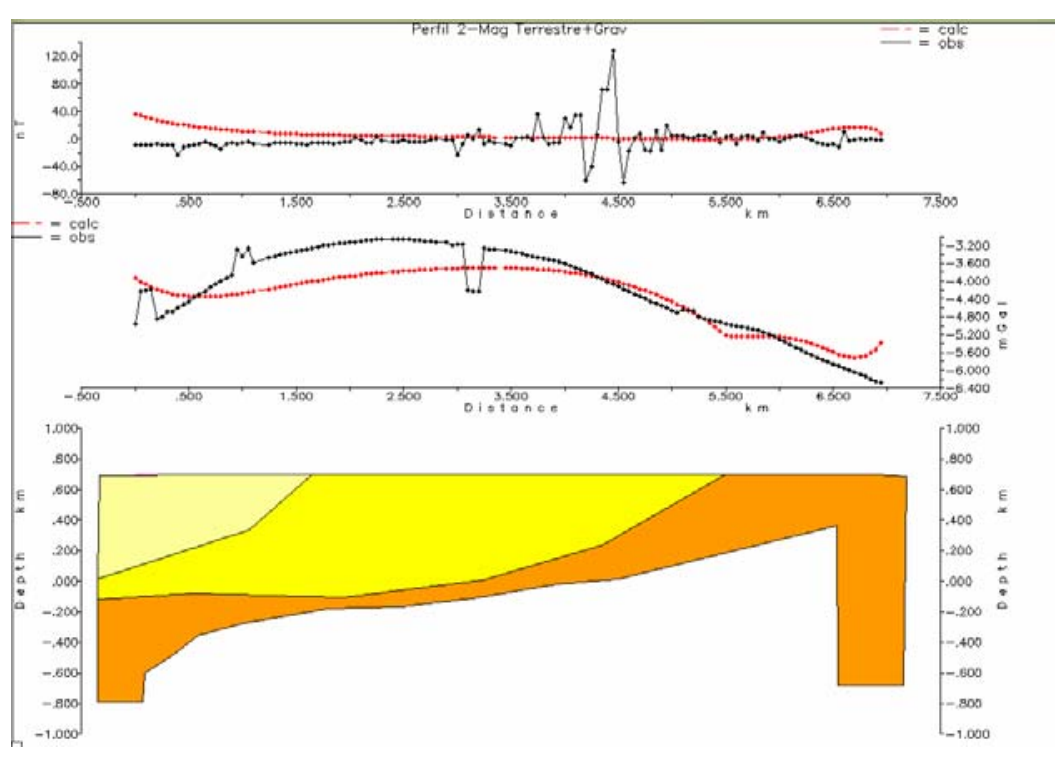

e)

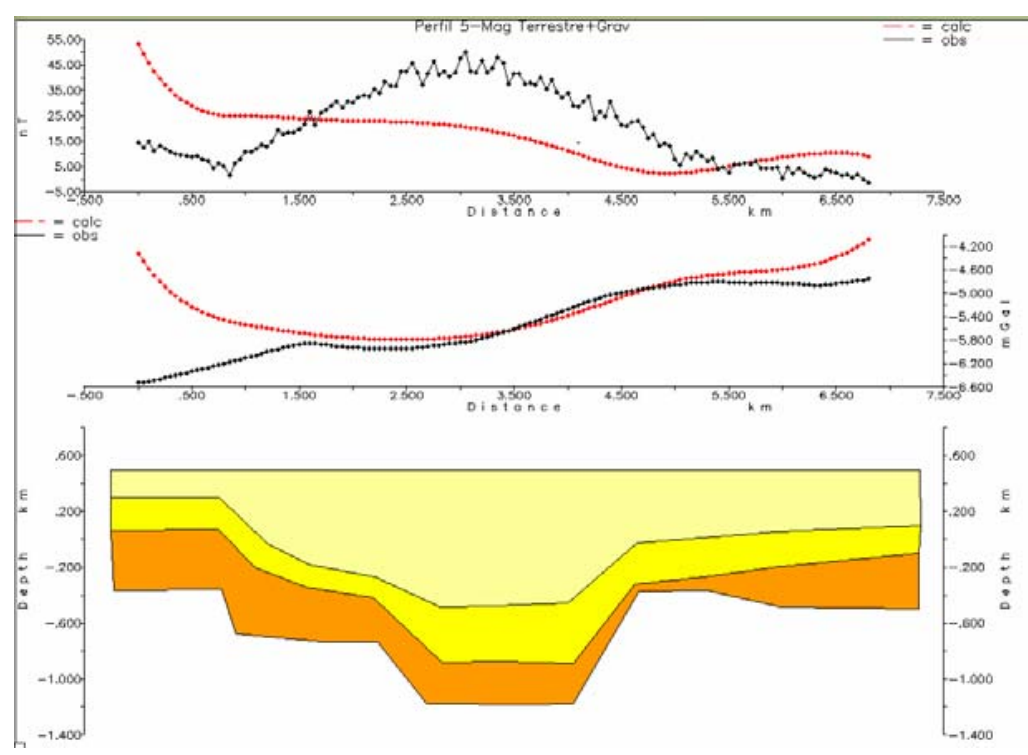

c)

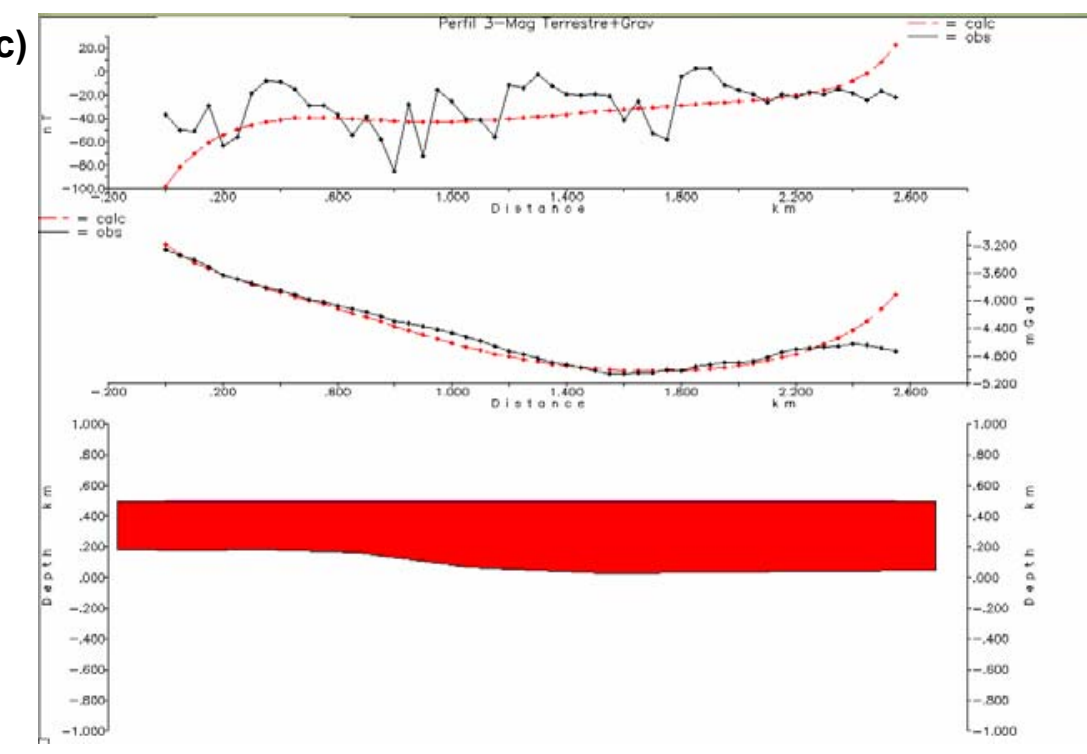

f)

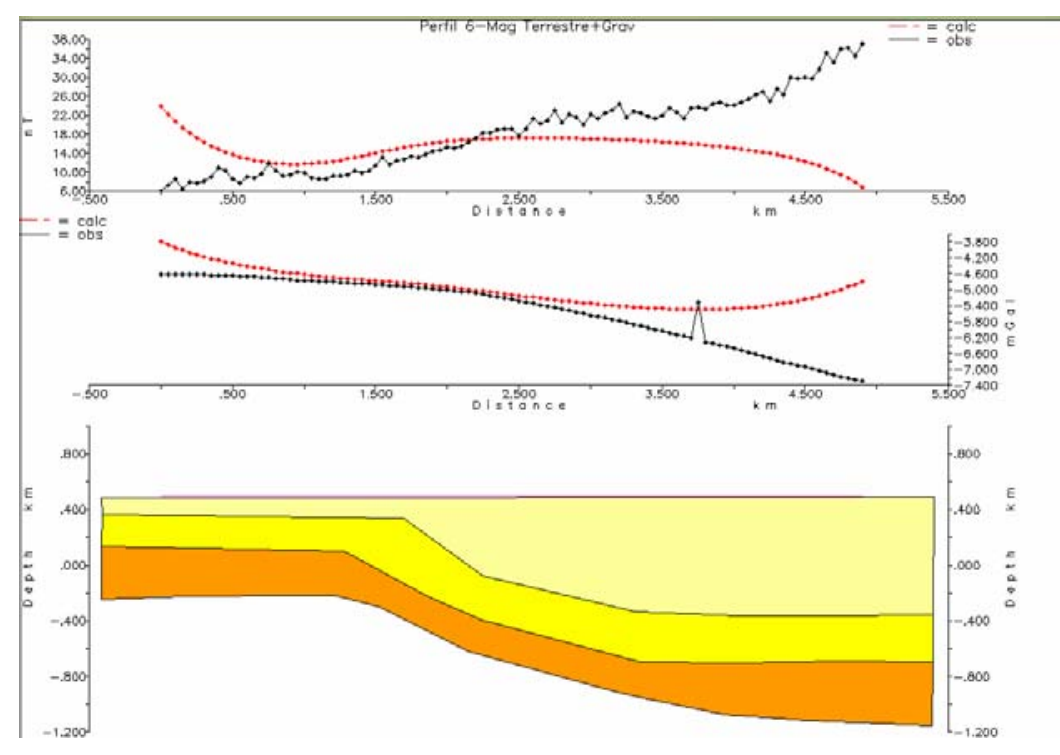



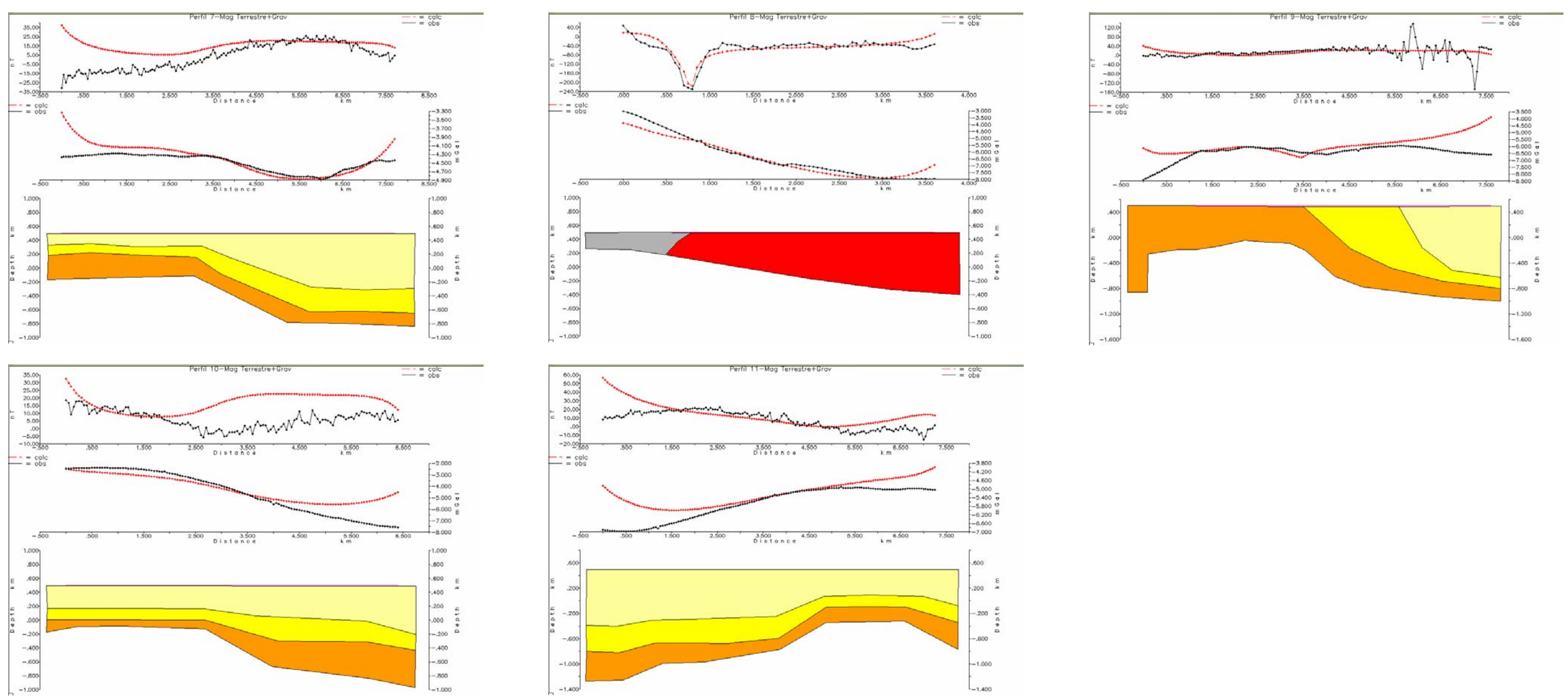

Figura F- Resultados dos modelamentos diretos conjuntos realizados com dados magnéticos terrestres e gravimétricos. De "a" até "l", modelos gerados ao longo dos perfis 1 a 11 , respectivamente. A localização dos perfis é mostrada na Figura 4.26.

\begin{tabular}{|c|}
\hline Propriedades físicas (SI) \\
\hline Fm. Aquidauana/G.Passa-Dois $-\mathrm{d}=2,36 ; \mathrm{k}=$ desprezível \\
\hline Fm. Ponta Grossa-d=2,36; k=desprezivel \\
\hline Fm. Funnas-d=2,22; k=desprezivel \\
\hline EGS- $d=2,15 ; \mathrm{k}=0,0015 ; \mathrm{M}_{\mathrm{R}}=0,5 ; \mathrm{inc}=-40^{\circ}$ \\
\hline Brecha- \\
\hline$\square$ Embasamento-d=2,45; $\mathrm{k}=0,006$ \\
\hline 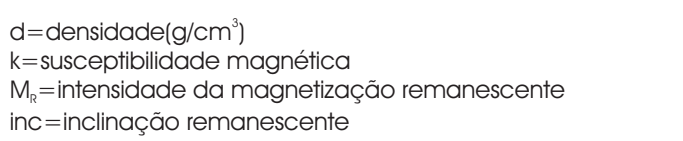 \\
\hline
\end{tabular}

